\title{
Papel de los adaptadores de clatrina GGA y Ent3, y de la SNARE Fsv1 en el tráfico entre \\ la red trans del Golgi, el endosoma prevacuolar y la vacuola.
}
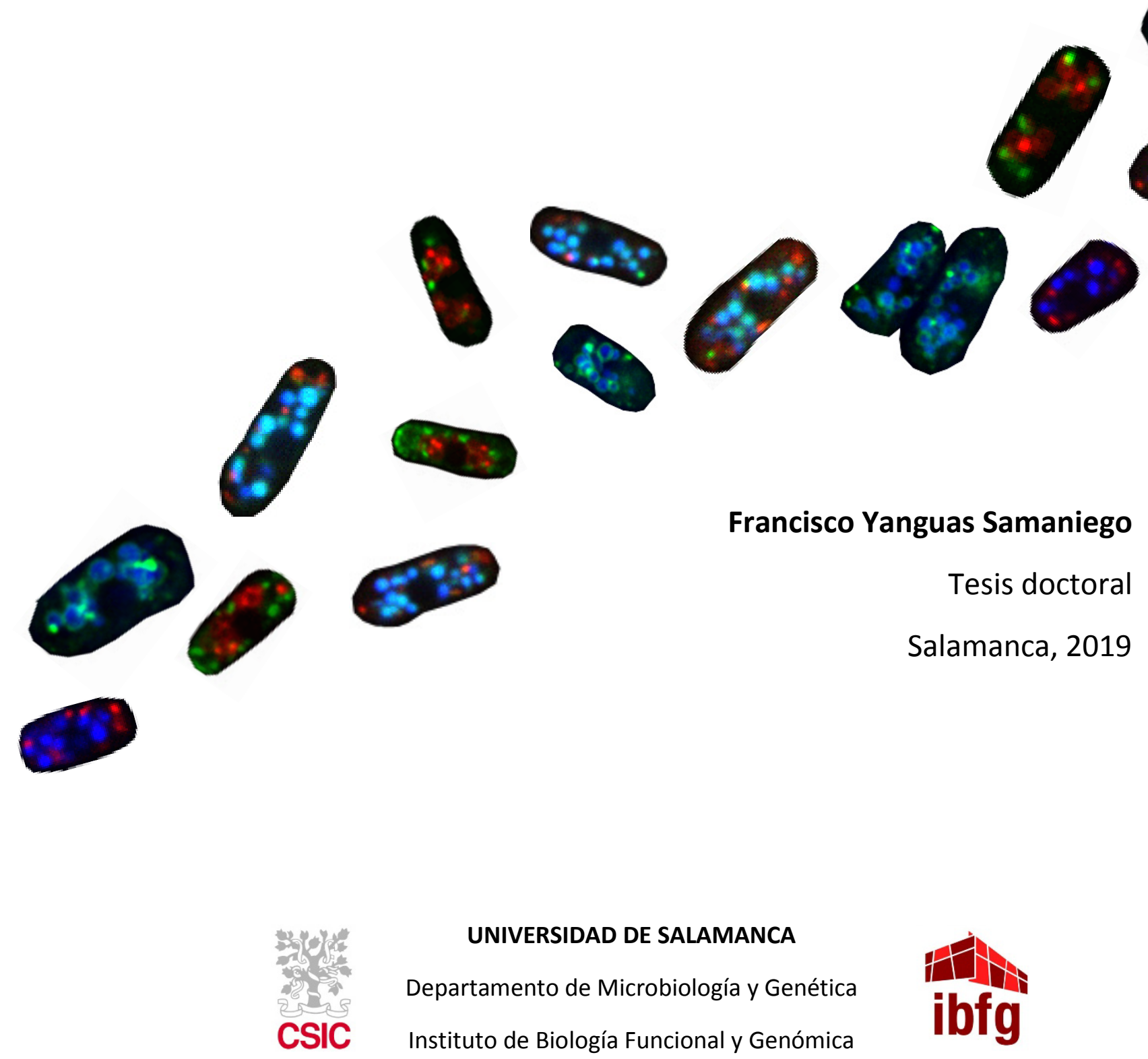



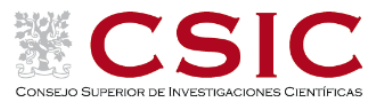

Papel de los adaptadores de clatrina GGA y Ent3, y de la SNARE Fsv1 en el tráfico entre la red trans del Golgi, el endosoma prevacuolar y la vacuola.

Francisco Yanguas Samaniego

Tesis doctoral

Salamanca, 2019 


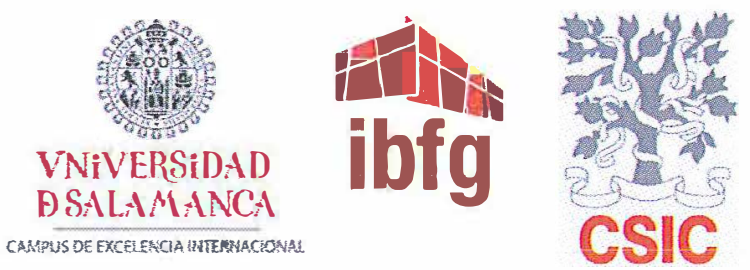

La Dra. Ma Henar Valdivieso Montero, Profesora Titular del Departamento de Microbiología y Genética de la Universidad de Salamanca

\section{CERTIFICA:}

Que la memoria titulada "Papel de los adaptadores de clatrina GGA y Ent3, y de la SNARE Fsv1 en el tráfico entre la red trans del Golgi, el endosoma prevacuolar y la vacuola ", presentada por el licenciado Francisco Yanguas Samaniego para optar al grado de Doctor en Biología, ha sido realizada bajo su dirección en el Instituto de Biología Funcional y Genómica, centro mixto de la Universidad de Salamanca (Departamento de Microbiología y Genética) y el Consejo Superior de Investigaciones Científicas.

Y para autorizar su presentación y evaluación por el tribunal correspondiente, firma el presente certificado en Salamanca, a $\_4$ de julio de 2019.

Fdo. Dra. Ma Henar Valdivieso Montero 


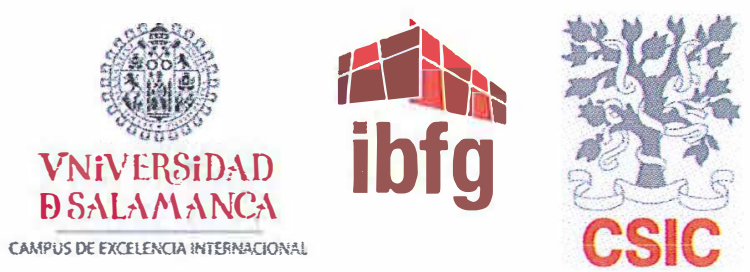

El Dr. Francisco del Rey Iglesias, Catedrático del Departamento de Microbiología y Genética de la Universidad de Salamanca y coordinador del programa de doctorado Biología Funcional y Genómica

\section{CERTIFICA:}

Que la memoria titulada "Papel de los adaptadores de clatrina GGA y Ent3, y de la SNARE Fsv1 en el tráfico entre la red trans del Golgi, el endosoma prevacuolar y la vacuola", presentada por el licenciado Francisco Yanguas Samaniego para optar al grado de Doctor en Biología, ha sido realizada bajo la dirección de la Dra. Ma Henar Valdivieso Montero en el Instituto de Biología Funcional y Genómica, centro mixto de la Universidad de Salamanca (Departamento de Microbiología y Genética) y el Consejo Superior de Investigaciones Científicas.

Y para autorizar su presentación y evaluación por el tribunal correspondiente, firma el presente certificado en Salamanca, a _5_ de julio de 2019.

Fdo. Dr. Francisco del Rey Iglesias 

Esta tesis doctoral se ha realizado gracias a una beca predoctoral del Programa de Formación del Profesorado Universitario (2015-2019) del Ministerio de Educación, Cultura y Deporte del Gobierno de España, los proyectos del MINECO (BFU2013-48582C2-2-P y BFU2017-84508-P concedido a H. Valdivieso), de la Junta de Castilla y León (SA073U14 concedido a H. Valdivieso), proyecto "escalera de excelencia" (CLU-201703/14-20 concedido al IBFG) y por la ayuda UEX $18 X 00$ concedida al IBFG por la Universidad de Salamanca.

Agradezco a M. Cabrera, L.L. Du, I. Hagan, E. Hidalgo, T. Kuno, S. Oliferenko, P. Pérez, Y. Toyoshima y a YGRC (http://yeast.nig.ac.jp/yeast/) por las cepas y plásmidos cedidos. 



\begin{tabular}{|c|c|}
\hline aa' & Aminoácidos \\
\hline ADN & Ácido desoxirribonucleico \\
\hline ALP & Fosfatasa alcalina (ALkaline Phosphatase) \\
\hline AP & Proteína adaptadora (Assembly Polypeptides) \\
\hline APP & Proteína precursora amiloidea (Amyloid Precursor Protein) \\
\hline ARN & Ácido ribonucleico \\
\hline ATP & Adenosina $5^{\prime}$ tri-fosfato \\
\hline BAR & Bin/Amphiphysin/Rvs-homology \\
\hline ChAPs & Chs5 and Arf1 binding Proteins. \\
\hline Cl-MPR & $\begin{array}{l}\text { Receptor de manosa 6-fosfato independiente de cationes (Cation- } \\
\text { Independent Mannose 6-Phosphate Receptor) }\end{array}$ \\
\hline CORVET & Class C core Vacuole/Endosome Tethering \\
\hline COP & Coatomer Protein. \\
\hline CPY & Carboxipeptidasa $Y$ \\
\hline CSC & Complejo de selección de cargo (Cargo Selective Complex) \\
\hline DMSO & Dimetil Sulfóxido \\
\hline dNTP & Desoxinucleótido tri-fosfato. \\
\hline DO & Densidad óptica \\
\hline EDTA & Ácido etilén diamino tetra-acético \\
\hline $\mathrm{EE}$ & Endosomas tempranos (Early Endosomes) \\
\hline EMM & Medio mínimo para S. pombe (Edinburgh Minimal Media) \\
\hline ENTH & Epsin N-Terminal Homology domain \\
\hline ERES & Sitios de exprotación del retículo (Endoplasmic Reticulum Exit Sites) \\
\hline ESCRT & Endosomal Sorting Complex Required for Transport \\
\hline FM4-64 & $\begin{array}{l}\text { Dibromuro de N-(3-trietilamoniopropil)-4-(6-(dietilamino) fenil) } \\
\text { hexatrienil) piridina. }\end{array}$ \\
\hline FYVE & Dominio Fab1, YOTB, Vac1 y EEA1 \\
\hline GAE & Gamma-Adaptin-Ear domain \\
\hline GAPs & GTPase-Activating Proteins \\
\hline
\end{tabular}




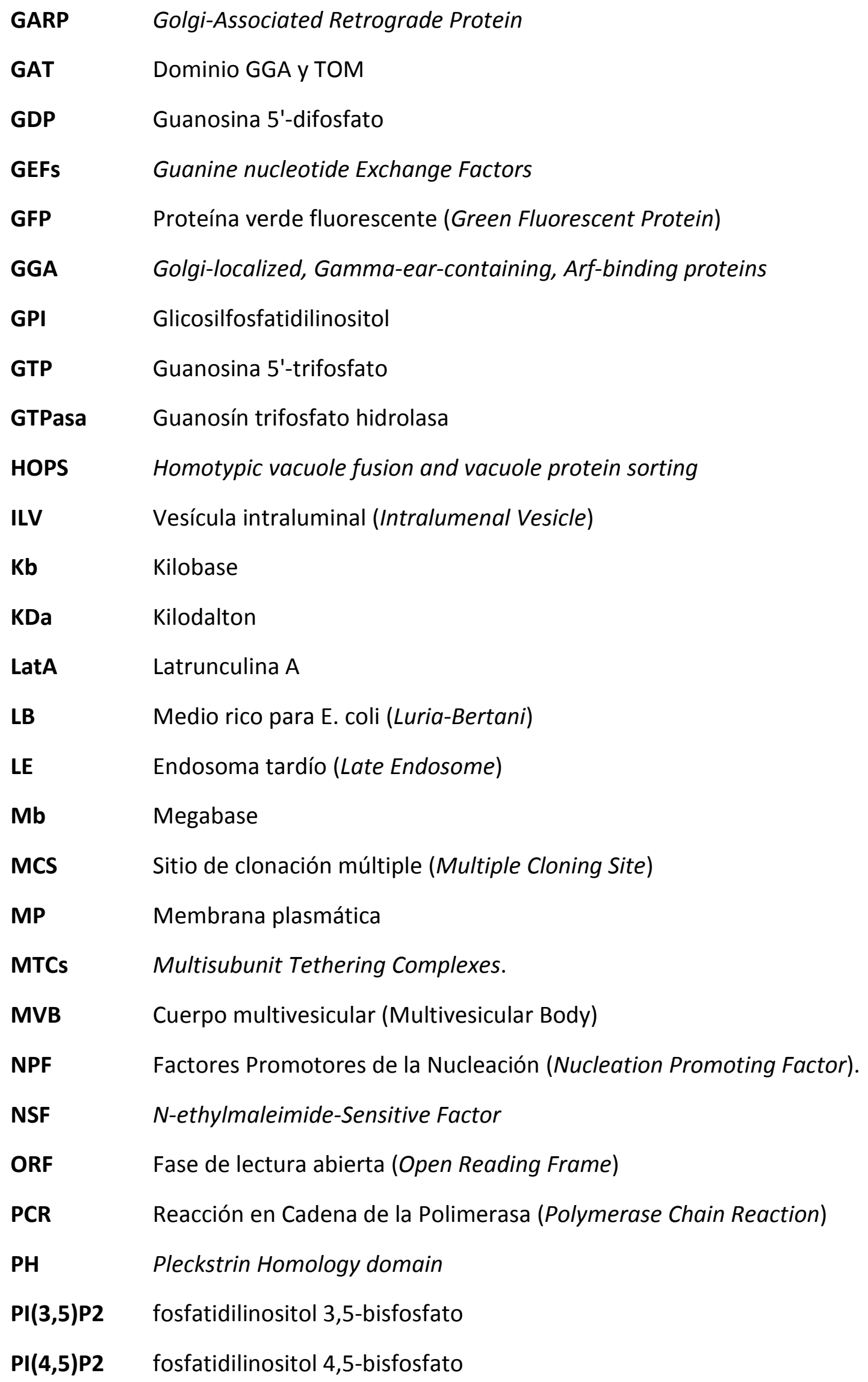




\begin{tabular}{ll} 
PI3P & fosfatidilinositol 3-fosfato \\
PI4P & fosfatidilinositol 4-fosfato \\
PVE & Endosoma prevacuolar (Prevacuolar Endosome) \\
PX & Phagocyte oxidase homology domain \\
RE & Retículo Endoplásmico \\
RFP & Proteína roja fluorescente (Red Fluorescent Protein) \\
rpm & Revoluciones por minuto \\
SDS & Dodecil sulfato sódico \\
SNAPS & Soluble NSF Attachment Protein \\
SNAREs & Soluble N-ethylmaleimide-sensitive factor Attachment protein Receptor \\
SNX & Sorting Nexin \\
TAE & Tampón Tris-Acético EDTA \\
TBST & Tampón tris salino con Tween-20 (Tris-buffered-saline Tween-20) \\
TCA & Ácido Tricloroacético \\
TGN & Red trans del Golgi (Trans Golgi Network). \\
Tris & Tris-(hidroximetilamino)-metano \\
VHS & Dominio Vps27, Hsr, Stam \\
WT & Cepa silvestre (Wild type) \\
X g & Veces la gravedad \\
YES & Medio rico para S. pombe (Yeast Extract Suplemented) \\
\hline & Medio rico para E. coli (2x Yeast Extract Tryptone) \\
\hline
\end{tabular}



Îndice 



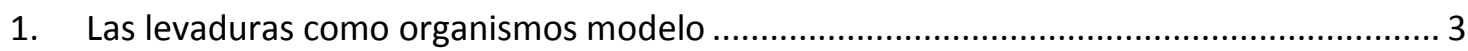

2. La levadura de fisión Schizosaccharomyces pombe …...................................................... 3

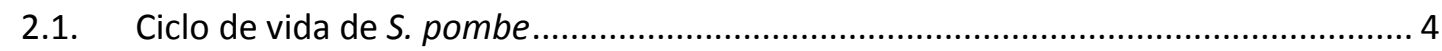

3. Visión general del tráfico intracelular de proteínas.......................................................... 6

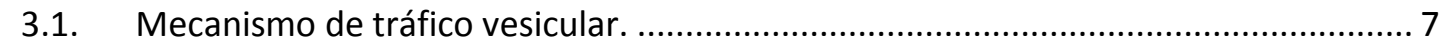

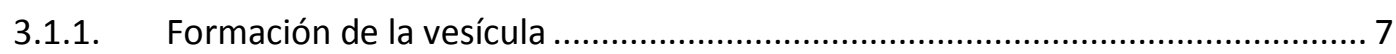

3.1.2. Transporte de la vesícula por el citoplasma................................................... 11

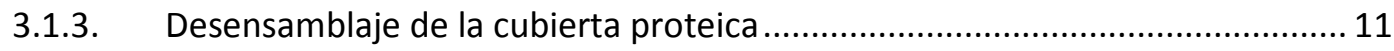

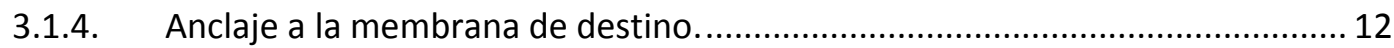

3.1.5. Fusión con el compartimento de destino o aceptor ....................................... 12

3.2. Otros mecanismos de transporte....................................................................... 15

4. Rutas de tráfico vesicular intracelular. Cubiertas y adaptadores implicados .................... 15

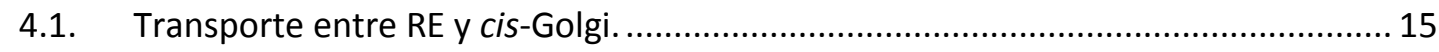

4.1.1. Vesículas COPII (COatomer Protein II)................................................................ 16

4.1.2. Vesículas COPI (COatomer Protein I)................................................................ 16

4.2. Tráfico dentro del complejo de Golgi.................................................................... 17

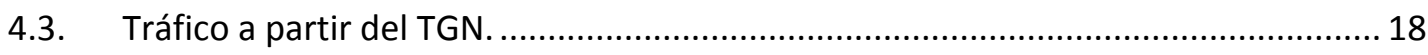

4.3.1. Diferencias entre los modelos de sistema endosomal de mamíferos y

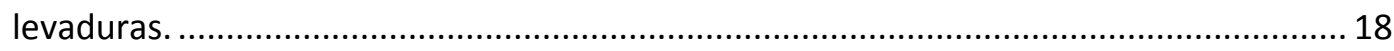

4.3.2. Tráfico mediado por clatrina. Clatrina: estructura y función ............................... 21

4.3.3. Tráfico mediado por clatrina. Los adaptadores. ................................................ 22

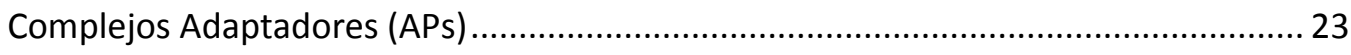

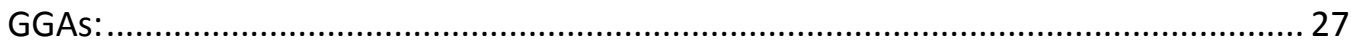

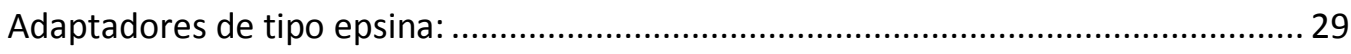

4.3.4. Coordinación de los adaptadores de clatrina en el TGN .................................. 31

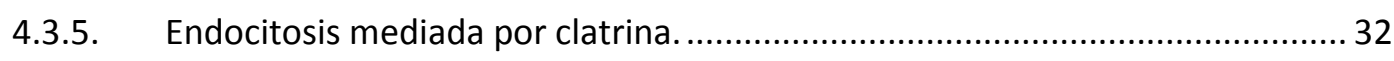

4.3.6. Tráfico independiente de clatrina................................................................... 33

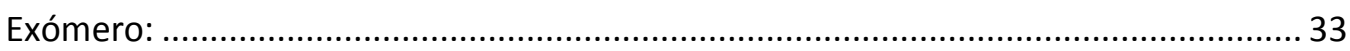

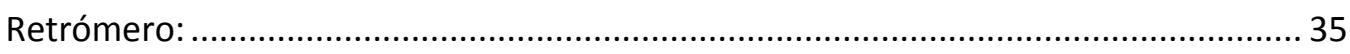

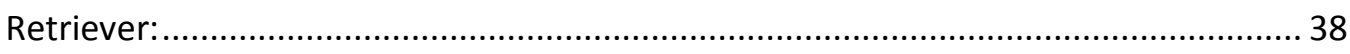

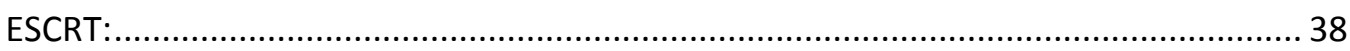

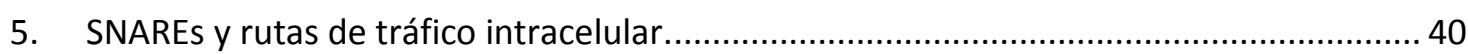


5.1. SNARES y tráfico hacia la vacuola. 40

6. Cargos modelo en el tráfico TGN-PVE-Vacuola.................................................................. 43

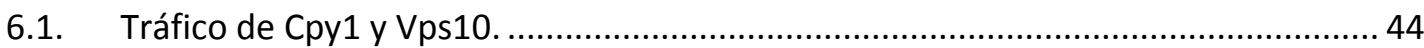

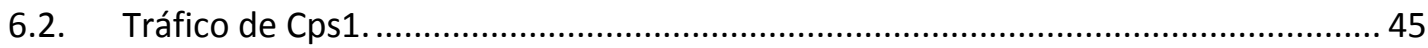

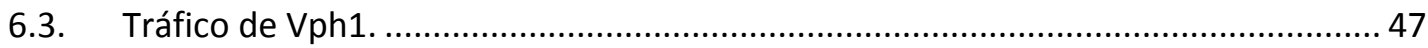

Capítulo I:_Los adaptadores de clatrina GGAs y Ent3 participan en múltiples pasos del tráfico anterógrado y retrógrado a través del PVE. ........................................................................49

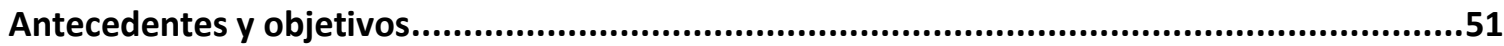

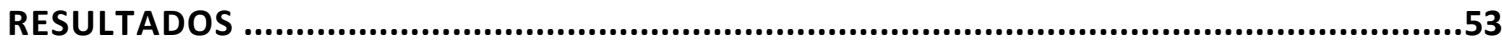

1. Uso de Vps10 como cargo modelo para el análisis del tráfico desde el TGN al PVE. .......55

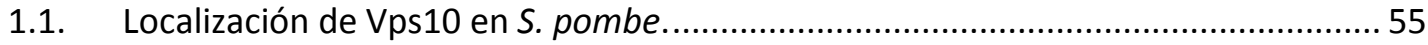

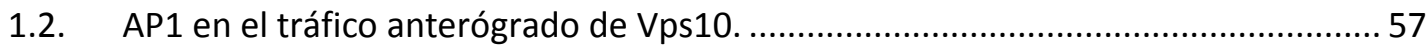

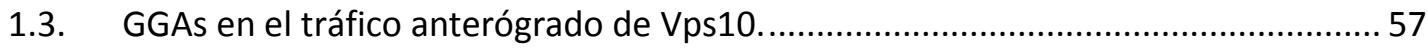

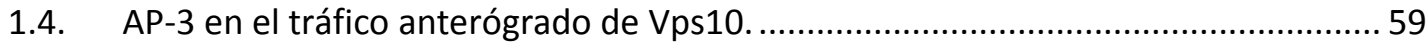

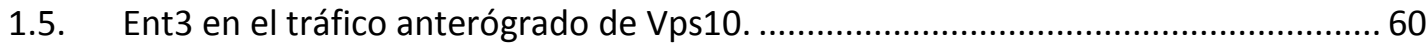

1.6. Endocitosis en el tráfico de Vps10 hacia el PVE en ausencia de GGAs-Ent3..............62 62

2. Uso de Cps1 para analizar la función de GGAs y Ent3 en el tráfico entre el TGN, el PVE y

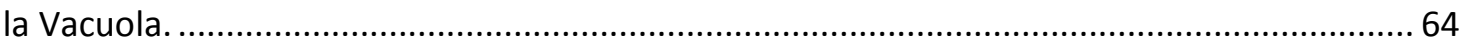

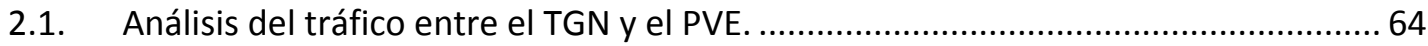

2.2. Análisis del tráfico desde el PVE hacia la vacuola..................................................67

3. Análisis del transporte hacia la vacuola de otras proteínas (Vph1) en ausencia de GGAs y

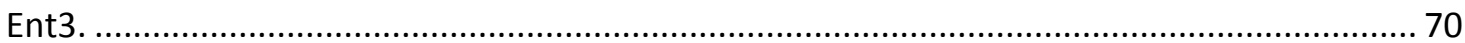

4. Papel de los GGAs y de Ent3 en el reciclaje de proteínas desde el PVE........................... 71

4.1. Tráfico retrógrado de Vps10 desde el PVE............................................................. 71

4.1.1. Caracterización del tráfico retrógrado de Vps10 en S. pombe. ........................ 71

4.1.2. Análisis de los mutantes sin los adaptadores GGAs-Ent3................................ 73

4.2. Reciclaje de Syb1 en mutantes sin los adaptadores GGAs-Ent3...............................76

5. Morfología del PVE en los mutantes carentes de GGAs-Ent3 .......................................... 77

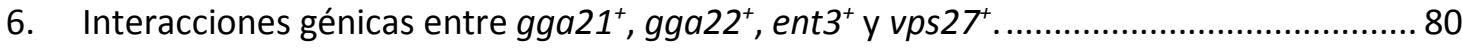

Capítulo II:_Estudio de la SNARE Fsv1 y de su papel en el tráfico entre el TGN y la vacuola...83

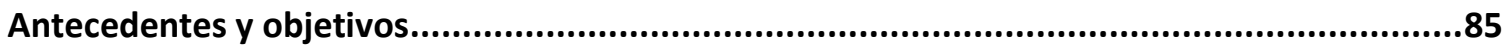

RESULTADOS

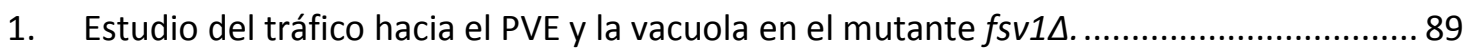

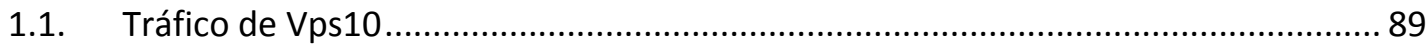

1.2. Organización del PVE en el mutante $f s v 1 \Delta$......................................................... 91 


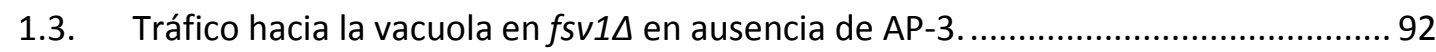

1.4. Funcionalidad del PVE en fsv1 $1 \Delta$ : tráfico de Cps1 .................................................. 93

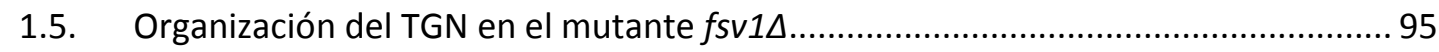

2. Relación funcional de Fsv1 y Vsl1 en el tráfico hacia el PVE y la vacuola......................... 95

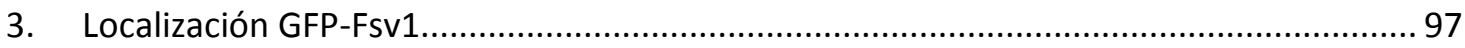

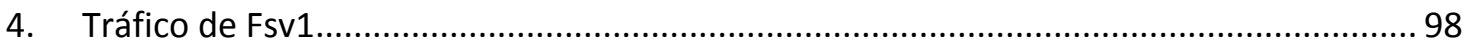

4.1. Búsqueda de dominios o señales de Fsv1 importantes para su reciclaje. ................. 99

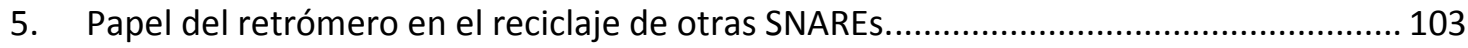

5.1. SNAREs que median el tráfico entre TGN y vacuola. ............................................... 103

5.2. Reciclaje de SNAREs implicadas en otras rutas de tráfico...................................... 103

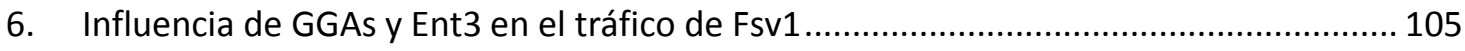

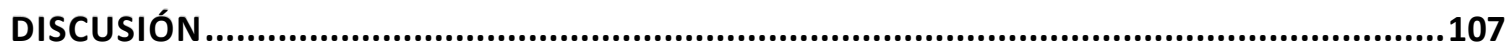

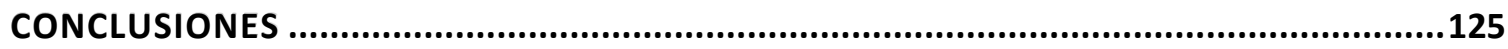

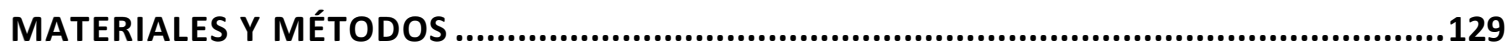

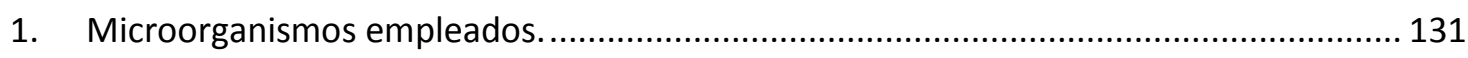

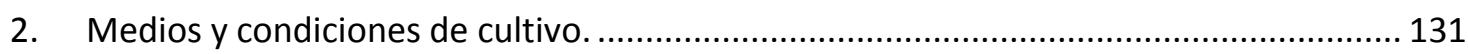

2.1. Medios y condiciones de cultivo para E. coli ........................................................ 131

2.2. Medios y condiciones de cultivo generales para S. pombe.................................... 131

2.3. Ensayos de crecimiento en gota..................................................................... 133

3. Conjugación y aislamiento de ascosporas al azar ......................................................... 133

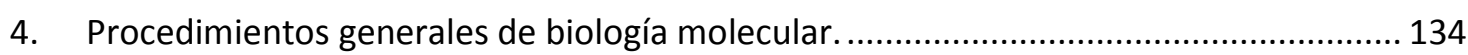

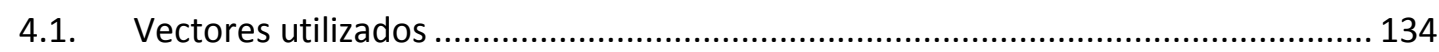

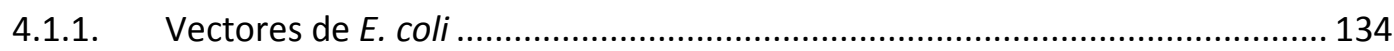

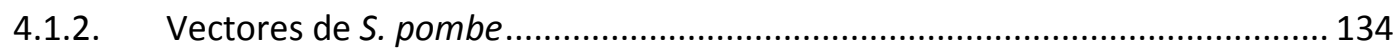

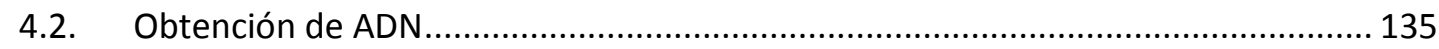

4.3. Reacción en cadena de la polimerasa (PCR)....................................................... 136

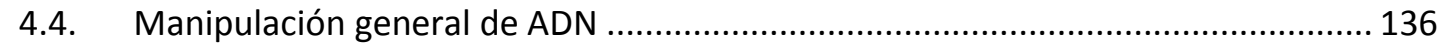

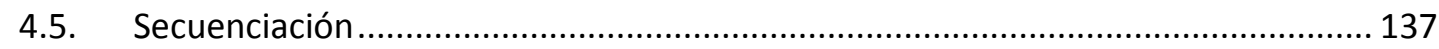

4.6. Mutagénesis dirigida in vitro ……..................................................................... 137

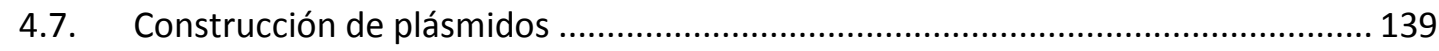

4.8. Deleción de genes y marcaje de proteínas en su locus............................................ 141

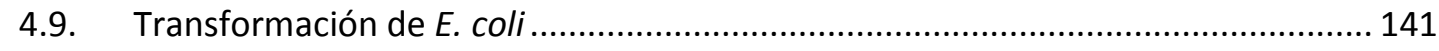

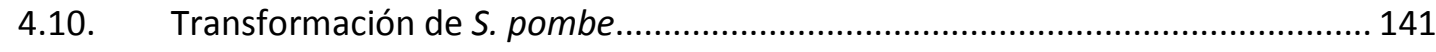

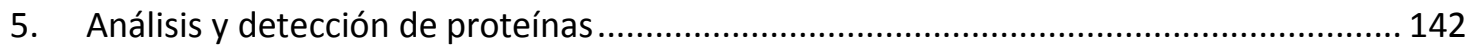

5.1. Obtención de extractos proteicos ........................................................................ 142 
5.2. Electroforesis y electrotransferencia de proteínas ................................................ 142

5.3. Inmunodetección de proteínas ........................................................................ 143

5.4. Ensayo de inmunoblot de colonias (dot blot) ...................................................... 144

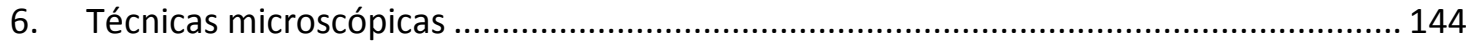

6.1. Microscopía de campo claro y contraste de fases ................................................. 144

6.2. Microscopía de fluorescencia.......................................................................... 144

6.2.1. Fluorescencia directa con proteínas de fusión................................................ 145

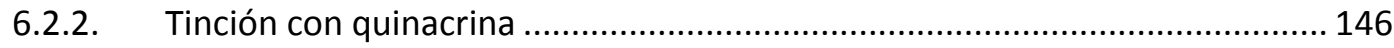

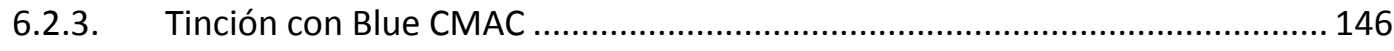

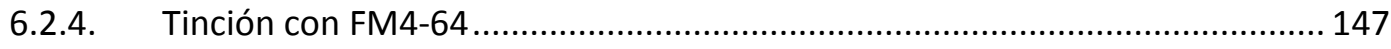

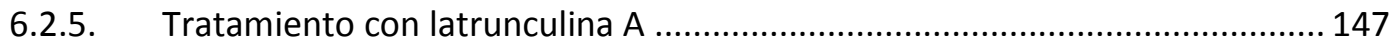

6.2.6. Procesamiento y análisis de las imágenes adquiridas...................................... 148

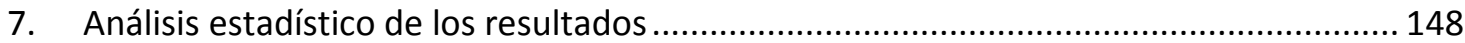

8. Bases de datos y programas bioinformáticos utilizados .................................................. 149

ANEXO

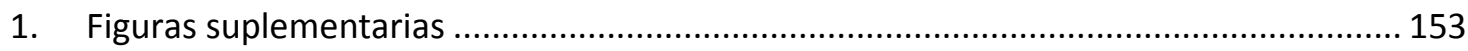

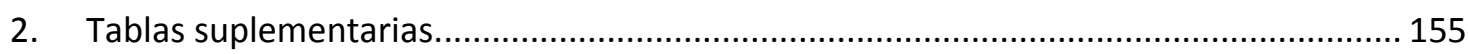

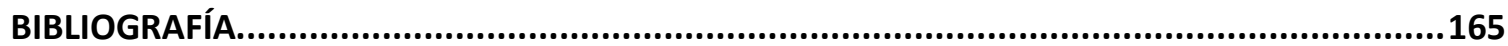


Introducción 



\section{Las levaduras como organismos modelo}

El término levadura se refiere al conjunto de hongos microscópicos unicelulares. Saccharomyces cerevisiae y Schizosaccharomyces pombe son dos especies de levadura ampliamente empleadas en los estudios de biología molecular y celular. Ambas especies comparten una serie de características que las hacen interesantes como organismos modelo en estos campos de estudio. Entre estas cualidades destacan que crecen fácilmente en medios de cultivos simples, presentan tiempos de generación cortos, se pueden almacenar a largo plazo de forma sencilla y no son patógenos. Además, se pueden manipular genéticamente en el laboratorio con facilidad, lo que permite realizar diferentes análisis genéticos y moleculares. Todo esto, unido a la secuenciación del genoma de S. cerevisiae en 1996 y de S. pombe en 2002, explica el amplio uso de estos microorganismos en los laboratorios de investigación (Goffeau et al., 1996; Wood et al., 2002).

Estas levaduras, pese a encontrarse evolutivamente distantes de los metazoos, presentan muchos procesos celulares en común con ellos. En este sentido, el estudio de la fisiología celular de las levaduras ha ayudado (y sigue ayudando) a comprender el funcionamiento de las células humanas. Además, la investigación con levaduras también es útil para entender los mecanismos moleculares de diversas enfermedades humanas como el cáncer, procesos degenerativos, enfermedades metabólicas y distintas enfermedades infecciosas. De hecho un $25 \%$ de los genes de humanos causantes de enfermedades tienen su homólogo en levaduras (Bassett et al., 1996).

A pesar de presentar ciertas características compartidas, S. pombe y S. cerevisiae son dos especies muy alejadas evolutivamente, ya que divergieron de un ancestro común hace entre 330 y 420 millones de años (Sipiczki, 2000). Por tanto, estudiar diferentes procesos celulares en ambos organismos puede aportar información complementaria, además de ayudar a comprender las características conservadas en estos procesos.

\section{La levadura de fisión Schizosaccharomyces pombe.}

El presente trabajo se ha llevado a cabo utilizando la levadura de fisión Schizosaccharomyces pombe. Este microorganismo es un hongo unicelular perteneciente 
a los ascomicetos. Tiene un genoma de $13,8 \mathrm{Mb}$ que contiene 5064 genes codificantes de proteínas y está repartido en tres cromosomas: I (5,7 Mb), II (4,6 Mb) y III (3,5 Mb; Pombase, https://www.pombase.org/).

Esta levadura fue aislada por primera vez por Paul Linder en 1893 de una muestra de cerveza africana. A este descubrimiento debe su nombre, ya que "pombe" significa cerveza en suajili. Sin embargo, la mayoría de las estirpes usadas en el laboratorio derivan de una cepa aislada en un zumo de uva por A. Osterwalder en 1921. Tiempo después U. Leupold observó que en la muestra de Osterwalder había una cepa homotálica (tipo sexual $h^{90}$ ) y dos cepas heterotálicas (tipo sexual $h^{+}$y $h^{-}$) que provenían de la primera (Leupold, 1949). El hecho de que las cepas usadas actualmente en los laboratorios desciendan de estas, hace que se trabaje con cepas prácticamente isogénicas entre los diferentes grupos de investigación. Esto reduce la variabilidad de los resultados obtenidos entre distintos laboratorios con respecto a S. cerevisiae, donde existen diferentes fondos genéticos.

\subsection{Ciclo de vida de S. pombe}

La levadura de fisión presenta un ciclo de vida en el que se alternan las fases haploide y diploide en función de una serie de factores ambientales y de la interacción entre células de distinto tipo sexual (figura 1). Las células de esta levadura son haploides en condiciones normales y presentan una morfología cilíndrica que se mantiene a lo largo del ciclo celular. Las células haploides pueden ser de dos tipos sexuales complementarios $h^{+}$o $h^{-}$. Estas células poseen un tamaño de 3-4 $\mu \mathrm{m}$ de diámetro y 7-8 $\mu \mathrm{m}$ de largo tras dividirse. A continuación, van a ir creciendo por los polos celulares manteniendo un diámetro constante y aumentando su longitud hasta las 12-15 $\mu \mathrm{m}$. Cuando alcanzan este tamaño se forma un septo de división que divide a las células por la mitad produciendo dos células hijas idénticas en tamaño. Este proceso de división se denomina fisión celular y por ello S. pombe también es conocida como la levadura de fisión. Esta parte de la fase haploide se denomina ciclo celular mitótico o vegetativo y en ella ocurre el aumento poblacional de la levadura. Cuando las condiciones del medio cambian y se agota la fuente de nitrógeno, las células del tipo sexual complementario $\left(h^{+}\right.$y $\left.h^{-}\right)$entran en contacto, en un proceso conocido como conjugación, y se fusionan formando un zigoto 
diploide. Este es inestable y su núcleo sufre una división meiótica, lo cual da lugar a un asca zigótica con cuatro ascosporas haploides en su interior. Cuando el asca está madura se produce su dehiscencia y se liberan las ascosporas. Estas germinan cuando las condiciones del medio vuelven a ser favorables, generando de nuevo células haploides y reiniciándose así el ciclo. Los zigotos diploides se pueden mantener si se inoculan en medio rico antes de que ocurra la meiosis. Esto daría lugar a un ciclo mitótico diploide. Si el medio se empobrece, los diploides esporularían originando un asca azigótica.

Las estirpes $h^{+}$y $h^{-}$son heterotálicas, por lo que necesitan un compañero de tipo sexual opuesto para conjugar. Sin embargo, también existe una estirpe homotálica denominada $h^{90}$ que es capaz de conjugar consigo misma. Esto es así porque las células de esta estirpe pueden cambiar de tipo sexual entre $h^{+}$y $h^{-}$cada dos generaciones. (Leupold, 1958).

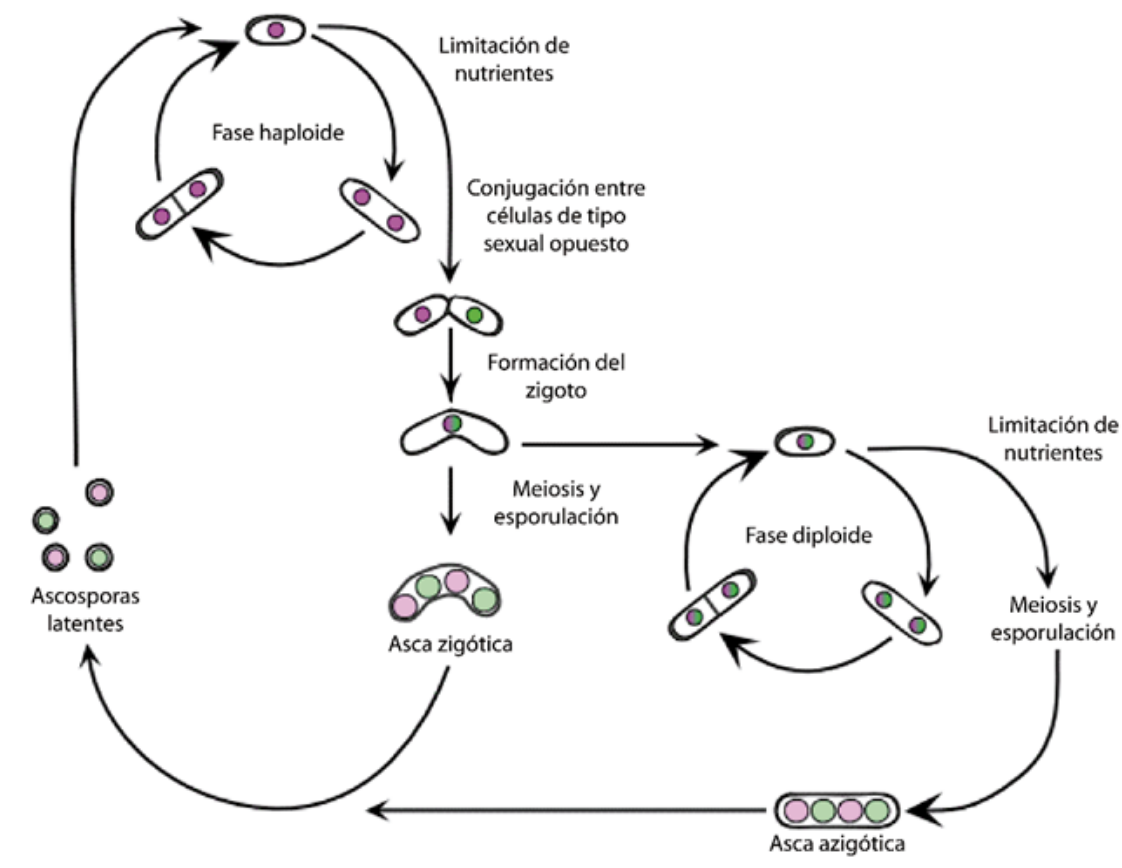

Figura 1. Ciclo de vida de S. pombe. Representación de las distintas fases del ciclo de vida de la levadura de fisión. Los colores rosa y verde indican dos tipos sexuales diferentes $\left(h^{+}\right.$y $\left.h^{-}\right)$. Consultar el texto para más detalles. 


\section{Visión general del tráfico intracelular de proteínas.}

La célula eucariota contiene diversos compartimentos membranosos intracelulares u orgánulos. Cada uno de ellos se ha especializado en la realización de unas funciones determinadas. Sin embargo, los diferentes orgánulos no son estructuras aisladas, sino que existe comunicación entre ellos para integrar las diferentes funciones celulares. Permitir esta comunicación y el intercambio de diferentes elementos (proteínas, lípidos...), es la función principal del tráfico intracelular. Además, este facilita la comunicación de la célula con el medio exterior mediante fenómenos como la secreción o la endocitosis. En estos procesos participa la membrana plasmática y el sistema de endomembranas que está formado por una serie de compartimentos intercomunicados. Estos son el retículo endoplásmico (RE), el complejo de Golgi, los endosomas y los lisosomas en mamíferos o las vacuolas en plantas y levaduras. Las proteínas son uno de los elementos a transportar o "cargos" más importantes. Estas tienen que ser llevadas desde el lugar en el que se sintetizan hasta el lugar donde realizan su función. Las proteínas solubles en el citoplasma pueden alcanzar la membrana de un determinado orgánulo uniéndose a una proteína y/o a un lípido presente en él. Sin embargo, las proteínas transmembrana y las proteínas solubles del lumen de los orgánulos necesitan mecanismos especializados para transportarse. Estas proteínas se sintetizan en el RE donde tiene lugar un complejo proceso de plegamiento y ensamblaje. Posteriormente son transportadas hacia el complejo de Golgi desde donde se distribuyen hacia otros compartimentos celulares como los endosomas, las vacuolas o la membrana plasmática.

El tráfico intracelular es un proceso complejo que tiene que suceder de manera regulada y coordinada. La alteración de este proceso a distintos niveles es la base de una gran variedad de enfermedades humanas como el cáncer, ciertos procesos neurodegenerativos y algunas patologías metabólicas (Abubakar et al., 2017; Howell et al., 2006; Leto and Saltiel, 2012; Tzeng and Wang, 2016; Wang et al., 2014). En este sentido, los estudios realizados en levaduras han permitido la identificación de gran parte de los efectores, los complejos proteicos y las rutas de tráfico presentes en las células eucariotas, la mayor parte de los cuales se encuentran conservados en metazoos (Feyder et al., 2015). De ahí la importancia de su estudio en estos microorganismos. 


\subsection{Mecanismo de tráfico vesicular.}

La teoría del transporte vesicular de proteínas fue propuesta por George Palade en 1975, basándose principalmente en estudios de microscopía electrónica. En ella se postula que el tráfico de proteínas entre los distintos orgánulos celulares se produce a través de vesículas que geman desde un compartimento membranoso donador y son transportadas hasta un compartimento receptor (Palade, 1975). Posteriormente, gracias al trabajo de numerosos grupos de investigación, se ha conseguido profundizar en el conocimiento de los mecanismos moleculares que facilitan el tráfico vesicular. De forma resumida este proceso consta de los siguientes pasos: formación y escisión de la vesícula en el compartimento donador, transporte de la misma a través de la célula, desensamblaje de la cubierta, anclaje a la membrana del compartimento de destino y fusión con el mismo (figura 2). Todos estos pasos están muy regulados para asegurar que las proteínas lleguen a su destino correcto. A continuación se va a hablar con más detalle de cada una de estas etapas y de las proteínas que participan en ellas.

\subsubsection{Formación de la vesícula.}

La formación de la vesícula comienza por una acumulación de ciertos elementos en una zona concreta de la membrana del orgánulo donador. Así el material lipídico y proteico a transportar se va agrupando en esas zonas. Aunque se desconoce el mecanismo preciso que inicia el proceso, se sabe que las GTPasas y ciertos lípidos como los fosfoinositoles juegan un papel importante.

\section{GTPasas pequeñas}

Las GTPasas pequeñas pertenecen a la superfamilia Ras y son reguladores esenciales del tráfico vesicular. Estas proteínas son interruptores moleculares y su estado de activación depende de la unión a nucleótidos de guanina. Así, si están unidas a GTP se encuentran en estado activo, lo que promueve su unión a la membrana. Esto facilita la posterior interacción con diferentes factores presentes en ella y el reclutamiento de otras proteínas que participan en tráfico como los adaptadores y las cubiertas. Además, también inducen la curvatura de las membranas. La hidrólisis de GTP a GDP promueve su inactivación y liberación al citosol. Los GAPs (GTPase-Activating Proteins) promueven la 
hidrólisis de GTP a GDP y los GEFs (Guanine nucleotide Exchange Factors) catalizan el intercambio de GDP por GTP. Dentro de las GTPasas pequeñas hay tres familias con importancia en el tráfico intracelular (Goitre et al., 2014; Song et al., 2019):

- GTPasas de la familia Rab (Ras-related in Brain): participan en distintos procesos del tráfico vesicular como en la formación de la vesícula, en su transporte y en su posterior anclaje y fusión con la membrana receptora (Grosshans et al., 2006).

- GTPasas de la familia Arf (ADP-Ribosylation Factor): facilitan el reclutamiento de diversas cubiertas. Arf1 participa en el reclutamiento de las cubiertas COPI, de los adaptadores asociados a la clatrina y del exómero. Sar1 facilita el reclutamiento de las cubiertas COPII (Gillingham and Munro, 2007; Trautwein et al., 2006; Wang et al., 2006).

- GTPasas de la familia Rho (Ras HOmolog): importantes en el establecimiento de la polaridad celular y en la regulación del citoesqueleto de actina. Dentro de esta familia, Cdc42 participa en secreción polarizada reclutando al exocisto y Rho1 participa en endocitosis independiente de clatrina en levaduras (Perez and Rincon, 2010; Prosser et al., 2011).

Diferentes GTPasas participan en distintos pasos y rutas de tráfico aportando especificidad al sistema. En este sentido, se ha visto que actúan en lo que se ha denominado cascadas de GEFs y de GAPs. Así, una GTPasa recluta al GEF (activador) de la GTPasa que tiene que actuar a continuación y al GAP (inhibidor) de la GTPasa que actuaba en el paso anterior (Mizuno-Yamasaki et al., 2012; Novick, 2016). De esta manera se coordina el sistema.

\section{Fosfoinosítidos:}

Los lípidos tienen un papel importante en el proceso de vesiculación. Algunos son importantes para conferir curvatura a la membrana. Por su parte los fosfoinosítidos facilitan el reclutamiento y/o la activación de proteínas efectoras como las GTPasas o los adaptadores de clatrina (De Craene et al., 2017). Los fosfoinosítidos están formados por una molécula de inositol unida por un fosfato al diacil-glicerol (es decir, un glicerol unido a dos ácidos grasos). Esta molécula se puede fosforilar en diferentes posiciones dentro 
del inositol, dando lugar a distintos fosfoinositidos. Cada uno de ellos predomina en un orgánulo determinado y es capaz de unir diferentes efectores, lo que confiere identidad a las membranas (De Craene et al., 2017). Así, en el complejo de Golgi predomina el fosfatidilinositol 4-fosfato (PI4P) cuyo gradiente de concentración permite el reclutamiento gradual de diferentes adaptadores de clatrina en la red trans del Golgi (Daboussi et al., 2012). En la membrana plasmática predomina el fosfatidilinositol 4,5bisfosfato (PI(4,5)P2) que facilita la unión del complejo adaptador de clatrina AP-2 (Collins et al., 2002; Gaidarov and Keen, 1999; Rohde et al., 2002). En los endosomas tempranos de mamíferos o en el compartimento prevacuolar de levaduras predomina el fosfatidilinositol 3-fosfato (PI3P) que posibilita la unión del complejo ESCRT (Endosomal Sorting Complex Required for Transport) y del retrómero a estos compartimentos (Raiborg et al., 2001; Stahelin et al., 2002; Yu and Lemmon, 2001). Por último, en los lisosomas de mamíferos o vacuolas de levaduras predomina el fosfatidilinositol 3,5bisfosfato (PI(3,5)P2) que es importante para la unión de una subunidad del ESCRT en mamíferos y de las epsinas Ent3 y Ent5 en levaduras (Eugster et al., 2004; Friant et al., 2003; Whitley et al., 2003).

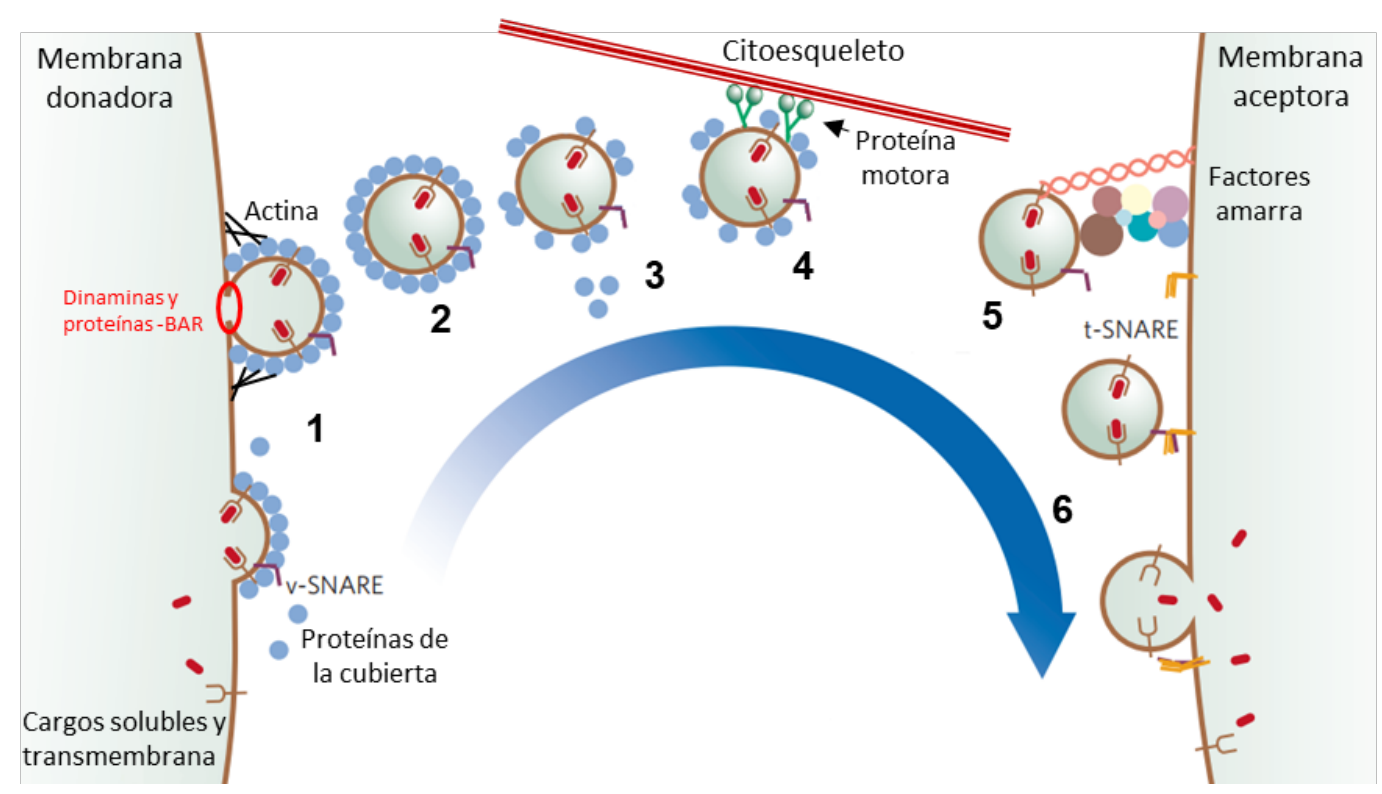

Figura 2. Distintos pasos del tráfico vesicular. 1) Formación de la vesícula: concentración de los cargos y deformación inicial de la membrana promovida por el comienzo de la asociación de la cubierta proteica. Elongación posterior de la vesícula con la colaboración del citoesqueleto. 2) Escisión de la vesícula de la membrana donadora. 3) Desensamblaje (total o parcial) de la cubierta proteica. 4) transporte por el citoplasma a través del citoesqueleto. 5) Reconocimiento y anclaje a la membrana aceptora mediado por los factores amarra. 6) Fusión de la vesícula con la membrana aceptora facilitada por las SNAREs. Adaptado de Behnia and Munro, 2005. 


\section{Proteínas de la cubierta y adaptadores:}

En la mayoría de las ocasiones la formación de las vesículas de transporte está mediada por proteínas "de cubierta" que son proteínas solubles presentes en el citoplasma (figura 2). Al unirse a la membrana estas proteínas promueven su curvatura, facilitando el proceso de vesiculación. Además, reconocen a los cargos de manera directa o de manera indirecta a través de adaptadores solubles y/o receptores transmembrana. De esta forma participan en el proceso de selección y agrupación de los cargos. El reclutamiento de las proteínas de la cubierta a las membranas está mediado por su interacción, directa o indirecta, con distintos elementos como los cargos, los lípidos y las GTPasas (Bonifacino and Glick, 2004; Paczkowski et al., 2015). Hay distintas proteínas de cubierta y adaptadoras que participan en diferentes rutas de tráfico. En apartados posteriores se hablará con más detalle de cada una de ellas

\section{Citoesqueleto y proteínas accesorias: elongación de la vesícula.}

Tras la deformación inicial de la membrana es necesario que se produzca la elongación de la vesícula naciente (figura 2). En este proceso tiene importancia el citoesqueleto y las proteínas accesorias. Así la polimerización de F-actina promovida por las proteínas nucleadoras, junto con la formación de la cubierta permiten que la vesícula crezca. En este sentido, se ha visto que la F-actina es totalmente necesaria para que se lleve a cabo el proceso de endocitosis en levaduras. Así mismo, se ha visto que el citoesqueleto de microtúbulos junto con el de actina es importante para promover la formación de estructuras membranosas tubulares en mamíferos (Anitei and Hoflack, 2012; Boettner et al., 2012; Girao et al., 2008; Weinberg and Drubin, 2012).

\section{Escisión de la vesícula:}

Para que ocurra la liberación de la vesícula de la membrana de origen se necesita la tensión generada por la polimerización de actina, cambios en la composición lipídica y la intervención de diferentes proteínas que ayuden a estrangular la porción de membrana que une a la vesícula con el compartimento donador (figura 2; McMahon and Boucrot, 2015). En este último proceso participan las dinaminas y las proteínas con dominios N- y F-BAR como la anfifisina. Las proteínas con dominios BAR facilitan la formación de túbulos 
induciendo la curvatura de la membrana. Las dinaminas son GTPasas que oligomerizan formando un collar en el cuello de la vesícula naciente y se constriñen al hidrolizar GTP posibilitando la escisión de la vesícula (Antonny et al., 2016; Daumke et al., 2014; Ramachandran, 2011). Además, interaccionan con diversos reguladores de actina (Anitei and Hoflack, 2012).

\subsubsection{Transporte de la vesícula por el citoplasma.}

Tras la liberación de la vesícula del compartimento de salida, esta se desplaza por el citoplasma hacia su destino final (figura 2). Este transporte está mediado por el citoesqueleto. Los cables de actina y los microtúbulos sirven como vías para conducir a la vesícula por la célula. Las proteínas motoras aportan la fuerza necesaria para que se produzca el movimiento vesicular. Las proteínas motoras que actúan sobre los cables de actina son las miosinas, mientras que las quinesinas y dineínas actúan sobre los microtúbulos (Anitei and Hoflack, 2012; Boettner et al., 2012; Weinberg and Drubin, 2012).

\subsubsection{Desensamblaje de la cubierta proteica.}

Para que se produzca la fusión de la vesícula con la membrana del orgánulo de destino es necesario que se produzca el desensamblaje de la cubierta proteica de la vesícula, al menos parcialmente, dejando la membrana descubierta en algunas zonas (figura 2). En este proceso son importantes los cambios en la composición lipídica y la inactivación de las GTPasas que controlan la formación de la cubierta. En el caso de la cubierta de clatrina es necesario el reclutamiento de ciertos factores como la ATPasa Hsp70 y otras proteínas accesorias para que se produzca su desensamblaje (Boettner et al., 2012; Kirchhausen et al., 2014).

Inicialmente se creía que el desensamblaje de las cubiertas se producía poco después de la escisión de la vesícula de la membrana donadora. Sin embargo, más recientemente se ha visto que algunas cubiertas se mantienen en la vesícula hasta el anclaje con la membrana de destino. De hecho, ciertas cubiertas interaccionan con los complejos amarra para facilitar este proceso, siendo esta interacción importante para que se produzca el desensamblaje completo de la cubierta. En estos casos las proteínas de la 
cubierta podrían tener un papel en la identificación de la vesícula por el orgánulo diana (Cai et al., 2007; Schroeter et al., 2016; Trahey and Hay, 2010).

\subsubsection{Anclaje a la membrana de destino.}

Tras su viaje por el citoplasma la vesícula debe reconocer y anclarse al orgánulo diana para fusionarse con él posteriormente (figura 2). Este reconocimiento está mediado por los factores amarra o "tethers", que forman un puente entre la vesícula y el orgánulo diana. Aunque algunos tienen dominios transmembrana, la mayoría son proteínas solubles y se reclutan a las membranas por la interacción con GTPasas. Algunos pueden interaccionar también con fosfolípidos, con proteínas de la cubierta o con SNARES (Soluble N-ethylmaleimide-sensitive factor Attachment protein REceptor). Estas últimas proteínas median la fusión de membranas y se ha propuesto que la interacción con los factores amarra facilita su función (Bröcker et al., 2010; Cai et al., 2007). Los factores amarra se pueden separar en dos categorías:

- Proteínas largas con múltiples hélices superenrolladas (dominios "coiled-coil”): Estas proteínas se disponen en dímeros que constan de dos cabezas globulares conectadas por dominios coiled-coil muy largos. Ejemplos de estas proteínas serían las golginas presentes en el complejo de Golgi, y el factor EEA1 (Early Endosomal Antigen 1) presente en los endosomas.

- Complejos con múltiples subunidades o MTCs (Multisubunit Tethering Complexes): Suelen estar compuestos por entre tres y diez subunidades y se pueden dividir en tres grupos: Aquellos que participan en procesos de fusión en los orgánulos de la ruta de secreción (Dsl1, COG, GARP y el exocisto), los que participan en la ruta endosomal (CORVET y HOPS) y los complejos TRAPP $(I, I I, I I I)$ que son GEFs multiméricos que promueven la fusión de las membranas (Bröcker et al., 2010; Gillingham, 2018; Schroeter et al., 2016; Sztul and Lupashin, 2006).

\subsubsection{Fusión con el compartimento de destino o aceptor.}

El último paso en el tráfico vesicular es la fusión de la vesícula con el compartimento aceptor (figura 2). Este proceso se desencadena por la interacción entre sí de las 
proteínas SNAREs. Todas ellas tienen un dominio característico con plegamiento en $\alpha$ hélice formado por unos 60-70 aminoácidos denominado SNARE. Estos dominios tienen la capacidad de formar estructuras en hélice superenrollada o "coiled-coil". Además, la mayoría de estas proteínas se une a la membrana a través de una hélice transmembrana presente en su extremo C-terminal, aunque algunas carecen de esta hélice y se unen a la membrana por modificaciones lipídicas post-traduccionales (como palmitoilación) o mediante dominios de unión a fosfolípidos (Cheever et al., 2001; Fukasawa et al., 2004; Hosomi et al., 2015; Lee et al., 2006).

Las SNAREs están presentes tanto en la membrana de la vesícula como en la del orgánulo aceptor. La interacción entre ellas (a través de su dominio SNARE) desencadena un cambio conformacional que produce la formación de un complejo SNARE. Esto libera energía suficiente para que suceda el acercamiento de las dos membranas lipídicas y se venza su repulsión, dando como resultado su fusión (figura 3A; Risselada and Grubmüller, 2012). El complejo SNARE está formado por una SNARE presente en la vesícula (denominada V-SNARE) y dos o tres SNAREs presentes en la membrana aceptora ( $t$ SNARES) formando un haz de cuatro hélices dispuestas en paralelo (figura 3B). Algunas SNAREs pueden actuar como t-SNAREs y como v-SNAREs por lo que se ha hecho otra clasificación en base a su estructura. De esta forma, dependiendo de si presentan una arginina $(R)$ o una glutamina $(Q)$ en la posición central del dominio SNARE se denominan R- o Q-SNAREs respectivamente. Además, las Q-SNAREs se pueden dividir a su vez en Qa, Qb y Qc basándose en homología de secuencia de los dominios SNAREs. Así, un complejo SNARE estaría formado por una R-SNARE y tres Q-SNAREs cada una de un tipo diferente (Qa, Qb y Qc; figura 3B). Muchas R-SNARES actúan como v-SNAREs y muchas Q-SNARES como t-SNAREs aunque no siempre es así (Hong, 2005; Hong and Lev, 2014; Wang et al., 2017; Yoon and Munson, 2018). En diferentes pasos del tráfico participan diferentes complejos SNAREs contribuyendo a la especificidad del reconocimiento de las membranas (explicado con más detalle en el apartado 5).

Tras la fusión de la vesícula con la membrana de destino el complejo SNARE se tiene que disociar. Esto ocurre por la acción de las AAA ATPasas NSF (N-ethylmaleimideSensitive Factor) y sus proteínas adaptadoras SNAPs (Soluble NSF Attachment Protein; 
figura 3A). Así se permite que puedan participar en otro evento de fusión (Hong, 2005; Wang et al., 2017; Yoon and Munson, 2018). Finalmente, las V-SNARE son recicladas hacia el compartimento del que proceden para mediar nuevas rondas de transporte (figura 3A; Bonifacino and Glick, 2004; Hong, 2005).

En resumen, se puede decir que la perfecta coordinación del transporte vesicular depende del reconocimiento específico y de la captura de los cargos por las distintas cubiertas vesiculares, del reconocimiento de la vesícula por factores amarra y de la fusión de las membranas mediada por las SNAREs. A su vez, la regulación de todos estos factores se debe a la acción de las distintas GTPasas y fosfolípidos. Estos mecanismos de transporte vesicular están conservados en todos los eucariotas.

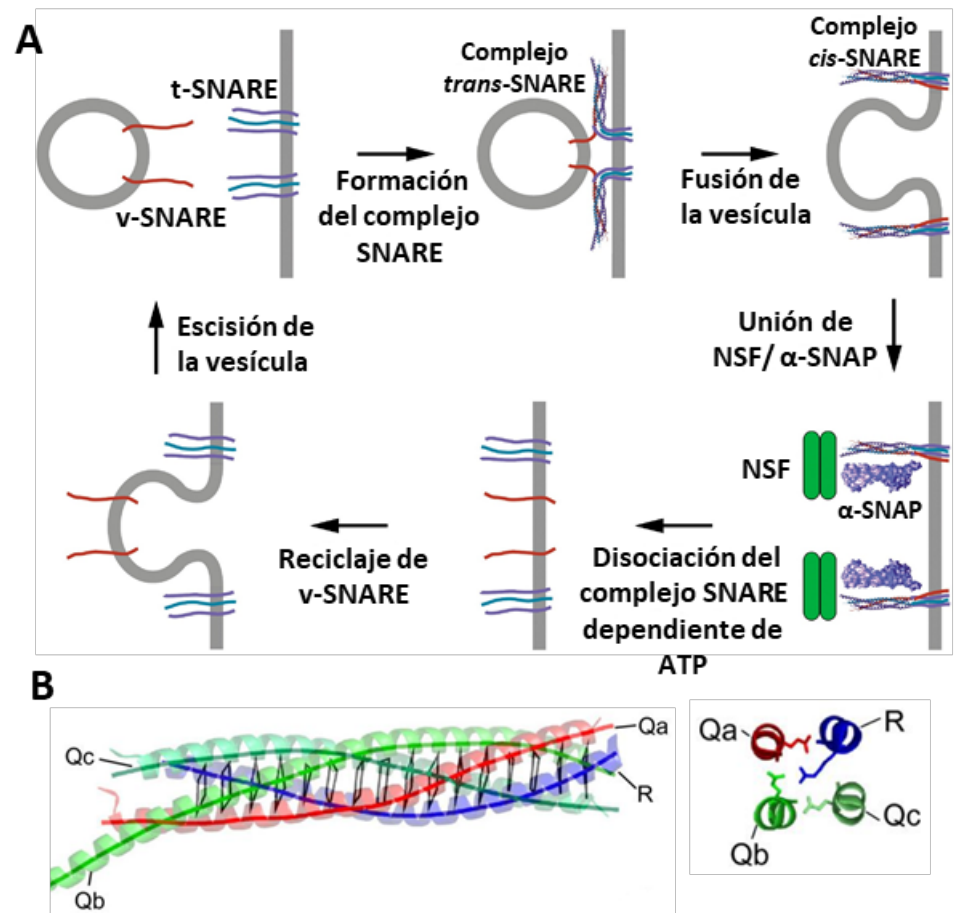

Figura 3. Función y estructura de las SNAREs. A: ciclo de las SNAREs. Una SNARE presente en la vesícula (vSNARE) interacciona con otras presentes en el compartimento aceptor (t-SNARE) formando un complejo de cuatro hélices que promueve el acercamiento y fusión de las membranas. Tras esto, se unen al complejo las proteínas SNAPs y reclutan a las ATPasas NSF que disocian el complejo SNARE mediante la hidrólisis de ATP. Finalmente se produce el reciclaje de la V-SNARE. Adaptado de Bonifacino and Glick, 2004. B: estructura del complejo SNARE. A la izquierda se muestra la representación del complejo SNARE neuronal formado por cuatro SNAREs. A la derecha se muestra una ampliación de la zona central del complejo. Cada hélice posee una glutamina (Q) o una arginina (R) que promueven la interacción entre las helices. Adaptado de Kienle et al., 2009. 


\subsection{Otros mecanismos de transporte:}

Aunque inicialmente se pensó que todo el transporte entre orgánulos se llevaba a cabo por pequeñas vesículas esféricas, el tamaño y la morfología de los intermediarios de transporte pueden variar. En este sentido, en mamíferos se ha observado la existencia de estructuras tubulares en el transporte entre los endosomas y el TGN. Además, en diferentes organismos se han detectado eventos de fusión y escisión de algunos compartimentos membranosos entre sí, como las cisternas del Golgi o las vacuolas en levaduras y los endosomas en mamíferos (Bhave et al., 2014; Gautreau et al., 2014; Wickner and Haas, 2000). Sin embargo, hasta donde se conoce, el mecanismo de formación de las estructuras tubulares y la fusión de estos compartimentos es parecido al descrito anteriormente, así como la maquinaria implicada (Bonifacino and Rojas, 2006; De Matteis and Luini, 2008; Gautreau et al., 2014; Naslavsky and Caplan, 2018).

Otro mecanismo de transporte de proteínas puede llevarse a cabo a través de la maduración de ciertos compartimentos. Este proceso se ha propuesto para el transporte de proteínas a través del complejo de Golgi, en base a estudios de microscopía realizados en levadura, y para el tráfico desde los endosomas tempranos a los tardíos en mamíferos (Huotari and Helenius, 2011; Losev et al., 2006; Matsuura-Tokita et al., 2006). Ambos procesos se explican más adelante.

\section{Rutas de tráfico vesicular intracelular. Cubiertas y adaptadores implicados}

A continuación, se van a detallar las diferentes rutas de tráfico vesicular existentes entre las distintas membranas celulares y las proteínas que posibilitan este tráfico, con especial atención en la función de los adaptadores y cubiertas en cada paso.

\subsection{Transporte entre RE y cis-Golgi.}

Como se ha mencionado anteriormente, las proteínas transmembrana o aquellas presentes en el lumen de los compartimentos que forman parte del sistema de endomembranas son sintetizadas en el RE. Aquí se asegura su correcto plegamiento mediante mecanismos de control de calidad y sufren cierta glicosilación. A continuación, 
las proteínas que tienen que llegar a otros orgánulos son transportadas hacia el complejo de Golgi. Este transporte está mediado por vesículas con cubierta COPII.

\subsubsection{Vesículas COPII (COatomer Protein II)}

Las proteínas que deben salir del RE se concentran en unos dominios especializados de la membrana de este orgánulo denominados ERES (Endoplasmic Reticulum Exit Sites). Ahí se van a concentrar también los componentes de las cubiertas COPII y diferentes proteínas accesorias (Okamoto et al., 2012; Spang, 2009). La GTPasa Sar1 es la responsable del reclutamiento de las proteínas de la cubierta a estas zonas. Esta GTPasa es activada por el GEF Sec12, lo que promueve su unión a la membrana. La cubierta COPII está formada por una capa interna y otra externa. La primera está formada por heterodímeros compuestos por las proteínas $\operatorname{Sec} 23$ y $\operatorname{Sec} 24$ y es la que interacciona con Sar1 y la que reconoce a los cargos. La capa externa interacciona con la capa interna y está formada por heterotetrámeros compuestos por dos unidades de la proteína Sec13 y dos unidades de Sec31 (Gomez-Navarro and Miller, 2016; Jensen and Schekman, 2011). Otra proteína importante en este proceso es Sec16 que actúa de andamio entre los componentes de la cubierta (Whittle and Schwartz, 2010).

Esta cubierta vesicular puede reconocer a las proteínas cargo de manera directa o mediante receptores. Entre estos receptores destacan los de la familia p24 que median el tráfico de proteínas con anclaje GPI (Glicosilfosfatidilinositol), la proteína Erv29 que facilita el tráfico de la carboxipeptidasa Y (CPY) y ERV14 que actúa como receptor de proteínas transmembrana dirigidas a la ruta de secreción (Dancourt and Barlowe, 2010; Muñiz and Zurzolo, 2014).

\subsubsection{Vesículas COPI (COatomer Protein I)}

Este tipo de vesículas participan en el tráfico retrógrado desde el Golgi al retículo y dentro del complejo de Golgi. Este tráfico es importante para la recuperación tanto de proteínas propias de un compartimento que hayan podido escapar al siguiente, como de proteínas que circulan entre dos compartimentos (como los receptores). También es importante para la recuperación de membrana desde compartimentos posteriores. 
Las cubiertas COPI están formadas por siete subunidades: $\alpha$-COP, $\beta^{\prime}-C O P, \varepsilon-C O P, \beta-$ COP, $\delta$-COP, $ү$-COP y $\zeta$-COP. En levaduras se denominan Ret1, Sec27, Sec28, Sec26, Ret2, Sec21 y Ret3 respectivamente. En mamíferos estas subunidades se asocian en heptámeros al reclutarse a la membrana. Sin embargo, en levaduras esta cubierta está ya presente en el citoplasma en forma de heptámeros (Arakel and Schwappach, 2018; Beck et al., 2009; Jackson, 2014). La asociación de COPI a la membrana se produce a través de la interacción con la GTPasa Arf1, que a su vez es activada por los GEFs Gea1 y Gea2 (Peyroche et al., 2001, 1996; Yu et al., 2012). Además, el heptámero interacciona con el cargo reconociendo señales di-lisina o di-arginina, lo que facilita también su reclutamiento a la membrana (Duden et al., 1994; Anne Eugster et al., 2004; Jackson et al., 2012; Ma and Goldberg, 2013).

Además de reconocer al cargo de manera directa, el complejo COPI puede interaccionar con receptores transmembrana que se unen a su vez a otras proteínas. Así, existen ciertos receptores que facilitan la vuelta de algunas proteínas desde el Golgi al retículo. Uno de ellos es el receptor KDEL de mamíferos (Erd2 en levaduras) que reconoce proteínas solubles que presentan el motivo KDEL (o HDEL/ADEL en levaduras; Lewis and Pelham, 1990; Semenza et al., 1990). Otro receptor es Rer1 que reconoce diferentes cargos transmembrana como Mns1, Sec12, Sec63 y Sec71 en levaduras y ciertas subunidades del complejo $r$-secretasa en mamíferos (Boehm et al., 1997; Dancourt and Barlowe, 2010; Kaether et al., 2007; Massaad et al., 1999; Nishikawa and Nakano, 1993; Sato et al., 1997; Spasic et al., 2007).

\subsection{Tráfico dentro del complejo de Golgi.}

El complejo de Golgi es el orgánulo receptor de las proteínas procedentes del RE. Su morfología varía entre diferentes organismos, incluso entre diferentes especies de levaduras. En mamíferos el complejo de Golgi está formado por múltiples agregados de varias cisternas denominados dictiosomas. Dentro de las levaduras, S. cerevisiae presenta un complejo de Golgi compuesto por diversas cisternas no apiladas, mientras que en $S$. pombe y Pichia pastoris este orgánulo se presenta en forma de varios agregados de unas pocas cisternas (Suda and Nakano, 2012). En cualquier caso, funcionalmente el complejo de Golgi se puede separar en diferentes partes. La región adyacente al retículo o región 
cis, se encarga de recibir y enviar material al RE. En las regiones medial y trans se produce la modificación del estado de glicosilación de las proteínas. Finalmente, en la red trans del Golgi o TGN se produce el reparto de proteínas y lípidos hacia otros compartimentos celulares.

Entre los modelos propuestos de transporte a través del Golgi parece que el modelo de la maduración cisternal es el más aceptado, al menos en levaduras. Según este modelo las proteínas que deben salir del complejo de Golgi lo atraviesan permaneciendo en una cisterna mientras esta avanza y madura (cambia su composición de proteínas residentes) desde la zona cis a la trans. Las proteínas residentes y características de cada zona se irán reciclando desde las cisternas trans a las cis a través de vesículas COPI. Aunque el mecanismo de maduración no se conoce con precisión, diferentes estudios de microscopía apoyan este modelo en levaduras (Casler et al., 2019; Kurokawa et al., 2019; Losev et al., 2006; Matsuura-Tokita et al., 2006). La existencia de cascadas de activación de GEFs y GTPasas de la familia Rab parece ser importante para que tenga lugar este proceso de maduración (Kim et al., 2016; Novick, 2016; Papanikou and Glick, 2014; Suda and Nakano, 2012).

\subsection{Tráfico a partir del TGN.}

EI TGN es un centro de distribución de proteínas. Desde aquí estas pueden ser transportadas hacia distintos orgánulos a través de diferentes rutas. Así, se pueden enviar a la membrana plasmática, al sistema endosomal o a las vacuolas/lisosomas. Además, todas estas rutas son bidireccionales por lo que el TGN puede recibir también material celular de todos estos compartimentos. Coordinar la llegada de material de diferente procedencia con la salida hacia distintos destinos es un proceso complejo. Para ayudar a regular todo este tráfico la célula posee diferentes proteínas de la cubierta y adaptadoras que se irán describiendo en las secciones sucesivas.

\subsubsection{Diferencias entre los modelos de sistema endosomal de mamíferos y levaduras.}

Los endosomas son compartimentos celulares que pertenecen al sistema de endomembranas. Están comunicados entre sí y con otros componentes del sistema. 
Existen diferentes tipos de endosomas dependiendo de la función que llevan a cabo, además la organización y la composición del sistema endosomal varía entre organismos (figura 4). Las células de los mamíferos tienen un sistema endosomal muy desarrollado poseyendo distintos tipos de endosomas. Los endosomas tempranos o EE (Early Endosomes) pueden intercambiar material celular con el TGN y son el primer destino de los cargos endocitados desde la membrana plasmática. Desde aquí, una parte de las proteínas endocitadas puede reciclarse directamente hacia la membrana plasmática y otra parte puede reciclarse de una manera más lenta a través de los endosomas de reciclaje. Además, algunas de las proteínas transmembrana que llegan al EE pueden ser reconocidas para su degradación. Estas se conducen a un dominio específico del EE donde son incluidas en invaginaciones que dan lugar a vesículas intraluminales o ILVs (IntraLumenal Vesicles). Posteriormente estas regiones con las ILVs se escinden del EE formando cuerpos multivesiculares o MVB (MultiVesicular Bodies). Estos pueden fusionarse entre sí y madurar dando lugar a un endosoma tardío o LE (Late Endosome) o fusionarse con un LE preexistente. EI LE recibe proteínas del TGN (como hidrolasas) y también puede reciclar proteínas hacía esta estructura. Finalmente, el LE se fusiona con un lisosoma liberando su contenido en él. En el lisosoma se produce la degradación de las proteínas presentes en las ILVs. También se han visto eventos de fusión transitorios entre el LE y el lisosoma denominados "kiss-and-run"(Bright et al., 2005; Huotari and Helenius, 2011; Naslavsky and Caplan, 2018; Scott et al., 2014). Por tanto, en el paso de EE a LE además de eventos de tráfico vesicular y de fisión y fusión de endosomas se da un proceso de maduración. En este proceso se produce una disminución del pH luminal, un cambio en la composición de los fosfoinosítidos, así como el reclutamiento y la activación de distintas GTPasas de la familia Rab de manera secuencial (Huotari and Helenius, 2011).

En levaduras el sistema endosomal está menos desarrollado que en mamíferos (figura 4). En estos microorganismos la distinción entre TGN y endosomas tempranos ha resultado siempre complicada. En este sentido, un estudio reciente ha establecido que los endosomas tempranos se corresponden en realidad con diferentes estadios de maduración del TGN (Day et al., 2018). Por tanto, en levaduras las proteínas procedentes 
de la endocitosis son transportadas al TGN desde donde pueden ser recicladas a la membrana plasmática o desviadas hacia el denominado endosoma prevacuolar o PVE (PreVacuolar Endosome) para su degradación. Desde el TGN también se envían proteínas procedentes de la ruta biosintética a este endosoma. Además, existe un tráfico retrógrado desde el PVE al TGN. A diferencia de lo que ocurre con el LE de mamíferos, el PVE en levaduras no parece generarse por maduración, sino que es una estructura estable (Day et al., 2018). Así pues, en levadura las funciones realizadas por los diferentes endosomas de mamiferos se reparten entre el TGN y el PVE. La vacuola en levaduras es el equivalente al lisosoma de mamíferos y en ella se produce la degradación de proteínas que ya no son necesarias. Las células de $S$. cerevisiae presentan normalmente una o dos vacuolas grandes, mientras que las de S. pombe poseen varias vacuolas de un tamaño menor. Este orgánulo puede recibir material de la ruta biosintética directamente desde el TGN o a través del PVE. Las proteínas que son reconocidas para su degradación llegan a la vacuola a través del PVE (Cowles et al., 1997; Frankel and Audhya, 2018; Stepp et al., 1997).

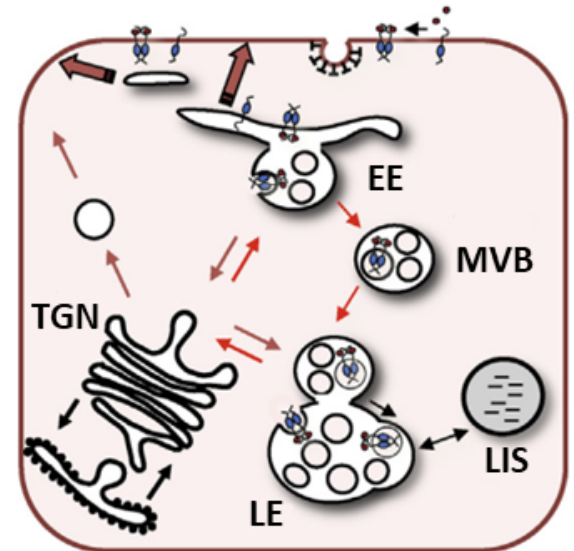

Mamífero

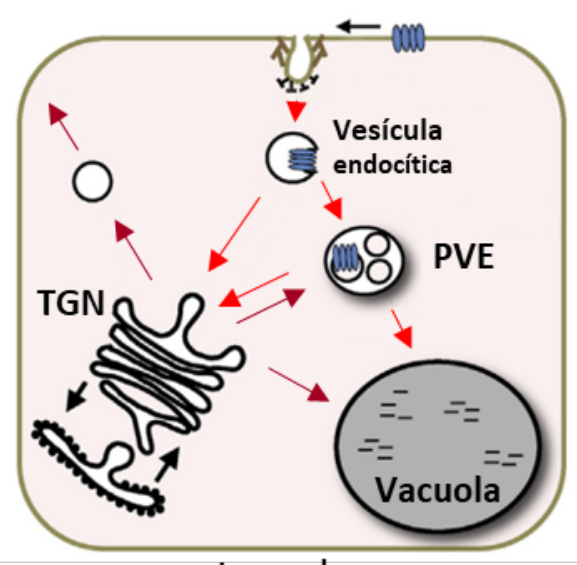

Levadura

Figura 4. Comparativa del sistema endosomal de mamíferos y levaduras. Los esquemas muestran una visión general de la organización del sistema de endomembranas en células de mamífero (izquierda) y en levaduras (derecha). Abreviaturas: TGN o red trans del Golgi, EE o endosomas tempranos, MVB o cuerpo multivesicular, LE o endosoma tardío, PVE o endosoma prevacuolar, LIS o lisosoma. Adaptado de Scott et al., 2014.

A continuación, se van a describir las diferentes cubiertas y adaptadores que participan en el tráfico entre el TGN, la membrana plasmática, los endosomas y la vacuola (figura 5A). 


\subsubsection{Tráfico mediado por clatrina. Clatrina: estructura y función}

La cubierta que poseen las vesículas recubiertas de clatrina está compuesta por la propia clatrina y por un complejo adaptador. Este tipo de cubiertas participan en el tráfico desde el TGN/EE y desde la membrana plasmática (endocitosis). Existen diferentes proteínas adaptadoras que participan en diferentes rutas de tráfico (figura 5A). Estos adaptadores pueden actuar en forma de complejos proteicos como los adaptadores APs o pueden ser monoméricos como los GGAs y las epsinas (Boehm and Bonifacino, 2001; Bonifacino and Lippincott-Schwartz, 2003; Lafer, 2002).

La unidad estructural o de ensamblaje de la clatrina se denomina trisquelión. Este está compuesto por un trímero de cadenas pesadas de clatrina (Chc1) unidas por su extremo C-terminal de forma radial, al que se unen tres cadenas ligeras (Clc1). En esta estructura cada cadena ligera se une a una cadena pesada de forma paralela (figura 5B; Kirchhausen and Harrison, 1981; Ungewickell and Branton, 1981). Para formar una vesícula se ensamblan en la membrana aproximadamente 36 trisqueliones, dando lugar a una estructura poliédrica con caras hexagonales y pentagonales que constituye un enrejado de clatrina alrededor de la membrana de la vesícula (figura 5B). Para formar esta estructura los brazos de cada uno de los trisqueliones se interconectan a través de las cadenas pesadas. La región amino-terminal de estas cadenas queda libre para contactar con los diferentes adaptadores y proteínas accesorias. Las cadenas ligeras de clatrina quedan expuestas hacia el exterior de esta estructura (Boettner et al., 2012; Brodsky, 2012; Faini et al., 2013; Fotin et al., 2004).

En mamíferos se ha visto que Clc1 no es esencial, pero es necesaria para la estabilidad de los trisqueliones (Ybe et al., 2007, 2003). La deleción o la sobreexpresión de CLC1 sólo provoca un leve defecto en el proceso de endocitosis, sin embargo, produce diversos defectos en el tráfico al nivel del TGN y los endosomas (Chen and Brodsky, 2005; Huang et al., 2004; Poupon et al., 2008).

En S. cerevisiae se ha descrito que la deleción del gen $\mathrm{CHC1}$ provoca multitud de defectos como crecimiento lento y morfología aberrante. Sin embargo, la ausencia del gen no es letal (Lemmon and Jones, 1987; Munn et al., 1991; Payne and Schekman, 1985). 
A pesar de los defectos observados en el mutante chc1 $\Delta$, algunas proteínas como la fosfatasa ácida o la invertasa se secretan de manera eficiente (Payne et al., 1987; Payne and Schekman, 1985). En este organismo los mutantes $c l c 1 \Delta$ y $c h c 1 \Delta$ presentan fenotipos similares (Chu et al., 1996; Silveira et al., 1990).
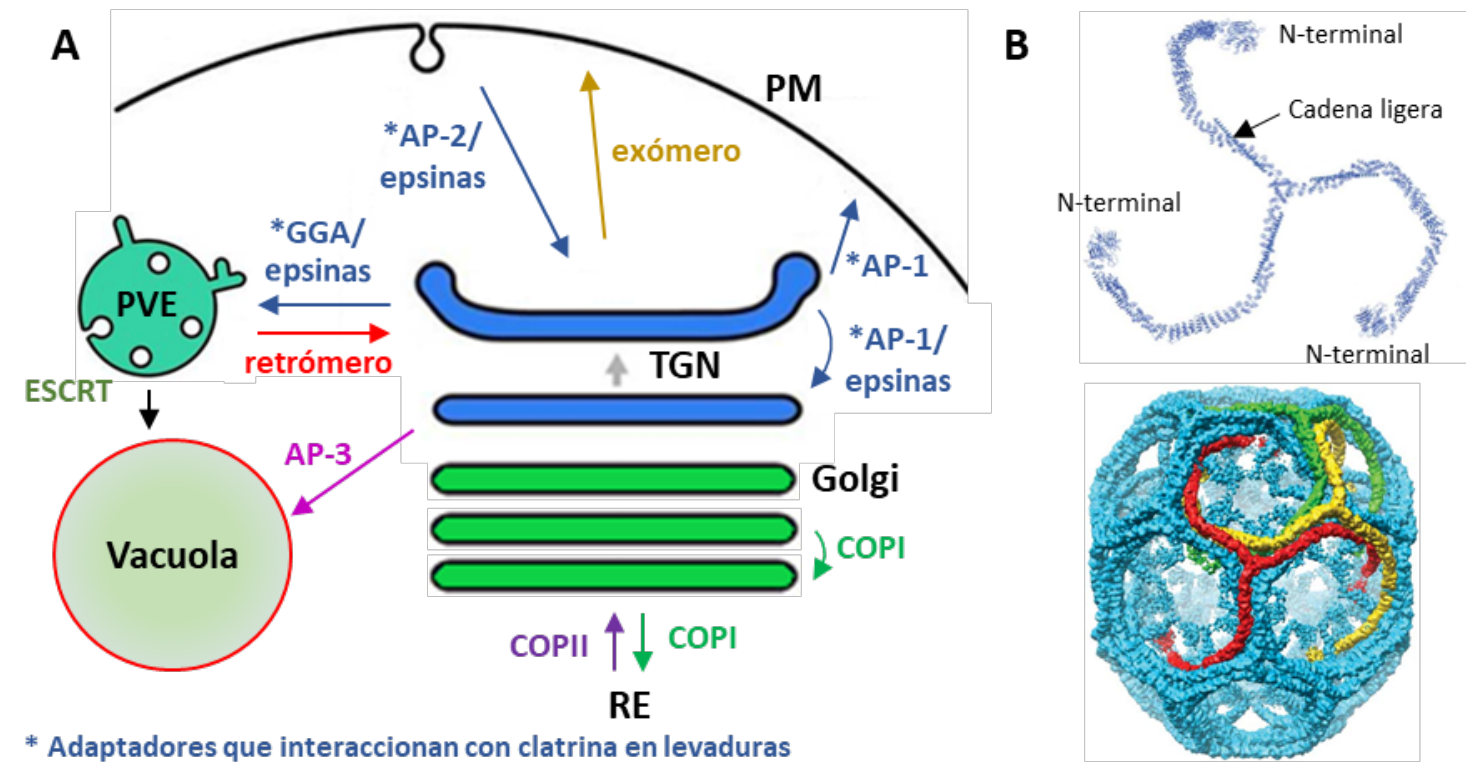

Figura 5. Cubiertas y adaptadores en el tráfico vesícular en levaduras. A: esquema con las distintas rutas de tráfico vesicular y las cubiertas y adaptadores implicadas en ellas. Abreviaturas: RE, retículo endoplásmico; TGN, red trans del Golgi; PM, membrana plasmática; y PVE, endosoma prevacuolar. Adaptado de Day et al., 2018. B: Parte superior: Representación de la estructura de un trisquelión. Se muestran las cadenas pesadas y ligeras de clatrina. Parte inferior: Ilustración de la organización de la cubierta de clatrina. Se destacan tres trisqueliones coloreados de rojo, amarillo y verde. Adaptado de Fotin et al., 2004; Kirchhausen et al., 2014.

En S. pombe tanto la deleción del gen $c / c 1^{+}$como la de $c h c 1^{+}$es letal. Esta letalidad se debe principalmente a alteraciones graves en la síntesis de la pared celular y es rescatada cuando las células se incuban en un medio estabilizado osmóticamente (de Leon et al., 2013). Las células del mutante clc1 $\Delta$ incubadas en presencia de sorbitol presentan múltiples defectos como crecimiento lento, morfología aberrante, incremento de tamaño, y defectos en el desarrollo sexual (de Leon et al., 2013).

\subsubsection{Tráfico mediado por clatrina. Los adaptadores.}

La clatrina carece de dominios de unión a las membranas por lo que necesita interaccionar con otras proteínas denominadas adaptadores que facilitan su reclutamiento a las mismas. Los adaptadores a su vez se asocian a la membrana mediante 
la interacción con las GTPasas, los fosfoininosítidos y los cargos, aunque estas interacciones varían dependiendo del adaptador. Los adaptadores difieren tanto en su estructura como en las distintas rutas de tráfico en las que intervienen (figura 5A).

\section{Complejos Adaptadores (APs)}

En mamíferos se conocen hasta el momento cinco complejos adaptadores APs (Assembly Polypeptides) denominados AP-1-5. Estos complejos se asocian a la membrana plasmática, al TGN y a los endosomas, mediando el tráfico entre estos compartimentos. De estos complejos sólo AP-1, AP-2 y AP-3 interaccionan con clatrina, mientras que AP-4 y AP-5 ejercen su función sin unirse a ella. En levaduras solamente se han descrito tres complejos pertenecientes a esta familia, AP-1, AP-2 y AP-3 (Boehm and Bonifacino, 2001; Hirst et al., 2013; Park and Guo, 2014). En S. cerevisiae se ha visto interacción física de la clatrina con el adaptador AP-1 pero no con los otros dos adaptadores (Lemmon and Traub, 2000; Yeung et al., 1999). En S. pombe por el momento sólo se ha detectado interacción física de AP-2 con clatrina (de Leon et al., 2016).

Los complejos adaptadores de tipo AP son heterotetrámeros formados por dos subunidades mayores (una subunidad $\gamma, \alpha, \delta, \varepsilon$ o $\zeta$ y una subunidad $\beta$ 1-5) con un peso molecular comprendido entre los 70-100 KDa; una subunidad mediana ( $\mu$ 1-5) de unos 50 KDa, y una subunidad pequeña ( $\sigma$ 1-5) de unos $20 \mathrm{KDa}$ (figura 6A; Boehm and Bonifacino, 2001; Park and Guo, 2014). De modo general las subunidades de los distintos complejos no son intercambiables entre sí. Sin embargo, existen algunas excepciones como las subunidades $\beta 1$ y $\beta 2$ de mamíferos que pueden formar parte tanto del complejo AP-1 como del AP-2 (Boehm and Bonifacino, 2001; Sosa et al., 2012).

Todos los complejos APs presentan una estructura similar. Las regiones amino terminales de las subunidades mayores forman un núcleo donde se unen las subunidades mediana y pequeña, mientras que las regiones carboxilo terminales forman unos apéndices (también llamados orejas) que se unen al núcleo a través de una región bisagra flexible (figura 6A). Esta última es la zona por la que el adaptador se une al dominio amino terminal de la cadena pesada de clatrina a través de motivos específicos de unión a clatrina (Clathrin box). La subunidad $\mu$ es la encargada de la interacción del complejo con 
algunos cargos y la subunidad $\sigma$ tiene un papel estabilizador del complejo y también interacciona con algunos cargos. La ausencia de alguna de las cuatro subunidades afecta drásticamente a la formación de un complejo estable (Brodsky, 2012; Fotin et al., 2004; Paczkowski et al., 2015). A continuación se va a describir con más detalle cada uno de estos complejos:

Complejo AP-1:

Este complejo está formado por las subunidades grandes $\curlyvee(A p \mid 4)$ y $\beta 1$ (Apl2), la subunidad mediana $\mu 1$ (Apm1) y la subunidad pequeña o1 (Aps1; figura 6A; Boehm and Bonifacino, 2001).

En mamíferos el complejo AP-1 se recluta a la membrana del TGN y endosomas mediante su interacción con la GTPasa Arf1, con el PI4P y con el cargo (figura 6B; Ren et al., 2013; Wang et al., 2003). En estos organismos el complejo AP-1 participa en el transporte del receptor de la manosa 6-fosfato (MPR) entre el TGN y endosomas. También está implicado en el transporte de diferentes proteínas de membrana desde el complejo de Golgi o los endosomas hasta la membrana plasmática basolateral de las células epiteliales (Boehm and Bonifacino, 2002; Bonifacino, 2014).

En S. cerevisiae diferentes mutaciones en los componentes del complejo AP-1 producen letalidad sintética con mutaciones en el gen $\mathrm{CHC1}$ y producen pequeños defectos en el procesamiento de la feromona factor $\alpha$ (Phan et al., 1994). Además, AP-1 es necesario para el reciclaje o retención de distintas proteínas dentro del TGN como las proteasas Kex2 y Ste13 (Foote and Nothwehr, 2006; Ha et al., 2003), la SNARE TIg1 (Yeung and Payne, 2001), la enzima quitín sintasa Chs3 (Valdivia et al., 2002), la permeasa general de aminoácidos Gap1 (O’Donnell et al., 2010), la proteína necesaria en el proceso de conjugación Fus1 (Barfield et al., 2009), la proteína priónica Pin2 (Ritz et al., 2014) y la translocasa de fosfolípidos Drs2 (Liu et al., 2008). En ausencia de algunos de los componentes del complejo AP-1 estas proteínas aparecen deslocalizadas en la membrana plasmática o en la vacuola en lugar de ser retenidas de forma eficiente en el TGN. 
En S. pombe la ausencia de alguna de las subunidades del complejo AP-1 provoca fenotipos más severos que en S. cerevisiae. Los fenotipos observados son sensibilidad térmica, defectos en citocinesis y alteraciones en la integridad de la pared celular, en la fusión de vacuolas, en la secreción de diversas enzimas y en la morfología del complejo de Golgi (Kita et al., 2004). En los mutantes de las subunidades del complejo AP-1 se deslocalizan algunas proteínas como la SNARE Syb1, la enzima $\beta(1,3)$-glucán sintasa Bgs1 y la GTPasa Rho3 que disminuyen de los sitios de secreción polarizada, quedando parcialmente retenidas en el TGN. Esto indica la importancia que tiene el complejo AP-1 en el tráfico vesicular desde esta estructura (Kita et al., 2004, 2011; Ma et al., 2009; Yu et al., 2012, 2013).

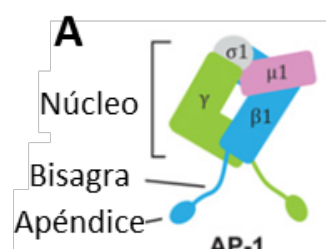

AP-1

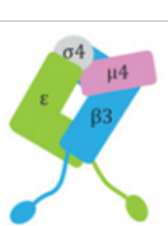

AP-4

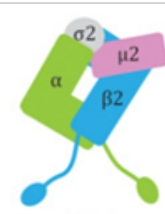

AP-2

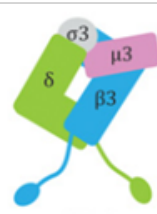

AP-3
B Membrana del TGN

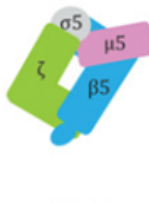

AP-5

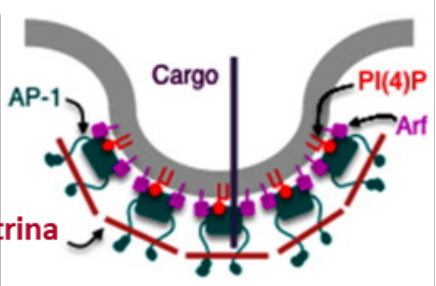

\section{C}
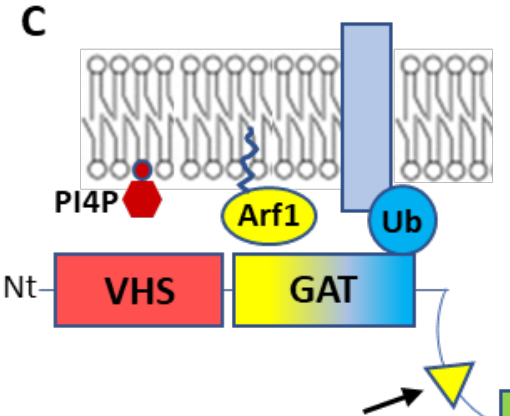

Motivo de unión a clatrina
D

1

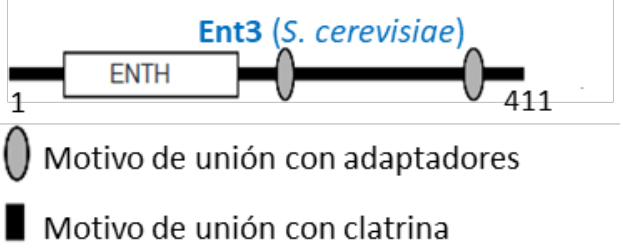

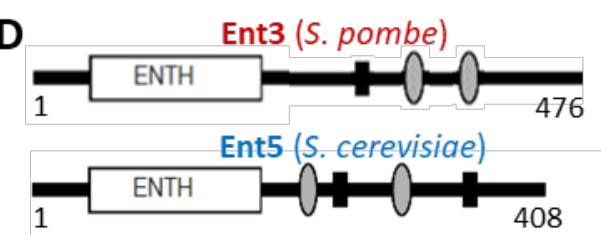

Figura 6. Estructura de diferentes adaptadores de clatrina. A: representación de la estructura de los complejos APs. Se muestran las subunidades que los componen y algunos dominios importantes para su función. Adaptado de Park and Guo, 2014. B: Esquema que muestra la interacción de AP-1 con clatrina y con distintos factores del TGN que permiten su reclutamiento. Adaptado de Canagarajah et al., 2013 C: representación de los dominios de los adaptadores GGAs y de los factores con los que interaccionan. Ub: ubiquitina. D: esquema con los dominios y motivos de las epsinas endosomales de $S$. pombe y $S$. cerevisiae. Se indica el tamaño de estas proteínas en número de aminoácidos. Adaptado de Duncan et al., 2003. 


\section{Complejo AP-2:}

Está compuesto por las subunidades mayores $\alpha(A p \mid 3)$ y $\beta 2$ (Apl1), la subunidad mediana $\mu 2$ (Apm4) y la subunidad pequeña o2 (Aps2) (figura 6A; Yeung et al., 1999). Este adaptador se localiza en la membrana plasmática donde participa en la endocitosis mediada por clatrina (Boehm and Bonifacino, 2001). AP-2 es reclutado a la membrana plasmática al interaccionar con el PI(4,5)P2. En mamíferos la interacción de AP-2 con la GTPasa Arf6 también podría facilitar su reclutamiento (Krauss et al., 2003; Paleotti et al., 2005). Además, el complejo interacciona con los cargos para permitir su endocitosis (Jackson et al., 2010). En mamíferos este adaptador participa en la endocitosis mediada por clatrina de una amplia variedad de proteínas incluyendo receptores, moléculas de adhesión y proteínas virales (Goh et al., 2010; Huang et al., 2012; Kamiguchi et al., 1998; Kastning et al., 2007; Lakadamyali et al., 2006; Maurer and Cooper, 2006; Motley et al., 2003)

En S. cerevisiae, al igual que ocurre en otros organismos, el complejo AP-2 se localiza en los lugares de endocitosis activa (Carroll et al., 2009; Kaksonen et al., 2005). Sin embargo, en esta levadura no se ha encontrado interacción física entre el adaptador y la clatrina ni una alteración general de la endocitosis cuando falta alguna subunidad del complejo (Carroll et al., 2009; Yeung et al., 1999). Hasta el momento sólo se han encontrado dos proteínas que parecen ser cargos de AP-2: la toxina Killer K28 y el sensor de estrés Mid2 (Carroll et al., 2009; Chapa-y-Lazo et al., 2014). Estos datos sugieren que en S. cerevisiae AP-2 podría participar en la internalización de cargos específicos y no en el proceso general de endocitosis.

En S. pombe el complejo AP-2 interacciona físicamente con la clatrina. Además, en ausencia de Apl3 la dinámica de los parches endocíticos se altera y se produce un defecto en la endocitosis y en la polaridad celular (de Leon et al., 2016).

\section{Complejo AP-3:}

El último de los complejos APs presentes en levaduras es AP-3. Este está formado por las subunidades grandes $\delta(A p l 6)$ y $\beta 3$ (Apl5), la subunidad mediana $\mu 3$ (Apm3) y la subunidad pequeña o3 (Aps5; figura 6A). En S. cerevisiae este complejo media el tráfico 
de forma directa desde el TGN a la vacuola, es decir, sin pasar por los endosomas. Esta ruta también se denomina ALP, ya que se descubrió al analizar el tráfico de la proteína fosfatasa alcalina o ALP (ALkaline Phosphatase) que depende de AP-3 para su correcto tráfico hacia la vacuola (Cowles et al., 1997; Stepp et al., 1997). Otras proteínas que siguen esta ruta de transporte son la SNARE Vam3, la quinasa de la caseína Yck3, una proteína involucrada en el metabolismo de esfingolípidos (Ncr1) y los transportadores de aminoácidos básicos Ypq1, Ypq2 e Ypq3 (Anand et al., 2009; Cowles et al., 1997; Llinares et al., 2015). En levaduras AP-3 actúa de manera independiente de clatrina; sin embargo, estudios realizados en mamíferos han demostrado la interacción de este adaptador con clatrina y su importancia en el tráfico de proteínas hacia los lisosomas (Dell'Angelica, 2009; Robinson, 2004).

\section{Complejos AP-4 y AP-5:}

Estos complejos están ausentes en levaduras. AP-4 participa en el transporte desde el TGN hacia los endosomas y la superficie celular en mamíferos (Hirst et al., 2013). AP-5 ha sido el último de los complejos APs en descubrirse y parece participar en el reciclaje de proteínas desde el endosoma tardío hacia el TGN (Hirst et al., 2011, 2018). Ninguno de estos dos complejos interacciona con clatrina.

\section{GGAs:}

Los GGAs (Golgi-localized, Gamma-ear-containing, Arf-binding proteins) son adaptadores de clatrina monoméricos que se identificaron inicialmente en base a su similitud con la secuencia del dominio apéndice del complejo AP-1. Participan en el tráfico desde el TGN al PVE/LE, aunque también se ha descrito su papel en la retención de proteínas en el TGN. En mamíferos hay tres GGAs denominados GGA1, GGA2 y GGA3. En S. cerevisiae hay dos de estos adaptadores, GGA1 y GGA2. En S. pombe también hay dos denominados $g g a 21^{+}$y $g g a 22^{+}$por presentar mayor similitud con el gen GGA2 de $S$. cerevisiae (Bonifacino, 2004).

Todos los GGAs presentan una estructura similar conteniendo tres dominios que, ordenados desde la zona N-terminal de la proteína, son: VHS (Vps27, Hsr, Stam), GAT (GGA y TOM) y GAE (Gamma-Adaptin-Ear; figura 6B). El dominio VHS en mamíferos es el 
encargado de unirse al cargo mediante el reconocimiento de motivos acídicos dileucina en las partes citosólicas de los mismos (Misra et al., 2002). En levaduras este dominio presenta una función diferente, siendo importante para la localización del adaptador, ya que facilita la interacción con el PI4P presente en el TGN y con otras proteínas accesorias (Daboussi et al., 2017; Demmel et al., 2008; Singer-Krüger et al., 2008). El dominio GAT presenta un sitio de unión a la GTPasa Arf1 importante para el reclutamiento de los GGAs al TGN (Dell'Angelica et al., 2000; Puertollano et al., 2001b). Además, este dominio contiene otro sitio por el que reconoce cargos ubiquitinados (Scott et al., 2004; Shiba et al., 2004). El dominio GAE, que presenta similitud con el dominio oreja de la subunidad $\checkmark$ del complejo AP-1, permite la unión con otras proteínas accesorias como $\curlyvee$-sinergina, p56 y epsinR en mamíferos y Ent3 y Ent5 en levaduras (Duncan et al., 2003; Lui et al., 2003; Page et al., 1999). Los dominios GAT y GAE están separados por una región denominada bisagra que es por donde se produce la interacción con clatrina (Bonifacino, 2004).

En mamíferos las proteínas GGAs son esenciales para el transporte de diferentes hidrolasas y de sus receptores hacia los lisosomas. Además, muestran una relación funcional con el complejo AP-1 en el transporte entre el TGN y los EE. Esta relación no está clara porque AP-1 y GGAs parecen actuar en la misma ruta según algunos datos y en rutas paralelas según otros (Doray et al., 2002; Hirst et al., 2012).

En S. cerevisiae la deleción conjunta de GGA1 y GGA2 produce alteraciones en el tráfico de algunas proteasas vacuolares como la carboxipeptidasa $Y$ (Cpy1) que es una proteina soluble y la carboxipeptidasa S (Cps1) que es una proteína transmembrana (Costaguta et al., 2001; Dell'Angelica et al., 2000; Hirst et al., 2000; Zhdankina et al., 2001). También se han visto defectos en el tráfico hacia los endosomas tardíos de la SNARE Pep12, de la proteasa Kex2 y de Ego1 (subunidad del complejo EGO/GSE regulador de TORC1) en estos mutantes (Black and Pelham, 2000; Costaguta et al., 2001; De et al., 2013; Hatakeyama et al., 2019). Además, los GGAs regulan el tráfico hacia la vacuola de proteínas ubiquitinadas como Gap1, Sit1, Fur4 y Arn1 (Bilodeau et al., 2004; Deng et al., 2009; Erpapazoglou et al., 2008; Scott et al., 2004). Los resultados de todos estos estudios indican que los GGAs son importantes para el tráfico desde el TGN hacia el PVE y la 
vacuola. Sin embargo, la zona de actuación de estos adaptadores podría ser más amplia debido a que presentan interacción física con otras proteínas implicadas en el transporte dentro del propio TGN como AP-1, Ent3 y Ent5 (Costaguta et al., 2001; Duncan et al., 2003). En consonancia con esto, los GGAs están implicados en la retención de la quitín sintasa Chs3 en el TGN y en el reciclaje de la SNARE Snc1 hacia la membrana plasmática (Black and Pelham, 2000; Copic et al., 2007).

\section{Adaptadores de tipo epsina:}

Las epsinas son otra clase de adaptadores monoméricos de clatrina. Estructuralmente se caracterizan por poseer un dominio ENTH (Epsin N-Terminal Homology) en su zona N-terminal (figura 6D). A través de este dominio pueden interactuar con fosfatidilinositoles y con los cargos. Además, las epsinas suelen tener zonas de unión a clatrina fuera de este dominio. Algunas de estas proteínas pueden tener también zonas de interacción con ubiquitina (Duncan et al., 2003; Friant et al., 2003; Mills et al., 2003). Dependiendo del organismo existen distintas epsinas que pueden participar en el proceso de endocitosis o en el tráfico desde el TGN y los endosomas. A continuación, se van a describir con más detalle las epsinas implicadas en este último proceso.

En mamíferos se ha visto que epsinR es importante para el correcto tráfico de ciertas SNAREs (Vti1, sintaxina 7 y sintaxina 8) entre el TGN, los endosomas y los lisosomas (Chidambaram et al., 2004b, 2008; Hirst et al., 2004). El dominio ENTH de epsinR es necesario para la interacción con los cargos y con el PI4P presente en el TGN y su inserción en la membrana favorece la deformación de la misma (Mills et al., 2003). Además, esta proteína interacciona con otros adaptadores de clatrina como AP-1 y GGAs (Mills et al., 2003).

En S. cerevisiae hay cinco proteínas de tipo epsina. Ent1 y Ent2 participan en el proceso de endocitosis (Reider and Wendland, 2011). Ent3 y Ent5 participan en el tráfico desde el TGN y el PVE. Así, se ha visto que facilitan el transporte de algunas SNAREs que participan en el tráfico entre TGN, PVE y vacuola como Vti1, Pep12 y Syn8 (Black and Pelham, 2000; Chidambaram et al., 2008; Zimmermann et al., 2010). Además, participan en el transporte de las proteasas vacuolares Cpy1, Cps1 y Phm5 hacia la vacuola (Eugster 
et al., 2004; Friant et al., 2003). También son necesarias para el correcto tráfico hacia la vacuola de proteínas ubiquitinadas como Arn1 (Deng et al., 2009). Además de participar en el tráfico anterógrado hacia el PVE y la vacuola también participan en la retención de Chs3 en el TGN y en el reciclaje de la SNARE Snc1 y de la casein quinasa Yck2 hacia la membrana plasmática (Black and Pelham, 2000; Copic et al., 2007; Zimmermann et al., 2010). Aunque en los mutantes sencillos ent3 3 y ent5 $\Delta$ se produce algún fenotipo específico, en general es necesario delecionar ambos genes para observar defectos en el tráfico de proteínas, indicando que poseen funciones parcialmente redundantes.

Las epsinas interaccionan con las proteínas cargo, con otras proteínas adaptadoras y con la clatrina para facilitar el transporte. En este sentido Ent3 y Ent5 presentan una relación compleja con las otras proteínas adaptadoras y con la clatrina. Así, Ent3 y Ent5 interaccionan con Gga2 en ensayos in vitro e in vivo. Además Ent5 interacciona con AP-1 y con clatrina en ambos tipos de ensayos, lo cual está de acuerdo con que sólo esta última epsina presenta los motivos consenso de interacción con la cubierta (figura 6D; Duncan et al., 2003). Sin embargo, también se ha visto inmunoprecipitación de Ent3 con clatrina, aunque esta interacción podría ser indirecta a través de Gga2 (Friant et al., 2003). La interacción de las epsinas con los dominios "oreja" de los adaptadores Gga2 y AP-1 se produce a través de motivos acídicos con fenilalanina. Tanto Ent3 como Ent5 poseen dos de estos motivos (figura 6D; Duncan et al., 2003).

Ambas epsinas presentan diferencias en cuanto a su reclutamiento a la membrana y a su localización. En este sentido, Ent3 depende para su localización de los GGAs, mientras que Ent5 no. En consonancia con esto, Ent3 colocaliza más con Gga2 que con AP-1, mientras que Ent5 colocaliza por igual con estos dos adaptadores. Además, se ha observado que existe una mayor interacción génica de ENT3 con las subunidades del complejo AP-1 que de ENT5 con este complejo. Por todo esto se ha propuesto que Ent3 actuaría principalmente con los GGAs, mientras que Ent5 actuaría tanto con AP-1 como con los GGAs, siendo más importante para el tráfico mediado por AP-1 (Costaguta et al., 2006). Además de estas interacciones, se ha observado que Ent3 y Ent5 se unen al (PI(3,5)P2) en el PVE y a la subunidad del ESCRT Vps27 a través de su dominio ENTH. En 
este sentido, se ha visto que son importantes para la internalización de proteínas ubiquitinadas en el PVE (Eugster et al., 2004; Friant et al., 2003).

Además de las epsinas anteriores, en $S$. cerevisiae existe otra epsina poco caracterizada denominada Ent4. Se sabe que es importante para el tráfico del transportador de ferricromo Arn1 desde el TGN hacia la vacuola (Deng et al., 2009) y que el mutante doble ent3 $\Delta$ ent4 $\Delta$ presenta defectos en la maduración de Cpy1 (Chidambaram et al., 2004b).

En S. pombe hay dos epsinas. Ent1 participa en endocitosis (Sakamoto et al., 2004) y Ent3 no está caracterizada pero sería la proteína homóloga a Ent3 de S. cerevisiae. Estructuralmente posee un dominio ENTH en su zona N-terminal y dos motivos acídicos con fenilalanina que podrían ser importantes para la interacción con otros adaptadores (figura 6D; Duncan et al., 2003). Además, en su secuencia hay un posible motivo de unión a clatrina.

\subsubsection{Coordinación de los adaptadores de clatrina en el TGN}

Como se ha expuesto en los apartados anteriores, existen diversos adaptadores de clatrina que actúan en el TGN. Por ello debe existir una coordinación entre todos ellos para que se produzca una salida correcta de los cargos hacia otros compartimentos celulares. En este sentido, mediante estudios de microscopía en los que se ha analizado la colocalización y dinámica de estas proteínas, se ha observado que existe una regulación temporal de los adaptadores en el TGN (Daboussi et al., 2012). Así se ha propuesto un modelo en el que primero se uniría a la membrana del TGN la GTPasa Arf1 y pequeños niveles de la quinasa Pik1 que se encarga de la síntesis de PI4P. La unión de Gga2 a Arf1 y al PI4P permitiría su reclutamiento al TGN. Este a su vez reclutaría a Ent3 y facilitaría la unión a la membrana de más Pik1, que aumentaría los niveles locales de PI4P y permitiría el reclutamiento de más Gga2. El aumento de estos adaptadores hace que se reclute la clatrina y que se produzca una primera ola de transporte. Una vez se alcanzan unos niveles determinados de PI4P se produce el reclutamiento de AP-1 al TGN para producir una segunda ola de transporte. Así pues, el aumento progresivo en los niveles de PI4P permitiría el reclutamiento secuencial de estos adaptadores. Ent5 se recluta en bajos 
niveles durante la primera ola de transporte y sus niveles alcanzan un máximo durante la segunda (Daboussi et al., 2012, 2017). Además se ha visto que Ent5 es importante para coordinar este proceso secuencial (Hung and Duncan, 2016).

\subsubsection{Endocitosis mediada por clatrina.}

La endocitosis es el proceso que permite la internalización de proteínas y lípidos desde la membrana plasmática hacia otros compartimentos celulares. En este proceso interviene también la clatrina. En primer lugar, se produce el reclutamiento de las proteínas tempranas mediante su unión al $\mathrm{PI}(4,5) \mathrm{P} 2$ presente en la membrana plasmática, marcando los sitios de formación de la vesícula (Antonescu et al., 2011; Stefan et al., 2002). En levaduras las primeras proteínas en llegar son la clatrina, Ede1 (homóloga a Eps15 de mamíferos) y Syp1 (proteína con dominios F-BAR/ $\mu$ ) que interviene en la formación de los parches de actina (Boettner et al., 2012; Henne et al., 2010; Reider et al., 2009; Stimpson et al., 2009). A continuación, sucede la formación de la cubierta, para lo cual es necesaria la presencia de diversos adaptadores. El complejo adaptador AP-2 es el principal mediador de la endocitosis en mamíferos. En S. cerevisiae los adaptadores tipo epsina Ent1 y Ent2 y las proteínas Yap1801/2 (AP180) parecen ser los principales adaptadores en este proceso (Maldonado-Báez et al., 2008). El reconocimiento de los cargos se puede producir a través de secuencias aminoacídicas concretas presentes en los mismos o a través de la detección de ubiquitin, que es una señal de endocitosis (Goode et al., 2015; Jackson et al., 2010; MacGurn et al., 2012). Tras los adaptadores se reclutan una serie de proteínas como Sla2/End4 y Sla1 que forman parte de las cubiertas intermedia y tardía y que van a promover la unión de los Factores Promotores de la Nucleación o NPFs. Estos van a inducir la formación de una densa red de actina para facilitar la invaginación de la membrana. Lo hacen promoviendo la activación del complejo Arp2/3 que es el principal responsable de la polimerización de actina (Boettner et al., 2012; Moseley and Goode, 2006). La formación de estos filamentos, junto con la fuerza motora ejercida por las miosinas produce la invaginación de la membrana para permitir la posterior escisión de la vesícula. En S. cerevisiae para que se produzca esta escisión son importantes las anfifisinas Rvs161 y Rvs167. En S. pombe las proteínas Cdc15 y Bzz1 que poseen dominios F-BAR parecen ser críticas en este proceso (Arasada and 
Pollard, 2011; Idrissi and Geli, 2014). También son necesarias las fosfatasas Slj1 y Slj2 (sinaptojaninas) que defosforilan el $\mathrm{PI}(4,5) \mathrm{P} 2$ adyacente a la vesícula para permitir la deformación de la membrana y favorecer la acción de las anfifisinas (Liu et al., 2009). Una vez ocurre la escisión de la vesícula tiene lugar la despolimerización de la cubierta (Boettner et al., 2012; Doherty and McMahon, 2009).

\subsubsection{Tráfico independiente de clatrina.}

\section{Exómero:}

El exómero es un complejo proteico con características intermedias entre adaptador y cubierta. Fue descrito inicialmente en S. cerevisiae donde participa en el transporte de proteínas desde el TGN hacia la membrana plasmática de una forma polarizada (Sanchatjate and Schekman, 2006; Trautwein et al., 2006; Wang et al., 2006). Estructuralmente el exómero es un heterotetrámero compuesto por dos copias de la proteína Chs5, que forma un andamio proteico al que se unen otras dos proteínas de la familia de las ChAPs (Chs5 and Arf1 binding Proteins) que pueden ser Chs6, Bud7, Bch1 y Bch2 (figura 7A; Paczkowski et al., 2012). Chs5 tiene una función estructural dentro del complejo y media el reclutamiento de las ChAPs a la membrana que serían las encargadas de reconocer al cargo (Rockenbauch et al., 2012; Sanchatjate and Schekman, 2006). Este complejo se localiza en el TGN y depende de la interacción con la GTPasa Arf1 para su asociación a la membrana (Trautwein et al., 2006; Wang et al., 2006). Esta interacción se produce tanto a través de Chs5 como de las ChAPs (figura 7A; Paczkowski et al., 2012). Se ha descrito que un complejo con las ChAPs Bch1 o Bud7 puede potenciar la capacidad de Arf1 para deformar membranas. Además, Bch1 ayuda a estabilizar al complejo en la membrana. Por su parte Chs6 y Bch2 tendrían un papel más relevante en el reconocimiento de los cargos (Huranova et al., 2016; Paczkowski and Fromme, 2014). Por tanto, cada ChAP tendría una función diferente dentro del complejo.

En S. cerevisiae el exómero es necesario para el transporte de ciertas proteínas desde el TGN hacia la membrana plasmática de manera polarizada. Así, promueve el transporte de la quitín sintasa Chs3 y de Pin2 (proteína con un dominio priónico y de función desconocida) a la yema incipiente de la levadura en gemación y a la zona del cuello en 
citoquinesis (Ritz et al., 2014; Sanchatjate and Schekman, 2006; Santos and Snyder, 1997; Ziman et al., 1998). También facilita el transporte de Fus1 (proteína que participa en fusión celular) hacia la punta de las proyecciones celulares durante el proceso de conjugación (Barfield et al., 2009; Santos and Snyder 2003) . Además, se ha visto que el exómero promueve el transporte polarizado de la bomba de sodio Ena1 hacia la yema de la levadura en gemación (Anton et al., 2017).

Este complejo está conservado en todo el clado de los hongos, aunque el número de ChAPs varía entre organismos. Sin embargo, no está presente en metazoos (Anton et al., 2018; Ramirez-Macias et al., 2018). En S. pombe existe una proteína homóloga a Chs5 denominada Cfr1 (Cartagena-Lirola et al., 2006) y una proteína homóloga a las ChAPs denominada Bch1. Ambas proteínas forman un complejo y son interdependientes para su correcta localización en el TGN. Cfr1 co-inmunoprecipita con Gga22 y con AP-1 y colabora con estos adaptadores en el tráfico hacia diferentes comparimentos, de manera que en ausencia del exómero se agravan los fenotipos observados en los mutantes de estos adaptadores de clatrina (Hoya et al., 2017). Por tanto, en este organismo el exómero parece presentar una función más general en el tráfico de proteínas que en $S$. cerevisiae.

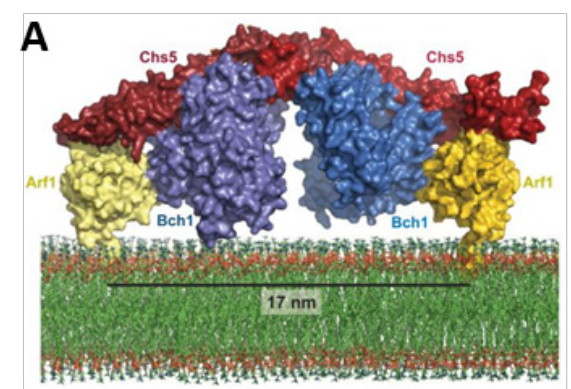

Figura 7. Estructura de exómero y retrómero. A: modelo estructural del exómero en la membrana del TGN interaccionando con dos moléculas de Arf1. Adaptado de Paczkowski and Fromme, 2014. B: parte superior e inferior, representación de las estructuras cristalizadas de las subunidades del retrómero humano. Parte central, modelo de ensamblaje del retrómero en una vesícula tubular. Se indican las diferentes subunidades en código de colores. Adaptado de Bonifacino and Hurley, 2008; Hierro et al., 2007.
B
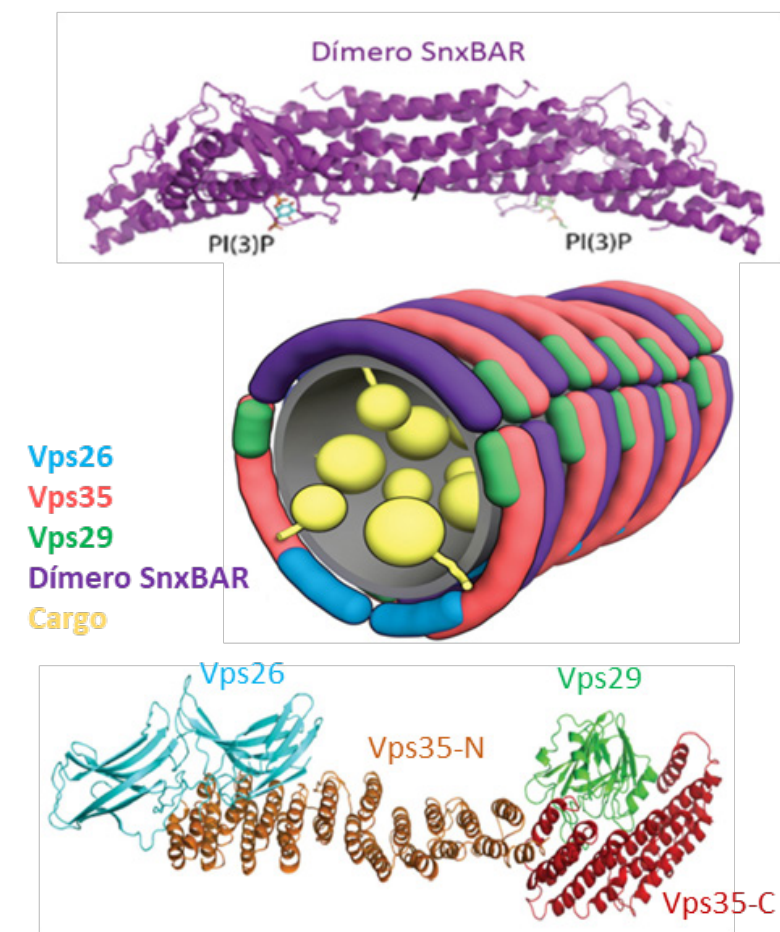


\section{Retrómero:}

El retrómero es un complejo proteico que fue identificado inicialmente en levaduras como una cubierta capaz de transportar proteínas desde el compartimento prevacuolar hacia el TGN (Seaman et al., 1997, 1998). Posteriormente este complejo se describió también en mamíferos, donde además participa en el reciclaje de proteínas desde los endosomas a la membrana plasmática. El retrómero está formado por dos subcomplejos (figura 7B). Uno es un heterotrímero formado por las proteínas Vps26, Vps35 y Vps29, y está conservado en todos los eucariotas (Haft et al., 2000; Seaman, 2004). Este subcomplejo se ha denominado CSC (Cargo Selective Complex), ya que inicialmente se identificó como el responsable de la interacción con el cargo (Arighi et al., 2004; Nothwehr et al., 2000, 1999). Dentro de este subcomplejo Vps35 interacciona con Vps29 por su extremo C-terminal y con Vps26 por su extremo N-terminal (figura 7B; Hierro et al., 2007; Shi et al., 2006). El otro subcomplejo está formado por proteínas de la familia SNX (Sorting NeXin), que pueden unirse a las membranas y deformarlas reconociendo fosfatidilinositoles (figura 7B; Gallon and Cullen, 2015; Liu, 2016). Estudios recientes han demostrado que también pueden colaborar con el CSC en el reconocimiento del cargo (Clairfeuille et al., 2016; Gallon et al., 2014; Lucas et al., 2016; Strochlic et al., 2007). Dependiendo del organismo existen diferentes SNXs capaces de interaccionar con el CSC. Así en mamíferos existen múltiples SNX que permiten al complejo asociarse a diferentes cargos y actuar en diferentes rutas (Abubakar et al., 2017; Gallon and Cullen, 2015; Liu, 2016; Wang et al., 2018). En estos organismos la interacción entre SNXs y CSC parece ser más débil que en levaduras. En S. cerevisiae el subcomplejo SNX es un dímero formado por las proteínas Vps17 y Vps5 e interacciona de manera fuerte con el CSC formando un auténtico complejo pentamérico. En este organismo Snx3 también puede interaccionar y colaborar con el CSC en el tráfico de proteínas (Strochlic et al., 2007).

El retrómero se recluta a la membrana a través de la interacción con varios elementos: el PI3P presente en los endosomas, la GTPasa Rab7 (Ypt7 en levaduras) y el cargo. El PI3P es reconocido a través del dominio PX (Phagocyte oXidase homology domain) presente en las proteínas SNXs. La interacción con la GTPasa Rab7 es esencial para el reclutamiento del CSC a la membrana en mamíferos. En levaduras esta interacción 
es importante para la función del retrómero pero no es imprescindible para su asociación con la membrana (Liu et al., 2012; Rojas et al., 2008). La interacción del retrómero con el PI3P y con Rab7/Ypt7 hace que este complejo se localice en los endosomas en los que predominan estos factores. En cuanto a la interacción con el cargo, se ha visto que para algunas proteínas es importante la presencia de ciertas secuencias de aminoácidos. Así, en levaduras la secuencia YSSL es necesaria para el reciclaje del receptor de proteasas vacuolares Vps10 hacia el TGN (Cooper and Stevens, 1996). En mamíferos la secuencia $\phi X(L / M)$ (donde $\phi$ representa un aminoácido aromático) es importante para la interacción de varias proteínas con el retrómero (Lucas et al., 2016; Seaman, 2007; Tabuchi et al., 2010). También se ha observado que el motivo FANSHY es importante para la interacción de SorLA con Vps26 (Fjorback et al., 2012). Sin embargo, no todos los cargos del retrómero contienen estas señales, por lo que serían necesarios mecanismos adicionales de reconocimiento en estos casos. Estudios recientes han establecido la importancia de algunos SNX (además del complejo CSC) en el reconocimiento del cargo. Así, en mamíferos SNX27 es importante para la interacción con dominios de unión a PDZ (PSD95-Dlg-ZO1) presentes en algunos cargos y SNX3 participa en la interacción del retrómero con proteínas con motivos $\phi X(L / M)$ (Clairfeuille et al., 2016; Gallon et al., 2014; Lucas et al., 2016). En levaduras Snx3 se une al transportador de hierro Ftr1 para facilitar su reconocimiento por el retrómero (Strochlic et al., 2007).

Tras el reclutamiento del retrómero a la membrana y la unión con el cargo se produce la deformación de la membrana. Este proceso está facilitado por los dominios BAR presentes en algunas proteínas SNXs que inducen la formación de túbulos en la membrana (figura 7B; van Weering et al., 2012). Además, el retrómero interacciona con otras proteínas como factores promotores de nucleación de actina (NPF) y dinamina que facilitan la deformación de la membrana y la escisión de la vesícula (Arlt et al., 2015; Gomez and Billadeau, 2009; Harbour et al., 2012, 2010; Jia et al., 2012).

Ciertos defectos en la función del retrómero están relacionados con la aparición de enfermedades neurodegenerativas en humanos. Así, este complejo está implicado en el reciclaje de la proteína precursora amiloidea (APP) desde los endosomas hacia el TGN al facilitar el tráfico de su receptor SorLA entre estos compartimentos (Choy et al., 2012; 
Fjorback et al., 2012). Defectos en el tráfico de APP están relacionados con la enfermedad de Alzheimer (Sannerud and Annaert, 2009). Además, se ha observado que ciertas mutaciones en Vps35 están ligadas a la manifestación de la enfermedad de Parkinson (Vilariño-Güell et al., 2011; Zimprich et al., 2011). En este sentido, el retrómero facilita el reciclaje del receptor de manosa 6-fosfato independiente de cationes (CI-MPR) desde los endosomas al TGN (Arighi et al., 2004; Seaman, 2004). Este receptor facilita el transporte de hidrolasas lisosomales como la catepsina D que está implicada en la degradación de $\alpha$-sinucleína. Ante la pérdida de función del retrómero se producen defectos en el tráfico de Cl-MPR y de catepsina $\mathrm{D}$ y como consecuencia una acumulación de $\alpha$-sinucleína en los endosomas. Esta última parece ser la responsable de la toxicidad celular en la enfermedad de Parkinson (Follett et al., 2014; Miura et al., 2014; Qiao et al., 2008). Además de los receptores anteriores, el retrómero facilita el tráfico desde los endosomas hacia el TGN de otras proteínas como sortilina, SorCS1 (sortilin-related Vps10 domain related receptor 1), DMT1 (Divalent Metal Transproter 1) y el receptor de señalización Wntless. (Gallon and Cullen, 2015; Liu, 2016). También es necesario para el reciclaje de otras proteínas desde los endosomas hacia la membrana plasmática como TGF- $\beta$ (Transforming Growth Factor $\beta$ ), el receptor $\beta 2 A R$ ( $\beta 2$ Adrenergic Receptor), la proteína de adhesión celular cadherina-E y los receptores de glucosa GLUT1 y GUT4 (Gallon and Cullen, 2015; Liu, 2016; Pan et al., 2017).

En S. cerevisiae el retrómero facilita el reciclaje de diferentes proteínas transmembrana desde el PVE hacia el TGN. El primer cargo en caracterizarse fue el receptor vacuolar Vps10 (del cual se habla en detalle en el apartado 6.1), que facilita el transporte de algunas proteasas desde el TGN hacia la vacuola (Seaman et al., 1998, 1997). Posteriormente, se han descubierto más cargos de este complejo como las proteasas Kex2 y Ste13, Yif1, la permeasa de arginina Can1 y el complejo transportador de hierro Fet3-Ftr1 (Kama et al., 2007; Nothwehr et al., 2000; Nothwehr and Hindes, 1997; Shi et al., 2011; Strochlic et al., 2007). Además, recientemente se ha visto que parte de la quitín sintasa Chs3 es reciclada hacia el TGN por el retrómero (Arcones et al., 2016). 
En S. pombe el retrómero es necesario para el reciclaje de Vps10 hacia el TGN. Así, esta proteína se observa en la membrana de la vacuola en ausencia de este complejo (Iwaki et al., 2006).

\section{Retriever:}

Recientemente se ha descubierto en mamíferos un complejo denominado retriever que participa en el reciclaje de proteínas desde los endosomas hacia la membrana plasmática de manera independiente del retrómero (McNally et al., 2017). El retriever es un heterotetrámero formado por DSCR3 (parálogo de Vps26), C16orf62 (parecido estructuralmente a Vps35) y Vps29 (subunidad que también forma parte del retrómero). Este complejo colabora con la sintaxina SNX17 para reciclar proteínas desde los endosomas (McNally and Cullen, 2018; Wang et al., 2018). El retriever surgió pronto en la evolución, sin embargo, DSCR3 y C16orf62 se han perdido en muchos organismos, entre los que se encuentran los hongos (McNally et al., 2017).

\section{ESCRT:}

Algunas proteínas de membrana deben ser degradadas, ya sea en un momento concreto debido a una señal determinada, o de una manera continua para que ocurra un cierto recambio de las mismas. Otras proteínas transmembrana deben sufrir una proteólisis parcial en la vacuola o lisosoma para alcanzar su estado maduro. En todos estos casos las proteínas deben ser internalizadas en el lumen del endosoma mediante la generación de vesículas intraluminales o ILVs (Intra-Lumenal Vesicles) en un proceso que da lugar a la formación del cuerpo multivesicular o MVB (MultiVesicular Body). Posteriormente este MVB se fusionará con la vacuola o lisosoma para que se produzca la degradación o procesamiento de las proteínas presentes en las ILVs. El reconocimiento de estas proteínas y la formación de las ILVs es un proceso que requiere una maquinaria especializada denominada ESCRT (Endosomal Sorting Complex Required for Transport). Este complejo está formado por cinco subcomplejos altamente conservados: ESCRT-0, ESCRT-I, ESCRT-II, ESCRT-III y la ATPasa Vps4 (figura 8). 


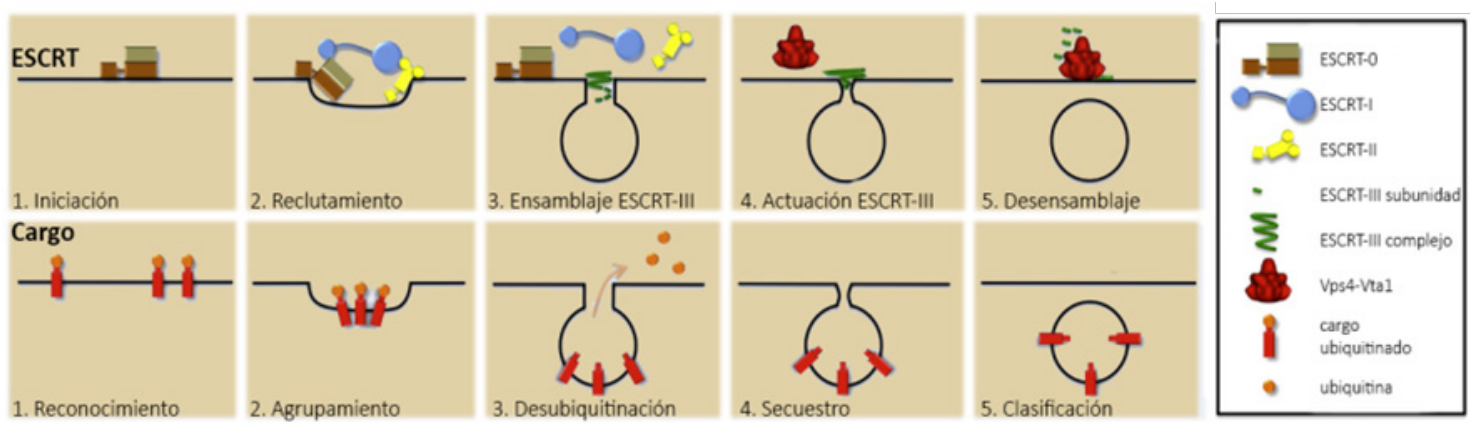

Figura 8. Mecanismo de funcionamiento del ESCRT. Se representa el proceso de formación de ILVs en cinco etapas. En la parte superior se detalla el proceso desde el punto de vista del ESCRT y en la inferior desde el punto de vista del cargo. EI ESCRT-0 recluta al cargo ubiquitinado (1) al que también se unen posteriormente los ESCRTs I y II, creando regiones enriquecidas en cargo (2). El ESCRT III promueve la formación de la vesícula y la desubuquitinación del cargo (3 y 4). Finalmente el ESCRT III se desensambla por la acción de la ATPasa Vps4 (5). Adaptado de Henne et al., 2011.

EI ESCRT-0 es el responsable del reconocimiento del cargo. En levaduras este complejo está formado por las subunidades Vps27 y Hse1 que interaccionan entre sí a través de sus dominios GAT. Vps27 posee un dominio de dedos de zinc FYVE (Fab1, YOTB, Vac1 y EEA1) que reconoce el PI3P presente en los endosomas y que permite el reclutamiento del complejo a la membrana de estos orgánulos. Ambas subunidades reconocen ubiquitina que suele ser una señal de degradación para las proteínas a las que está unida. Vps27 presenta también un dominio de unión a clatrina. La clatrina se cree que facilita el agrupamiento del ESCRT-0 en microdominios de membrana. EI ESCRT-0 media el reclutamiento del ESCRT-I (Frankel and Audhya, 2018; MacGurn et al., 2012; Schuh and Audhya, 2014).

EI ESCRT-I está formado por las proteínas Vps23, Vps28, Vps37 y Mvb12. Este complejo interacciona con Vps27 (del ESCRT-0) a través del extremo N-terminal de vps23. EI ESCRT-I también reconoce ubiquitina (Frankel and Audhya, 2018; Schuh and Audhya, 2014).

El ESCRT-II está compuesto por las proteínas Vps22, Vps36 y Vps25. Interacciona con el ESCRT-I a través del dominio GLUE (GRAM-Like Ubiquitin-binding in EAP45) de Vps36. Este dominio también se une al PI3P y reconoce ubiquitina.

Mientras que los complejos anteriores tienen como función principal el anclaje a los endosomas y el reconocimiento y agrupación de los cargos, el cometido principal del 
ESCRT-III es la formación y escisión de las ILVs (figura 8). Está formado por Vps20, Snf7, Vps24 y Vps2, y su reclutamiento ocurre gracias a la interacción entre Vps20 y Vps25 (ESCRT-II). La oligomerización de Snf7 promueve la deformación de la membrana y potencia la formación de ILVs. EI ESCRT-III también promueve el reclutamiento de la desubiquitinasa Doa4 para que ocurra la desubuiquitinación de los cargos antes de su inclusión en las ILVs. Una vez que se ha formado la vesícula intraluminal, el ESCRT-III debe disociarse de la membrana. Este proceso requiere energía y la ATPasa Vps4 es la encargada de proporcionarla (Frankel and Audhya, 2018; Henne et al., 2011; Schuh and Audhya, 2014).

La deleción de cualquiera de los elementos que forman parte de la maquinaria del ESCRT produce una pérdida de su función. En S. cerevisiae esta pérdida de función provoca la aparición de un PVE aberrante denominado endosoma E. Este es una estructura anormalmente agrandada adyacente a la vacuola, que contiene marcadores de TGN y PVE. Además quedan retenidas en él proteasas vacuolares y la ATPasa vacuolar, por lo que se produce la degradación de otras proteínas que quedan atrapadas en él (Cereghino et al., 1995; Piper et al., 1995; Raymond et al., 1992).

Además de su función en el tráfico hacia la vacuola, el ESCRT participa en otros procesos biológicos como en la citoquinesis, en la internalización de virus, en la secreción exosomal y en la autofagia (Christ et al., 2017; Henne et al., 2011).

\section{SNAREs y rutas de tráfico intracelular.}

Como se ha explicado anteriormente (apartado 3.1.5) otras proteínas importantes en el tráfico vesícular son las SNAREs. Existen diferentes complejos de estas proteínas, formados por cuatro SNAREs (R, Qa, $Q b$ y $Q c)$, que participan en distintas rutas de transporte, aunque una misma SNARE puede participar en más de una ruta (figura 9).

\subsection{SNARES y tráfico hacia la vacuola.}

En el tráfico desde el TGN hacia la vacuola participan diferentes complejos mediando distintos pasos. En este sentido, en mamíferos el complejo SNARE compuesto por Stx16 (Qa), Vti1a (Qb) Stx6 (Qc) y VAMP4 (R) media el tráfico bidireccional entre el TGN y los 
endosomas tempranos (Dingjan et al., 2018). Además se ha visto que las SNAREs Stx7 (Qa), Vti1b (Qb), Stx8 (Qc) y VAMP8 (R) forman un complejo que media la fusión homotípica de los endosomas tardíos (Antonin et al., 2000; Pryor et al., 2004), mientras que el mismo complejo pero con VAMP7 (R) media la fusión de los endosomas tardíos con los lisosomas (figura 9; Pryor et al., 2004). Stx8 también participa en la endocitosis de algunas proteínas desde la membrana plasmática (Renigunta et al., 2014).

En S. cerevisiae Tlg2 (Qa), Vti1 (Qb), Tlg1 (Qa) e Ykt6 (R) o Snc1/Snc2 (R) participan en el transporte entre TGN y EE, o según el modelo propuesto por Day y colaboradores, entre diferentes cisternas del TGN con diferentes estados de maduración (figura 9; Brickner et al., 2001; Coe et al., 1999; Holthuis et al., 1998). En S. pombe no se ha investigado la función de las SNAREs implicadas en este paso del tráfico, aunque se sabe que Syb1 (homóloga a Snc1/Snc2) circula entre estructuras internas y la membrana plasmática como ocurre en S. cerevisiae (Lewis et al., 2000; Ma et al., 2009).

A

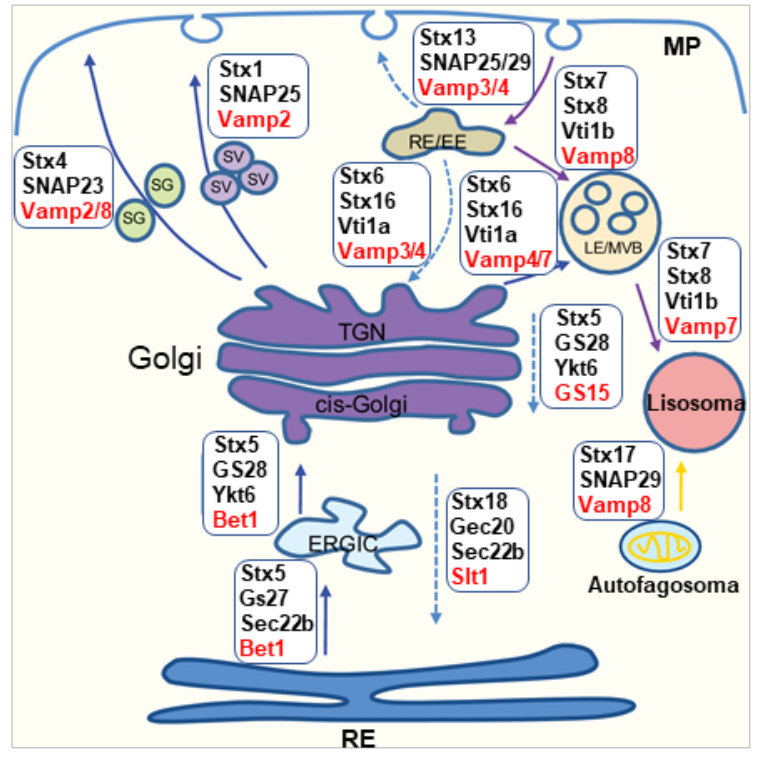

B

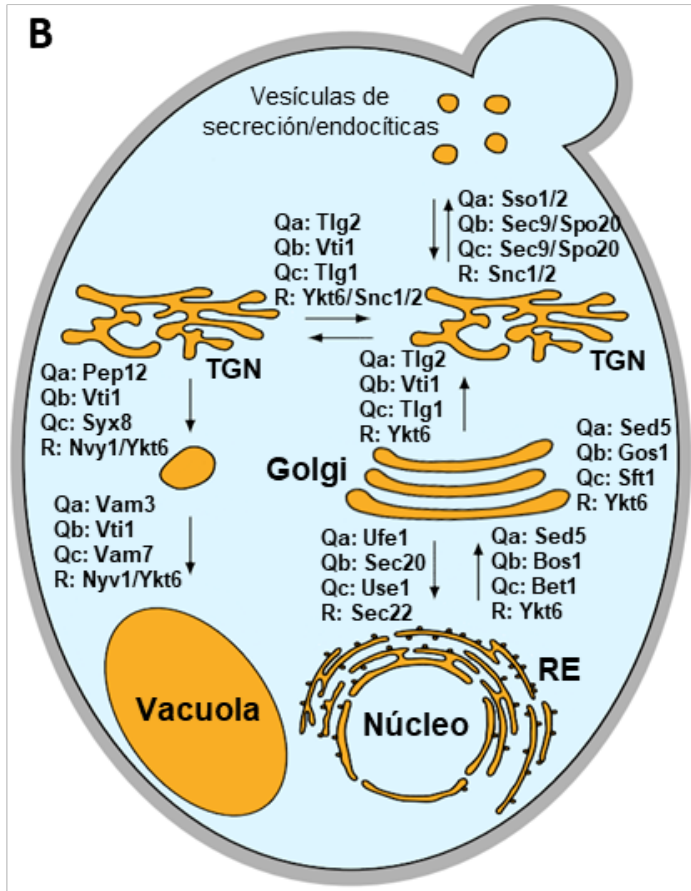

Figura 9. Papel de los diferentes complejos SNARE en los distintos pasos del tráfico. Comparativa entre células de mamífero (A) y levadura (B). En A las V-SNAREs están marcadas en rojo. Abreviaturas: RE, retículo endoplásmico; ERGIC, compartimento intermedio Golgi-RE; TGN, red trans del Golgi; RE/EE, endosomas de reciclaje/tempranos; MP, membrana plasmática; LE/MVB, endosoma tardío/cuerpo multivesicular; SG, gránulo secretor; SV, vesícula sináptica. Adaptado de Wang et al., 2017; Kienle et al., 2009. 
En S. cerevisiae Pep12 (Qa), Vti1 (Qb), Syn8 (Qc) y Nyv1 o Ykt6 (R) colaboran en el transporte entre el TGN y el PVE (Kweon et al., 2003; Lewis and Pelham, 2002; von Mollard and Stevens, 1999), mientras que Vam3 (Qa), Vti1 (Qb), Vam7 (Qc) y Nyv1 o Ykt6 (R) facilitan el transporte entre PVE y vacuolas y la fusión homotípica de estas últimas (figura 9; Ungermann et al., 1999; Ungermann and Wickner, 1998). La participación de estas proteínas en las diferentes rutas de tráfico se ha establecido en base a su localización intracelular, a la interacción con otras SNAREs y a la presencia de defectos morfológicos en determinados compartimentos. Además, las SNAREs implicadas en el tráfico desde el TGN hacia la vacuola presentan problemas de maduración de proteasas vacuolares como CPY y ALP. En S. pombe la mayoría de estas SNAREs están conservadas excepto Nyv1, que se perdió durante la evolución de este organismo, y Vam3 que está presente exclusivamente en el linaje Saccharomycotina, donde Pep12 y Vam3 se duplicaron a partir de una SNARE común (Kienle et al., 2009). En la levadura de fisión Vti1 e Ykt6 son proteínas que están sin caracterizar y que son esenciales para la viabilidad celular (Hayles et al., 2013; Kim et al., 2010). Pep12 se localiza en la membrana vacuolar y en el PVE. Se ha descrito que en su ausencia se producen defectos en la maduración de CPY y su secreción parcial hacía el exterior celular, indicando defectos en el tráfico hacia la vacuola (Hosomi et al., 2011). Sin embargo, según los resultados de otros investigadores (Hayles et al., 2013; Kim et al., 2010) y los de nuestro laboratorio, esta proteína es esencial. Fsv1 es la proteína homóloga a Syn8 de S. cerevisiae y en su ausencia se producen alteraciones en el tráfico de Cpy1 (Takegawa et al., 2003). Vsl1 es la proteína homóloga a Vam7 de S. cerevisiae y se localiza en la membrana de la vacuola y en el PVE (Hosomi et al., 2015).

Además de poseer un dominio SNARE, del que se ha hablado anteriormente, las SNAREs presentan otras características estructurales que varían en función de la proteína (figura 10). Así, la mayoría de estas proteínas presenta una hélice transmembrana cercana a su extremo C-terminal, aunque otras como Vam7/Vsl1 o Ykt6 carecen de ella. Vam7/Vsl1 se une a la membrana reconociendo el PI3P presente en el PVE mediante su dominio PX (Cheever et al., 2001; Hosomi et al., 2015). Ykt6 sufre prenilación y palmitoilación en su extremo C-terminal y se une a la membrana a través de estas 
modificaciones (Fukasawa et al., 2004; McNew et al., 1997). Además, algunas de estas proteínas presentan otros dominios como el Habc o el "longin" (figura 10). En mamíferos se ha visto que en Stx7, Ykt6 y VAMP7 estos dominios actúan uniéndose al dominio SNARE y previenen la formación del complejo SNARE, actuando de manera autoinhibitoria. En otros casos estos dominios facilitan la unión con otros elementos implicados en tráfico como los complejos amarra o los adaptadores (Dingjan et al., 2018). En este sentido, en S. cerevisiae se ha visto que Ent3 interacciona con Vti1 a través de su dominio Habc para permitir su correcta localización. Resultados parecidos se han obtenido en mamíferos entre Vti1b y epsinR (Chidambaram et al., 2004a; Miller et al., 2007; Wang et al., 2011). También se ha visto que el extremo $\mathrm{N}$-terminal es importante para el reconocimiento de Stx8 y Stx7 por epsinR en mamíferos y de Pep12 y Syn8 por Ent3 en levaduras (Chidambaram et al., 2008). Además, esta parte de la proteína es necesaria para el transporte de Vam3 hacia la vacuola mediado por AP-3 (Darsow et al., 1998).

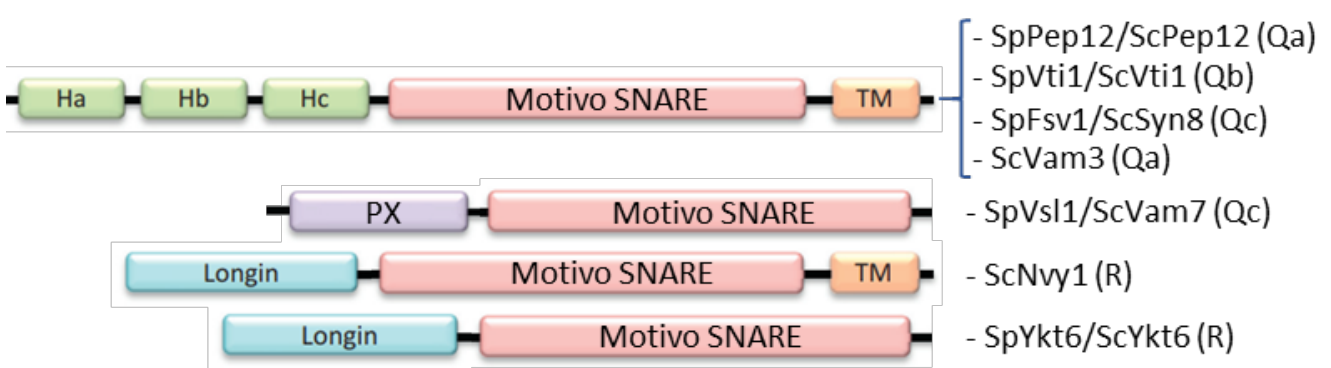

Figura 10. Organización de los dominios de las SNAREs que participan en el tráfico entre TGN y vacuola. Se muestran las SNARE de $S$. pombe $(\mathrm{Sp})$ y $S$. cerevisiae $(\mathrm{Sc}$ ) y sus dominios, en algunos casos inferidos de sus homólogos en humanos. Adaptada de Hong and Lev, 2014.

\section{Cargos modelo en el tráfico TGN-PVE-Vacuola.}

Algunas proteínas tienen que ser transportadas hacia la zona endosomal tardía o hacia la vacuola/lisosoma para ejercer su función. Entre ellas están las proteasas vacuolares que permiten la degradación de proteínas en estos orgánulos. También la ATPasa vacuolar que produce la acidificación del lumen de la vacuola o lisosoma necesaria para que tengan lugar las reacciones características de estos compartimentos. Entre las distintas proteasas presentes en levaduras existen dos (Cpy1 y Cps1) cuyo transporte ha sido muy estudiado para caracterizar el tráfico entre el TGN y la vacuola. Vph1, la 
subunidad a del complejo $V_{0}$ de la ATPasa vacuolar, también se ha utilizado con este propósito.

\subsection{Tráfico de Cpy1 y Vps10.}

Cpy1 (Carboxipeptidasa 1) es una proteasa vacuolar soluble que elimina aminoácidos del extremo C-terminal de las proteínas para producir su degradación (Hayashi et al., 1973). Esta proteína se sintetiza en el retículo endoplásmico como un precursor y sufre una serie de procesamientos postraduccionales a lo largo de su viaje hacia la vacuola. EI procesamiento es parecido en S. pombe y en S. cerevisiae. El precursor inicial se denomina preproCPY y contiene un péptido señal en la zona $\mathrm{N}$-terminal, seguido de otra secuencia denominada propéptido y de la secuencia correspondiente a la proteína madura. EI péptido señal se elimina tras la entrada de la proteína en el retículo. Después la proteína se transporta al complejo de Golgi donde aumenta su estado de glicosilación. De aquí se dirige hacia la vacuola a través del PVE, una ruta que se ha denominado ruta CPY debido al tráfico de esta proteasa a través de ella. En la vacuola se elimina el propéptido de la proCPY mediante la acción de proteasas y se obtiene la proteína activa (figura 11). La misión del propétido es evitar la activación de la enzima hasta que esta llega a la vacuola, además contiene las señales para su tráfico hacia este compartimento (Hasilik and Tanner, 1978; Sørensen et al., 1994; Tabuchi et al., 1997; Valls et al., 1987).

Para que Cpy1 viaje desde el TGN hacia la vacuola es necesaria la participación del receptor Vps10. Este es una proteína con un paso transmembrana que posee una parte $\mathrm{N}$-terminal luminal larga y una parte citoplásmica corta. A través de su extremo $\mathrm{N}$ terminal reconoce y se une a Cpy1 en el TGN y la transporta hasta el PVE donde ambas proteínas se disocian. Finalmente, Vps10 retorna al TGN para realizar una nueva ronda de transporte (figura 11). En ausencia de Vps10, Cpy1 no llega adecuadamente a la vacuola, sino que es secretada al exterior celular (Iwaki et al., 2006; Jørgensen et al., 1999; Marcusson et al., 1994). El transporte de Cpy1 y de su receptor ha sido muy estudiado y ha permitido identificar diferentes proteínas implicadas en el tráfico entre el TGN y el PVE. En este sentido, se sabe que el tráfico retrógrado de Vps10 desde el PVE al TGN depende del retrómero que reconoce una señal (YSSL) presente en la parte citosólica del receptor (Cooper and Stevens, 1996; Iwaki et al., 2006; Seaman et al., 1998, 1997). En 
S.cerevisiae también se sabe que los GGAs tienen un papel en el tráfico anterógrado del receptor desde el TGN hacia el PVE, aunque en este caso existen algunos resultados contradictorios. Así, ciertos experimentos apoyan la función de los GGAs en este paso del tráfico de Vps10. Se ha visto que en células sin estos adaptadores se producen alteraciones en la maduración de Cpy1 y parte de esta proteína se secreta, algo que no se observa en la cepa silvestre. También se ha observado que el dominio VHS de los GGAs en levaduras interacciona con el extremo C-terminal de Vps10 por dos híbridos. Además, Vps10 se degrada en un mutante del ESCRT (vps284), al quedar atrapado en el endosoma E. Sin embargo, en un mutante gga1 $\operatorname{gga} 2 \Delta$ vps $28 \Delta$ la proteína se estabiliza, indicando que en ausencia de los GGAs este receptor no llega al endosoma $E$ y queda bloqueado en un punto anterior del tráfico (Costaguta et al., 2001; De et al., 2013; Dell'Angelica et al., 2000; Hirst et al., 2000; Zhdankina et al., 2001). Otros experimentos contradicen a los anteriores. En este sentido, se ha visto que al delecionar la parte citoplásmica de Vps10 (por dónde interaccionaría con los GGAs), queda retenido en la vacuola, indicando que esta parte no es necesaria para la salida desde el TGN. Además, en mutantes nulos de clatrina no se produce secreción de Cpy1, habiéndose propuesto que en ausencia de esta cubierta el receptor viaja a través de la membrana plasmática hacia el endosoma tardío para permitir el transporte de la proteasa (Cooper and Stevens, 1996; Deloche et al., 2001; Deloche and Schekman, 2002; Payne et al., 1988; Seeger and Payne, 1992).

En mamíferos existe una familia de receptores con dominios Vps10 formada por cinco miembros: Sortilina, SorCS1, SorCS2, SorCS3 y SorLA (Hermey, 2009). Estos receptores ayudan a transportar diferentes proteínas en distintas rutas celulares y las alteraciones en su funcionamiento están relacionadas con diferentes enfermedades neurodegenerativas, cardiovasculares, metabólicas e incluso cáncer (Fjorback et al., 2012; Goettsch Claudia et al., 2018; Wang et al., 2014; Wilson et al., 2016).

\subsection{Tráfico de Cps1.}

En S. cerevisiae Cps1 (Carboxipeptidasa S) es una proteasa vacuolar que se sintetiza en el RE como un precursor. Este posee una parte C-terminal intraluminal larga seguida de un dominio transmembrana y una parte $\mathrm{N}$-terminal citosólica corta (figura 11). El precursor alcanza el TGN y desde allí se dirige hacia el PVE. Aquí se incluye en ILVs en un 
proceso dependiente de ubiquitinación y mediado por el ESCRT. Posteriormente, mediante la fusión del PVE con la vacuola, las ILVs se liberan en el interior de esta y Cps1 es cortada por proteasas vacuolares. Debido a este corte, gran parte del extremo luminal de la proteína se separa del resto liberándose de la membrana y alcanzando su estado maduro (figura 11; Odorizzi et al., 1998; Reggiori and Pelham, 2001; Katzmann et al., 2001; Spormann et al., 1992). Además del ESCRT, los GGAs y las epsinas (Ent3 y Ent5) son importantes para la maduración de esta proteasa. En el mutante doble ent3 $\Delta$ ent5 $\Delta$ parte de Cps1 queda retenida en la membrana de la vacuola (Costaguta et al., 2001; Duncan et al., 2003; Eugster et al., 2004; Friant et al., 2003). En S. pombe se ha visto que Cps1 depende del ESCRT para su llegada al lumen de la vacuola (Iwaki et al., 2007).

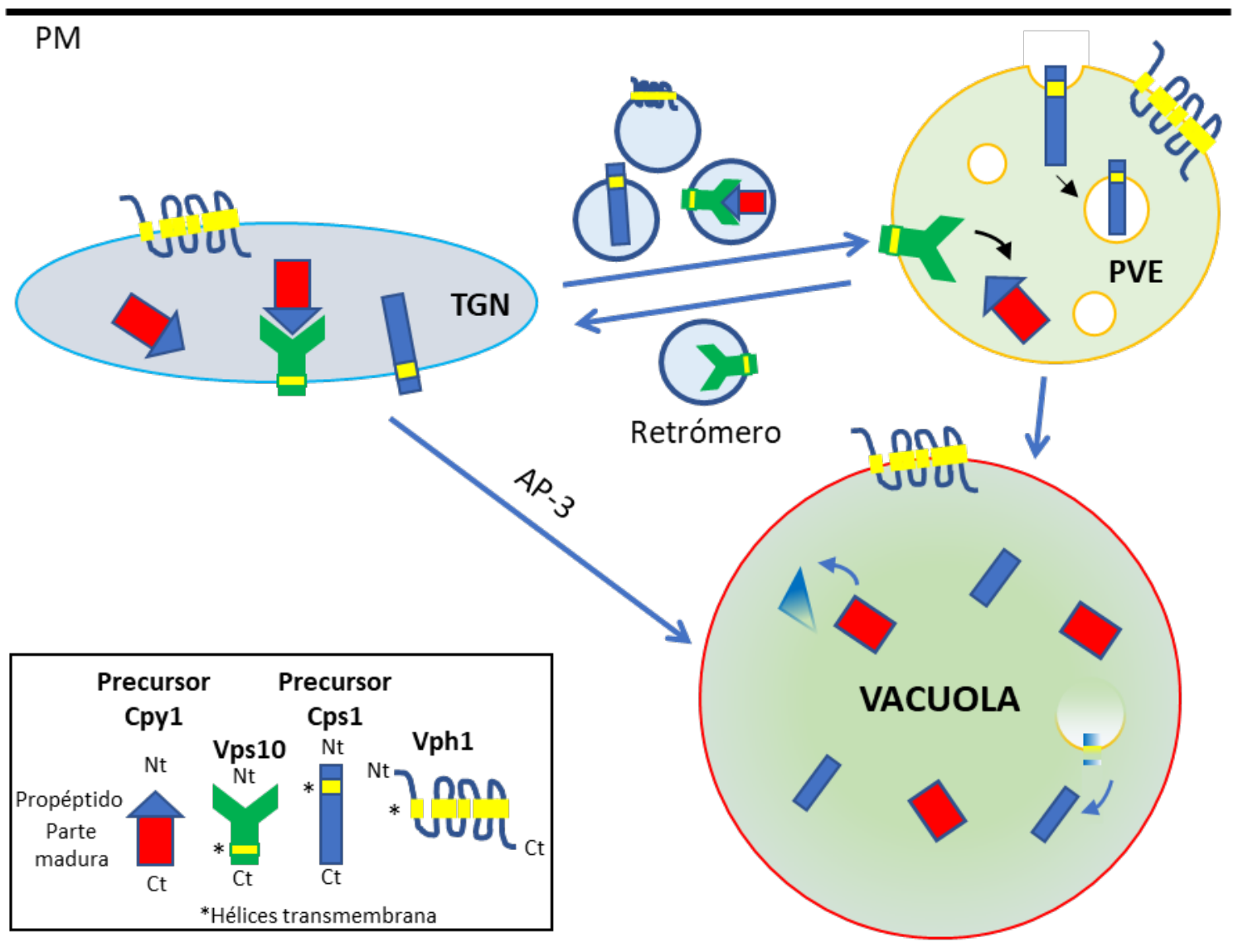

Figura 11. Esquema del tráfico de Vps10-CPY, Cps1 y Vph1. Se muestra alguna característica estructural de estas proteínas. Vps10 se une a CPY en el TGN y viajan juntas hacia el PVE donde se disocian. CPY llega a la vacuola donde es procesada, mientras que el retrómero facilita la vuelta de Vps10 hacia el TGN. Cps1 llega al PVE donde es internalizada en ILVs, posteriormente es procesada en la vacuola. Vph1 llega a la vacuola viajando a través del PVE. 


\subsection{Tráfico de Vph1.}

La ATPasa vacuolar es un complejo proteico que se encarga de bombear protones hacia el interior de la vacuola mediante la hidrólisis de ATP. Esto produce la acidificación de este orgánulo, necesaria para su funcionalidad. En S. cerevisiae la ATPasa vacuolar está formada por 14 subunidades que se ensamblan en 2 subcomplejos. El subcomplejo $V_{1}$ está en la parte citoplásmica y se encarga de la hidrólisis de ATP. El subcomplejo $V_{0}$ está embebido en la membrana y sirve de canal para transportar los protones. Vph1 es una subunidad del complejo $V_{0}$ que posee varios pasos transmembrana. Esta proteína viaja hacia la vacuola pasando por el PVE, aunque se desconoce que adaptadores median su tráfico y se ha propuesto que puede viajar de manera inespecífica (figura 11 ;Conibear and Stevens, 1998; Gerrard et al., 2000; Manolson et al., 1992; Piper et al., 1995).

Además de estas y otras proteínas que viajan hacia la vacuola a través del PVE (por la ruta CPY), otras proteínas pueden viajar directamente desde el TGN hasta la vacuola por una ruta mediada por AP-3 (visto en el apartado 4.3.3). 



\section{Capítulo I:}

Los adaptadores de clatrina GGAs y Ent3 participan en múltiples pasos del tráfico anterógrado y retrógrado a través del PVE. 

Como se ha mencionado, las alteraciones en el tráfico vesicular están en la base de algunas enfermedades de gran impacto en la población. Por tanto, conocer los procesos implicados en dicho transporte puede ayudar a encontrar soluciones terapéuticas para las mismas. En este sentido, las levaduras han sido modelos de estudio muy útiles para caracterizar múltiples aspectos del tráfico intracelular. El trabajo presentado en esta Tesis Doctoral se engloba en un proyecto más amplio destinado a caracterizar los procesos de reparto de proteínas en el TGN en S. pombe, con la idea de obtener más información acerca de estos procesos, intentando buscar respuesta a aquellas cuestiones que aún quedan abiertas. Esto ayudará a determinar aquellos aspectos que son específicos de organismo y aquellos que están conservados.

En este primer capítulo se ha estudiado el papel de algunos adaptadores monoméricos de clatrina (GGAs y Ent3) en el tráfico entre el TGN, el PVE y la vacuola. Una gran parte de la información existente sobre este papel se ha obtenido en $S$. cerevisiae de manera indirecta, analizando la secreción de CPY, que ocurre cuando el tráfico de Vps10 está alterado. Además, muchos de los estudios llevados a cabo en esta levadura se han realizado usando quimeras, que es posible que no se comporten como las proteínas nativas, y/o usando plásmidos. Algunos de estos resultados son contradictorios. Algo parecido ocurre con el tráfico de Cps1, y con el papel de los GGAs en el PVE.

En S. pombe el tráfico entre el TGN, el PVE y las vacuolas está muy poco caracterizado, a pesar de que la mayoría de elementos que juegan algún papel en esta ruta en otros organismos (como los GGAs y Ent3) están conservados. El objetivo general de este capítulo ha sido caracterizar el tráfico entre el TGN, el PVE y las vacuolas en este organismo mediante el uso de técnicas de microscopía cuantitativa en vivo utilizando proteínas marcadas con proteínas fluorescentes, integradas en el cromosoma. Los resultados se han complementado con técnicas bioquímicas y genéticas. Los objetivos específicos han sido:

- Analizar el papel de los GGAs y la epsina Ent3 en el tráfico de Vps10, Cps1, y Vph1 entre el TGN, el PVE y la vacuola.

- Analizar la existencia de colaboración entre estos adaptadores en este tráfico 

Resultados 



\section{Uso de Vps10 como cargo modelo para el análisis del tráfico desde el TGN al PVE.}

En primer lugar, se utilizó la proteína Vps10 como cargo modelo para analizar el papel de diferentes adaptadores de clatrina en el tráfico entre el TGN y el PVE. Como se ha mencionado en la introducción, Vps10 es un receptor transmembrana que cicla entre estos dos compartimentos (Cooper and Stevens, 1996; Seaman et al., 1997), por lo que su estudio es interesante para el análisis del tráfico entre ellos.

\subsection{Localización de Vps10 en S. pombe.}

En S. cerevisiae Vps10 se encuentra mayoritariamente en el TGN, si bien una parte colocaliza con marcadores del PVE (Marcusson et al., 1994; Cooper and Stevens, 1996; Chi et al., 2014; Papanikou et al., 2015). En S. pombe Vps10 se observó inicialmente en puntos discretos en el interior celular, colocalizando parcialmente con el marcador de Golgi Gms1 (Iwaki et al., 2006). Sin embargo, posteriormente se vio que la mayoría de Vps10 no colocalizaba con este marcador, sino que se encontraba en estructuras cercanas (Codlin and Mole, 2009). Por tanto, en este organismo no se conoce con exactitud la localización de este receptor, aunque se sabe que circula entre el TGN y el PVE, ya que en los mutantes del retrómero se observa en la membrana vacuolar (Iwaki et al., 2006)

Dado que la localización exacta de Vps10 en S. pombe era desconocida se decidió analizarla en detalle. Con este fin se construyó una cepa que expresaba la proteína de fusión Vps10-GFP desde su locus y bajo su propio promotor y se analizó su colocalización con un marcador de TGN y otro de PVE. Como marcador de TGN se utilizó la subuinidad del exómero Cfr1 marcada con RFP y como marcador de PVE se usó la sonda de unión al fosfatidilinositol 3-fosfato (PI3P) Cherry-FYVE (Hoya et al., 2017; Day et al., 2018). Tras realizar el análisis de colocalización, se observó que sólo una pequeña parte de los puntos de Vps10-GFP (7,54 $\pm 1,52 \%)$ coincidían con los puntos del marcador de TGN (figura 12A y C). Sin embargo, muchos de ellos $(41,10 \pm 2,82 \%)$ coincidían con el marcador de PVE, especialmente aquellos más brillantes (figura 12B y D). Esto indicaba que gran parte de Vps10-GFP se encontraba en este último compartimento. No obstante, un porcentaje de los puntos de Vps10-GFP no coincidía con ninguno de estos marcadores, por lo que se 
evaluó la colocalización de este receptor con un componente del complejo manosiltransferasa presente en el cis-Golgi (Anp1-Cherry; Jungmann and Munro, 1998; Vjestica et al., 2008), para analizar si otra parte de esta proteína se encontraba en este compartimento. Sin embargo, no se detectó colocalización entre estas dos proteínas (Figura S1, anexo). Por tanto, existe una cierta cantidad de puntos de Vps10-GFP que no colocalizan con el marcador de TGN ni con el de PVE y que, en general, presentan un tamaño pequeño. Estos puntos se podrían corresponder con proteína en tránsito entre TGN y PVE presente en vesículas o en pequeños endosomas inmaduros. En estos la cantidad de Cfr1-RFP sería ya muy escasa y la de PI3P sería todavía muy baja como para que se una la sonda Cherry-FYVE.

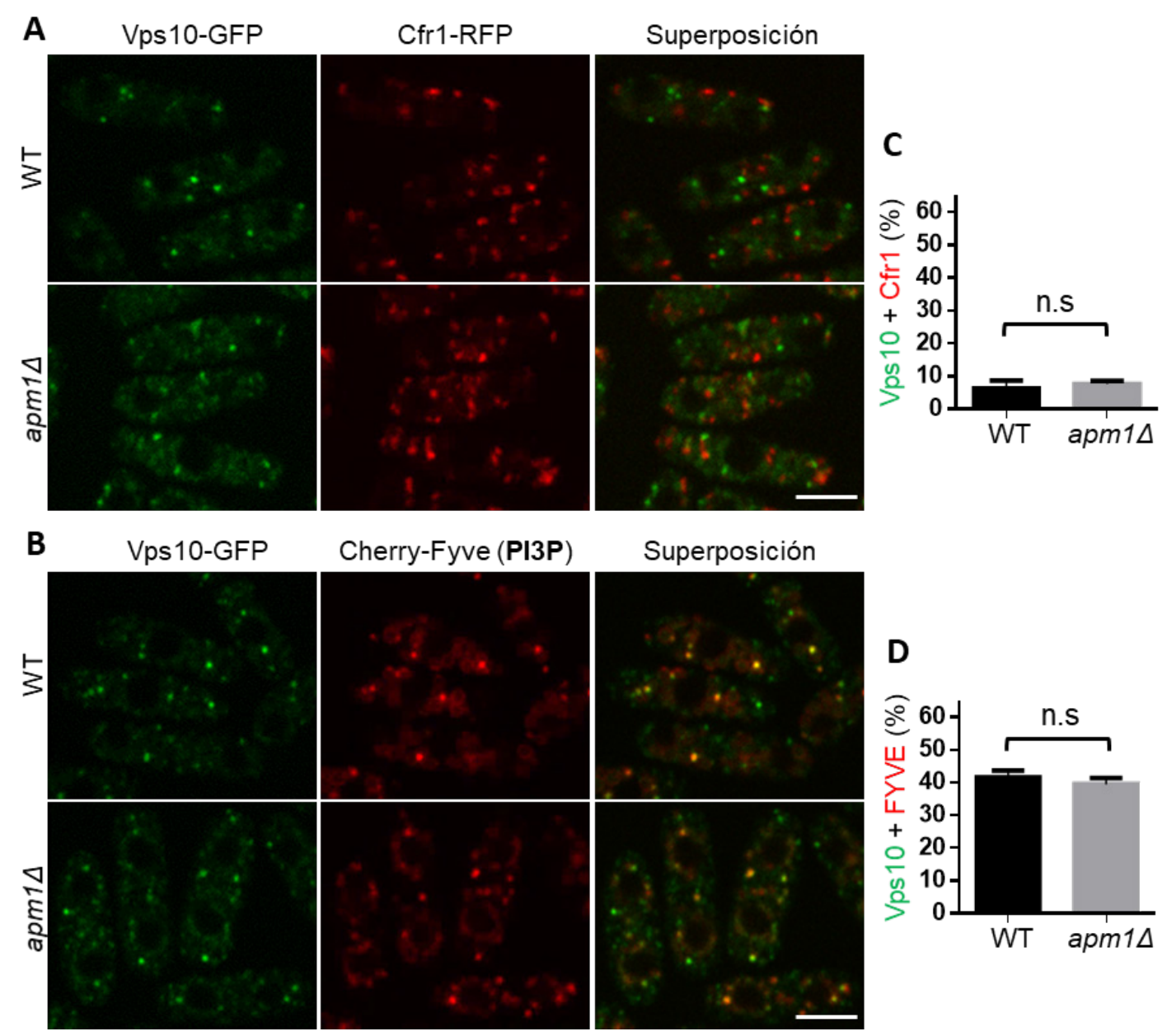

Figura 12. Análisis de la localización de Vps10-GFP en las cepas WT y apm1 1 . A: Células del WT y de apm1 con Vps10-GFP y Cfr1-RFP. B: Células del WT y de apm1 1 con Vps10-GFP y Cherry-FYVE. En A y B las imágenes se capturaron con un microscopio confocal spinning disk y son el plano medio celular. C: Porcentaje de colocalización de los puntos de Vps10-GFP y Cfr1-RFP. D: Porcentaje de colocalización de los puntos de Vps10GFP y Cherry-FYVE. En C y D se muestra la media, desviación típica y significación estadística de tres experimentos independientes y en cada uno de ellos se ha evaluado un mínimo de 400 puntos de Vps10-GFP. La significación estadística se ha determinado usando un test-t. ns, no significativo. Barras de escala, $5 \mu \mathrm{m}$. 
El hecho de que una buena parte de Vps10-GFP se encontrase en el PVE o en estructuras post Golgi concordaba con resultados publicados previamente en los que se había visto que la mayoría de Vps10 se encontraba en estructuras resistentes al tratamiento con Brefeldina A, una droga que inhibe a la GTPasa Arf1 y produce la disgregación de las cisternas del Golgi (Codlin and Mole, 2009). En definitiva, Vps10 se localiza mayoritariamente en el PVE, lo que nos permite realizar un análisis detallado de los factores que facilitan el tráfico de esta proteína hasta dicho orgánulo. Con este fin, se procedió a la cuantificación de su colocalización con marcadores de este compartimento y del TGN en diferentes mutantes.

\subsection{AP1 en el tráfico anterógrado de Vps10.}

En primer lugar, siguiendo esta estrategia experimental, se decidió analizar el papel del complejo adaptador de clatrina AP1 en el tráfico de Vps10. Al cuantificar el nivel de colocalización de Vps10-GFP con Cfr1-RFP (TGN) y con Cherry-FYVE (PVE) en el mutante $a p m 1 \Delta$, se vio que este era similar al del WT (figura 12). Esto indicaba que AP1 no tenía un papel relevante en la salida de Vps10 del TGN, lo cual estaba de acuerdo con lo descrito en S. cerevisiae utilizando otras aproximaciones experimentales (Deloche et al., 2001; Abazeed and Fuller, 2008).

\subsection{GGAs en el tráfico anterógrado de Vps10.}

A continuación, se analizó la posible implicación de los adaptadores de clatrina GGAs en el tráfico de Vps10. De acuerdo con la base de datos de S. pombe (Pombase, https://www.pombase.org/), en este organismo existen dos genes homólogos al gen GGA2 de S.cerevisiae que se han denominado $g g a 21^{+}$y $g g a 22^{+}$. Los productos de estos genes presentan un $60 \%$ y un $52 \%$ de similitud respectivamente con la proteína Gga2 de S. cerevisiae. Por tanto, se analizó la llegada de Vps10-GFP al PVE al delecionar estos genes. En el mutante gga21 1 el nivel de colocalización de Vps10-GFP con Cherry-FYVE era similar al del WT, indicando que la llegada al PVE no estaba alterada en este mutante

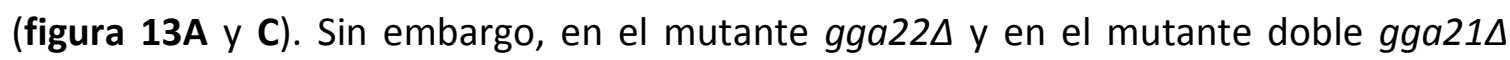
gga22 $\Delta$ se producía una reducción del nivel de colocalización de estas dos proteínas de aproximadamente un $45 \%$ con respecto al control (figura $13 \mathrm{~A}$ y C). Esto apuntaba a un 
defecto en la llegada de Vps10-GFP al PVE en estos mutantes. A continuación, para complementar estos resultados, se analizó si esta menor llegada al PVE se correspondía con una menor salida de Vps10-GFP del TGN. Para ello se cuantificó la colocalización de esta proteína con el marcador de TGN Cfr1-RFP en estos mutantes. Se vio que en ambos se producía un aumento de la coincidencia de los puntos de Vps10-GFP con los del exómero, pasando de un $7,46 \pm 1,74 \%$ en el WT a un $16,49 \pm 0,94 \%$ en gga22 $\Delta$ y a un $25,38 \pm 3,28 \%$ en gga21 gga22 (figura 13B y D). Además, se constató que en estos mutantes no se estaba produciendo una alteración de la localización de los marcadores de TGN y PVE usados, de manera que coincidiesen más (figura 14A). Por tanto, se confirmó que el defecto del tráfico de Vps10 observado en estos mutantes era específico y no un efecto indirecto de la alteración de los marcadores. En consonancia con este defecto, en el mutante gga21 $\operatorname{gga22\Delta }$ parte de Cpy1 se secretaba de forma anómala hacia el exterior celular, como se observa en el dot-blot de la figura 14B. En conjunto estos resultados muestran que los GGAs están involucrados en la salida de Vps10 del TGN hacia el PVE, jugando Gga22 un rol mayoritario y Gga21 uno minoritario y parcialmente redundante. Conclusiones similares han sido propuestas por otros grupos utilizando como organismo modelo S. cerevisiae y usando otras técnicas diferentes (Dell'Angelica et al., 2000; Hirst et al., 2000; Zhdankina et al., 2001; Abazeed and Fuller, 2008), lo cual valida nuestra aproximación experimental.

Los resultados anteriores muestran que hay una reducción de la llegada de Vps10GFP al PVE en el mutante gga21 gga22 $\Delta$, sin embargo, no se produce un bloqueo total del receptor en el TGN. De acuerdo con esto, se observó por microscopía que al menos parte de Cpy1 llegaba a la vacuola (figura 14C). Esto indicaba que parte del tráfico de Vps10 y de Cpy1 hacia el PVE y la vacuola tenía lugar de forma independiente a la función de los GGAs, por lo que se decidió estudiar qué otros factores estarían facilitando su

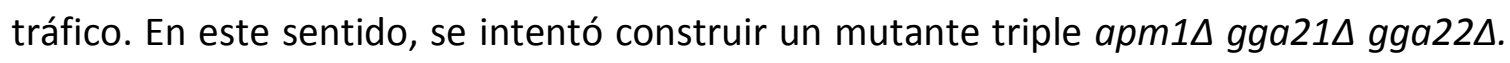
Tras varios intentos se consiguió obtener un único clon de esta cepa, aunque era muy difícil trabajar con él y no se pudo estudiar el tráfico de Vps10 en ausencia de AP1 y de los GGAs. 
A Vps10-GFP
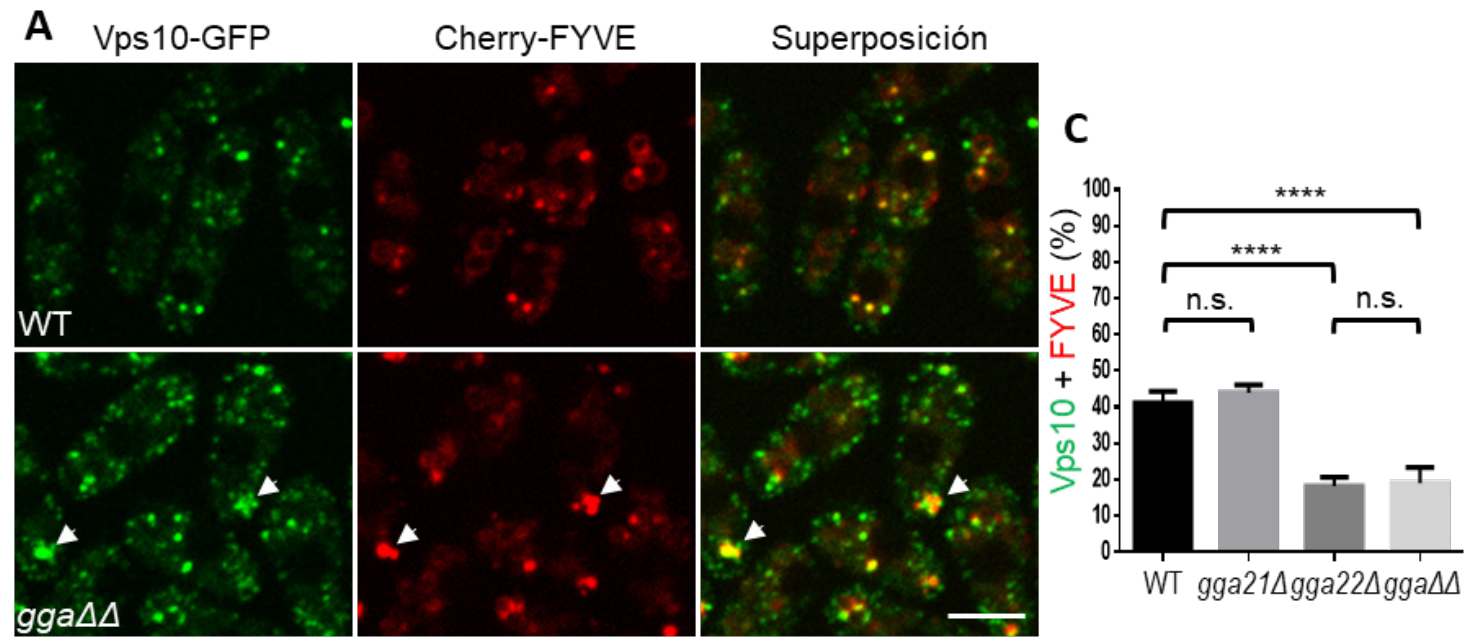

B
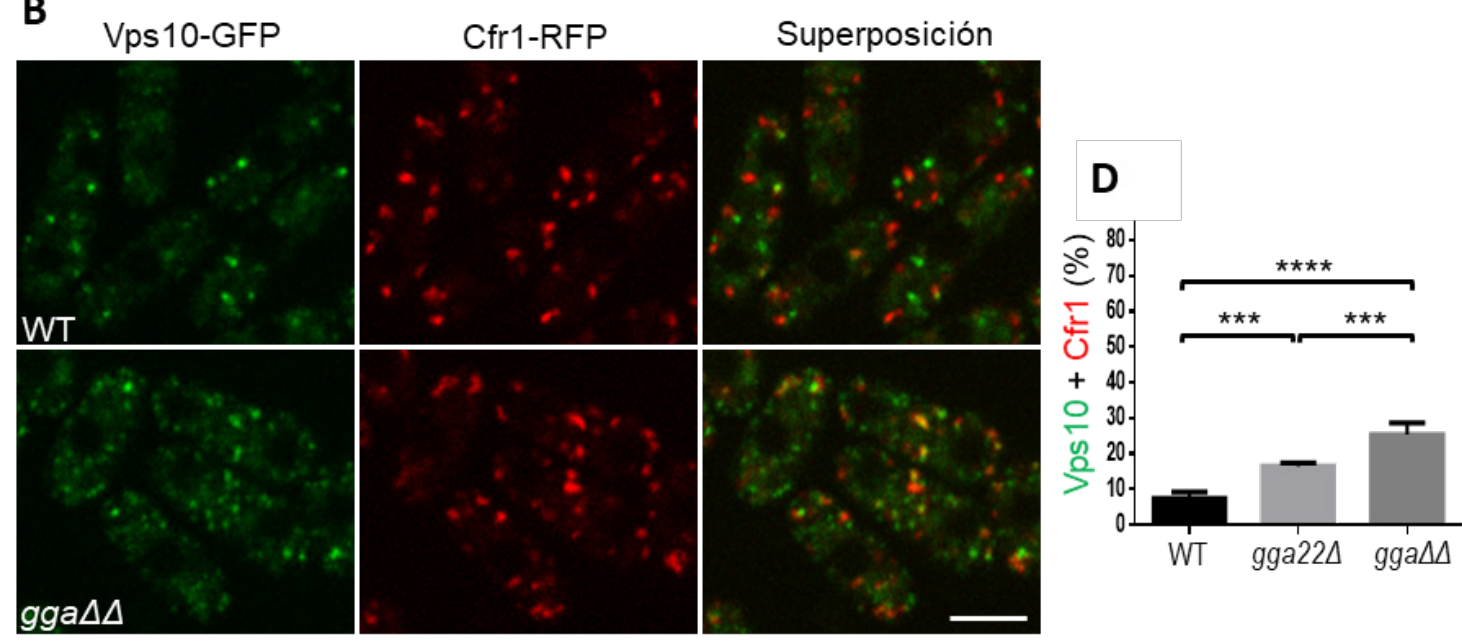

Figura 13. Análisis de la localización de Vps10-GFP en ausencia de los GGAs. A: Células del WT y de gga21D gga22 2 expresando Vps10-GFP y Cherry-FYVE. Las flechas indican endosomas alterados. B: Células del WT y de gga21 gga22 $\Delta$ expresando Vps10-GFP y Cfr1-RFP. En A y B las imágenes se capturaron con un microscopio confocal spinning disk y son el plano medio celular. C: Porcentaje de colocalización de los puntos de Vps10-GFP y Cherry-FYVE en las cepas indicadas. D: Porcentaje de colocalización de los puntos de Vps10-GFP y Cfr1-RFP en las cepas indicadas. En C y D se muestra la media, desviación típica y significación estadística de tres experimentos independientes, en cada uno de los cuales se ha evaluado un mínimo de 400 puntos de Vps10-GFP. La significación estadística se ha determinado usando el test de comparación múltiple de Sidak (c) o de Tukey (d) tras ANOVA. ns, no significativo $* * *, p<0,001 ; * * * *, p<0,0001$. Barras de escala, $5 \mu \mathrm{m}$. gga $\Delta \Delta$, gga21 $\operatorname{coga} 22 \Delta$

\subsection{AP-3 en el tráfico anterógrado de Vps10.}

A continuación, se decidió analizar si en ausencia de los GGAs el tráfico de Vps10GFP hacia el PVE estaría siendo mediado por el complejo AP-3 siguiendo la ruta ALP. Al analizar la localización de Vps10-GFP con respecto a Cherry-FYVE en el mutante triple

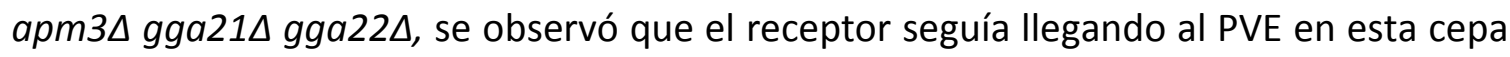
(figura 15). Esto indicaba que en ausencia de los GGAs el complejo AP-3 no era el 
encargado de facilitar el transporte de Vps10 hacía el PVE. Este resultado está de acuerdo con los resultados previos obtenidos en S. cerevisiae en los que no se observan defectos en el tráfico de las proteínas que siguen la ruta CPY en mutantes del complejo AP-3 (Cowles et al., 1997; Stepp et al., 1997).

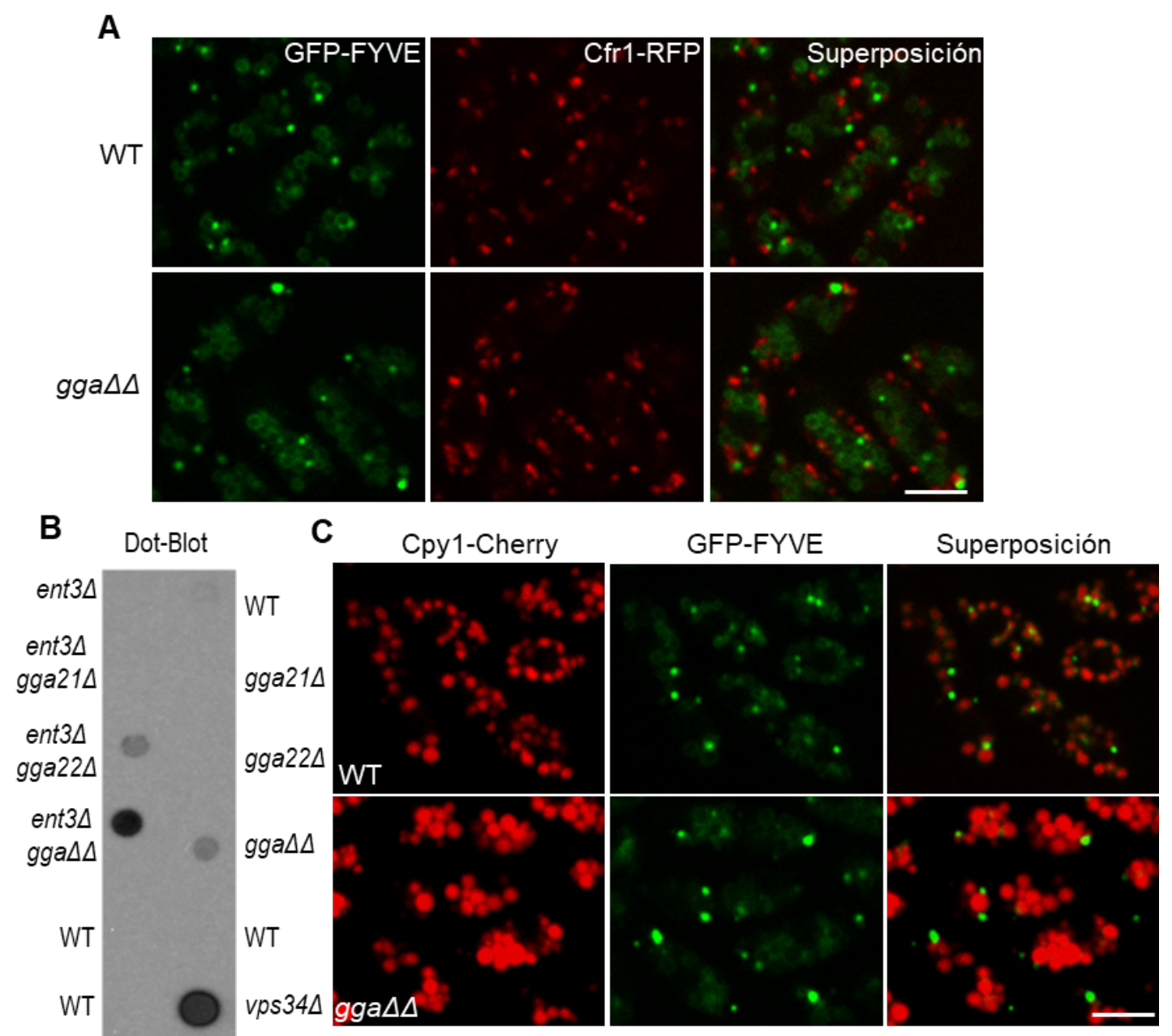

Figura 14. Localización marcadores de TGN y PVE y tráfico de Cpy1 en ausencia de los GGAs. A: Células del WT y de gga21 gga22 $($ gga $\Delta \Delta$ ) con GFP-FYVE y Cfr1-RFP. B: análisis de secreción de Cpy1 mediante ensayo dotblot de colonias de las cepas indicadas, incubadas en EMM durante 4 días a 28ㄷ․ C: Células del WT y de gga21 gga22 $(g g a \Delta \Delta)$ con GFP-FYVE y Cpy1-Cherry. En A y C las imágenes fueron capturadas con un microscopio confocal spinning disk y son el plano medio celular. Barras de escala, $5 \mu \mathrm{m}$.

\subsection{Ent3 en el tráfico anterógrado de Vps10.}

Como se ha indicado en la introducción, en $S$. cerevisiae hay dos epsinas que participan en el tráfico desde el TGN (Ent3 y Ent5). En S. pombe hay una única epsina (Ent3) homóloga a estas (Pombase, https://www.pombase.org/) que está sin caracterizar. Esta epsina, de la misma manera que Gga22, se encuentra mayoritariamente 
en el TGN de acuerdo a su colocalización con el marcador Cherry-PH (dominio Pleckstrin Homology de la proteína humana Fapp1) que reconoce el PI4P presente en este orgánulo (figura S2, anexo). Esto concuerda con una posible función de Ent3 en el tráfico desde el TGN. Por ello se analizó el papel de esta epsina en la salida de Vps10 desde esta estructura. Este estudio se llevó a cabo tanto en presencia como en ausencia de los GGAs.

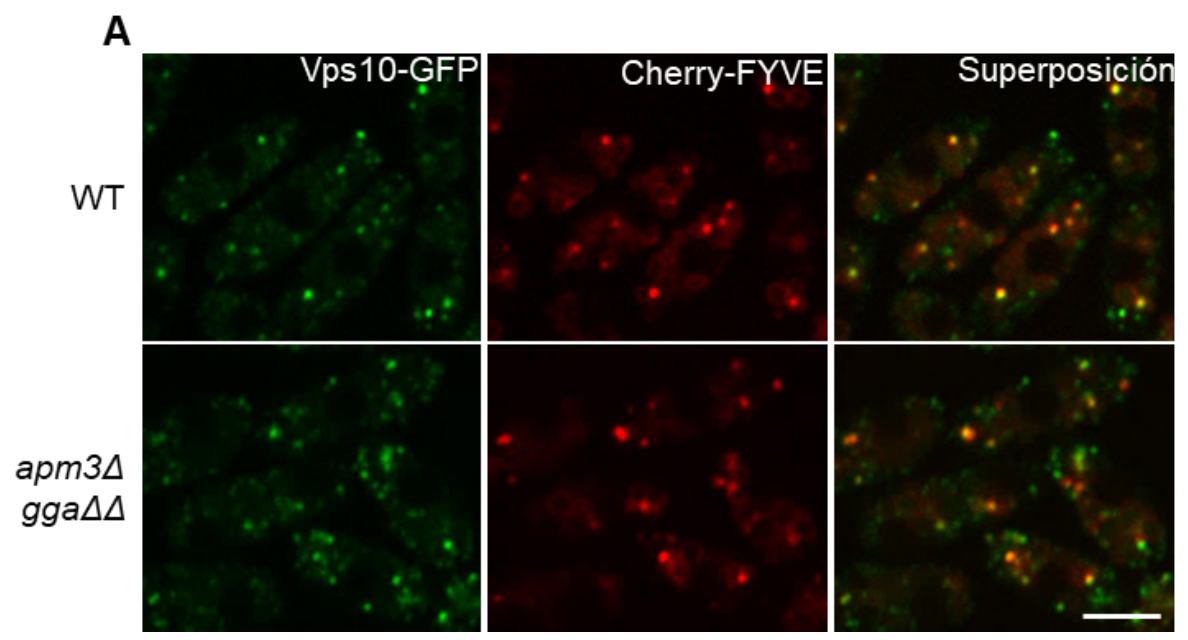

Figura 15. Contribución de AP-3 al tráfico de Vps10 en ausencia de los GGAs. A: Células del WT y de apm3 gga21 gga22 $(a p m 3 \Delta$ gga $\Delta \Delta$ ) con Vps10-GFP y Cherry-FYVE. Las imágenes fueron capturadas con un microscopio confocal spinning disk y son el plano medio celular. Barras de escala, $5 \mu \mathrm{m}$.

Primero se evaluó la llegada de Vps10-GFP al PVE, cuantificando la coincidencia de los puntos de esta proteína con el marcador Cherry-FYVE. Como se observa en la figura 16C, en el mutante ent3 $\Delta$ hay un ligero descenso del nivel de colocalización con este marcador $(37,46 \pm 0,75 \%$ frente a $42,07 \pm 2,08 \%$ del WT). Este descenso se corresponde con una menor salida del receptor desde el TGN, como se observa al analizar el nivel de colocalización con Cfr1-RFP (figura 16D), pasando de un $6.78 \pm 2,37 \%$ en el WT a un $14,68 \pm 3,16 \%$ en ent $3 \Delta$. Esta alteración no se debe a un efecto indirecto causado por una deslocalización de otras proteínas involucradas en el transporte entre el TGN y el PVE, ya que la cadena ligera de clatrina (Clc1), Apm1, Gga22 y la SNARE Pep12 presentan una localización similar en la cepa WT y en ent3 $\Delta$ (figura S3, anexo). El resultado anterior está de acuerdo con el defecto observado en el procesamiento de Cpy1 en el mutante ent3-1

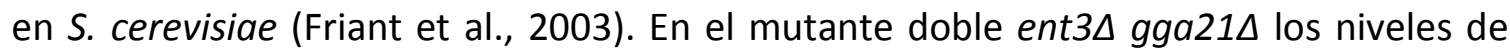
colocalización de Vps10 con Cherry-FYVE y con Cfr1-RFP son similares a los de ent3A 
(figura 16). En el mutante doble ent3 $\Delta$ gga22 $\Delta$ y en el triple ent3 $\Delta$ gga21 $\Delta$ gga22 $\Delta$ el porcentaje de colocalización de Vps10-GFP con Cherry-FYVE se reduce más que en las cepas anteriores (hasta el $21,25 \pm 2,18 \%$ y el $16,03 \pm 0,73 \%$ respectivamente, frente al $42,07 \pm 2,08 \%$ del WT; figura $16 \mathrm{~A}$ y C). Esto se corresponde con un mayor aumento del nivel de colocalización con el marcador de TGN $(21,47 \pm 1,36 \%$ en ent3 $\Delta$ gga $22 \Delta$ y $19,75 \pm 3,69 \%$ en ent3 $\Delta$ gga21 gga22 2 , frente al $6.78 \pm 2,37 \%$ del WT; figura 16B y D). Además, al analizar la secreción de Cpy1 mediante un ensayo de dot-blot se vio que esta proteína se secreta parcialmente en ent3 $\operatorname{gga} 22 \Delta$ y esta secreción es algo más severa en el mutante triple ent3 $\operatorname{gga21\Delta }$ gga22 $\Delta$, aunque sin llegar a alcanzar los niveles de pik3A (que no sintetiza PI3P; figura 14B). En conjunto estos resultados nos indican que Ent3 facilita la salida de Vps10 desde el TGN y colabora con Gga22 en este proceso.

\subsection{Endocitosis en el tráfico de Vps10 hacia el PVE en ausencia de GGAs-Ent3.}

A pesar de los defectos vistos en la llegada de Vps10-GFP al PVE en los mutantes sin los GGAs, sin la epsina o en la combinación de sus deleciones, en todos los casos llega una parte de Vps10 a dicho compartimento. Debido a esto se quiso explorar la posibilidad de que esta fracción de proteína estuviera alcanzando el PVE mediante su secreción y endocitosis a través de la membrana plasmática. Un mecanismo similar se había descrito en S. cerevisiae para mutantes de clatrina (Deloche and Schekman, 2002). Para analizar esta posibilidad se trató a diferentes mutantes con la droga Latrunculina A que inhibe la polimerización de la actina, de manera que en su presencia se bloquea la endocitosis. De esta forma, si una parte de Vps10-GFP se estuviera secretando hacia la membrana plasmática en alguna de las cepas, esta quedaría retenida (al menos parcialmente) en la superficie celular tras el tratamiento. Como control se analizó la localización de GFP-Syb1, una SNARE homóloga a Snc1 de S. cerevisiae que cicla entre el TGN y la membrana plasmática (Lewis et al., 2000). Como se observa en la figura 17, GFP-Syb1 se visualiza en la membrana plasmática en los polos celulares y la zona del septo tras 10 minutos de tratamiento. Sin embargo, en ninguna de las cepas analizadas en estas condiciones (WT,

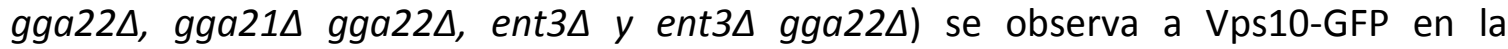
membrana plasmática. Esto demuestra que en ausencia de estos genes Vps10-GFP no llega al PVE a través de la membrana plasmática. 
A

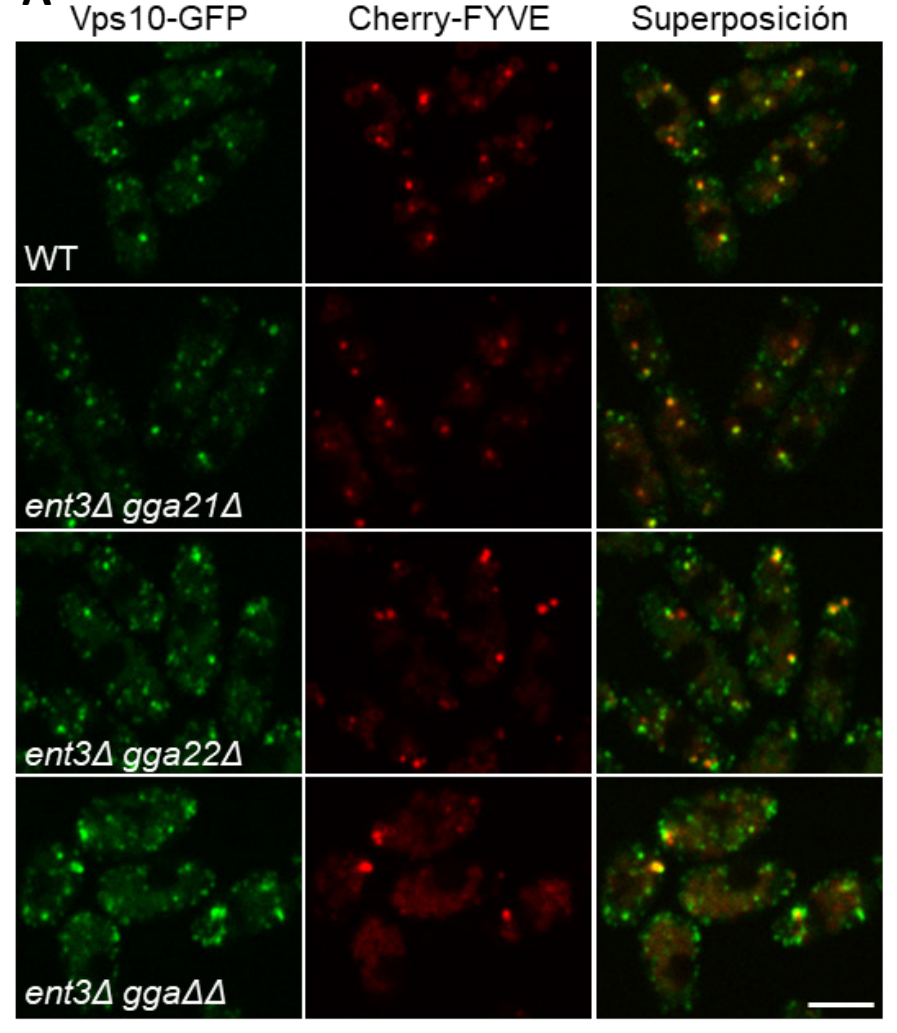

B

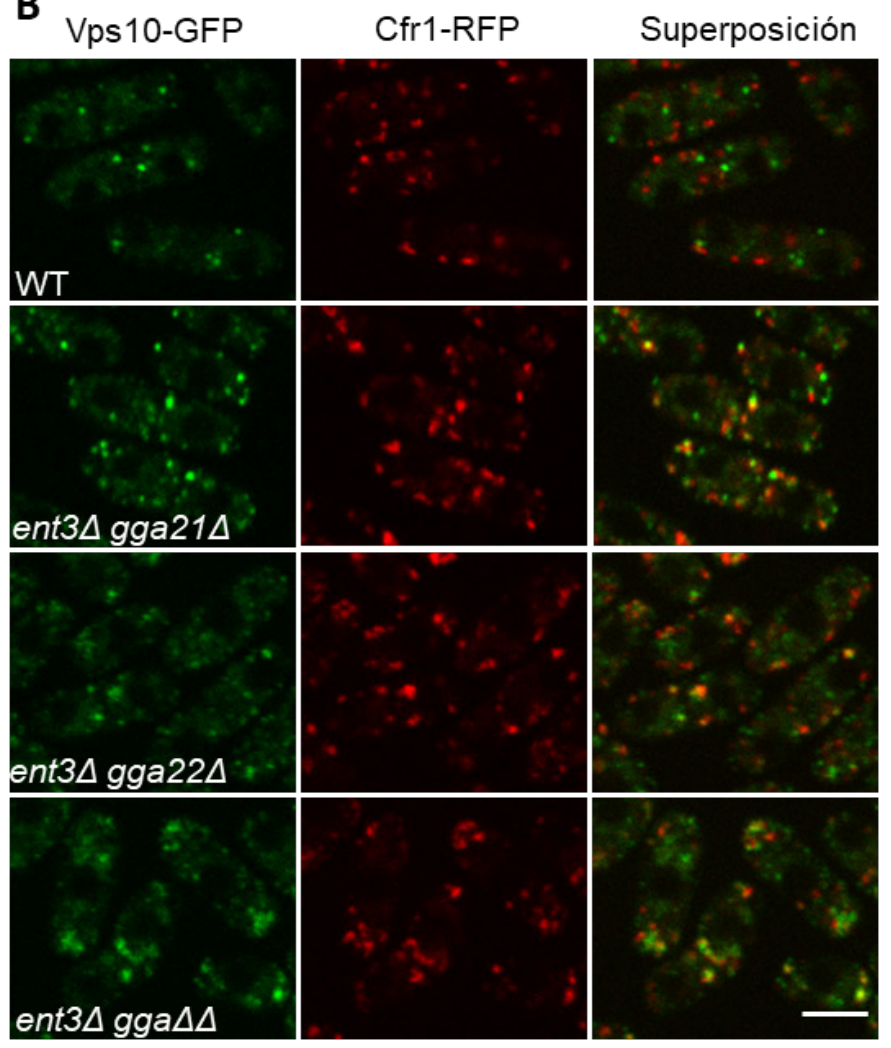

C
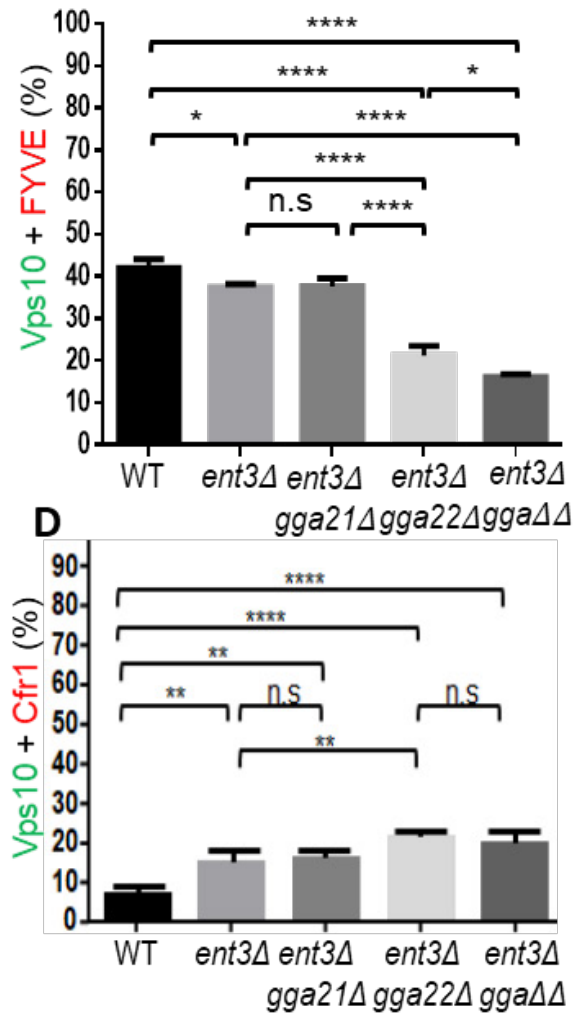

Figura 16. Análisis del tráfico de Vps10GFP en ausencia de Ent3 y GGAs. A: Células del WT, ent3 $\Delta$ gga21 $\Delta$, de ent3 $\Delta$

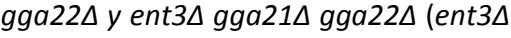
gga $\Delta \Delta$ ) con Vps10-GFP y Cherry-FYVE. B: Células del WT, ent3 $\Delta g g a 21 \Delta$, de ent3 $\Delta$ gga $22 \Delta$ y ent $3 \Delta$ gga $21 \Delta$ gga $22 \Delta$ (ent $3 \Delta$ gga $\Delta \Delta$ ) con Vps10-GFP y Cfr1-RFP. Las imágenes se capturaron con un microscopio confocal spinning disk y son el plano medio celular. C: Porcentaje de colocalización de los puntos de Vps10GFP y Cherry-FYVE en las cepas indicadas. D: Porcentaje de colocalización de los puntos de Vps10GFP y Cfr1-RFP en las cepas indicadas. En C y D se muestra la media, desviación típica y significación estadística de tres experimentos independientes. En cada uno de ellos se ha evaluado un mínimo de 350 puntos de Vps10-GFP. La significación estadística se ha determinado usando el test de comparación múltiple de Sidak tras ANOVA. ns, no significativo; ${ }^{*}, p<0,05$; ${ }^{* *}, \mathrm{p}<0,01 ; * * * *, p<0,0001$. Barras de escala, $5 \mu \mathrm{m}$. 
En conjunto, los resultados obtenidos nos indican que una parte de Vps10-GFP llega al PVE con la colaboración de los GGAs y Ent3 y otra fracción alcanza esta estructura de manera independiente a la función de estos adaptadores. Además, esta última parte no alcanza su destino por la ruta mediada por AP-3 o a través de la membrana plasmática. Esto muestra que existen mecanismos adicionales actuando en el tráfico de Vps10 desde el TGN hacia el PVE.
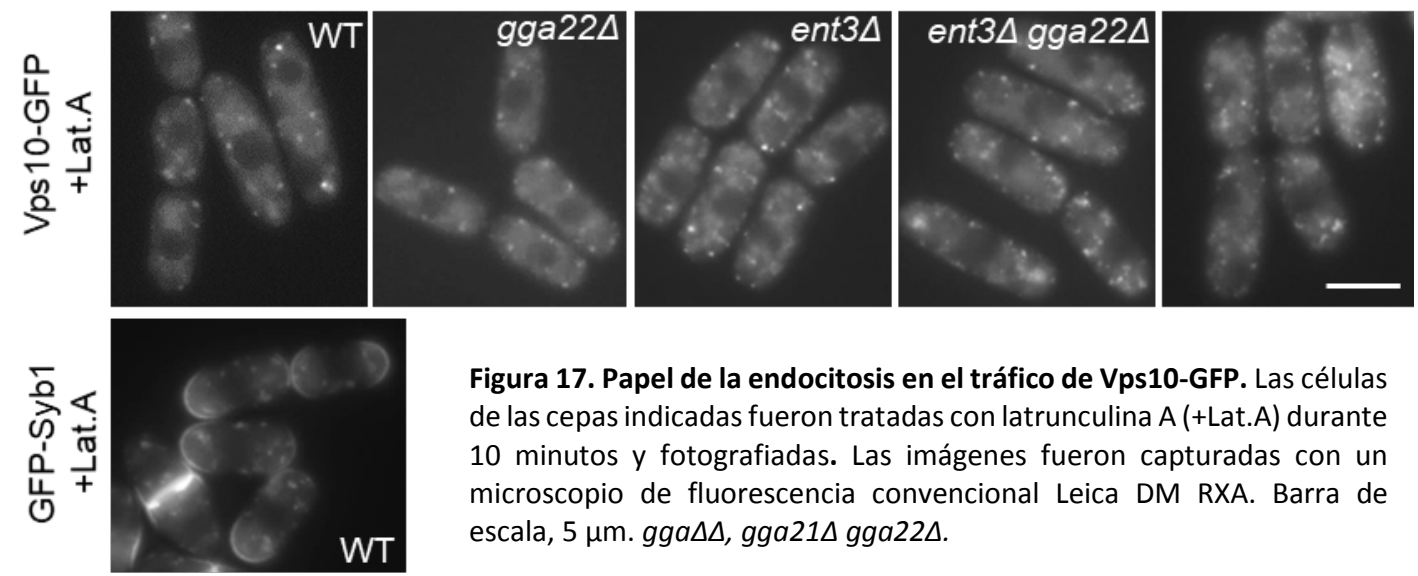

Figura 17. Papel de la endocitosis en el tráfico de Vps10-GFP. Las células de las cepas indicadas fueron tratadas con latrunculina A (+Lat.A) durante 10 minutos y fotografiadas. Las imágenes fueron capturadas con un microscopio de fluorescencia convencional Leica DM RXA. Barra de escala, $5 \mu \mathrm{m}$. $g g a \Delta \Delta$, gga21 $\operatorname{gga} 22 \Delta$.

\section{Uso de Cps1 para analizar la función de GGAs y Ent3 en el tráfico entre el TGN, el PVE y la Vacuola.}

A continuación, se quiso explorar si los GGAs y Ent3 facilitarían el transporte de otras proteínas que viajasen por la misma ruta que Vps10. En este sentido, se decidió analizar el tráfico de la proteasa Cps1 que también sigue la ruta CPY hacia la vacuola (explicado en el apartado 6.2 de la introducción).

\subsection{Análisis del tráfico entre el TGN y el PVE.}

Para analizar el tráfico de Cps1, primero se construyó una cepa con Cps1 marcada con GFP en el extremo N-terminal, la cual estaba unida a su vez a ubiquitina (Ub:GFPCps1). Esta construcción se integró en el cromosoma. Construcciones similares se han usado para seguir el tráfico de esta proteína, aunque siempre expresadas en plásmidos (Iwaki et al., 2007; Odorizzi et al., 1998). A continuación, se observó su localización tanto en la cepa WT como en diferentes mutantes. Se usó como marcador de las vacuolas el 
colorante fluorescente Blue CMAC que tiñe el lumen de estos orgánulos (Davidson et al., 2016). De acuerdo a lo esperado, Ub:GFP-Cps1 en la cepa silvestre se encontraba localizada principalmente en el interior de las vacuolas, observándose también en puntos brillantes cercanos a este orgánulo (figura 18A). En el mutante del ESCRT vps27A, donde el proceso de formación de vesículas internas en el PVE está bloqueado (Frankel and Audhya, 2018), esta construcción se observó en la membrana de las vacuolas y en puntos

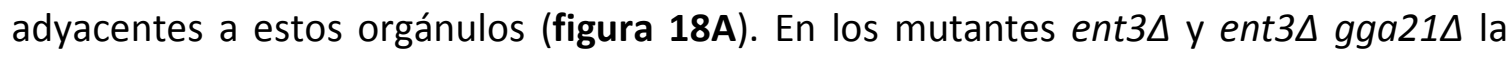
localización de esta proteína era similar a la del WT (figura S4, anexo), si bien se apreciaban vacuolas de menor tamaño que en este (observadas también con otros

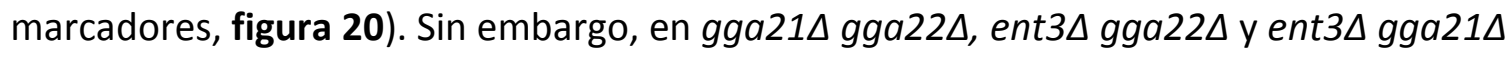
gga22 $\Delta$ se veía menos fluorescencia en el lumen de las vacuolas y más fluorescencia en puntos intracelulares que, en algunos casos, parecían tener un mayor tamaño que en el WT (figura 18A). La menor intensidad de fluorescencia de Ub:GFP-Cps1 en las vacuolas de estos mutantes se confirmó realizando un line scan en estas estructuras (figura 18B). Esto indicaba que existía una alteración en el tráfico de Ub:GFP-Cps1 hacia la vacuola en estos mutantes. Además, esta alteración parecía diferente a la observada en el mutante del ESCRT.

A continuación, se decidió estudiar con más detalle el tráfico de Ub:GFP-Cps1 en ausencia de los adaptadores para determinar a qué nivel se estaban produciendo las alteraciones. En primer lugar, se evaluó si Ub:GFP-Cps1 se estaba quedando parcialmente retenida en el TGN como le sucedía a Vps10-GFP. Para explorar esta posibilidad se observó la colocalización de los puntos de esta proteína con los del marcador de TGN usado previamente (Cfr1-RFP). Como se puede observar en la figura 18C, mientras que en el WT resultaba difícil detectar puntos en los que coincidiesen estas dos proteínas, en los mutantes gga21 1 gga22 $\Delta$ y ent3 $\Delta$ gga22 $\Delta$ se observaban algunos puntos en los que colocalizaban (flechas, figura 18C). Esto sugería que parte de Ub:GFP-Cps1 podía estar quedando retenida en el TGN. Para analizar esto con más detalle se decidió cuantificar el nivel de colocalización de los puntos de estas dos proteínas. Primero se tuvo que eliminar la señal procedente de las vacuolas, que eran especialmente brillantes en el WT. Con este fin, se realizó una tinción de las cepas anteriores con el colorante fluorescente Blue 
CMAC. Posteriormente, se sustrajo esta señal de la del canal de la GFP eliminando así la fluorescencia de Ub:GFP-Cps1 presente en las vacuolas. De esta manera en la imagen resultante quedaron sólo los puntos de proteína presentes en otras estructuras.
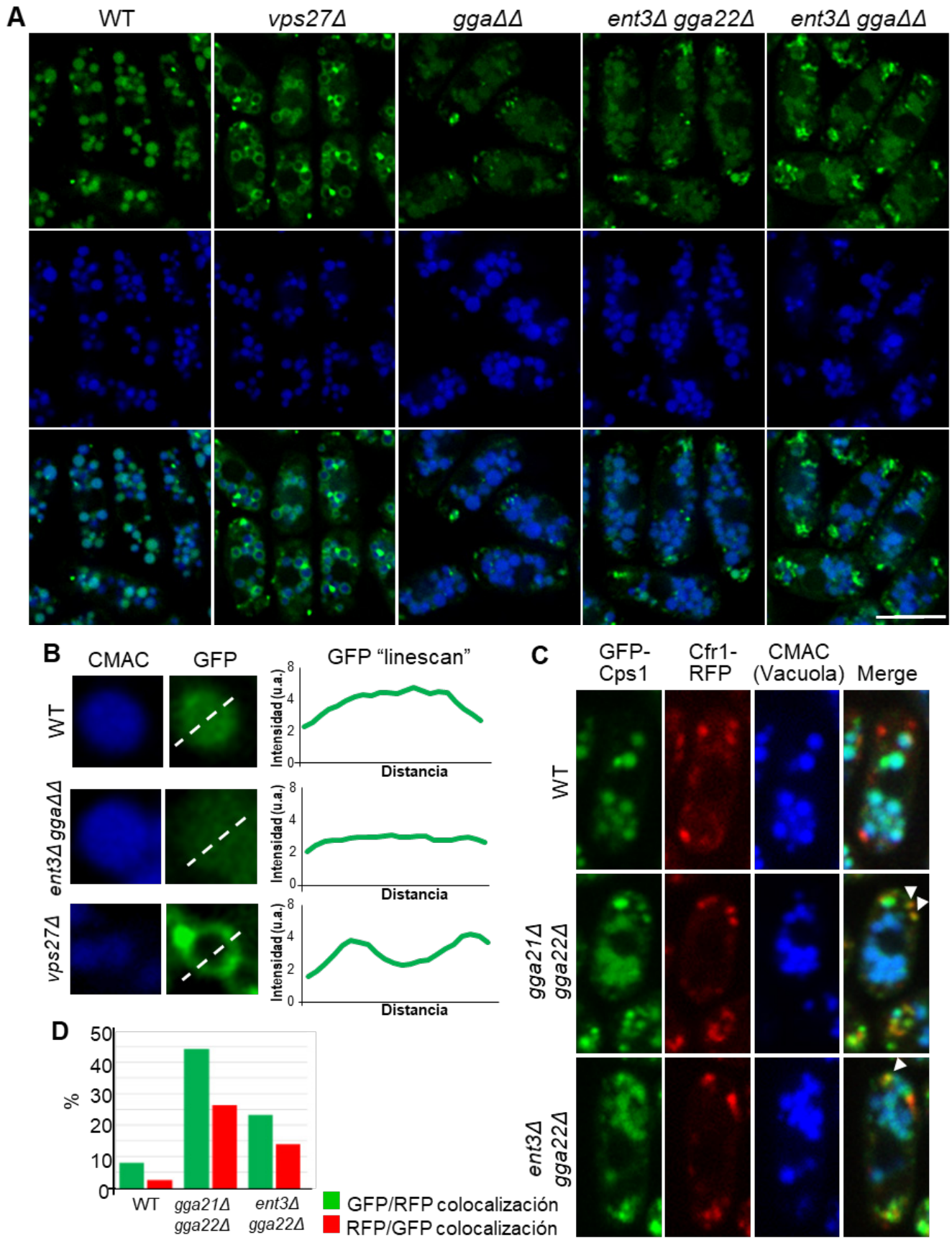

Figura 18. Localización de Ub:GFP-Cps1 en ausencia de los adaptadores Ent3 y GGAs. A: Distribución de Ub:GFPCps1 y de las vacuolas (CMAC) en las cepas indicadas. B: Ampliación de vacuolas representativas en las cepas indicadas. Las gráficas representan la intensidad de fluorescencia (u.a.) de la GFP a lo largo de las líneas discontinuas. C: colocalización de Ub:GFP-Cps1 y Cfr1-RFP. Las flechas muestran puntos donde coexisten. Se muestran las vacuolas teñidas con Blue CMAC. D: Porcentaje de colocalización de los puntos de Ub:GFP-Cps1 y Cfr1-RFP en las diferentes cepas indicadas. Se cuantificaron al menos 150 puntos de Cps1 procedentes de un único experimento. Las fotos son de un único plano, adquiridas con un sistema de microscopía Delta Vision (A y B) o con un microscopio confocal spinning disk (C). Barra de escala, $5 \mu \mathrm{m}$. gga $\Delta \Delta$, gga21 $\operatorname{gg} g a 22 \Delta$. 
Finalmente, se cuantificó la colocalización de esos puntos con los de Cfr1-RFP. Así se observó que sólo un 8\% de los puntos de Ub:GFP-Cps1 colocalizaban con el marcador de

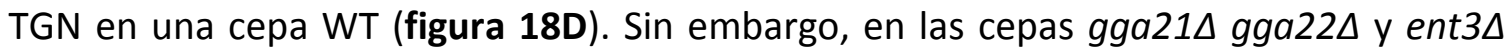
gga22 2 este porcentaje aumentaba hasta el $44 \%$ y el $23 \%$ respectivamente. Esto confirmaba que parte de la proteína se estaba quedando retenida en el TGN en estos mutantes.

\subsection{Análisis del tráfico desde el PVE hacia la vacuola.}

Tras los resultados anteriores se decidió explorar si parte de Ub:GFP-Cps1 estaba presente también en el PVE, ya que en el WT los puntos de esta proteína no coincidían prácticamente con el marcador del TGN y en los mutantes la colocalización era parcial. Además, en estos últimos, los puntos más grandes no parecían coincidir con el marcador de TGN. Para examinar esto, se observó la localización de Ub:GFP-Cps1 con respecto al marcador de PVE usado anteriormente (Cherry-FYVE). En el WT la mayoría de puntos extravacuolares de Ub:GFP-Cps1 coincidían con el marcador de PVE (figura 19A). En los mutantes gga $21 \Delta$ gga $22 \Delta$ y ent $3 \Delta$ gga $22 \Delta$ también existía bastante coincidencia de estos puntos con los de Cherry-FYVE, especialmente de aquellos más grandes (figura 19A y flechas). Estas estructuras más grandes no estaban presentes en el WT, lo cual apuntaba a una alteración morfológica de este orgánulo a la que se hará referencia más adelante.

Debido a las observaciones anteriores, y teniendo en cuenta también que existía una

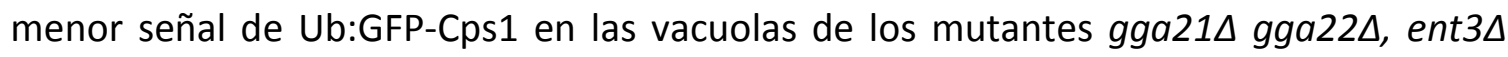

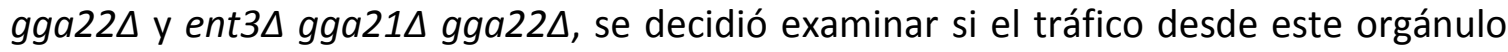
hacia la vacuola podía estar alterado. Para ello, se analizó por western blot el estado de Ub:GFP-Cps1 en los diferentes mutantes. Cuando esta proteína alcanza el lumen de la vacuola (tras ser incluida en las vesículas internas del PVE), sufre un corte proteolítico. Como consecuencia, se libera por una parte la proteína madura y por otra la GFP unida a una pequeña porción de la proteína (con el dominio transmembrana) que será degradada, liberándose así la GFP (Reggiori and Pelham, 2001). De esta forma, la banda de GFP libre detectada mediante western blot es un buen indicador para determinar la cantidad de Ub:GFP-Cps1 que alcanza el lumen de la vacuola. 

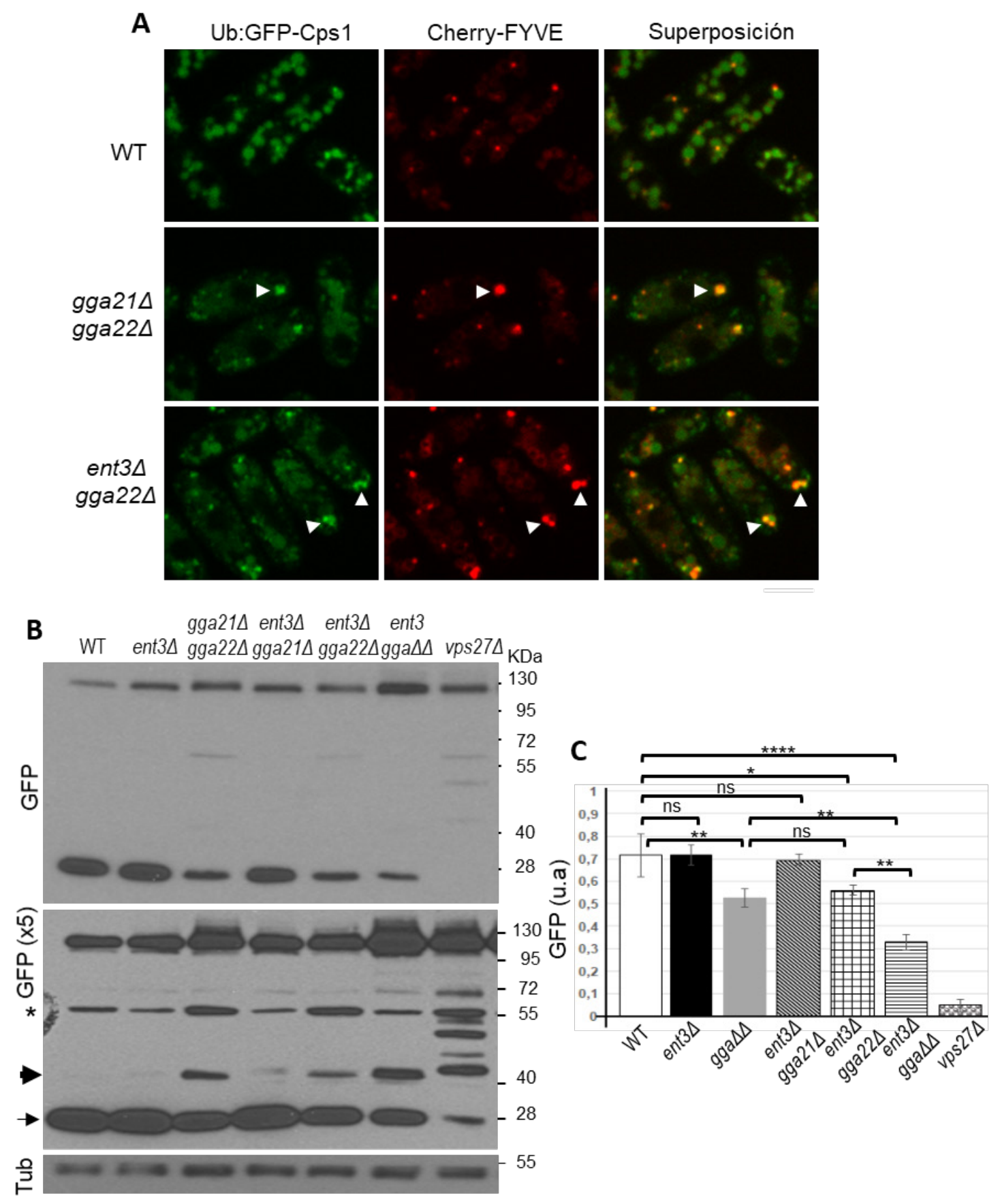

Figura 19. Localización y procesamiento de Ub:GFP-Cps1 en ausencia de los adaptadores Ent3 y GGAs. A: Colocalización de Ub:GFP-Cps1 con Cherry-FYVE en las cepas indicadas. Las fotos son planos medios adquiridos con un microscopio confocal spinning disk. B: Western blot de extractos totales de las cepas señaladas que expresan Ub:GFP-Cps1. El mismo experimento se ha expuesto durante un tiempo corto (panel superior) o durante un tiempo más largo (x5; panel medio). El asterisco indica una banda inespecífica, la flecha señala la banda de la GFP y la punta de flecha señala una banda de $40 \mathrm{KDa}$ presente en algunos mutantes. Como control de carga se muestra la cantidad de tubulina (panel inferior). C: Cuantificación de la banda de la GFP con respecto a la cantidad de proteína total usando el programa ImageJ. Se muestra la media y desviación típica de tres experimentos independientes. El nivel de significación se ha calculado con el test de comparación múltiple de Sidak tras ANOVA. $\mathrm{ns}$, no significativo; ${ }^{*}, \mathrm{p}<0,05 ;{ }^{* *}, \mathrm{p}<0,01 ;{ }^{* * * *}, \mathrm{p}<0,0001$. Barra de escala, $5 \mu \mathrm{m}$. gga $\Delta \Delta$, gga21 $\Delta$ gga $22 \Delta$. 
Como se observa en la figura 19B, en los extractos proteicos procedentes del WT se ve una banda de 28 KDa muy fuerte (correspondiente al tamaño de la GFP). De acuerdo con lo esperado, en una cepa sin una de las subunidades del ESCRT (vps27 2 ), en la que Ub:GFP-Cps1 no llega al lumen de la vacuola, no se observa esta banda (figura 19B). En el mutante ent $3 \Delta$ y en el ent3 $\Delta$ gga21 $\Delta$ se aprecia la banda de $28 \mathrm{KDa}$ con una intensidad similar a la del WT (figura 19B). En los mutantes gga21 observa una reducción de la intensidad de esta banda con respecto al WT (figura 19B). Esta reducción es algo más evidente en el mutante triple ent3 $\operatorname{loga21\Delta }$ gga22 $\Delta$ (figura 19B). Esto mismo se aprecia en la gráfica con las cuantificaciones de tres experimentos independientes en la que se representa la cantidad de GFP con respecto a la cantidad de proteína total (figura 19C). Además, en los mutantes de los adaptadores en los que se observa una reducción de la banda de la GFP, se detecta una acumulación de una banda de unos 40 KDa que no está presente en el WT y que es diferente al patrón de bandas presente en vps27A (punta de flecha, figura 19B). Estos resultados señalan que en los

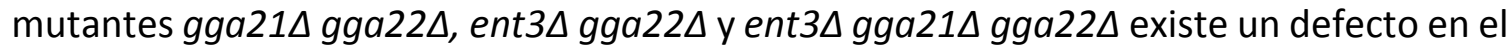
transporte de Ub:GFP-Cps1 desde el PVE al lumen de la vacuola y que este es diferente al defecto observado en vps27ム. Esto está en consonancia con los resultados previos obtenidos en S. cerevisiae en los que se han observado defectos en el procesamiento de

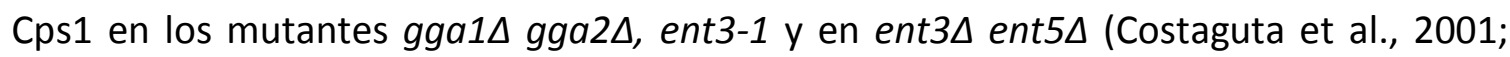
Duncan et al., 2003; Eugster et al., 2004; Friant et al., 2003).

Como resumen de esta parte, se puede decir que se requiere la colaboración entre Gga22 y Gga21, y entre Gga22 y Ent3 para que se produzca una salida eficiente de Cps1 desde el TGN. Además, la parte de Cps1 que llega al PVE en ausencia de estos adaptadores no se envía eficazmente hacia la vacuola, detectándose un procesamiento anormal. 


\section{Análisis del transporte hacia la vacuola de otras proteínas (Vph1) en ausencia de GGAs y Ent3.}

Vph1, una subunidad del dominio V0 de la ATPasa vacuolar, es una proteína con múltiples pasos transmembrana que sigue la ruta CPY para alcanzar la membrana de la vacuola (Conibear and Stevens, 1998; Gerrard et al., 2000; Piper et al., 1995). Se decidió analizar su localización para evaluar si todas las proteínas que viajaban por esta ruta presentaban una distribución alterada en cepas sin los GGAs y/o Ent3. Como se puede observar en la figura 20A, la distribución de Vph1-GFP en los mutantes carentes de los diferentes adaptadores era similar a la del WT, visualizándose en la membrana vacuolar. En vps27ム esta proteína, además de presentar esta localización, se observaba en algún punto intracelular que podría corresponderse con el PVE aberrante que se forma en ausencia del ESCRT (el endosoma E). Esto indica que Vph1 sigue esta ruta también en $S$. pombe. Además, se comprobó mediante una tinción con quinacrina que las vacuolas se estaban acidificando correctamente en los mutantes de los adaptadores, lo que demostraba que la ATPasa era funcional (figura 20B). Estos resultados indicaban que los GGAs y la epsina Ent3 no facilitan el transporte de todas las proteínas que siguen la ruta CPY.

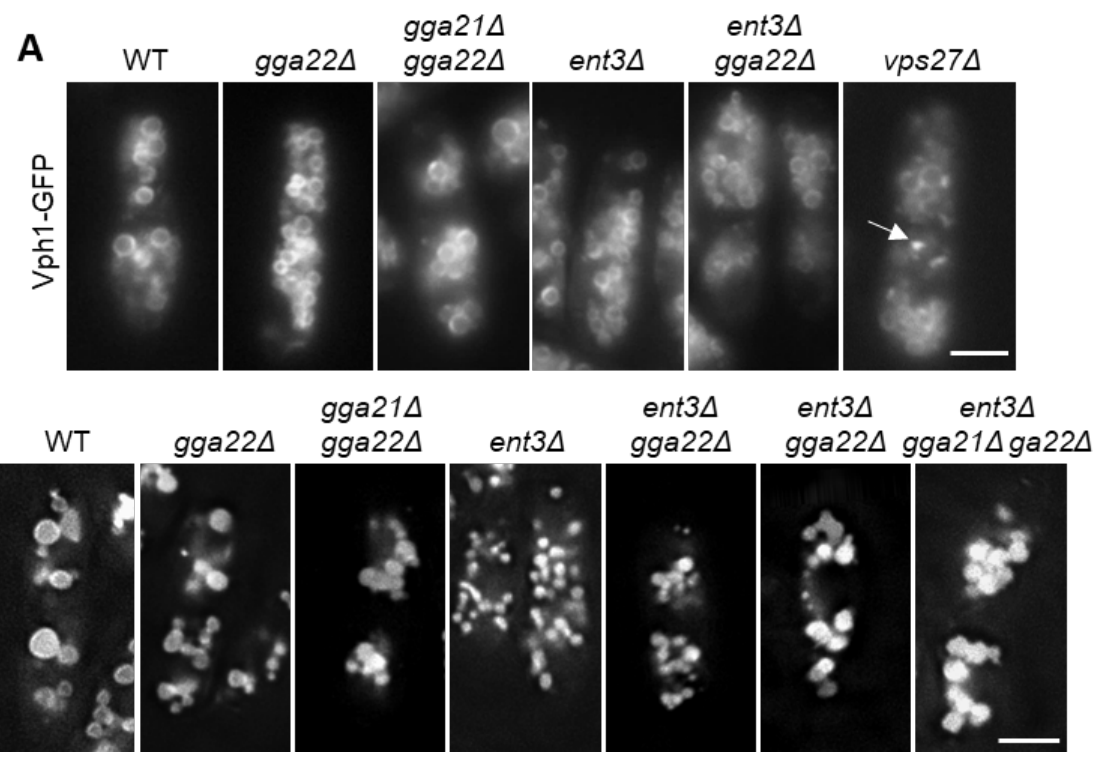

Figura 20. Localización y funcionalidad de la v-ATPasa vacuolar en ausencia de los adaptadores. A: distribución de Vph1-GFP en las cepas indicadas. Las imágenes se adquirieron con un microscopio Nikon 90i. La flecha señala la acumulación anómala de Vph1-GFP en vps27A. B: las vacuolas de las cepas indicadas se tiñeron con el colorante quinacrina. Las imágenes son planos medios adquiridos con un sistema de microscopía Delta Vision. Barra de escala, $5 \mu \mathrm{m}$. 


\section{Papel de los GGAs y de Ent3 en el reciclaje de proteínas desde el PVE.}

\subsection{Tráfico retrógrado de Vps10 desde el PVE.}

En S. cerevisiae la estabilidad del receptor Vps10 se ha utilizado como indicador de su tráfico. En ciertos mutantes o condiciones esta proteína sufre una degradación proteolítica parcial. Esto sucede, por ejemplo, en los mutantes del complejo ESCRT, en los que Vps10 queda atrapado en el endosoma $\mathrm{E}$ sin posibilidad de reciclar hacia el TGN y por ello se produce su degradación por proteasas presentes en dicha estructura (Cereghino et al., 1995; Piper et al., 1995; Raymond et al., 1992). Además, se ha detectado la degradación del receptor cuando se delecionan ciertas partes del extremo C-terminal del mismo y en algún mutante del retrómero. En estos dos últimos casos Vps10 queda retenido en la vacuola y expuesto a la acción de las proteasas (Cereghino et al., 1995; Seaman et al., 1997). En este sentido, se sabe que Pep4 es la proteasa vacuolar responsable del corte proteolítico del receptor (Cereghino et al., 1995; Piper et al., 1995). Como se puede deducir de estos resultados, Vps10 pierde la estabilidad en aquellas situaciones en las que queda retenido en la vacuola o en un PVE alterado.

\subsubsection{Caracterización del tráfico retrógrado de Vps10 en S. pombe.}

Teniendo en cuenta los resultados anteriores obtenidos en S. cerevisiae, se decidió profundizar en la caracterización del tráfico retrógrado del receptor en S. pombe. En este organismo se ha visto que Vps10 sufre una degradación parcial en los mutantes del retrómero (Iwaki et al., 2006). Se comprobó si esto también sucedía en mutantes del ESCRT. Para ello se analizó Vps10-GFP por western blot en los extractos de la cepa vps27A, en paralelo a los del WT y a los del mutante del retrómero vps35 4 . En este último mutante se detectó una banda por debajo de la correspondiente a la proteína entera (figura 21A), lo que coincidía con los resultados publicados anteriormente (Iwaki et al., 2006). Esta banda era poco intensa indicando que sólo una pequeña fracción de las moléculas de Vps10-GFP estaba sufriendo proteólisis. En el WT y en el mutante vps27ム no se observó esta banda, por lo que el receptor no se estaba degradando (figura 21A). Para obtener más información sobre el entorno donde ocurría la degradación parcial de Vps10, se analizaron extractos celulares del WT, de vps35 $\Delta$, de apm1 $1 \Delta$ (que en S. pombe presenta 
un TGN alterado; Kita et al., 2004) y de pik3/vps34L (figura 21B). Este último mutante no puede sintetizar PI3P, por lo que presenta un PVE y vacuola alterados (Takegawa et al., 1995) y Vps10-GFP se queda retenido en la membrana vacuolar (figura 21C). Como se observa en la figura 21B, la banda de degradación estaba presente en pik3/vps34 $\Delta$ y en vps35 pero no en $a p m 1 \Delta$, apoyando la idea de que la degradación parcial sucede en el entorno del PVE-vacuola y no en el TGN.
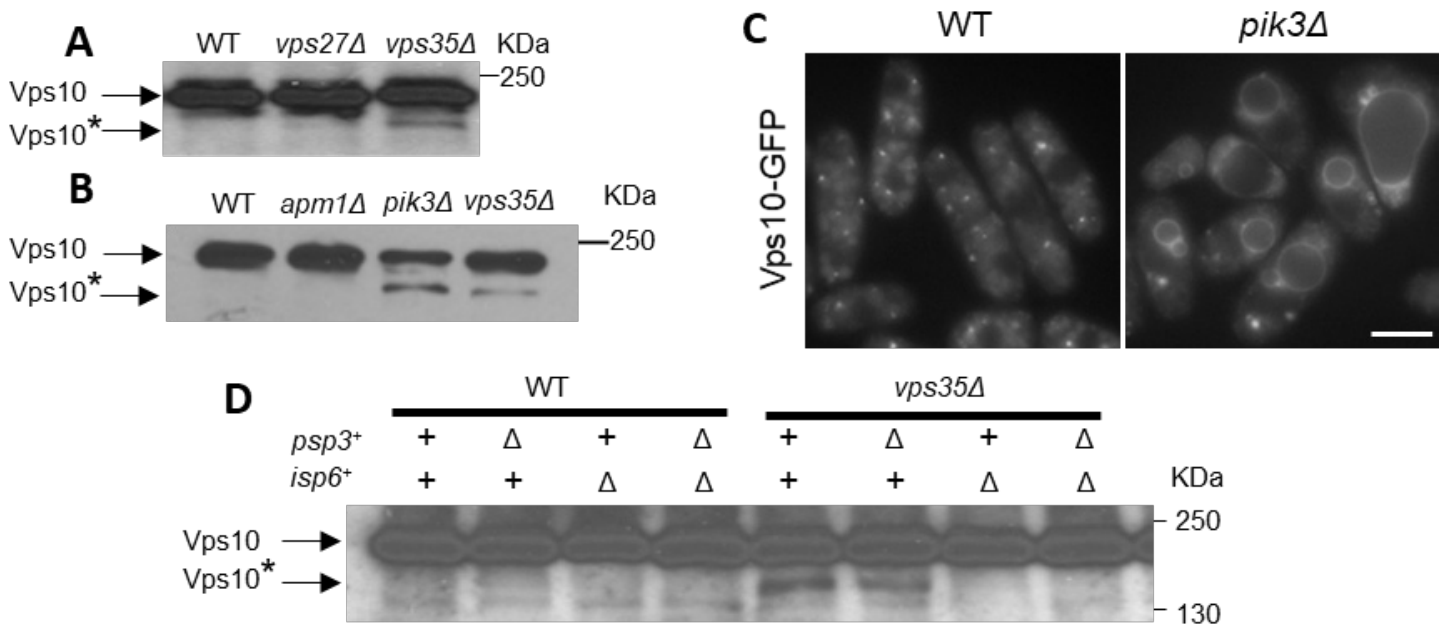

$\mathbf{E}$

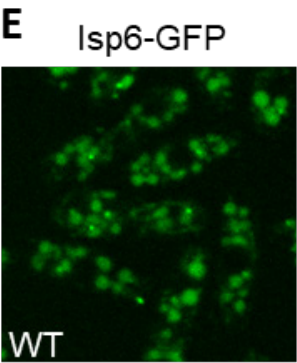

Cherry-FYVE

Superposición
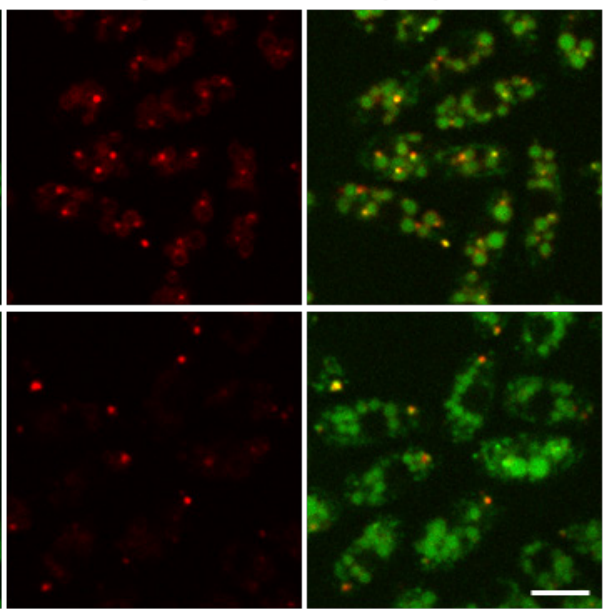

Figura 21. Vps10-GFP se degrada de manera dependiente de Isp6 cuando se altera su tráfico retrógrado. $A, B$ y $D$ son western blot de la proteína Vps10-GFP de extractos totales procedentes de las cepas indicadas. Vps10 indica la banda de Vps10-GFP y Vps10* señala la banda de la forma truncada de esta proteína. A: Vps10-GFP se procesa en vps354. B:

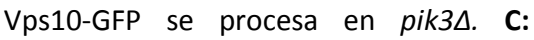
distribución de Vps10-GFP en WT y pik3 Fotos adquiridas con un microscopio Leica DM RXA. D: el procesamiento de Vps10-GFP en vps35 $\Delta$ depende de Isp6. E: colocalización de Isp6-GFP con CherryFYVE en WT y gga21 $\Delta$ gga22 $\Delta$ (gga $\Delta \Delta)$. Las imágenes son planos medios adquiridos con un microscopio confocal spinning disk. Barras de escala, $5 \mu \mathrm{m}$ 
A continuación, se quiso confirmar que la banda de menor tamaño de Vps10-GFP presente en los extractos de estos mutantes se estaba produciendo por la acción de proteasas. En S. pombe no hay un homólogo claro de la proteasa Pep4 de S. cerevisiae; sin embargo, las proteasas vacuolares Isp6 y Psp3 son necesarias para el procesamiento de Cpy1 y ALP, como ocurre con Pep4 en S. cerevisiae (Mukaiyama et al., 2011). Por tanto, se pensó que estas proteasas podrían ser las responsables del corte de Vps10-GFP. Para examinar esto se analizaron extractos de la cepa WT y del mutante vps35 $\Delta$ portando las deleciones de $i s p 6^{+} \mathrm{y} / 0$ de $p s p 3^{+}$. En la cepa WT no se apreciaba la banda de degradación

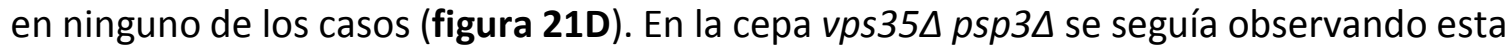
banda, sin embargo, se dejó de detectar en vps35 $\Delta$ isp6 6 y vps35 $p s p 3 \Delta$ isp6 6 (figura 21D). Esto confirmaba que esta banda de menor tamaño se estaba formando por la degradación proteolítica de Vps10-GFP y que esta se estaba produciendo por la acción de Isp6. Además, se evaluó la localización de Isp6-GFP y se constató que esta proteasa estaba presente en la vacuola, acorde con resultados publicados previamente (Mukaiyama et al., 2011) y en el PVE (figura 21E). Esto confirmaba la idea de que la degradación de Vps10GFP estaba ocurriendo en este entorno.

\subsubsection{Análisis de los mutantes sin los adaptadores GGAs-Ent3.}

Tras las conclusiones anteriores se decidió complementar los resultados de microscopía previos en los que se había visto un defecto en la salida de Vps10-GFP del TGN en mutantes sin los GGAs y/o Ent3. En este sentido, se pensó en delecionar diferentes combinaciones de GGAs y epsina junto con la deleción del retromero (vps35 $\Delta$ ). De esta manera, al existir una menor salida de Vps10-GFP desde el TGN en las cepas sin los adaptadores de clatrina, se vería una disminución en la intensidad de la banda de degradación presente en el mutante simple vps35 $\Delta$. Un experimento parecido se había

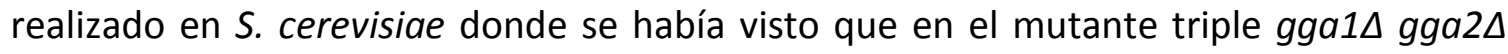
vps28 desaparecía la banda de degradación de Vps10 observada en el mutante simple del ESCRT vps28 (Costaguta et al., 2001). De este resultado se ha interpretado que existe un bloqueo del receptor en el TGN en ausencia de los GGAs y esto impide que Vps10 llegue al endosoma $\mathrm{E}$ y se degrade. Siguiendo esta estrategia, primero analizamos lo que

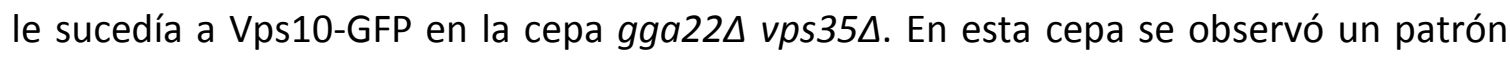


electroforético similar al observado en el mutante simple vps35 (figura 22A), lo cual está de acuerdo con que una parte del receptor sale del TGN en ausencia de Gga22. Después, se quiso ver lo que sucedía en el mutante gga21 $\operatorname{loga} 22 \Delta$ vps35 3 y en ent $3 \Delta$ vps $35 \Delta$, sin embargo, no se pudo construir estas cepas, indicando que existía una fuerte interacción génica entre $v p s 35^{+}$y los genes de los adaptadores. Este resultado apuntaba a un posible rol de los GGAs y Ent3 en el tráfico retrógrado desde el PVE hacia el TGN. Para explorar esta posibilidad se analizó la estabilidad de Vps10-GFP en mutantes carentes de GGAs y/o Ent3 con el gen silvestre vps35+. De esta forma, se detectó una banda de degradación de

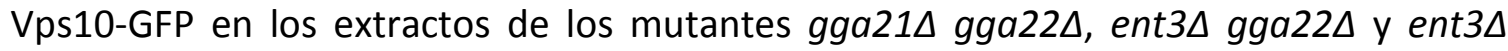

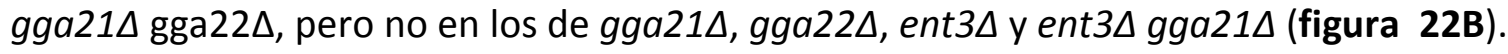
Además, esta banda se producía de manera dependiente de Isp6 de forma similar a lo que ocurría con el mutante del retrómero (figura 22C). Esta degradación no se debía a una deslocalización de Isp6-GFP (figura 21E) ni a un aumento de la cantidad de la proteasa en estos mutantes (no mostrado). Tampoco se debía a una deslocalización del retrómero ya que Vps35-GFP no cambia su distribución en estas cepas (ver más adelante). Todos estos resultados muestran que en el mutante del retrómero y en los mutantes gga21ડ

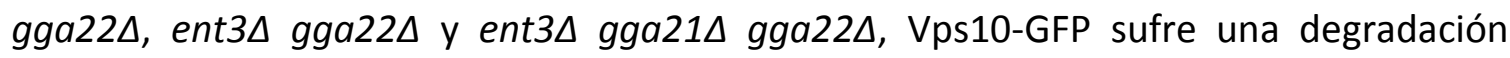
parecida y que esta tiene lugar en el entorno del PVE/vacuola. Esto indica que la colaboración de Gga22 con Ggga21 y/o Ent3 es necesaria para que se produzca un tráfico retrogrado eficiente del receptor desde el PVE al TGN. EI rol de estas proteínas en el tráfico retrógrado de Vps10-GFP está apoyado también por el hecho de que en los mutantes gga $22 \Delta$ vps $27 \Delta$ y ent $3 \Delta$ vps $27 \Delta$ se produce una banda de degradación similar a la de vps35 (figura 22D). 

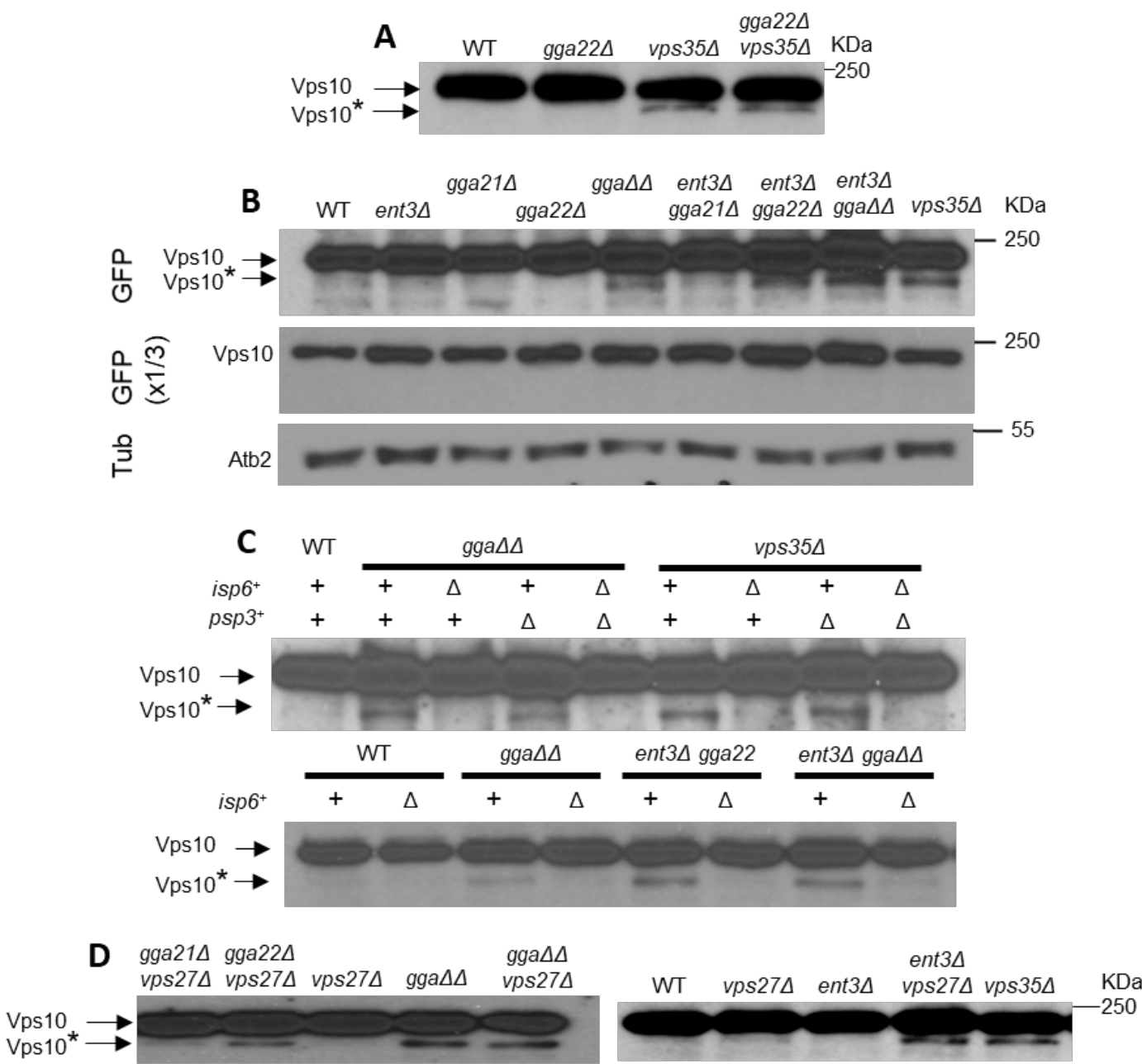

Figura 22. Análisis del procesamiento de Vps10-GFP en ausencia de Ent3 y GGAs. A-D. Western blots de la proteína Vps10-GFP en extractos totales de las cepas indicadas. Vps10 indica la banda de Vps10-GFP y Vps10* señala la banda de la forma truncada de esta proteína. A: Vps10-GFP se procesa en gga22 $\Delta$ vs35 $\Delta$. B: Vps10GFP se procesa en gga21 1 gga22 $\Delta$, ent $3 \Delta$ gga22 $\Delta$ y ent $3 \Delta$ gga21 $\Delta$ gga22 $\Delta$. El mismo experimento se ha expuesto durante un tiempo largo (panel superior) o durante un tiempo más corto (x1/3; panel medio). Se muestra también la cantidad de tubulina en cada cepa (panel inferior). C: el procesamiento de Vps10-GFP en gga21 gga22 $\Delta$, ent3 $\Delta$ gga22 $\Delta$ y ent3 $\Delta$ gga21 $\Delta$ gga22 $\Delta$ depende de Isp6. D: Vps10-GFP se procesa en gga22 $\Delta$ vps $27 \Delta$,

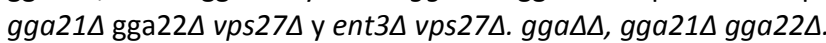




\subsection{Reciclaje de Syb1 en mutantes sin los adaptadores GGAs-Ent3.}

Syb1 es la SNARE homóloga a Snc1 de S. cerevisiae. En este último organismo se ha

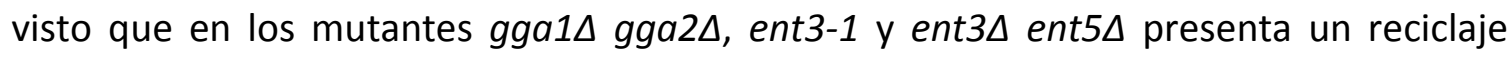
defectivo hacia la membrana plasmática (Black and Pelham, 2000; Zimmermann et al.,

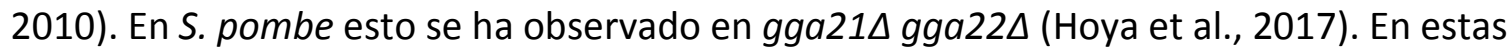
cepas, Syb1/Snc1 se ve mayoritariamente en compartimentos intracelulares, sin embargo, se desconoce la naturaleza de dichas estructuras. Tras observar los problemas de reciclaje de Vps10-GFP desde el PVE en algunos de los mutantes sin GGAs y Ent3, se decidió evaluar si estos compartimentos celulares dónde quedaba atrapada Syb1 podían ser PVEs (al menos en parte). Para ello se analizó la distribución de GFP-Syb1 con respecto al marcador Cherry-FYVE en las cepas con defectos en el tráfico retrógrado de Vps10-GFP

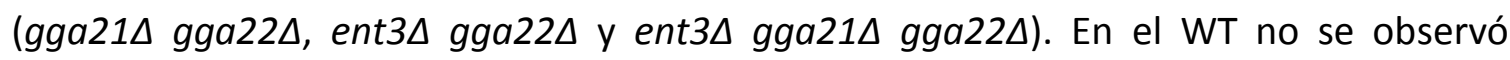
colocalización entre estas dos proteínas (figura 23A), sin embargo, en los mutantes ambas proteínas colocalizaban en algunos puntos intracelulares (figura 23A). Al seguir alguno de estos puntos a lo largo del tiempo (flechas, figura 23A), se vio que la coexistencia de ambas proteínas era duradera y no algo transitorio (figura 23B). Estos resultados muestran que parte de Syb1 se encuentra en el PVE de manera estable cuando faltan los dos GGAs o Gga22 y Ent3. En S. cerevisiae, aunque no se ha observado esta proteína en el PVE, algunos resultados indican que Snc1 recicla desde esta estructura hacia la membrana plasmática (Hettema et al., 2003; Ma et al., 2017). Los resultados aquí mostrados señalan que este reciclaje es considerablemente menos eficiente en ausencia de los adaptadores GGAs y Ent3. Además, muestran que la colaboración entre estos adaptadores se extiende al transporte de otras proteínas que no siguen la ruta CPY. 

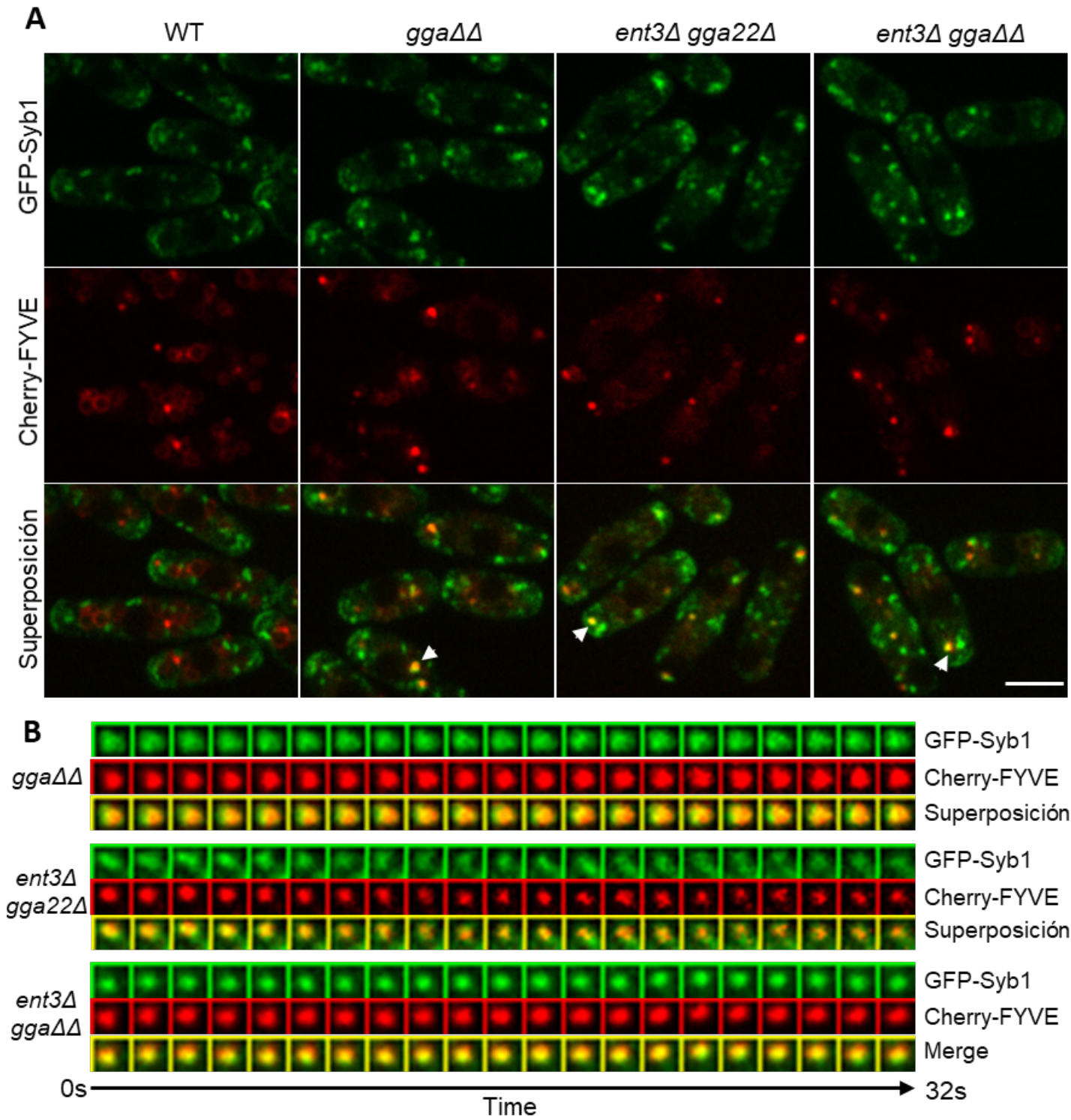

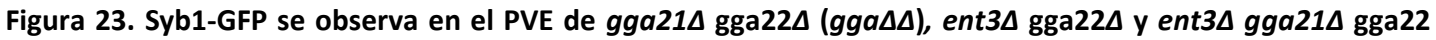
(ent3 $\mathbf{\Delta} g \boldsymbol{g} \boldsymbol{a} \Delta \mathbf{\Delta})$. A: colocalización de GFP-Syb1 con Cherry-FYVE en las cepas indicadas. Las imágenes son planos medios capturados con un microscopio confocal spinning disk. Las cabezas de flecha señalan los PVEs mostrados en B a tiempo 0. B: montajes de imágenes del seguimiento en el tiempo de los PVEs señalados en A. Cada imagen es un único plano. Se muestra la progresión en el tiempo cada 1,62 segundos. Las imágenes originales se corrigieron para el foto-blanqueamiento antes de realizar los montajes. Barra de escala, $5 \mu \mathrm{m}$.

\section{Morfología del PVE en los mutantes carentes de GGAs-Ent3.}

Cuando se analizó la localización de Vps10-GFP se observó que el tamaño de los puntos en los que estaba presente era más heterogéneo en los mutantes gga22 2 y gga21 gga22 $\Delta$ que en el WT. Además, al cuantificar los puntos con un tamaño similar a los del WT $\left(\geq 0,071 \mu \mathrm{m}^{2}\right)$, estos eran más numerosos en los mutantes (figura 24A). Esto 
A

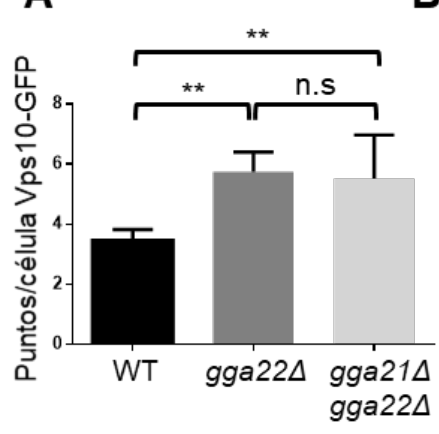

B

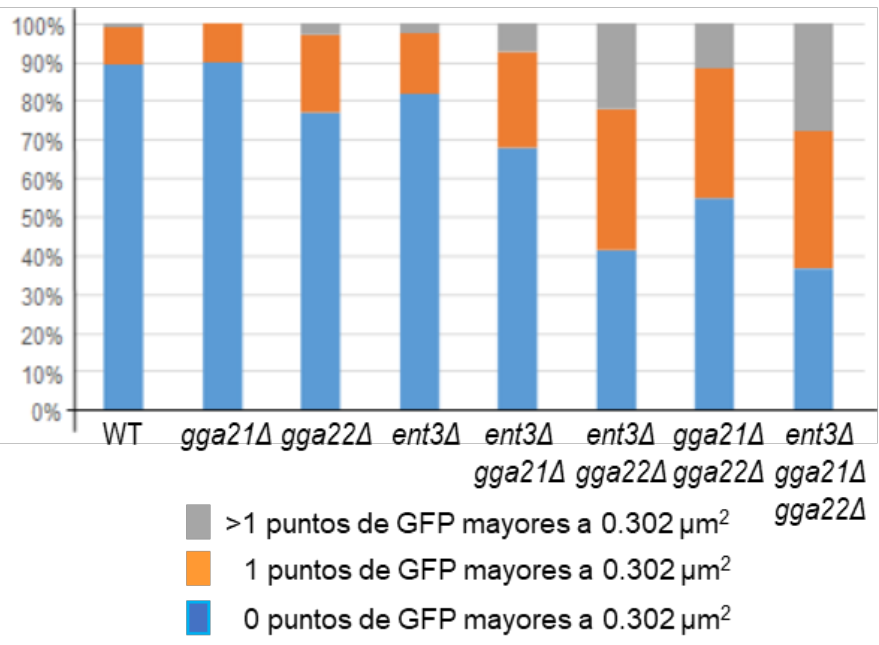

Figura 24. Características del PVE en los mutantes de los adaptadores. A: Número de puntos de Vps10-GFP por célula en las cepas indicadas. Se cuantificaron puntos $\geq 0,071 \mu \mathrm{m}^{2}$ en un único plano de las imágenes. Se muestra la media y desviación típica de seis experimentos independientes. El nivel de significación se calculó utilizando el test de Tukey tras ANOVA. ns, no significativo; ${ }^{* *}, p<0,01$. B: Porcentaje de células de las cepas indicadas con PVE muy grandes. Se cuantificaron puntos $\geq 0,302 \mu \mathrm{m}^{2}$ en proyecciones suma de imágenes con 13 planos, adquiridos a lo largo de toda la célula. Se representa la media de dos experimentos independientes. Las imágenes cuantificadas en $\mathrm{A}$ y $\mathrm{B}$ fueron adquiridas con un microscopio confocal spinning disk.

último se puede explicar porque en los mutantes parte de Vps10-GFP se está quedando retenida en el TGN, dando lugar a la aparición de nuevos puntos. Además, se observó que en la cepa gga21 $g g a 22 \Delta$ ciertas células presentaban algún punto de gran tamaño que no se observaba en las células del WT. En torno al 45\% de las células del mutante gga21ム gga22 2 presentaban uno o más puntos de Vps10-GFP mayores a 0,301 $\mu^{2}$, mientras que difícilmente se veían puntos de este tipo en el WT (figura 24B). De acuerdo con la colocalización con Cherry-FYVE, estos puntos eran PVE engrosados o alterados (flechas en figura 13A). Estas estructuras más grandes también se apreciaban al observar Ub:GFPCps1 en gga21 gga22 y colocalizaban con Cherry-FYVE (felchas en figura 19A). Para confirmar estos resultados se analizó la distribución de otros marcadores de PVE: Vps27RFP, Nhx1-GFP (un antiportador de $\mathrm{Na}^{+} / \mathrm{H}^{+}$presente en este compartimento; Nass and Rao, 1998), GFP-Pep12 (presente en la membrana vacuolar y el PVE; Hosomi et al., 2011) y Vps35-GFP (figura 25). Con todas estas proteínas se observaron puntos fluorescentes

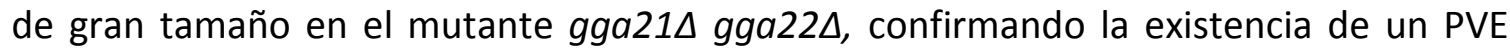
alterado. Estos resultados están de acuerdo con la alteración en la organización del PVE observada por microscopía electrónica en este mutante (Hoya et al., 2017). Estos PVE 


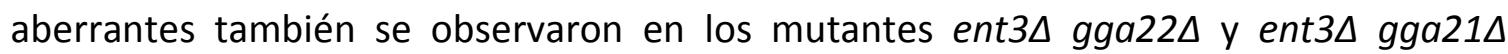
gga22 tanto con Vps10-GFP (figura 24B) como con otros marcadores (figuras 19A y 25). Estos resultados demuestran que la colaboración entre Gga22 y Gga21 y entre Gga22 y Ent3 es necesaria para la correcta organización del PVE.

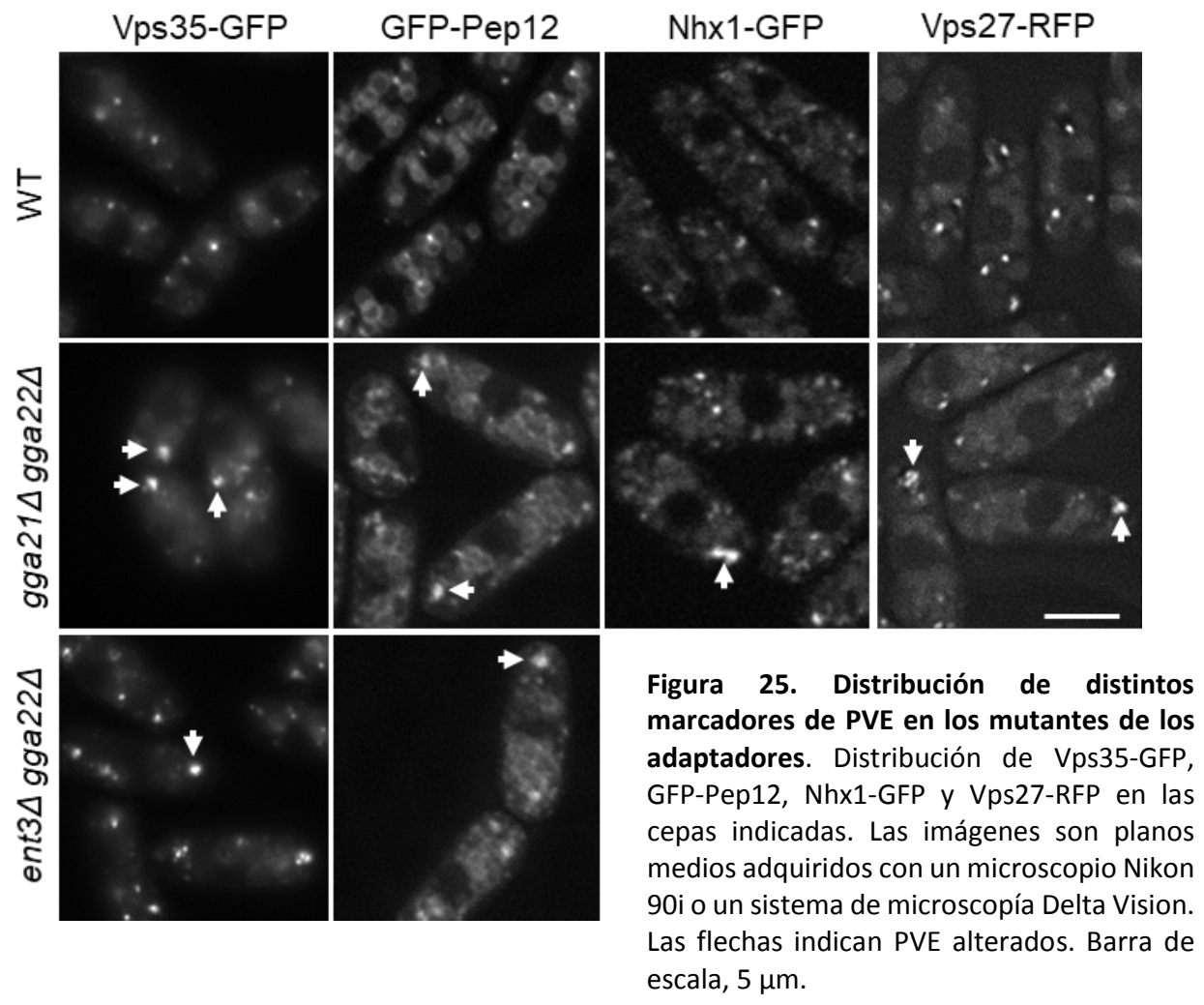

Como se ha mencionado anteriormente, en S. cerevisiae los mutantes del complejo ESCRT presentan un PVE aberrante denominado endosoma E. Esta estructura contiene marcadores de PVE/vacuola y de TGN (GGAs, Ent5, Vps10, Cpy1 y Vph1; Boman et al., 2002; Cereghino et al., 1995; Eugster et al., 2004; Hirst et al., 2001; Piper et al., 1995; Raymond et al., 1992; Urbanowski and Piper, 2001). Por ello se quiso explorar si el PVE

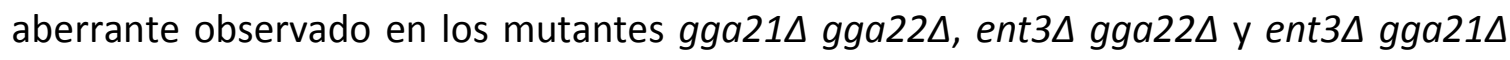
gga22 2 podría ser una estructura similar al endosoma E. Sin embargo, se encontraron una serie de evidencias en contra de esta hipótesis. En primer lugar, en el mutante gga21 g ga22 $\Delta$ no existía colocalización entre Cpy1-Cherry y GFP-FYVE (figura 14C) indicando que esta proteína no se quedaba atrapada en el PVE como sucede en mutantes del ESCRT. Tampoco se observó colocalización entre el marcador de PVE (FYVE) y el de 


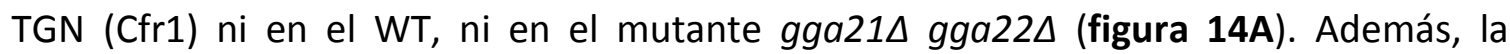
subunidad de la ATPasa Vph1 presentaba una localización vacuolar en las cepas gga21ム gga $22 \Delta$ y ent3 $\operatorname{sga} 22 \Delta$ similar a la del WT, mientras que en el mutante vps $27 \Delta$ esta localización estaba algo alterada (figura 20A). Asimismo, la degradación parcial de Vps10-

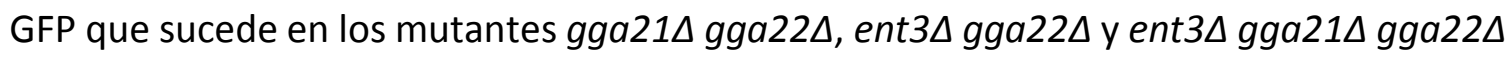
no ocurre en el mutante vps27A. Por último, el procesamiento y la localización de Ub:GFPCps1 es diferente en vps27 y en los mutantes de los adaptadores. Todos estos resultados

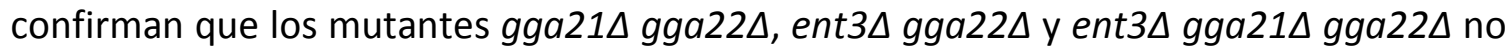
presentan un endosoma de clase E. Por tanto, aunque posean un PVE alterado, esta estructura es diferente a la observada en los mutantes del ESCRT.

\section{Interacciones génicas entre $g g a 21^{+}, g g a 22^{+}$, ent3 $3^{+}$y $v p s 27^{+}$.}

Los resultados descritos en este trabajo muestran que Gga22 colabora con Gga21 y con Ent3 en múltiples pasos del tráfico celular. Para entender si esta colaboración tiene relevancia para la fisiología celular, se estudiaron las posibles interacciones génicas. En primer lugar, se analizó el crecimiento de diferentes mutantes de estos adaptadores en distintas condiciones de temperatura. Se observó que, mientras los mutantes simples no presentaban un defecto de crecimiento a ninguna de las temperaturas analizadas, los mutantes dobles gga21 $\operatorname{gga} 22 \Delta$ y ent $3 \Delta$ gga22 $\Delta$ presentaban un defecto similar en el crecimiento a $37{ }^{\circ} \mathrm{C}$ (figura 26A). Además, el mutante ent3 $\log 21 \Delta$ gga22 $\Delta$ apenas crecía a esta temperatura (figura 26A). Posteriormente se analizó el crecimiento de estas cepas en condiciones de estrés osmótico/iónico, en presencia de $\mathrm{KCl}$ (figura 26B). En este caso se observó que el mutante ent $3 \Delta$ gga22 $\Delta$ era ligeramente sensible a concentraciones de 0,6 $\mathrm{M}$ de este compuesto. El mutante gga21 $\operatorname{gga} 22 \Delta$ presentaba una sensibilidad mayor y el mutante triple ent3 $\log 21 \Delta$ gga22 $\Delta$ apenas crecía en estas condiciones. Estos resultados demuestran que la colaboración entre estas proteínas es importante para el crecimiento celular y está de acuerdo con los fenotipos aditivos relacionados con el tráfico que se observan al delecionar $g g a 22^{+}$y gga $21^{+}$o ent $3^{+}$. Estas interacciones génicas concuerdan también con el hecho de que estas proteínas no son interdependientes para su correcta localización (figura 26C y S3, anexo). 

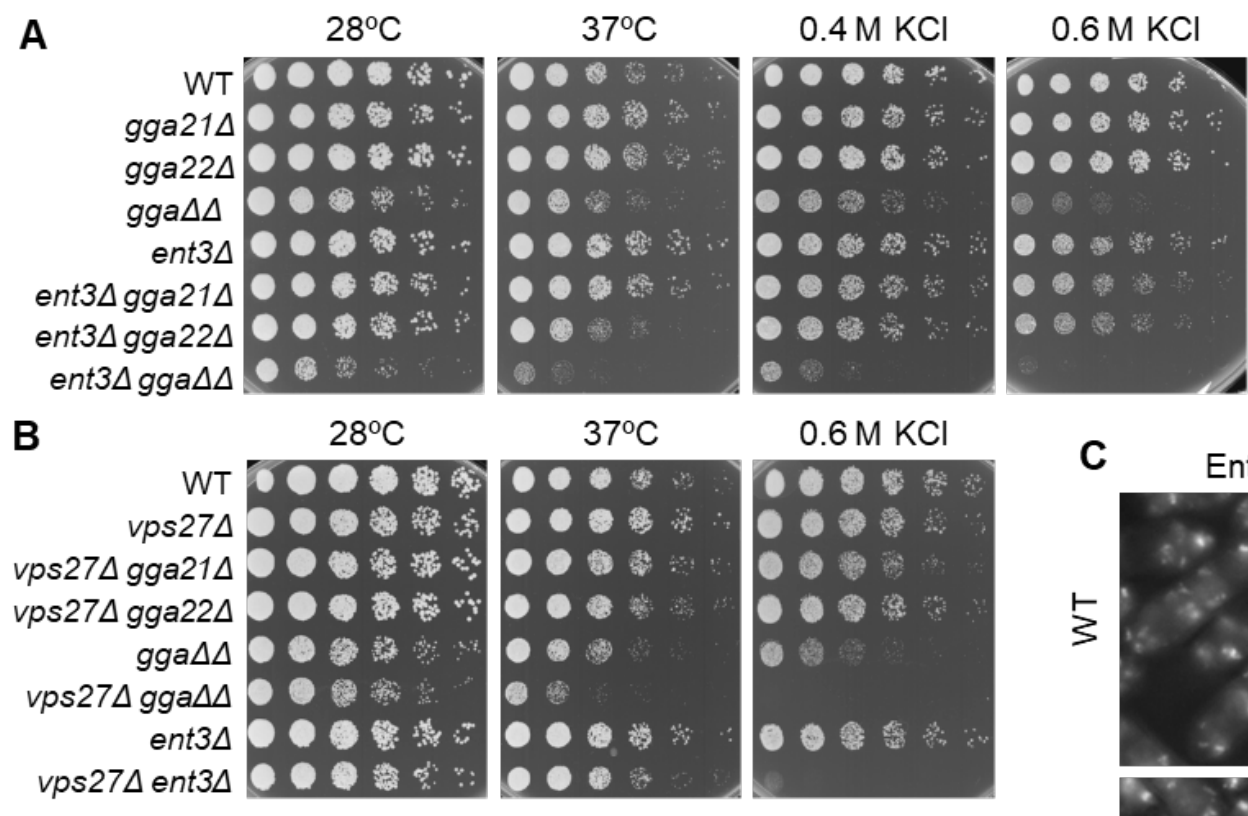

Figura 26. Los adaptadores GGAs y Ent3 son necesarios para el crecimiento en determinadas condiciones de estrés. A: interacción génica entre gga21 $\Delta$, gga22 $\Delta$ y ent $3 \Delta$. B: interacción génica entre gga21 $\Delta$, gga22 2 , ent3 $\Delta$ y vps $27 \Delta$. A y B ensayo de crecimiento en gota en medio rico (YES) en las condiciones indicadas. Se inocularon diluciones seriadas $1 / 4$ a partir de una suspensión inicial que contenía 3 $\times 10^{4}$ células. Las placas se incubaron durante tres días. C: distribución de Ent3-GFP
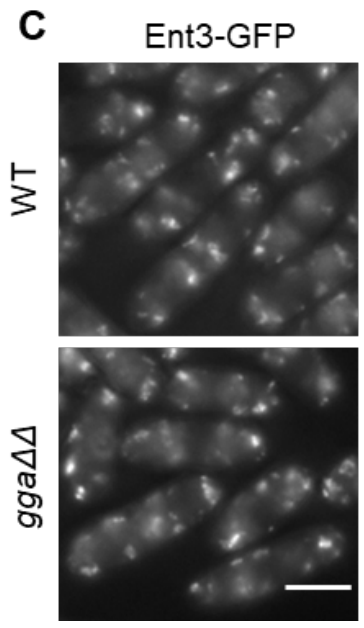
en WT y gga21 gga22 $\Delta$. Imágenes adquiridas con el microscopio Leica DM RXA. Barra de escala, $5 \mu \mathrm{m}$. gga $\Delta$, gga21 $\operatorname{gga} 22 \Delta$.

Como se mencionaba anteriormente, no se pudieron obtener las cepas vps35 $\Delta$

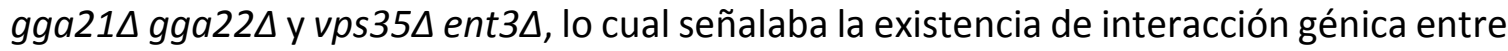
los mutantes de los adaptadores y del retrómero. En relación con esto, se quiso investigar la posible interacción génica con otros genes necesarios para el tráfico desde el PVE. Para ello se analizó la posible interacción entre los genes de los adaptadores y los del complejo

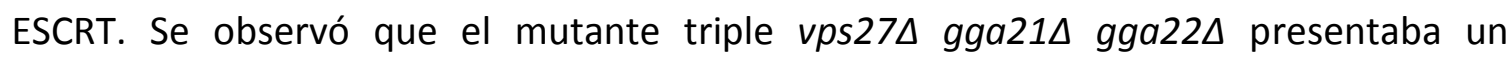
crecimiento reducido a $37^{\circ} \mathrm{C}$ con respecto a los mutantes vps $27 \Delta$ y gga $21 \Delta$ gga $22 \Delta$ (figura 26B). También existía interacción génica en presencia de $0,6 \mathrm{M}$ de $\mathrm{KCl}$, condiciones en las que el mutante triple apenas crecía (figura 26B). Además, el mutante doble ent3 $\triangle$ vps $27 \Delta$ crecía peor que los mutantes simples a 37으 y también con $\mathrm{KCl}$ (figura 26B). Estos resultados demuestran la existencia de interacción génica entre los genes de los adaptadores GGAs/Ent3 y otros genes cuya función está relacionada con el tráfico desde el PVE. 


\section{Capítulo I}

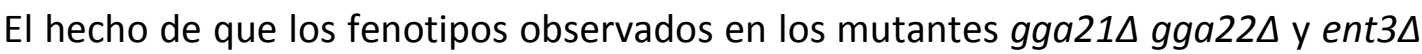

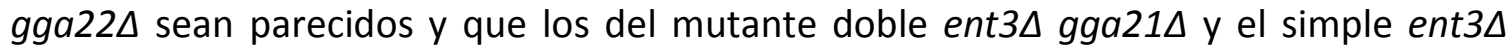
también, podría sugerir que Gga21 y Ent3 actuasen en la misma ruta. Sin embargo, la diferencia en fenotipos observada entre el mutante gga21 $\operatorname{vps} 27 \Delta$ y el ent $3 \Delta$ vps $27 \Delta$ (figura 22D y 26B) va en contra de esta hipótesis. Además, la observación de un fenotipo

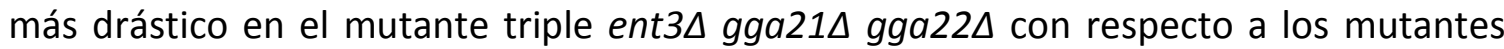

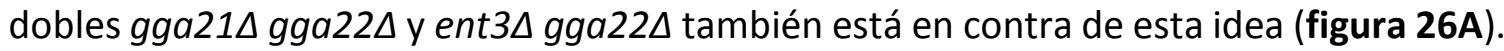
Estos resultados muestran que la relación funcional entre los GGAs y Ent3 es compleja. 


\section{Capítulo II:}

Estudio de la SNARE Fsv1 y de su papel en el tráfico entre el TGN y la vacuola. 

Como se ha expuesto en la introducción, las SNAREs realizan una función esencial en el tráfico intracelular mediando la fusión de membranas. Por ello, se ha querido explorar también el papel de las SNAREs dentro del ámbito de estudio del presente trabajo, es decir, en el tráfico entre el TGN, el PVE y las vacuolas. Una de las SNAREs que participan en este tráfico es la sintaxina 8, que en mamíferos participa en la fusión homotípica de endosomas y en la fusión de los endosomas tardíos con los lisosomas (Antonin et al., 2000; Pryor et al., 2004). Sin embargo, estas conclusiones se han obtenido sobre todo a partir de ensayos in vitro. Además, se conoce muy poco acerca de las consecuencias que producen estas alteraciones en el tráfico intracelular, a pesar de que esta SNARE se ha relacionado con infección y enfermedades como la fibrosis quística (Bilan et al., 2004; Singh et al., 2018). En este sentido, aunque se ha descrito que su ausencia produce un retraso en la endocitosis de algunos cargos y en la secreción de otros, poco se sabe sobre su efecto en el tráfico hacia el lisosoma (Chen et al., 2014; Renigunta et al., 2014). En S. cerevisiae Syn8 inmunoprecipita con otras SNAREs que participan en el tráfico entre el TGN y la vacuola, aunque su función se ha estudiado poco, ya que es parcialmente redundante con la de Tlg1 (Lewis and Pelham, 2002).

En S. pombe algunas de las SNAREs homólogas a las que participan en el tráfico entre el TGN, el PVE y las vacuolas en otros organismos son esenciales. Sin embargo, Fsv1 (homóloga a sintaxina 8/Syn8) no lo es. Se sabe que en ausencia de Fsv1 se produce un retraso en la maduración de Cpy1 y una secreción anómala de esta proteasa, apuntando a la participación de esta SNARE en el tráfico de Vps10 (Takegawa et al., 2003). Dado que esta SNARE está poco caracterizada tanto en esta levadura como en otros organismos, su estudio resultaba atractivo. Por todo esto el objetivo de esta parte del trabajo ha sido caracterizar la función de Fsv1 en el tráfico entre el TGN, el PVE y las vacuolas mediante análisis de microscopía in vivo. Los objetivos concretos han sido:

- Analizar el tráfico de diferentes proteínas entre el TGN, el PVE y las vacuolas en el mutante $f s v 1 \Delta$.

- Analizar la morfología del TGN, PVE y vacuolas en dicho mutante.

- Caracterizar la localización de Fsv1 y los elementos que participan en la misma. 

Resultados 



\section{Estudio del tráfico hacia el PVE y la vacuola en el mutante fsv1.}

\subsection{Tráfico de Vps10}

De forma similar a lo realizado con los adaptadores en el apartado anterior, se utilizó Vps10-GFP como herramienta para estudiar la función de Fsv1 en el tráfico entre el TGN y el PVE. El uso del receptor con este fin era apropiado, ya que en el mutante $f s v 1 \Delta$ de $S$. pombe se había descrito una alteración en el tráfico de Cpy1 (Takegawa et al., 2003). Así pues, se analizó la distribución de Vps10-GFP en un mutante $f s v 1 \Delta$. En esta cepa no se observaban los puntos brillantes de Vps10-GFP presentes en el WT, sino que la proteína aparecía con un patrón difuso (figura 27A). Por tanto, parecía que el receptor no estaba llegando correctamente al PVE en el mutante. Además, en la cepa $f s v 1 \Delta$ se observaban puntos con poca fluorescencia en el interior celular, alguno de los cuales se encontraba cerca de la membrana plasmática (flechas, figura 27A). Debido a esta observación, se pensó que quizás el receptor se estaba enviando hacia la superficie celular y endocitándose seguidamente, dando lugar a esas vesículas. Para explorar esta opción se analizó la distribución de Vps10-GFP tras inhibir la endocitosis mediante un tratamiento con Latrunculina A. De esta manera, si el receptor se estaba enviando a la membrana plasmática, se acumularía en ella al inhibir la endocitosis. Sin embargo, tras un tratamiento de 20 minutos con esta droga, Vps10-GFP no se acumulaba en la membrana plasmática en el mutante $f s v 1 \Delta$ (figura 27B). Este resultado nos indicaba que el receptor no se desviaba hacia esta estructura en ausencia de la SNARE. Como control de la efectividad de Latrunculina A se usó la SNARE Syb1. Como se ve en la figura 27B esta proteína se acumula claramente en la superficie celular en presencia de la droga.

La distribución de Vps10-GFP en el mutante $f s v 1 \Delta$ parecía indicar que no estaba alcanzando correctamente el PVE. Con el fin de estudiar esto con más detalle, se bloqueaó el retorno del receptor desde esta estructura para ver si se acumulaba en ella en ausencia de Fsv1. Como se ha mencionado anteriormente, el reciclaje del receptor desde el PVE se bloquea en los mutantes del retrómero y este queda atrapado en la vacuola (Iwaki et al., 2006; Seaman et al., 1997). Por tanto, se procedió a analizar la localización de Vps10-GFP en una cepa sin la subunidad del retrómero Vps35 y sin Fsv1. 
De acuerdo con resultados previos, Vps10-GFP se observó en la membrana de la vacuola y en el endosoma prevacuolar en el mutante vps35 (figura 27A; Iwaki et al., 2006; Seaman et al., 1997). En el mutante doble vps35 $4 s v 1 \Delta$ el receptor se encontraba también en la membrana de la vacuola indicando que llegaba a este compartimento en ausencia de la SNARE (figura 27A). De acuerdo con este resultado, Cpy1-Cherry alcanza la vacuola en el mutante $f s v 1 \Delta$ de manera similar a lo que ocurre en el WT (figura 27C). Estos resultados muestran que el tráfico hacia la vacuola no está bloqueado en ausencia de Fsv1.

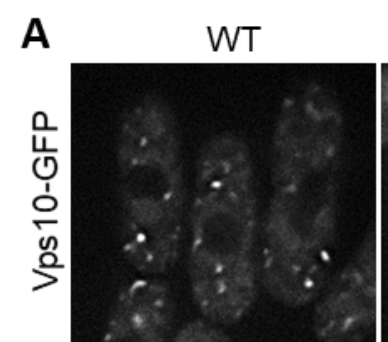

B
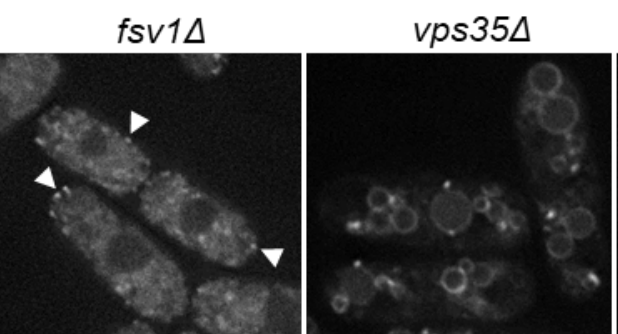

$f s v 1 \Delta v p s 35 \Delta$
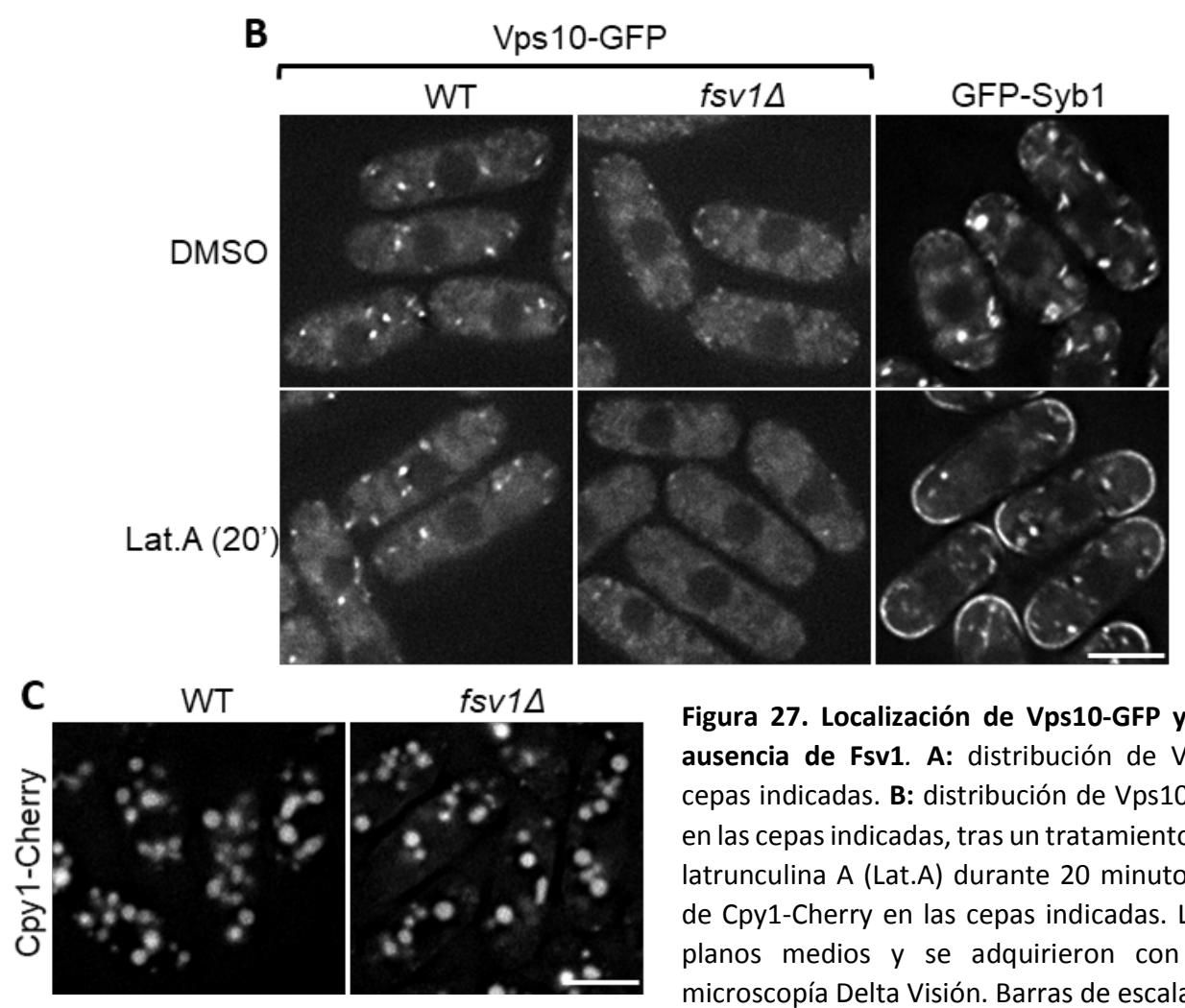

Figura 27. Localización de Vps10-GFP y Cpy1-Cherry en ausencia de Fsv1. A: distribución de Vps10-GFP en las cepas indicadas. B: distribución de Vps10-GFP o GFP-Syb1 en las cepas indicadas, tras un tratamiento con DMSO o con latrunculina A (Lat.A) durante 20 minutos. C: distribución de Cpy1-Cherry en las cepas indicadas. Las imágenes son planos medios y se adquirieron con un sistema de microscopía Delta Visión. Barras de escala, $5 \mu \mathrm{m}$. 


\subsection{Organización del PVE en el mutante fsv1}

Aunque Vps10-GFP se observaba en la membrana de las vacuolas tanto en vps35 como en vps $35 \Delta f s v 1 \Delta$, se podía apreciar una diferencia en la distribución de esta proteína entre las dos cepas. En el mutante vps35 $\Delta$ se observaban unos puntos brillantes cercanos a las vacuolas que no se apreciaban en el mutante doble vps35 $f s v 1 \Delta$. (figura 27A). Esos puntos probablemente se correspondían con proteína localizada en el PVE. Además, como se ha visto anteriormente, Vps10-GFP se distribuía de manera difusa en el mutante simple $f s v 1 \Delta$, a diferencia de lo que ocurría en el WT dónde se encontraba mayoritariamente en el PVE. Estas observaciones sugerían que el propio orgánulo podía estar alterado en el mutante $f s v 1 \Delta$. Para analizar esta posibilidad, se evaluó la localización de diferentes marcadores de PVE en esta cepa. Se usaron Vps27-RFP, Vps35-GFP y GFPPep12. En el WT, Vps27-RFP y Vps35-GFP se observaban mayoritariamente en puntos brillantes (PVE), aunque presentaban también una señal débil en las vacuolas (figura 28). En el mutante $f s v 1 \Delta$ estas proteínas se observaban en puntos con un tamaño menor y una fluorescencia más débil (además de en las vacuolas; figura 28). GFP-Pep12 se veía en la membrana de las vacuolas y en el PVE en el WT (Hoya et al., 2017), mientras que en fsv1 $1 \Delta$ se observaba fundamentalmente en la membrana de las vacuolas (figura 28). Además, en esta última cepa se apreciaba más fluorescencia difusa por el citoplasma. Estos resultados indicaban que el PVE estaba alterado en $f s v 1 \Delta$ y apuntaban a una posible fragmentación de esta estructura. Esto está de acuerdo con la participación de sintaxina 8 de mamíferos en la fusión de los endosomas tardíos (Antonin et al., 2000). Además, esta alteración explicaba la localización difusa de Vps10-GFP en este mutante.

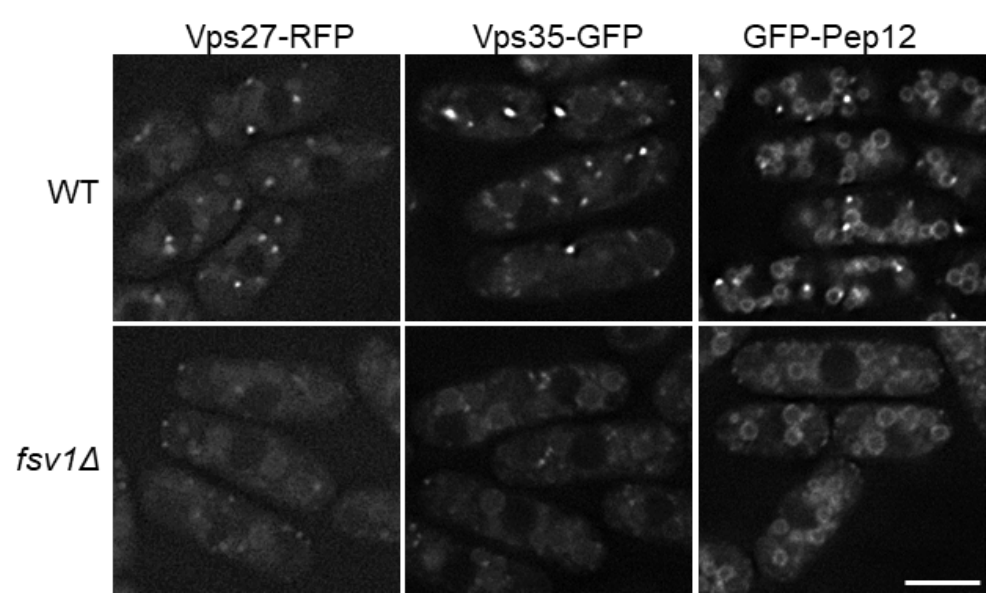

Figura 28. Distribución de distintos marcadores de PVE en ausencia de Fsv1. Localización de Vps27-RFP, Vps35-GFP y GFP-Pep12 en WT y $f s v 1 \Delta$. Las imágenes son planos medios de las células y se adquirieron con un sistema de microscopía Delta Vision. Barra de escala, $5 \mu \mathrm{m}$. 


\subsection{Tráfico hacia la vacuola en fsv1 $\Delta$ en ausencia de AP-3.}

Como se ha indicado, el tráfico de Vps10-GFP y GFP-Pep12 hacia la vacuola no está bloqueado en el mutante $f s v 1 \Delta$ (figuras 27A y 28). Por tanto, pese a poseer un endosoma prevacuolar aparentemente fragmentado, las proteínas alcanzan la vacuola. Esto planteaba la duda de cómo llegaban a este orgánulo. Una opción era que, pese a la alteración morfológica, las proteínas pudieran alcanzar la vacuola viajando a través del PVE (por la ruta CPY). Otra posibilidad era que, debido a la alteración del PVE, esta ruta estuviera bloqueada y las proteínas alcanzasen la vacuola por una ruta alternativa. Esta podía ser la ruta ALP que está mediada por el complejo AP-3 y que facilita el tráfico de ciertos cargos de manera directa desde el TGN a la vacuola sin pasar por el PVE (Berger et al., 2007; Cowles et al., 1997; Stepp et al., 1997; Sun et al., 2004). Para explorar estas opciones se decidió estudiar el tráfico de proteínas en ausencia de Fsv1 y de Apm3 (subunidad del complejo AP-3). En primer lugar, se analizó la localización de Vps10-GFP en el mutante triple vps35 $f s v 1 \Delta a p m 3 \Delta$. En esta cepa Vps10-GFP se observaba en la

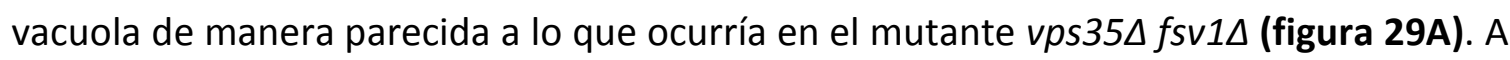
continuación, se analizó la localización de GFP-Pep12. Tanto en la cepa silvestre como en las cepas $f s v 1 \Delta, a p m 3 \Delta$ y $f s v 1 \Delta a p m 3 \Delta$ esta SNARE se veía en la membrana de la vacuola (figura 29B). Estos resultados indican que en ausencia de Fsv1 las proteínas destinadas a la vacuola no son desviadas por la ruta ALP, lo cual sugiere que alcanzan este orgánulo circulando a través del PVE alterado del mutante $f s v 1 \Delta$.

A
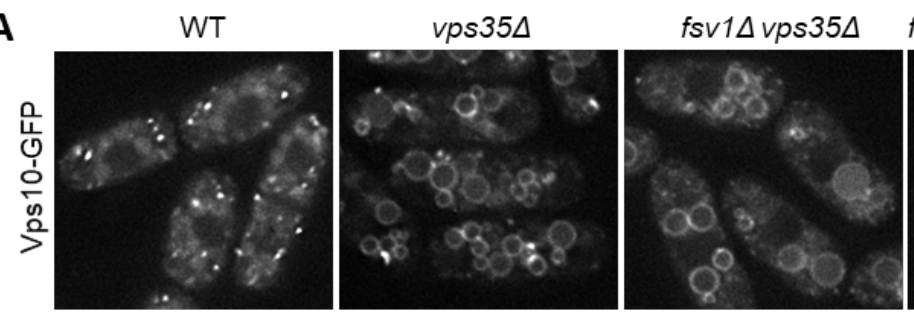

fsv1 1 vps35 $\operatorname{apm} 3 \Delta$

B

WT

fsv1 $1 \Delta$
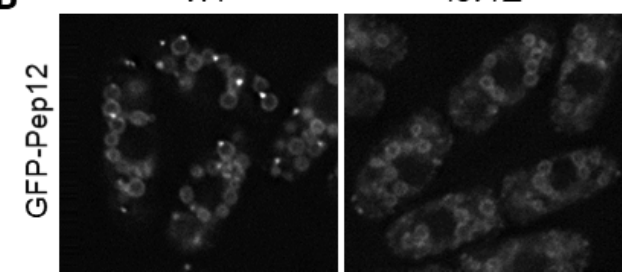

$\operatorname{apm} 3 \Delta$
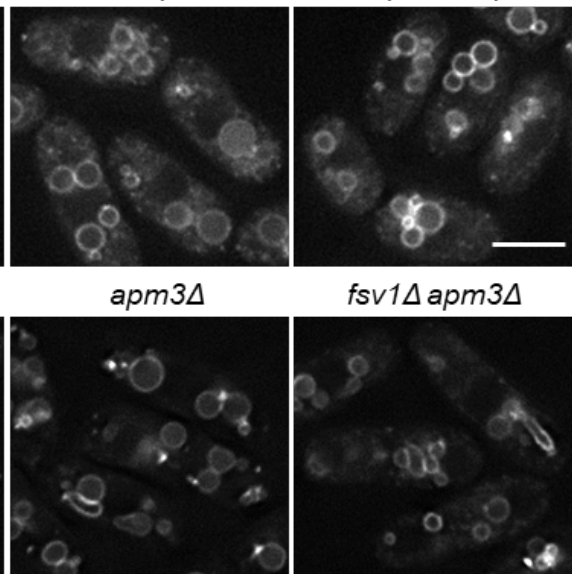

fsv1 $\operatorname{apm} 3 \Delta$

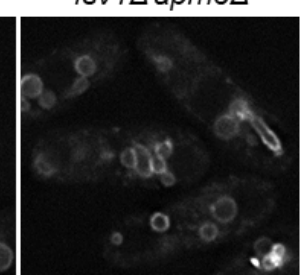

Figura 29. Papel de AP-3 en el tráfico de proteínas hacia la vacuola en ausencia de Fsv1. A: distribución de Vps10GFP en las cepas indicadas. B: distribución de GFP-Pep12 en las cepas indicadas. Las imágenes son planos medios de las células y se adquirieron con un sistema de microscopía Delta Vision. Barra de escala, $5 \mu \mathrm{m}$. 


\subsection{Funcionalidad del PVE en fsv1}

Después de observar alteraciones en la distribución de diferentes marcadores de PVE en el mutante $f s v 1 \Delta$ (figura 28) y tras ver que el tráfico hacia la vacuola a través de este orgánulo no estaba bloqueado (figura 29), se decidió estudiar con más detalle la funcionalidad de este compartimento. Como se ha mencionado anteriormente, las proteínas que tienen que ser degradadas o procesadas son incluidas en ILVs en este compartimento celular y posteriormente son liberadas en la vacuola (Frankel and Audhya, 2018). Ub:GFP-Cps1 sigue este mecanismo en su tráfico hacia la vacuola (Katzmann et al., 2001; Odorizzi et al., 1998; Reggiori and Pelham, 2001), por lo que se utilizó para estudiar cómo ocurre este proceso en el mutante $f s v 1 \Delta$. En primer lugar, se analizó su distribución por microscopía en este mutante. En el WT esta proteína se observaba en el interior de la vacuola y en puntos correspondientes al PVE (figura 30A). En el mutante del ESCRT vps27 27 esta construcción se observa en la membrana de la vacuola y en puntos adyacentes correspondientes al PVE (figura 30A). En el mutante fsv1 Ub:GFP-Cps1 presentaba una distribución diferente a la del WT, detectándose en la membrana de la vacuola, en pequeños puntos (alguno de ellos cercano a la superficie celular) y presentando un marcaje algo difuso en el citoplasma (figura 30A). Al comparar esta distribución con la del mutante del ESCRT vps27 $\triangle$ se observaron algunas diferencias: en la cepa sin Fsv1 se apreciaba algo de marcaje en el interior de la vacuola y no se observaban los puntos más grandes y brillantes presentes en vps27A. Estos datos parecían indicar que en $f s v 1 \Delta$ existía un defecto en la entrada de Ub:GFP-Cps1 en el interior de la vacuola y que esta alteración era algo diferente a la observada en el mutante vps270.

Para confirmar estos resultados, se procedió al análisis de esta proteína por western blot en las mismas cepas. Como se había visto anteriormente, en los extractos del WT se observaba una banda de unos 115 KDa de tamaño correspondiente a la proteína entera. Además, en esta cepa gran parte de Ub:GFP-Cps1 es procesada y por ello se apreciaba una banda intensa de 28 KDa que corresponde con el tamaño de la GFP libre (figura 30B). En el mutante vps27A, dónde el proceso de maduración de la proteína queda bloqueado, no se apreciaba la banda a la altura de la GFP y aparecían bandas intermedias (figura 
30B). En la cepa fsv1 $\Delta$ había una reducción significativa de la banda de $28 \mathrm{KDa}$ con respecto al WT (figura 30B y C). En concordancia con esta disminución, se producía un aumento en la cantidad de la proteína entera y la aparición de una banda intermedia de unos $40 \mathrm{KDa}$, que no se observaba en el WT ni en vps27 (figura 30B, punta de flecha).

En conjunto, todos estos resultados nos indican que el proceso de maduración de Ub:GFP-Cps1 está alterado en el mutante $f s v 1 \Delta$, no pudiendo llegar correctamente al lumen de la vacuola. También nos muestran que el PVE presenta un defecto funcional en ausencia de Fsv1, además de poseer una organización alterada.

A
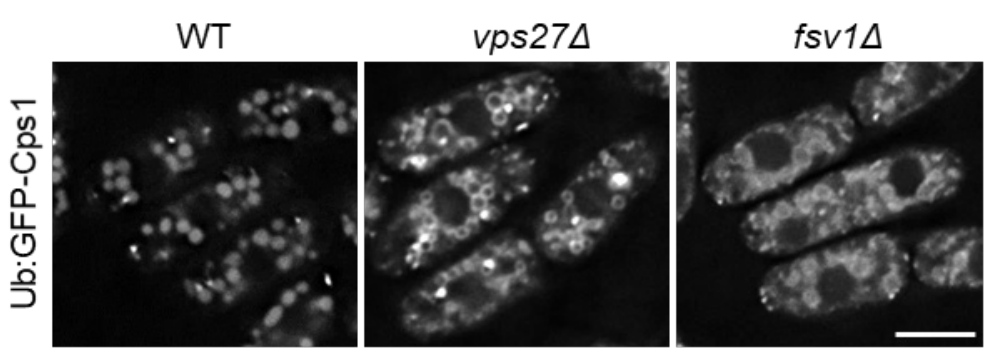

B

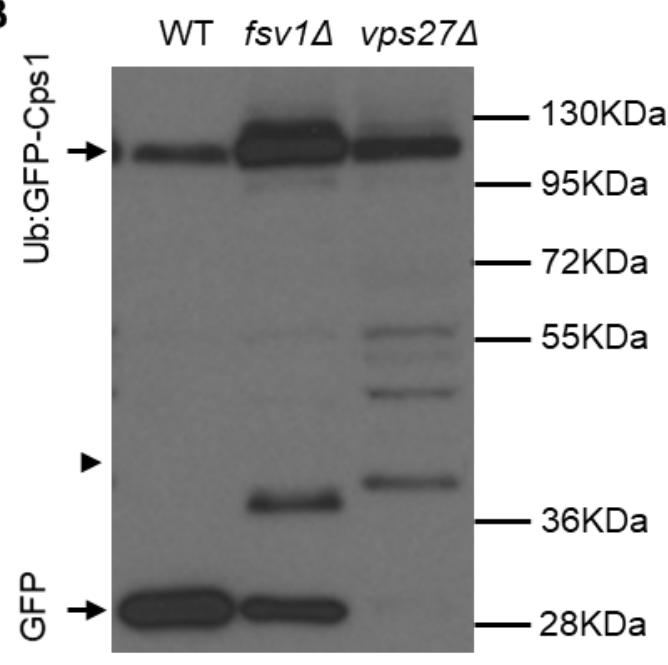

D

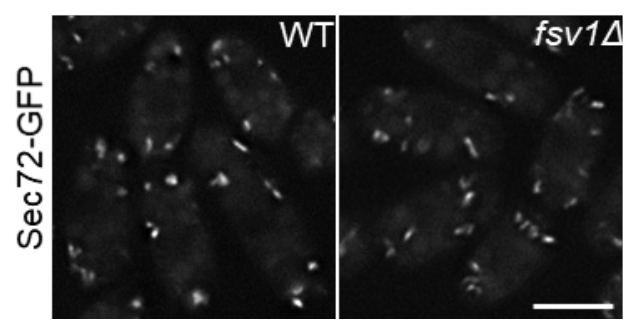

C

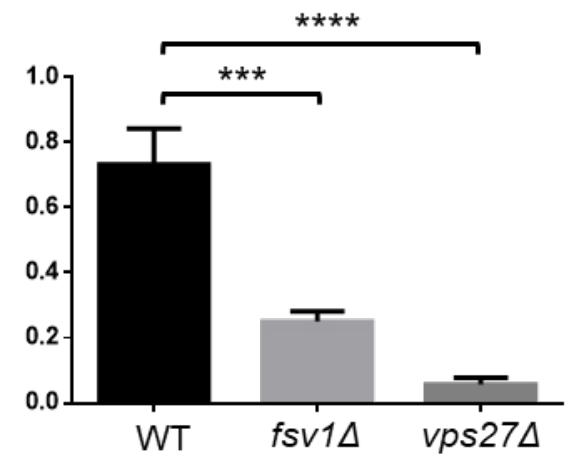

Figura 30. Funcionalidad del PVE y morfología del TGN en ausencia de Fsv1. A: distribución de Ub:GFP-Cps1 en las cepas indicadas. B: western blot de extractos totales de las cepas señaladas portando Ub:GFP-Cps1. Se señala la banda de la proteína entera y la de la GFP. La punta de flecha señala una banda de $40 \mathrm{KDa}$ presente en el mutante $f s v 1 \Delta$. C: Cuantificación de la banda de la GFP con respecto a la cantidad de proteína total. Se muestra la media y desviación típica de tres experimentos independientes. El nivel de significación se ha calculado con el test de comparación múltiple de Dunnett tras ANOVA; ${ }^{* *}, \mathrm{p}<0,001 ; * * * *, p<0,0001$. D: distribución de Sec72-GFP en las cepas indicadas. A y D son imágenes de planos medios adquiridas con un sistema de microscopía Delta Vision. Barras de escala, $5 \mu \mathrm{m}$. 


\subsection{Organización del TGN en el mutante fsv1}

Tras los resultados anteriores y dado que estaba descrito que parte de GFP-Fsv1 estaba localizada en el TGN (Takegawa et al., 2003), se quiso evaluar si este orgánulo se encontraría alterado en $f s v 1 \Delta$. Para analizar esto se observó la localización de Sec72-GFP (homólogo a Sec7 de S. cerevisiae), un GEF de las GTPasas de la familia Arf que se ha usado como marcador de TGN (Franzusoff et al., 1991; Vjestica et al., 2008). En el mutante $f s v 1 \Delta$ la distribución de esta proteína era similar a la del WT, apareciendo en estructuras intracelulares con la apariencia característica del TGN de S. pombe, de forma ligeramente alargada (figura 30D). Este resultado indica que el TGN no se encuentra alterado significativamente en la cepa $f s v 1 \Delta$.

\section{Relación funcional de Fsv1 y Vsl1 en el tráfico hacia el PVE y la vacuola.}

Vsl1 (homóloga a Vam7 de S. cerevisiae) es una SNARE del mismo tipo que Fsv1 (Qc) que se localiza en la vacuola y en el PVE. En su ausencia se agravan ciertas alteraciones observadas en el mutante $f s v 1 \Delta$ relacionadas con el tráfico hacia la vacuola (Hosomi et al., 2015). En este sentido, en el mutante doble $v s / 1 \Delta f s v 1 \Delta$ se produce un defecto mayor en el tráfico de Cpy1 que en el mutante sencillo $f s v 1 \Delta$. Además, el mutante doble tiene alterada la morfología vacuolar y presenta problemas de fusión de vacuolas. Por estos motivos se decidió profundizar en la relación funcional de $f s v 1^{+}$y $v s / 1^{+}$.

En primer lugar, se exploró si en el mutante vs/1 $\Delta$ se producía alguno de los fenotipos observados en la cepa $f s v 1 \Delta$. Con este fin se analizó la localización de Vps10-GFP en este mutante. Como vemos en la figura 31A, la localización de esta proteína en la cepa vs/1 $\Delta$ es similar a la del WT (observándose en puntos brillantes) y difiere de la de $f s v 1 \Delta$ (figura 27A). Se evaluó también la distribución de GFP-Pep12 en vs/1 $\Delta$. En este mutante la SNARE presentaba una localización similar a la del WT, observándose en la membrana de la vacuola y en el PVE (figura 31A). Por último, se analizó si la llegada de Ub:GFP-Cps1 al lumen de la vacuola estaba alterada en este mutante como ocurría en el mutante $f s v 1 \Delta$. Como vemos en la figura 31A, la distribución de Ub:GFP-Cps1 en el mutante vs/1 $\Delta$ no se altera con respecto a la del WT, observándose en el interior de la vacuola y en el PVE. 
Estos resultados muestran que vs/1 $\Delta$ no presenta una alteración del PVE similar a la de fsv1 $1 \Delta$.

Para completar los resultados anteriores se decidió sobreexpresar $v s / 1^{+}$en una cepa fsv1 $\Delta$ con el fin de determinar si la sobreexpresión de este gen rescataba el fenotipo de alteración del PVE observado en este mutante. Para ello se analizó la localización de Vps10-GFP. Como se ha mostrado anteriormente, en $f s v 1 \Delta$ esta proteína se observaba en pequeños puntos y con un patrón difuso (figura 31B). Al sobreexpresar vs/1+ en este mutante la distribución de Vps10-GFP no cambiaba, es decir, no aparecían los puntos brillantes observados en el WT (figura 31B). Esto indicaba que la sobreexpresión de vs/1+ no era capaz de suplir la ausencia de Fsv1 en cuanto a su función en la organización del PVE.

En conjunto estos resultados, junto con el hecho de que los mutantes simples no presenten alteraciones en la morfología ni en la fusión de las vacuolas y los mutantes dobles sí, indicarían que ambas proteínas pueden tener una función solapante a nivel de la vacuola pero no a nivel del PVE (Hosomi et al., 2015; Takegawa et al., 2003).

A
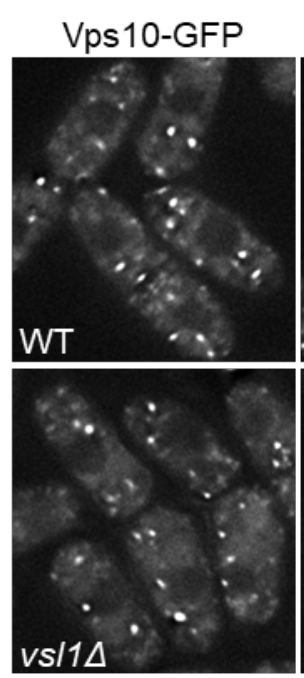
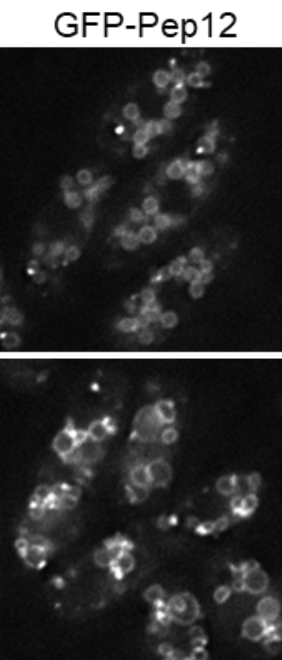

Ub:GFP-Cps1
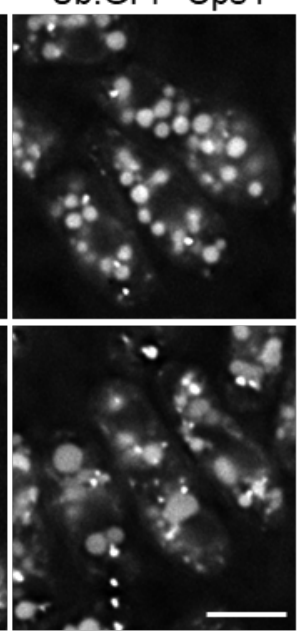

B

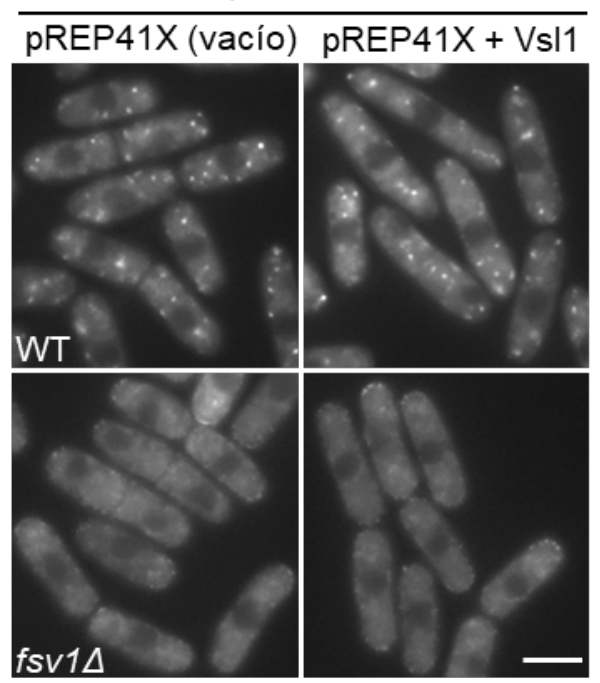

Figura 31. Análisis de la función de Vsl1 y de su relación con Fsv1. A: distribución de Vps10-GFP, GFP-Pep12 y Ub:GFP-Cps1 en las cepas indicadas. Las imágenes son planos medios y se adquirieron con un sistema de microscopía Delta Vision. B: distribución de Vps10-GFP durante la sobreexpresión de Vsl1 en las cepas indicadas. Las células mostradas se cultivaron durante 16 horas en EMM completo en ausencia de tiamina para inducir la sobreexpresión de $v s / 1^{+}$. Las imágenes se adquirieron con un microscopio Leica DM RXA. Barras de escala, $5 \mu \mathrm{m}$. 


\section{Localización GFP-Fsv1}

En un trabajo anterior se había visto que GFP-Fsv1 colocalizaba parcialmente con el marcador de Golgi Gms1-HA (Takegawa et al., 2003). Sin embargo, la localización de esta SNARE no estaba caracterizada en detalle. Para analizarla, se cuantificó el nivel de colocalización de GFP-Fsv1 con el marcador de TGN Cfr1-RFP y el marcador de PVE Vps27RFP. Así se determinó que aproximadamente el $20 \%$ de los puntos de la SNARE coincidían con puntos del marcador de TGN (figura 32A). Además, en torno al $40 \%$ de los puntos de GFP-Fsv1 coincidían con puntos del marcador de PVE (figura 32B). Por tanto, GFP-Fsv1 estaba presente en ambas estructuras, aunque se encontraba en mayor cantidad en el PVE. Esta localización estaba en consonancia con las alteraciones producidas en su ausencia en este último orgánulo. Además, la distribución de Fsv1 en S. pombe era similar a la de sintaxina 8 en mamíferos, que se ha detectado principalmente en endosomas tempranos y tardíos (Prekeris et al., 1999; Subramaniam et al., 2000).

Sintaxina 8 también se localiza en la membrana plasmática de manera minoritaria y se ha visto que cicla a través de ella dependiendo de señales presentes en su zona citoplásmica (Kasai et al., 2007; Kasai and Akagawa, 2001; Prekeris et al., 1999; Subramaniam et al., 2000) Además, se ha observado que su tráfico desde la membrana plasmática es importante para la endocitosis de alguna proteína (Renigunta et al., 2014). Aunque no se había detectado GFP-Fsv1 en la superficie celular en los experimentos anteriores, se analizó la posibilidad de que Fsv1 estuviera circulando a través de la membrana plasmática. Para explorar esto se trató con latrunculina A una cepa que expresaba la proteína de fusión GFP-Fsv1 y se evaluó su distribución. Tras 20 minutos de tratamiento la SNARE no se observó en la membrana plasmática (figura 32C). Este resultado confirmó que GFP-Fsv1 no era secretada hacia la esta estructura como ocurría con sintaxina 8. Como en ocasiones anteriores, se usó la SNARE Syb1 como control de la efectividad del tratamiento (figura 32C). 
A
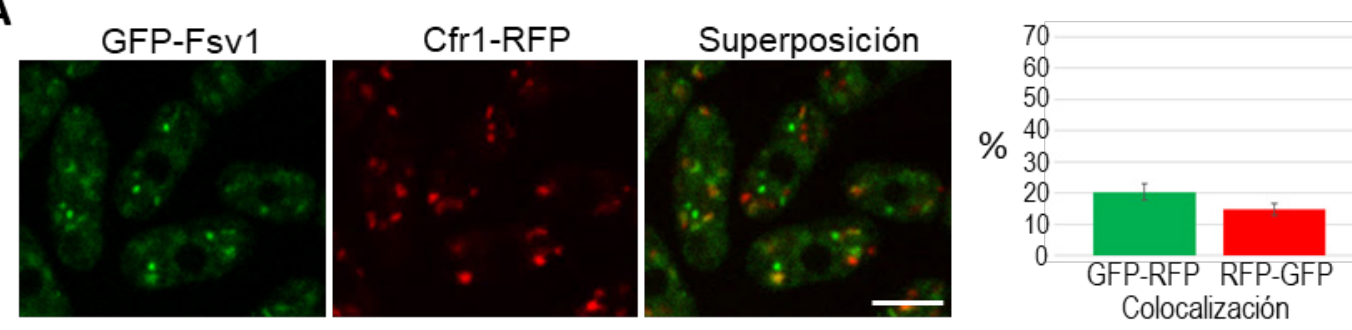

B
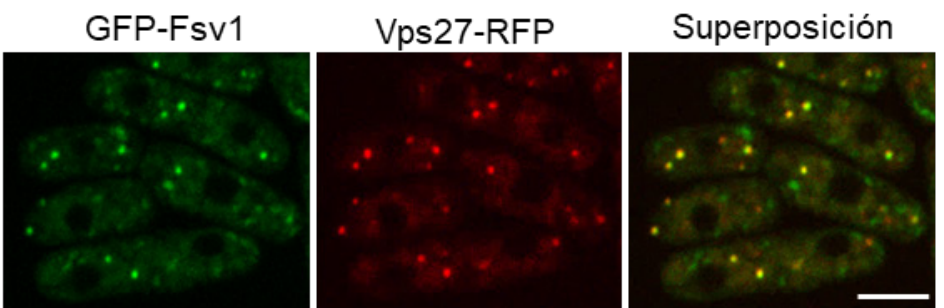

C

Lat.A 20'
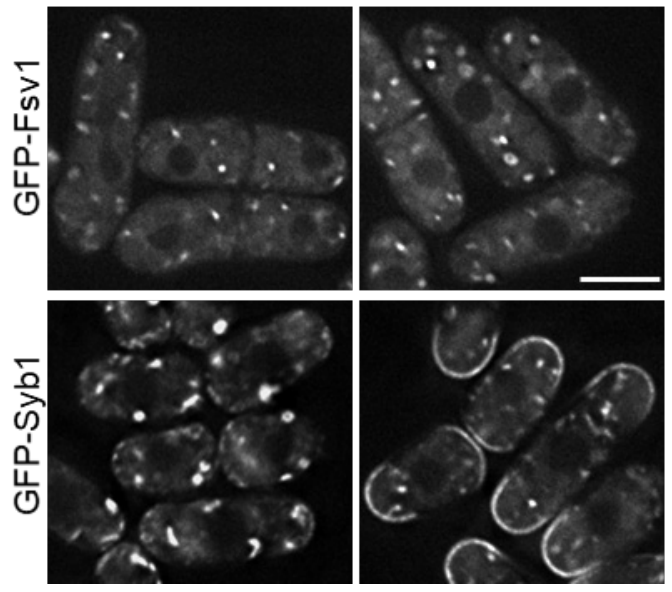

Figura 32. Localización de Fsv1. A: distribución de GFP-Fsv1 y Cfr1-RFP y cuantificación de los puntos donde coexisten estas proteínas. B: localización de GFP-Fsv1 y Vps27-RFP y cuantificación de los puntos donde coexisten estas proteínas. Las imágenes son planos medios y se adquirieron con un microscopio confocal spinning disk. Las gráficas representan la media y desviación típica de dos experimentos independientes en los que se cuantificaron un mínimo de 400 puntos de GFP-Fsv1. C: Distribución de GFPFsv1 y GFP-Syb1 tras un tratamiento de 20 minutos con DMSO o con latrunculina A (Lat.A). Las imágenes son planos medios y se adquirieron con un sistema de microscopía Delta Vision. Barras de escala, $5 \mu \mathrm{m}$.

\section{Tráfico de Fsv1.}

Una vez determinada la localización de Fsv1, se decidió explorar de qué factores podía depender esta. Esto resultaba interesante porque se conocía muy poco acerca del tráfico de la propia SNARE y de cómo mantenía su localización, tanto en S. pombe como en otros organismos. En este sentido, el hecho de que una parte de la proteína estuviera en el TGN y otra parte en el PVE sugería que Fsv1 podía estar circulando entre estos dos compartimentos de manera similar a Vps10. Para examinar esta posibilidad se analizó la localización de GFP-Fsv1 en una cepa carente de una subunidad del retrómero (vps354). Si GFP-Fsv1 ciclaba entre el TGN y el PVE de manera parecida a Vps10, quedaría retenida en la vacuola en ausencia de este complejo. Como marcador vacuolar se utilizó el colorante fluorescente FM4-64 tras una hora de incubación, que tiñe la membrana de 
este orgánulo y el PVE en estas condiciones (Vida and Emr, 1995). Como se observa en la figura 33, GFP-Fsv1 colocalizaba con el FM4-64 en la membrana de la vacuola en el mutante vps35 , algo que no ocurría en el WT. Estos resultados confirmaron la hipótesis de que esta SNARE circulaba entre el TGN y el PVE, e indicaban que el retrómero era el complejo responsable de su reciclaje desde este último orgánulo. En S. cerevisiae se ha propuesto que el retrómero es el responsable del reciclaje de Pep12 desde los endosomas tardíos (Hettema et al., 2003), lo cual sugiere que este complejo podría actuar como un mecanismo general de reciclaje de este tipo de proteínas desde el PVE.

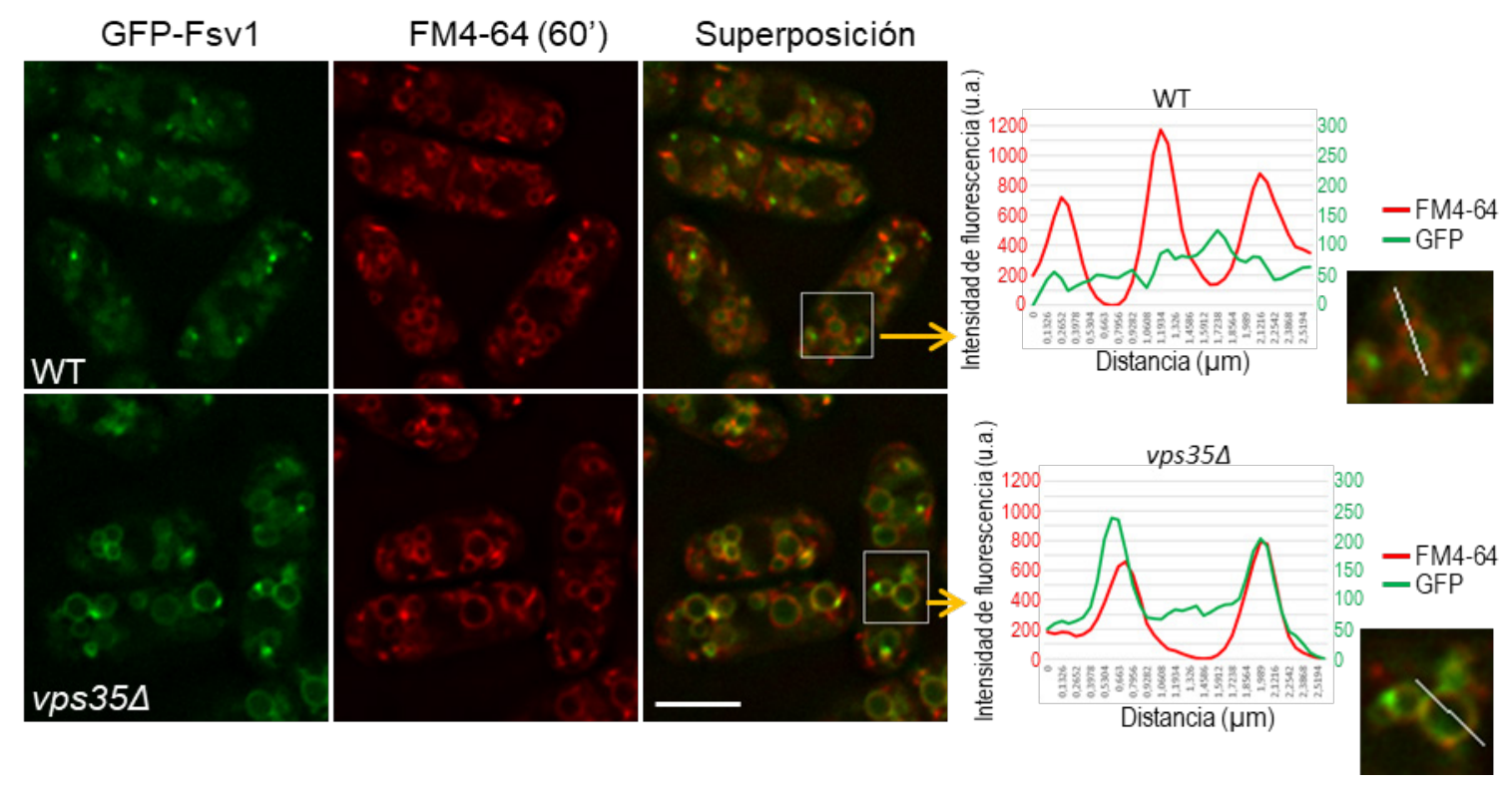

Figura 33. Papel del retrómero en el tráfico de Fsv1. A: Colocalización de GFP-Fsv1 con FM4-64 en WT y vps35 3 . Las imágenes se capturaron con un sistema de microscopía Delta Vision tras 60 minutos de incubación con el colorante FM4-64, para permitir la tinción de las vacuolas. Se muestra el aumento de unas vacuolas en las que se ha medido la intensidad de fluorescencia (u.a.) de GFP-Fsv1 y del FM464 a lo largo de la línea indicada. Los valores se representan en las gráficas. Barra de escala, $5 \mu \mathrm{m}$.

\subsection{Búsqueda de dominios o señales de Fsv1 importantes para su reciclaje.}

Tras los resultados anteriores, se decidió profundizar en el estudio del mecanismo de reciclaje de GFP-Fsv1. Con este fin, se quiso explorar si éste dependía de alguna parte específica de la proteína o de una secuencia de aminoácidos concreta. En una primera aproximación para analizar esto, se fusionó la GFP en el extremo $\mathrm{N}$-terminal de diferentes formas truncadas de Fsv1. Después se observó su distribución para determinar si alguna de ellas presentaba un reciclaje defectivo y se quedaba retenida en la vacuola. Para 
diseñar las truncaciones se tuvo en cuenta la estructura de la proteína y los diferentes dominios presentes en ella, de acuerdo con la base de datos de $S$. pombe (PomBase https://www.pombase.org/). Así, se realizaron cinco construcciones diferentes (figura 34A). A la más grande le faltaba la zona $\mathrm{N}$-terminal de la proteína, hasta el comienzo del primer coiled-coil (GFP-Fsv1 $\Delta N$ ). La segunda en tamaño carecía de la zona N-terminal y del primer coiled-coil (GFP-Fsv1 $\triangle N C 1$ ). La siguiente no tenía tampoco el segundo coiledcoil (GFP-Fsv1 $\triangle N C C$ ). La cuarta poseía la hélice transmembrana y el dominio SNARE (GFPFsv1TMSN) y la última tenía sólo la hélice transmembrana de la proteína (GFP-Fsv1TM).

Todas estas construcciones salían del retículo excepto la más pequeña (GFP-Fsv1TM) que parecía quedarse retenida en esta estructura, probablemente por problemas de plegamiento o por falta de reconocimiento por COPII (figura 34B).

Las formas truncadas GFP-Fsv1 $1 \Delta$, GFP-Fsv1 1 NC1 y GFP-Fsv1 $\Delta$ NCC se observaron como puntos brillantes en el interior celular (figura 34B). Por tanto, estas construcciones no quedaban retenidas en la membrana de la vacuola, lo que parecía indicar que ninguna presentaba problemas de reciclaje. Sin embargo, se analizó esto con más detalle evaluando si la más pequeña de estas truncaciones (GFP-Fsv1 $\triangle N C C$ ) dependía del retrómero para su reciclaje. Como se observa en la figura 34B, GFP-Fsv1 $\Delta$ NCC quedaba retenida en la membrana de la vacuola y en el PVE en vps35 $\Delta$. Esto indicaba que esta construcción salía del TGN y se seguía reciclando a través del retrómero; es decir, se comportaba como la proteína silvestre en este sentido. Por tanto, este resultado mostraba que la parte de Fsv1 ausente en esta construcción no era necesaria para la llegada de la proteína al PVE ni para su reciclaje desde esta estructura.

La truncación GFP-Fsv1TMSN se observó en la membrana de la vacuola y en puntos brillantes cercanos a esta (figura 34B), lo que indicaba que no retornaba al TGN desde estas estructuras. Este resultado, junto con el hecho de que GFP-Fsv1 $\Delta$ NCC todavía reciclase por el retrómero tras salir del TGN, señalaba que la zona de la proteína comprendida entre el segundo coiled-coil y el dominio SNARE era importante para el retorno de Fsv1 al TGN. Sin embargo, no se podía descartar que el dominio SNARE jugase también algún papel en este proceso. 


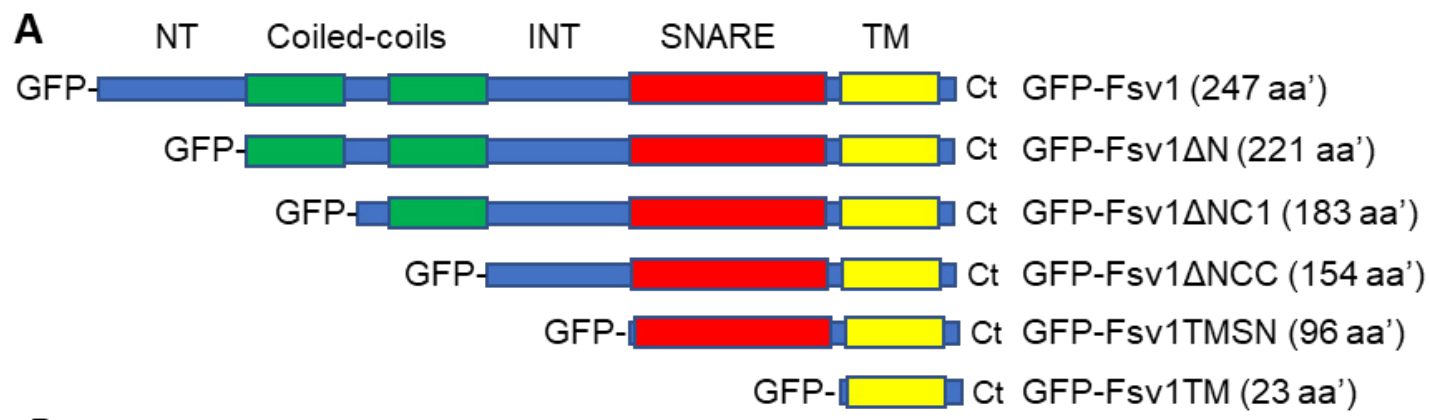

B
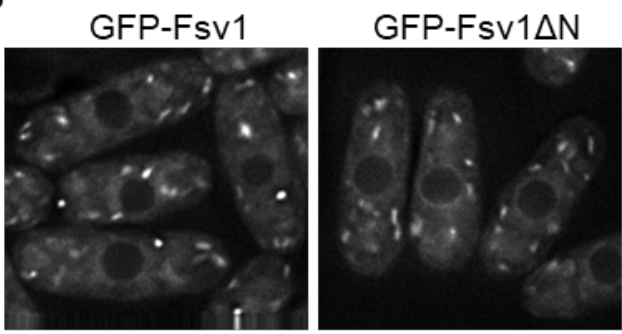

GFP-Fsv1 $1 \Delta \mathrm{NC} 1$
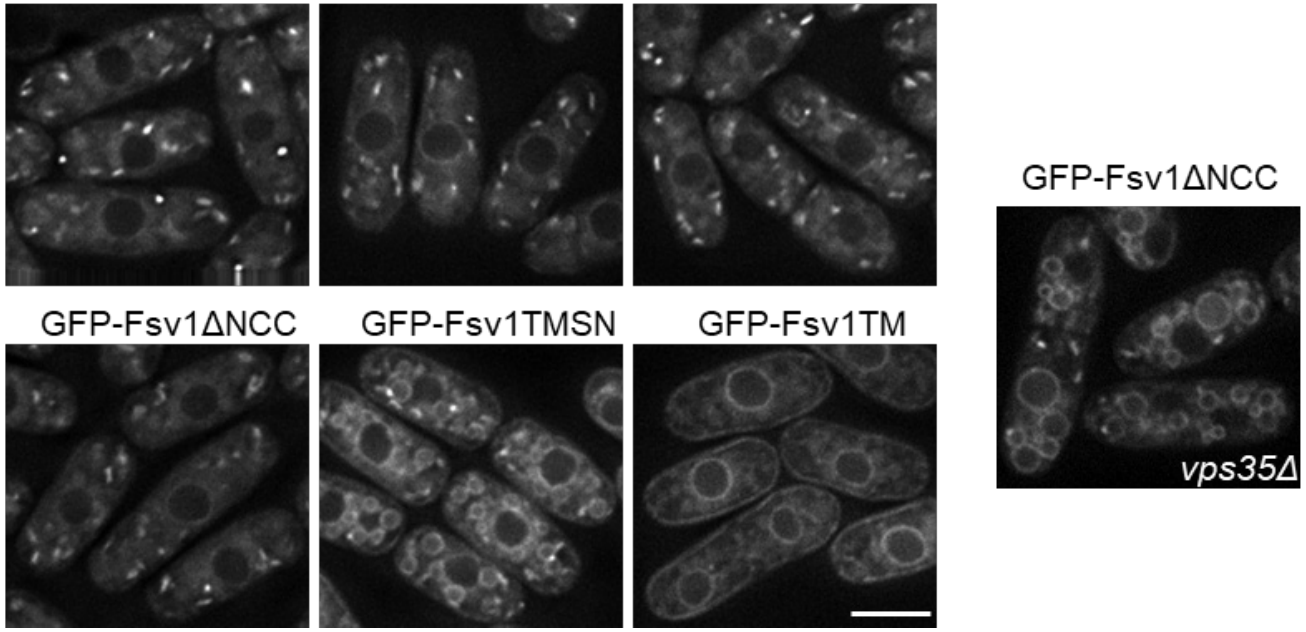

Figura 34. Localización de diferentes truncaciones de Fsv1. A: representación de diferentes construcciones de Fsv1 unidas a GFP. Se indican los dominios de cada una y su tamaño en aminoácidos (aa') excluyendo la GFP. B: distribución de las construcciones representadas en A en cepas WT. Se muestra también la distribución de GFPFsv1 1 NCC en el mutante vps35 . Las imágenes son planos medios y se adquirieron con un sistema de microscopía Delta Vision. Barra de escala, $5 \mu \mathrm{m}$.

Para analizar con más detalle el papel de estas regiones de Fsv1 en su reciclaje, se construyeron dos nuevas formas truncadas de la proteína. En una de ellas se delecionó la zona comprendida entre el segundo coiled-coil y el dominio SNARE (GFP-Fsv1 $\Delta$ INT) y en la otra se eliminó el dominio SNARE (GFP-Fsv1 $\triangle$ SN; figura 35A). Estas dos construcciones se realizaron como parte del trabajo de fin de máster de María del Mar Peña Ramón. Como se aprecia en la figura 35B, GFP-Fsv1 INNT se localizaba en la membrana de la vacuola y en puntos adyacentes. GFP-Fsv1 $\Delta$ SN también se observó en la membrana de la vacuola, aunque presentaba una distribución algo más difusa por el citoplasma celular (figura 35B). Estos resultados nos muestran que ambas regiones (la región INT y el dominio SNARE) son necesarias para el correcto reciclaje de Fsv1 hacia el TGN. Por tanto, en estas zonas podría radicar una posible señal de reconocimiento por el retrómero. 
Debido a esto se quiso explorar si el reciclaje de Fsv1 podría depender de una secuencia de aminoácidos concreta dentro de estas regiones, es decir, dentro de la construcción GFP-Fsv1 $\triangle$ NCC. Para ciertos cargos del retrómero se han establecido algunas señales de reconocimiento por este complejo. En S. cerevisiae se ha determinado que la secuencia YSSL es importante para el reciclaje de Vps10 desde el PVE (Cooper and Stevens, 1996). En S. pombe un motivo di-aromático es importante para el reciclaje de este receptor (Iwaki et al., 2006). Sin embargo, no se encontraron motivos similares a estos en Fsv1. En mamíferos una serie de proteínas presentan el motivo $\phi X(L / M)$, donde $\phi$ representa un aminoácido aromático, que es importante para su reciclaje por el retrómero (Lucas et al., 2016). Al buscar en Fsv1, se encontró una secuencia de aminoácidos que coincidía con este motivo. Esta era la secuencia YAM situada dentro del dominio SNARE (residuos 184186). Para analizar la implicación de esa secuencia en el reciclaje de Fsv1 se cambiaron los residuos $\mathrm{Y}$ y M por alaninas en la truncación GFP-Fsv1 $\triangle \mathrm{NCC}$ (figura 35A) y se observó su distribución. Esta construcción se localizaba en puntos intracelulares y no en la membrana de la vacuola (figura 35B). Esto indicaba que GFP-Fsv1 $\triangle$ NCC con el cambio de la secuencia YAM por AAA no tenía problemas de reciclaje. Por tanto, esta secuencia no era importante para el retorno de la SNARE hacia el TGN mediado por el retrómero.

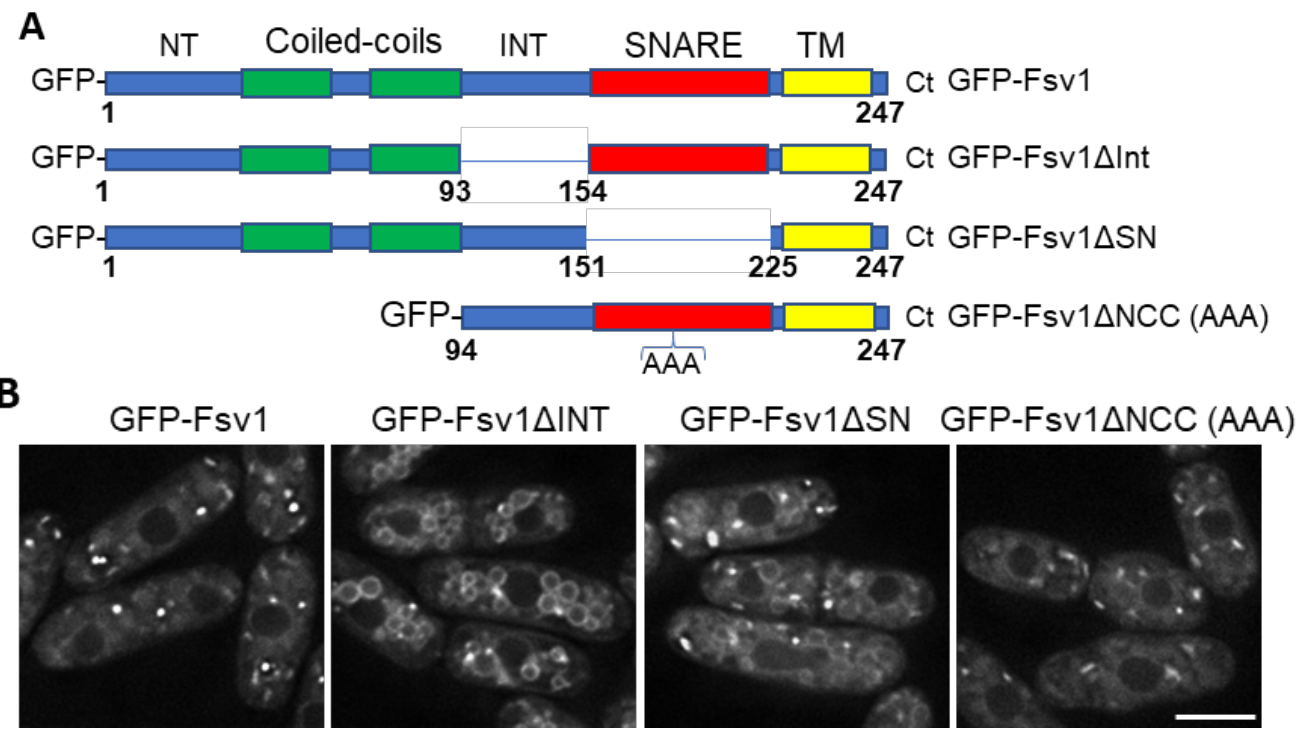

Figura 35. Localización de diferentes construcciones de GFP-Fsv1. A: representación de diferentes construcciones de Fsv1 unidas a GFP. Se indican los dominios de cada una y los residuos donde empiezan y acaban las truncaciones. La línea fina representa la porción excluida en la construcción. En GFP-Fsv1 $\triangle N C C$ (AAA) se ha cambiado la secuencia YAM presente en el dominio SNARE (entre los residuos 184 y 186) por la AAA. B: distribución de las construcciones representadas en A en cepas WT. Las imágenes son planos medios y se adquirieron con un sistema de microscopía Delta Vision. Barra de escala, $5 \mu \mathrm{m}$. 


\section{Papel del retrómero en el reciclaje de otras SNAREs.}

\subsection{SNAREs que median el tráfico entre TGN y vacuola.}

Como se ha mostrado, el retrómero es importante para el reciclaje de GFP-Fsv1 desde el PVE. Por ello se decidió analizar su papel en la localización de otras SNAREs que participan en la misma ruta de tráfico que Fsv1. En S. pombe las SNAREs que participan en el tráfico desde el TGN hacia la vacuola son Pep12 (Qa), Vti1 (Qb), Fsv1 (Qc), Ykt6 (R) y Vsl1 (Qa) (Hosomi et al., 2015, 2011; Takegawa et al., 2003). No todas están bien caracterizadas, y se ha asumido su función por la de su proteína homóloga en S. cerevisiae (Dilcher et al., 2001; Kweon et al., 2003; Mollard et al., 1997; Ungermann et al., 1999; von Mollard and Stevens, 1999). Vsl1 no posee hélice transmembrana y su localización depende de la unión al PI3P por su dominio PX (Boeddinghaus et al., 2002; Cheever et al., 2001; Hosomi et al., 2015; Lee et al., 2006), por lo que no se procedió a su estudio. El resto de las SNAREs se marcaron en su extremo N-terminal con GFP de forma similar a Fsv1 (ver materiales y métodos). GFP-Pep12 y GFP-Vti1 se localizaban en la membrana de la vacuola y en el PVE en un WT (figura 36A). La localización en un mutante vps35 $\Delta$ era similar a la observada en el WT (figura 36A). GFP-Ykt6 se distribuía en el WT por diversas membranas, observándose en el retículo, en algún punto y en la membrana de la vacuola (figura 36A). En el mutante vps35 3 presentaba una localización parecida (figura 36A). El hecho de que todas estas proteínas se observasen ya en la cepa WT en la vacuola, impedía determinar con claridad si reciclaban por el retrómero. Por otro lado, como ejercen parte de su función en la vacuola quizás este reciclaje no fuese necesario.

\subsection{Reciclaje de SNAREs implicadas en otras rutas de tráfico.}

A continuación, se decidió explorar si otras SNAREs implicadas en otras rutas de tráfico dependían del retrómero para su correcta localización. En primer lugar se analizó la localización de Syb1, que cicla entre la membrana plasmática y estructuras internas (Lewis et al., 2000). Acorde con esto GFP-Syb1 se observó en la membrana plasmática y en puntos intracelulares en el WT (figura 36A). En el mutante vps35 presentaba una distribución parecida, no observándose marcaje en la vacuola. Esto indicaba que el retrómero no era necesario para el reciclaje de GFP-Syb1 hacia la 
membrana plasmática o el TGN. Este resultado está de acuerdo con el hecho de que Syb1 y su homóloga en S. cerevisiae dependan tanto de los GGAs y Ent3 como del complejo Snx4-Atg20 para su reciclaje, por lo que no necesitarían al retrómero para esto (Black and Pelham, 2000; Hettema et al., 2003; Hoya et al., 2017; Ma et al., 2017; Zhao et al., 2016; Zimmermann et al., 2010, y este trabajo).
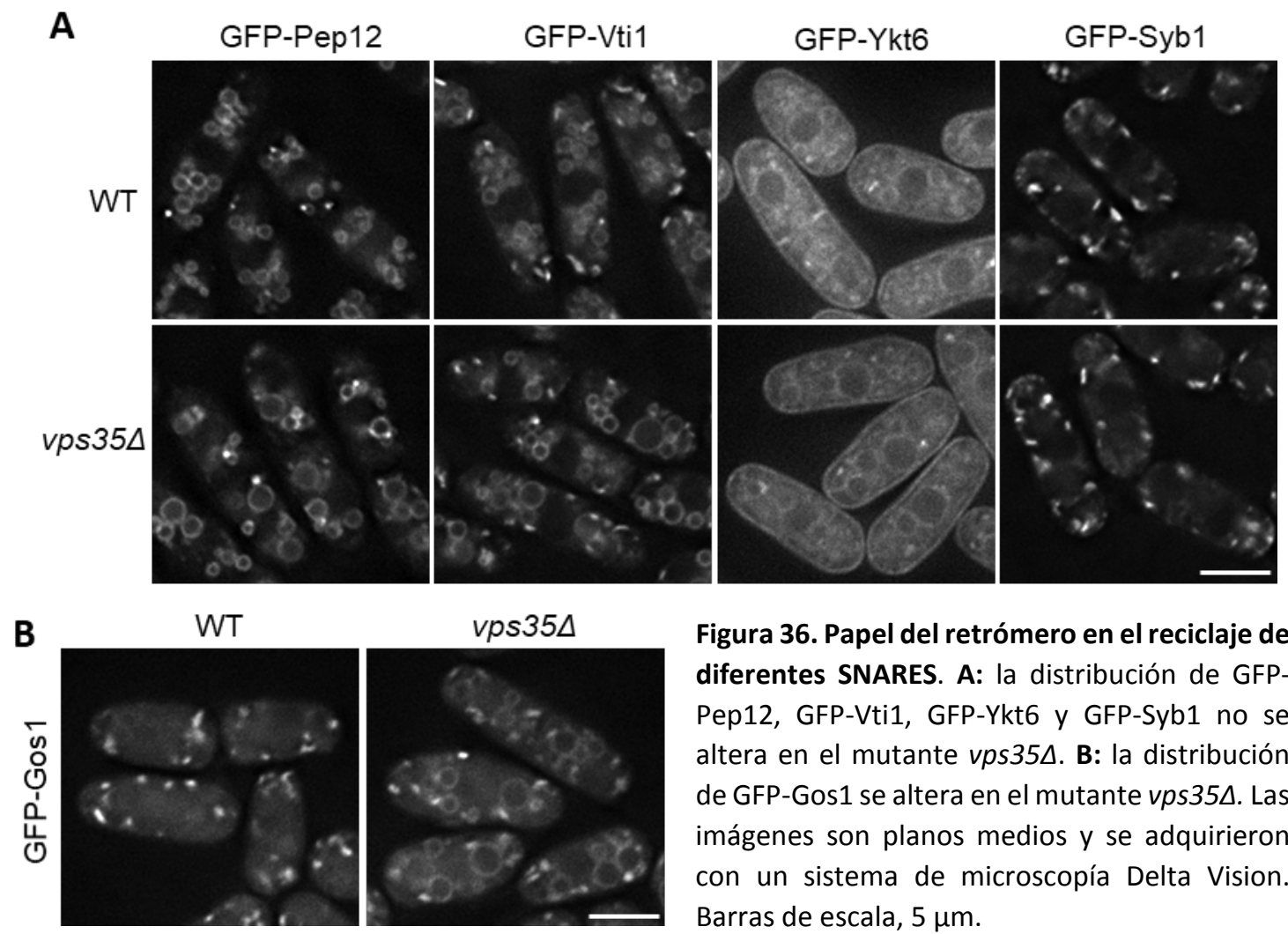

\begin{abstract}
Figura 36. Papel del retrómero en el reciclaje de diferentes SNARES. A: la distribución de GFPPep12, GFP-Vti1, GFP-Ykt6 y GFP-Syb1 no se altera en el mutante vps35 . B: la distribución de GFP-Gos1 se altera en el mutante vps35 4 . Las imágenes son planos medios y se adquirieron con un sistema de microscopía Delta Vision. Barras de escala, $5 \mu \mathrm{m}$.
\end{abstract}

También se analizó la localización de Gos1, una SNARE que participa en el tráfico dentro del complejo de Golgi (McNew et al., 1998). GFP-Gos1 se observó en puntos intracelulares en el WT (figura 36B). Sin embargo, en el mutante vps35 $\Delta$ se detectó en la membrana de la vacuola, además de observarse en puntos (figura 36B). Esto señalaba que la correcta localización de GFP-Gos1 dependía de su reciclaje por el retrómero. Este resultado sugería que en una cepa silvestre GFP-Gos1 podía estar circulando a través del PVE desde dónde sería devuelto al Golgi por la acción del retrómero. 


\section{Influencia de GGAs y Ent3 en el tráfico de Fsv1}

En la primera parte de este trabajo se ha visto que la colaboración de Gga22 con Gga21 y/o Ent3 es necesaria para que se produzca un tráfico retrógrado eficiente de Vps10-GFP desde el PVE al TGN. Este receptor depende también del retrómero para su reciclaje hacia el TGN (Iwaki et al., 2006; Seaman et al., 1997). Dado que GFP-Fsv1 presentaba problemas de reciclaje en mutantes del retrómero, se quiso explorar si los GGAs y Ent3 jugaban algún papel en su tráfico retrógrado. Con este fin, se analizó la

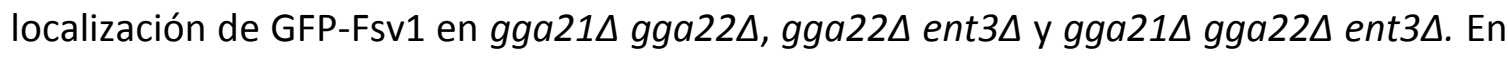
algunas células de estos mutantes, parte de GFP-Fsv1 se observaba en la membrana vacuolar (figura 37). Sin embargo, este marcaje era más débil que en el mutante vps35 $\Delta$. Este resultado indica que estos adaptadores colaboran en el reciclaje de GFP-Fsv1, aunque su función es menos importante que la del retrómero para este proceso. Además, apoya la hipótesis de que GGAs y Ent3 colaboran en el tráfico retrógrado desde el PVE.
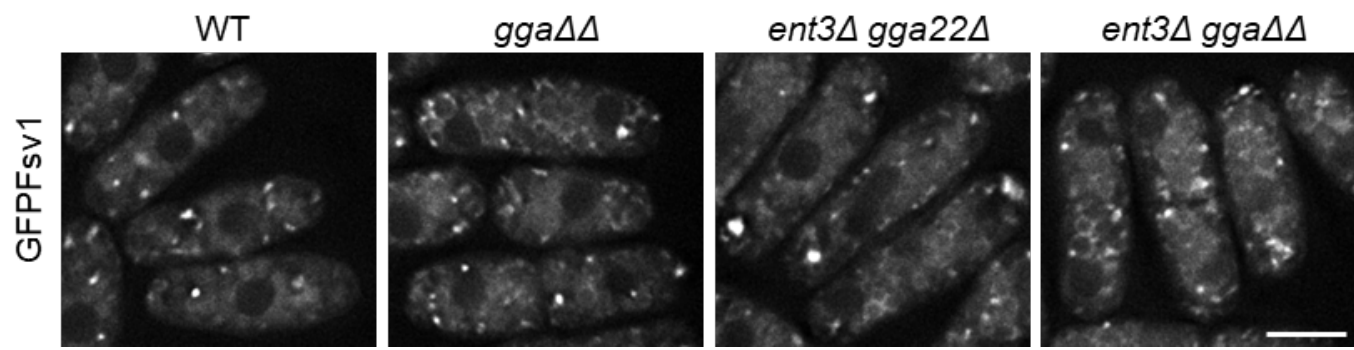

Figura 37. Papel de Ent3 y GGAs en el reciclaje de GFP-Fsv1. Distribución de GFP-Fsv1 en las cepas indicadas. Las imágenes son planos medios adquiridos con un sistema de microscopía Delta Vision. Barra de escala, $5 \mu \mathrm{m}$. 

Discusión 

El transporte de proteínas entre el complejo de Golgi y el lisosoma o la vacuola es un proceso complejo que todavía no está bien caracterizado. La función de los elementos reguladores de este paso de tráfico se ha ido dilucidando a lo largo de los últimos años, aunque todavía queda mucho por comprender. Avanzar en el conocimiento de la función de estos factores puede ayudar a comprender el funcionamiento de diferentes sistemas biológicos. También a entender el origen de diferentes enfermedades derivadas de alteraciones en el tráfico entre estos compartimentos.

El análisis del transporte de algunos cargos utilizados como modelo, ha ayudado a determinar la participación de las diferentes cubiertas vesiculares y de los adaptadores en determinados pasos de las rutas de tráfico (Bowers and Stevens, 2005; Conibear and Stevens, 1998; Gallon and Cullen, 2015; Guo et al., 2014). Los modelos iniciales establecían que cada adaptador funcionaba exclusivamente en una ruta o etapa del tráfico concretos, sin embargo, estudios posteriores han demostrado que esto es más complejo. Así, los distintos adaptadores de clatrina presentes en el TGN pueden interaccionar físicamente y funcionalmente entre sí. Se han descrito interacciones de las epsinas endosomales con Gga2 y con AP-1, y de Gga2 con AP-1 (Abazeed and Fuller, 2008; Copic et al., 2007; Costaguta et al., 2006, 2001; Daboussi et al., 2012; Deng et al., 2009; Doray et al., 2002; Eugster et al., 2004; Hirst et al., 2012, 2009, 2001; Hung et al., 2012). Además, se ha visto que cada adaptador puede participar en más de una ruta de tráfico. Así, en mamíferos AP-1 participa en el tráfico en ambas direcciones entre el TGN y los endosomas (Park and Guo, 2014). Los GGAs participan (tanto en mamíferos como en levaduras) en el transporte de diferentes proteínas hacia el endosoma prevacuolar (Bilodeau et al., 2004; Bonifacino, 2004; Costaguta et al., 2001; De et al., 2013; Dell'Angelica et al., 2000; Deng et al., 2009; Erpapazoglou et al., 2008; Hatakeyama et al., 2019; Hirst et al., 2000; Scott et al., 2004; Zhdankina et al., 2001). También intervienen en la retención de alguna proteína a nivel de TGN-endosomas (Copic et al., 2007) y en el reciclaje de otras hacia la membrana plasmática (Black and Pelham, 2000; He et al., 2005; Sahgal et al., 2019; Xie et al., 2006). Las epsinas endosomales participan en diferentes rutas de transporte desde el TGN y se ha propuesto que ejercen una función accesoria a la de los adaptadores (Black and Pelham, 2000; Chidambaram et al., 2008; Copic et al., 
2007; Deng et al., 2009; Duncan et al., 2003; Friant et al., 2003; Zimmermann et al., 2010). Además, en S. cerevisiae se ha visto que son capaces de interaccionar físicamente con la subunidad del ESCRT vps27 y que juegan un papel en la internalización de proteínas ubiquitinadas en el PVE (Deng et al., 2009; Eugster et al., 2004; Friant et al., 2003).

Distintos resultados expuestos en la primera parte de este trabajo indican que los GGAs y la epsina Ent3 colaboran en diferentes rutas del tráfico celular. Además, participan en varios pasos del tráfico de una misma proteína (Cps1 y Vps10). Por tanto, este trabajo apoya y amplia la idea de que los adaptadores realizan una función más amplia en el tráfico proteico, no restringida exclusivamente a la participación de cada uno de ellos en un paso determinado de este proceso.

\section{Salida de proteínas del TGN en ausencia de GGAs-Ent3:}

La implicación de los diferentes adaptadores de clatrina en el tráfico de Vps10 ha sido ampliamente estudiada en S. cerevisiae (Abazeed and Fuller, 2008; Costaguta et al., 2001; De et al., 2013; Friant et al., 2003; Hirst et al., 2001). Sin embargo, en la mayoría de estos estudios se ha analizado el tráfico del receptor de manera indirecta, atendiendo a la secreción y maduración de Cpy1 o a la estabilidad de Vps10. En el presente trabajo se han utilizado técnicas de microscopía cuantitativa in vivo para analizar la colocalización de Vps10-GFP con marcadores de TGN y PVE en diferentes mutantes de adaptadores de clatrina. Además, las construcciones utilizadas estaban integradas en el cromosoma y no en plásmidos. Por tanto, nuestros resultados aportan una información más real sobre el papel de estos adaptadores que la obtenida previamente. Los resultados obtenidos muestran que en ausencia de los dos GGAs, de Gga22 y Ent3 o de los tres adaptadores, Vps10-GFP sale del TGN con una menor eficiencia. Utilizando una aproximación experimental similar se ha observado que Ub:GFP-Cps1 también queda parcialmente retenida en el TGN en estos mutantes, lo cual no había sido descrito anteriormente. Algo similar podría pasar en S. cerevisiae donde existen problemas de maduración de Cps1 en ausencia de los dos GGAs o de Ent3 y Ent5 (Costaguta et al., 2001; Duncan et al., 2003; Eugster et al., 2004; Friant et al., 2003). De este modo nuestros resultados confirman algunos indicios anteriores y amplían la información disponible. Además, al obtenerse en 
otro organismo evolutivamente distante, permiten ver que la función de estos adaptadores en la salida de proteínas del TGN está conservada.

A pesar de que en los mutantes de los adaptadores se produce un defecto en la salida de Vps10 y Cps1 del TGN, no se produce un bloqueo total de estas proteínas. Esto indica que el tráfico anterógrado de estas proteínas (hacia el PVE) es muy flexible y que pueden alcanzar su destino por otras vías. En el caso de Vps10 hemos intentado determinar cuáles son esas vías. Para ello se ha inhibido la endocitosis o delecionado una subunidad del complejo AP-3 en los mutantes de los adaptadores. En ambos casos el receptor sigue llegando al PVE. Esto señala que existe otro mecanismo por el que el receptor alcanza este orgánulo. En este sentido, aunque no se altere la localización de Vps10 al delecionar Apm1, no podemos descartar la posibilidad de que en ausencia de GGAs/Ent3, Vps10 alcance el TGN por la acción de AP-1. Esto no lo hemos podido comprobar por los severos defectos en el crecimiento producidos al delecionar conjuntamente los genes de AP-1 y GGAs o de AP-1 y Ent3. En el futuro se podría analizar la localización del receptor al inhibir la expresión de clatrina. Otra opción es que una parte de Vps10 llegase al PVE por defecto, en lo que algunos autores han denominado "bulk flow". La existencia de este flujo por defecto es compatible con que en S. pombe parte de Cpy1 llege a la vacuola en ausencia del receptor. Esta y otras evidencias han llevado a algunos autores a proponer que una parte del tráfico de Cpy1 es dependiente de receptor y otra es independiente (Conibear and Stevens, 1998; Iwaki et al., 2006; Roberts et al., 1992). También es compatible con el hecho de que Vps10 sin su extremo citoplásmico se acumule en la vacuola en vez de quedar retenido en el TGN (Cooper and Stevens, 1996; Deloche et al., 2001). Un mecanismo que podría explicar este flujo por defecto hacia el PVE y la vacuola sería la maduración endosomal, un proceso que sucede en células de mamíferos. Así, los endosomas tempranos o ciertas regiones de ellos, maduran para dar lugar a endosomas tardíos (Huotari and Helenius, 2011). Este proceso no se ha descrito en levaduras para los endosomas, aunque sucede en otros orgánulos como el Golgi (Casler et al., 2019; Kurokawa et al., 2019; Losev et al., 2006; Matsuura-Tokita et al., 2006). En S. pombe, donde el tráfico entre el TGN y el PVE está poco caracterizado, no se puede descartar la posibilidad de que exista un mecanismo similar al de mamíferos para transportar 
proteínas hacia el PVE. En este sentido, el hecho de que haya puntos de Vps10-GFP que no colocalicen con el marcador de TGN ni con el de PVE, puede sugerir la existencia de estructuras intermedias entre estos dos últimos compartimentos. Estas estructuras podrían estar en un proceso de maduración y poseer ya poca cantidad de Cfr1. Además, no tendrían todavía suficiente cantidad de PI3P como para ser detectado. Sin embargo, no se pueden descartar explicaciones alternativas a la presencia de estas estructuras. Por tanto, para dilucidar la existencia del proceso de maduración endosomal en S. pombe sería necesaria más investigación al respecto. Podrían realizarse análisis de partículas a lo largo del tiempo con diferentes marcadores que pudieran estar entre el TGN y el PVE para evaluar si existe una transición entre ellos.

\section{Tráfico desde el PVE en ausencia de GGAs/Ent3:}

Distintos resultados mostrados en este trabajo indican que los GGAs y Ent3 colaboran para que suceda un transporte eficiente de proteínas desde el PVE. En ausencia de estos adaptadores, las moléculas de Cps1 que consiguen salir del TGN sufren una retención parcial en el PVE y son llevadas de manera más lenta hacia la vacuola. Esto produce un procesamiento anormal de la proteína, en consonancia con resultados

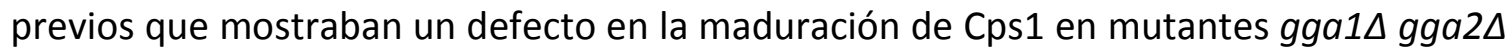
y ent3 $\Delta$ ent5 $\Delta$ en S. cerevisiae (Costaguta et al., 2001; Duncan et al., 2003; Eugster et al., 2004; Friant et al., 2003). Los defectos en la salida de Cps1 desde el TGN y el PVE provocan una menor llegada a la vacuola. La proteína que llega a este orgánulo se observa en el lumen y no en la membrana vacuolar. Esto indica que el defecto en el transporte de Cps1 desde el PVE en estos mutantes es diferente al que ocurre en el mutante del ESCRT (vps27ム).

En un WT el complejo Vps10-Cpy1 se desensambla cuando alcanza el PVE y el receptor es enviado de nuevo hacia el TGN en un proceso mediado por el retrómero (Iwaki et al., 2006; Seaman et al., 1997). En algunos mutantes (ESCRT o retrómero) o en ciertas condiciones (deleción extremo citoplásmico) Vps10 queda atrapado en la vacuola o en un PVE alterado y se produce su proteolísis parcial (Cereghino et al., 1995; Piper et al., 1995; Seaman et al., 1997). Nosotros hemos visto que el receptor sufre una proteolísis parcial en mutantes sin GGAs/Ent3, lo cual apunta a la existencia de un defecto en el 
tráfico retrógrado de Vps10 hacia el TGN. Esto resulta curioso porque los resultados de microscopía nos mostraban que estos adaptadores participan también en la salida de Vps10 del TGN. En conjunto, estos resultados nos indicarían que los GGAs y Ent3 colaboran en dos pasos del tráfico de una misma proteína, tanto en su salida del TGN como en su vuelta desde el PVE. Esto es algo complejo de entender; sin embargo, una posible explicación es la siguiente: en ausencia de los adaptadores parte de Vps10 se queda retenido en el TGN. Probablemente esta sea la función principal sobre el tráfico del receptor y por eso observamos un aumento de su colocalización con el marcador de TGN. Sin embargo, no se produce un bloqueo total y parte del receptor llega al PVE. En ausencia de los adaptadores la salida desde esta estructura también es más lenta, por lo que algunas moléculas quedan expuestas a las proteasas durante más tiempo. Esto hace que puedan sufrir una proteólisis parcial. La cantidad de moléculas de Vps10 afectadas por esta proteólisis debe ser pequeña, ya que la banda de degradación que se observa en los mutantes es poco intensa y no afecta a la cantidad total de la proteína. En S. cerevisiae en ausencia de clatrina se produce la degradación parcial de Vps10, algo a lo que no se le había dado una explicación clara y que concuerda con nuestras observaciones (Deloche et al., 2001).

En consonancia con la alteración en el tráfico de Vps10, parte de Cpy1 es secretada hacia el exterior celular. Otra parte, sin embargo, alcanza el lumen de la vacuola. Esta parte puede ser transportada por el receptor que todavía circula entre el TGN y el PVE en estos mutantes. Otra parte también podría hacerlo de manera independiente del receptor, ya que en ausencia de este una parte de Cpy1 sigue madurando (Iwaki et al., 2006).

En el segundo capítulo de los resultados se ha mostrado que Fsv1 queda parcialmente retenida en la vacuola en cepas carentes de GGAs/Ent3, lo cual apoya el papel de estos adaptadores en el transporte retrógrado desde el PVE. Esta retención no es tan fuerte como la que se produce en ausencia del retrómero. Esto puede indicar que la función en el reciclaje de proteínas de los adaptadores de clatrina no es tan crítica como la del retrómero. Atendiendo a las interacciones génicas, parece que ejercen su función 
en paralelo a la de este complejo. Esto también se apoyaría en el hecho de que Vps35 no se deslocalice en los mutantes de los adaptadores.

La SNARE Syb1 también queda parcialmente retenida en el PVE en cepas carentes de GGAs/Ent3. Esta proteína circula entre la membrana plasmática y estructuras internas que inicialmente se identificaron como TGN (Lewis et al., 2000). Posteriormente, a partir de una serie de evidencias, se ha propuesto también que circula a través del PVE. En este sentido, se ha visto que su reciclaje hacia la membrana depende de $\operatorname{Snx4}$, ya que en su ausencia parte de la SNARE se observa en la vacuola (Hettema et al., 2003; Ma et al., 2017; Zhao et al., 2016). Snx4 tiene un dominio PX que reconoce el PI3P presente mayoritariamente en el PVE (Yu and Lemmon, 2001). Además, Snc1 en S. cerevisiae interacciona físicamente con algunas SNAREs implicadas en el tráfico hacia la vacuola como Pep12 y Syn8 (Lewis and Pelham, 2002). Teniendo en cuenta esto, el hecho de que parte de Syb1 se observe en el PVE en mutantes sin GGAs/Ent3 es una prueba más de que colaboran en el tráfico de ciertas proteínas desde esta estructura. En ausencia de estos adaptadores Syb1 se observa en el PVE pero no en la vacuola, lo cual sugiere que actúan en un paso anterior a Snx4. Sería interesante determinar si median el tráfico de manera directa hacia la membrana plasmática o hacia el TGN, como paso previo a su secreción.

Todos estos resultados están de acuerdo con el hecho de que en S. cerevisiae los GGAs se hayan detectado en el PVE en ciertas condiciones (Boman et al., 2002; Hirst et al., 2001). Además, Ent3 se ha observado también en este compartimento y se une al $\mathrm{PI}(3,5) \mathrm{P} 2$ y a Vps27 (Eugster et al., 2004; Friant et al., 2003).

No todas las proteínas que salen del TGN o que se transportan a través del PVE están alteradas en los mutantes de los adaptadores como sucede con las anteriores. En estos mutantes Vph1 presenta una localización similar a la del WT. Por tanto, existe una diferencia entre proteínas en cuanto a su dependencia por los adaptadores para salir del TGN o PVE. Esto puede tener varias explicaciones. Una de ellas es que la naturaleza de estas proteínas es diferente. Mientras Vps10, Fsv1, Syb1 y Cps1 tienen un solo paso transmembrana, Vph1 es politópica. Puede que las proteínas con un dominio transmembrana dependan más de los adaptadores para concentrarse y estabilizarse en 
el lugar de salida de la vesícula. Es posible que las proteínas politópicas, que tienden a asociarse, sean más estables en esos sitios y no dependan de los adaptadores, o sean más proclives a viajar por defecto hacia adelante. En relación con esto, se sabe que el tamaño y la composición de los dominios transmembrana influencia la localización de las proteínas (Black and Pelham, 2000; Mercanti et al., 2010; Sharpe et al., 2010). Además, las proteínas anteriores presentan características diferenciales en su tráfico desde el PVE. Tras alcanzar esta estructura, Cps1 debe internalizarse en ILVs, Vps10 y Fsv1 deben volver al TGN y Syb1 tiene que reciclarse hacia la membrana. Vph1 no tiene que realizar estos pasos de tráfico y una vez en el PVE podría alcanzar la membrana de la vacuola mediante un flujo por defecto. Esto podría explicar también su diferente dependencia de los adaptadores.

\section{Defectos en la organización del PVE:}

Los resultados obtenidos muestran que los GGAs y Ent3 juegan un papel importante en el mantenimiento de la organización del PVE. Este papel lo pueden realizar de diversas maneras. Una opción es que al faltar estos adaptadores no lleguen ciertos cargos al PVE que sean importantes para mantener su estructura. Esto estaría ligado, por tanto, a su papel como adaptadores en la ruta CPY. Los cargos podrían ser proteínas involucradas en fusión o fisión de membranas, o en modificar su fluidez, aunque también podrían participar en otros procesos. Otra posibilidad es que en su ausencia, al alterarse varias rutas de tráfico, se perturbe el balance de entrada y salida de proteínas y membrana desde el PVE. Esto podría conducir a alteraciones en su morfología y funcionalidad. Otra opción es que los propios adaptadores realicen una función estructural transitoria en esta estructura. Aunque no los hayamos detectado en este orgánulo, no se puede descartar que se unan a él de manera transitoria o en determinadas condiciones para ejercer esta función o para facilitar el tráfico de proteínas.

Los defectos en el tráfico de Cps1, Vps10, Syb1 y Fsv1 a nivel de PVE podrían ser resultado de la alteración general de esta estructura. Es decir, deberse a un efecto indirecto. Aunque, como se ha mencionado, la alteración del tráfico desde esta estructura también podría ser la causa de sus defectos morfológicos. Ambos fenotipos pueden estar interconectados. Dilucidar cual es la causa y cual la consecuencia es difícil. La localización 
de Vph1 no está alterada y Pep12 llega adecuadamente a la vacuola en ausencia de los adaptadores. Esto sugiere que la alteración en el tráfico de Cps1, Vps10, Syb1 y Fsv1 no se debería a la alteración general de la estructura. Sin embargo, no podemos descartar esta posibilidad. Es necesario más investigación para dilucidar esto.

\section{Naturaleza de la colaboración entre GGAs y Ent3:}

En este trabajo hemos visto que existe colaboración entre los GGAs y Ent3 (concretamente de Gga22 con Gga21 o Ent3) en diferentes pasos del tráfico proteico. Por tanto, nos podemos preguntar cuál es la naturaleza de esta colaboración. Una posibilidad es que estos adaptadores cooperen realizando diferentes funciones mecánicas dentro de un mismo evento de tráfico. Algo similar sucede con las proteínas que participan en endocitosis (Schmid et al., 2006). Es posible que un adaptador contribuya a estabilizar la interacción del otro con un cargo o con clatrina. De hecho, en S. cerevisiae los mutantes de las epsinas endosomales presentan una reducción de la interacción entre Gga2 y Pep12, y entre Gga2 y clatrina. Otra opción no excluyente es que exista una regulación cruzada entre estos y otros adaptadores. Esto ocurre en el TGN de S. cerevisiae entre Gga2, Ent3, Ent5 y AP-1. De esta forma un adaptador podría facilitar (de manera directa o indirecta) o coordinar la llegada a la membrana de otro.

En S. cerevisiae Ent3 depende de los GGAs para su localización (Costaguta et al., 2006). En S. pombe esto no es así, lo cual concuerda con los defectos aditivos producidos al delecionar estos genes sobre el crecimiento y el tráfico celular en la levadura de fisión. Por tanto, en estas levaduras la relación entre Ent3 y GGAs es algo diferente. Estas diferencias podrían ser debidas al distinto número de epsinas endosomales presentes en estos organismos. S. cerevisiae tiene tres (Ent3, 4 y 5), de las cuales Ent4 es exclusiva del subfilo Saccharomycotina (De Craene et al., 2012). En S. pombe Ent3 es la única epsina endosomal, al igual que EntR en humanos. Esto podría haber hecho que la relación funcional entre las epsinas y los otros adaptadores de clatrina evolucionara de forma diferente en estas levaduras. El mayor número de epsinas endosomales presentes en $S$. cerevisiae podría haber hecho que diversificasen sus funciones. De hecho, en este organismo Ent5 no depende de otros adaptadores de clatrina para su localización (al contrario que Ent3) y parece que su función está más relacionada con AP-1, mientras que 
Ent3 está más relacionada funcionalmente con los GGAs (Costaguta et al., 2006). En S. pombe Ent3 podría presentar características intermedias en su relación con los adaptadores.

Como se ha comentado anteriormente no podemos descartar que alguno de los fenotipos observados en los mutantes de los adaptadores de deban a algún efecto indirecto. En este sentido, se sabe que las epsinas actúan como adaptadores de algunas SNAREs (Vti1, Pep12 y Syn8; Chidambaram et al., 2004a; Hirst et al., 2004; Zimmermann et al., 2010). Pep12 viaja a través de la ruta CPY y en su ausencia se producen defectos en el tráfico de Vps10 y Cpy1 (Black and Pelham, 2000; Hosomi et al., 2011). Por tanto, sería posible que en ausencia de GGAs/Ent3 se alterase el tráfico de Pep12 y esto afectase al tráfico de otras proteínas de la ruta CPY. Sin embargo, hemos visto que Pep12 llega a la vacuola adecuadamente. Esto argumentaría en contra de lo planteado anteriormente. $\mathrm{A}$ pesar de esto, no se puede descartar que alguno de los fenotipos vistos en los mutantes se deban a otro efecto indirecto. Las diferencias en el papel de GGAs y epsinas sobre el tráfico de Pep12 entre S. pombe y S. cerevisiae podrían ser debidas al uso de quimeras en este último microorganismo. Estas podrían comportarse de forma distinta a la proteína nativa. También podría ser que la secuencia de reconocimiento descrita en $S$. cerevisiae no esté conservada en la levadura de fisión.

\section{Relación genética y funcional entre los GGAs, Ent3 y Vps27:}

Las interacciones genéticas y funcionales entre los GGAs y Ent3, y entre estos adaptadores y Vps27 podrían estar relacionadas con su capacidad de unir ubiquitina (Eugster et al., 2004; Pelham, 2004). Esto estaría de acuerdo con que Cps1 esté ubiquitinada. De hecho, en S. cerevisiae se ha propuesto que los GGAs podrían transferirle el cargo ubiquitinado al ESCRT (Lauwers et al., 2009). Sin embargo, varios estudios de análisis masivo indican que Vph1 está ubiquitinado, mientras que Vps10 no, lo cual indicaría que las alteraciones en el tráfico de Vps10 no están relacionadas con ubiquitinación (Beckley et al., 2015; Swaney et al., 2013). Aunque Gga2 y Vps27 pueden unirse a ubiquitina de forma directa, las epsinas no tienen esta capacidad (Eugster et al., 2004; Scott et al., 2004). Además, los GGAs y Ent3 colaboran en el tráfico desde el TGN y el PVE. Sin embargo, la función de unión a ubiquitina de Gga2 es necesaria para su 
internalización en el PVE pero no para su transporte desde el TGN (Deng et al., 2009; Lauwers et al., 2009).

En mamíferos Hrs (Vps27) interacciona con clatrina, la cual forma un enrejado plano alrededor del ESCRT (Frankel and Audhya, 2018). Aunque se desconoce la relevancia funcional de esta estructura, se ha propuesto que podría ayudar a estabilizar al ESCRT en la membrana y/o a concentrar el cargo. Quizás en levaduras se forme una estructura similar. Los adaptadores de clatrina podrían participar en su formación, colaborando así con la función del ESCRT.

Nuestros resultados indican que en ausencia de GGAs/Ent3 no existen problemas de internalización de proteínas en el PVE, sino que presentan problemas de llegada a la vacuola (peor salida desde el TGN y desde el PVE). Esto indicaría que los adaptadores de clatrina y el ESCRT participarían en procesos diferentes dentro del tráfico hacia la vacuola. Además, sugiere que la función de los GGAs y Ent3 a nivel de PVE podría ser algo diferente en S. cerevisiae y en S. pombe, ya que en S. cerevisiae tienen un papel en la internalización de proteínas en esta esta estructura (Deng et al., 2009; Eugster et al., 2004; Friant et al., 2003; Lauwers et al., 2009). El análisis de la interacción de estos adaptadores con ubiquitina en S. pombe podría ayudar a explicar estas diferencias.

Resultados previos mostraban que los GGAs participaban en el tráfico desde el TGN de ciertos cargos a través de diferentes rutas (Black and Pelham, 2000; Boman, 2001; Copic et al., 2007; Dell'Angelica and Payne, 2001; He et al., 2005; Hinners and Tooze, 2003; Puertollano et al., 2001a; Watson et al., 2004). Nuestros resultados confirman esto y amplían esta percepción, mostrando que Ent3 y los GGAs también regulan diferentes eventos de tráfico desde el PVE (figura 38). Además, señalan que estos adaptadores facilitan el tráfico anterógrado y retrógrado de un mismo cargo (Vps10) a través de una misma ruta.

En el segundo capítulo de este trabajo se ha querido profundizar en el conocimiento de la función de las SNAREs en el tráfico entre el TGN, el PVE y la vacuola. Para ello nos hemos centrado en el estudio de Fsv1, obteniendo diversos resultados en relación a su función y a su propio tráfico que se discuten a continuación. 


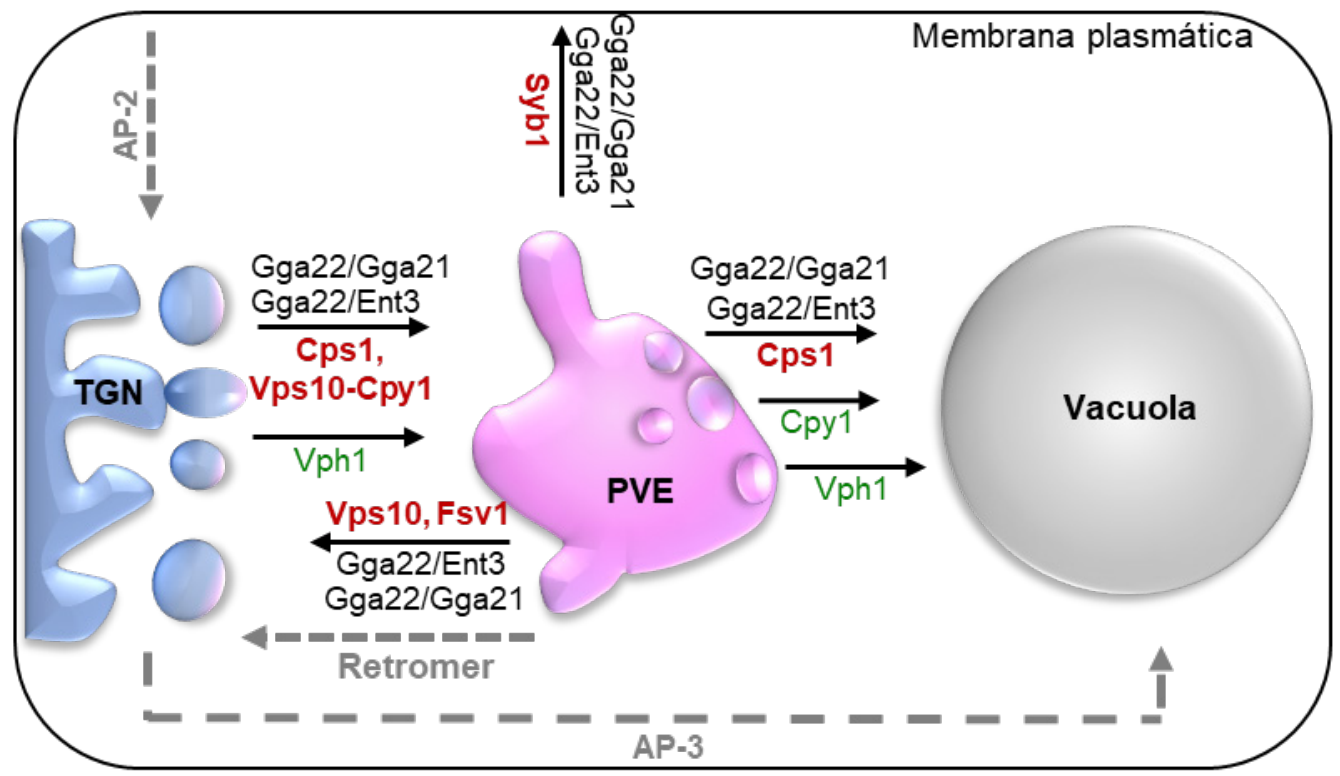

Figura 38. Rutas de tráfico en las que colaboran Gga22, Gga21 y Ent3. Las proteínas que se transportan con una menor eficiencia en ausencia de estos adaptadores se representan en rojo. Las que no presentan un transporte alterado se representan en verde. En gris y con líneas discontinuas se muestran otros adaptadores implicados en el tráfico entre el TGN, el PVE, la vacuola y la membrana plasmática, y las rutas de transporte en las que participan.

\section{Papel de Fsv1 en la funcionalidad y organización del PVE:}

Mediante la utilización de diferentes marcadores, hemos demostrado que el PVE está alterado en el mutante $f s v 1 \Delta$. Aparentemente esta estructura está fragmentada. En consonancia con esto, en mamíferos sintaxina 8 participa en la fusión de los endosomas tardíos in vitro (Antonin et al., 2000). Todo esto apunta a que Fsv1 participa en la fusión de vesículas con el PVE, lo cual sería importante para mantener su estructura. Esto concuerda con el papel descrito para las SNAREs en la fusión de membranas.

En ausencia de Fsv1 se altera también la funcionalidad del PVE. Hemos visto que Cps1 presenta defectos en su maduración. Además, se acumula parcialmente en la membrana de la vacuola, lo cual indica que su internalización en ILVs es ineficaz en $f s v 1 \Delta$. Es probable que los defectos en la funcionalidad del PVE estén ligados a la alteración de su organización. Al estar fragmentado es posible que la composición en proteínas y lipidos de estas vesículas sea diferente a la del orgánulo maduro. Esto produciría los defectos en su función. En consonancia con esto, Vps27 y otras proteínas se observan en puntos menos brillantes en $f s v 1 \Delta$ que en el WT. También es posible que estas estructuras sean 
más pequeñas y, por tanto, presenten una mayor curvatura de su membrana. Esto haría más difícil invertir su curvatura para formar ILVs desde un punto de vista físico. Pese a estas alteraciónes, el defecto en la maduración y localización de Cps1 no es tan severo como el que ocurre en el mutante del ESCRT. Por tanto, no existe un bloqueo total en la formación de las ILVs.

\section{Tráfico hacia la vacuola en ausencia de Fsv1}

Aunque el mutante $f s v 1 \Delta$ presente un PVE alterado, no tiene bloqueado el tráfico hacia la vacuola (incluso en ausencia de AP-3). Diferentes proteínas que viajan por la ruta CPY alcanzan este orgánulo. De hecho, Cps1 llega a la vacuola pese a no internalizarse en ILVs adecuadamente. Todo esto indica que en este mutante las vesículas se pueden fusionar con la vacuola sorteando la alteración del PVE. Por tanto, debe existir otra SNARE que medie este paso de tráfico en ausencia de Fsv1. En este sentido, Vsl1 (Vam7 en S.cerevisiae) puede ser un buen candidato para realizar esta función, ya que es una SNARE del mismo tipo que Fsv1 (Qc) y se localiza en el PVE y la vacuola. Además, el mutante doble $f s v 1 \Delta$ vsl1 $1 \Delta$ presenta defectos en la morfología y fusión vacuolar (Hosomi et al., 2015). Sin embargo, los mutantes sencillos no presentan estos defectos ni un bloqueo en el tráfico hacia la vacuola (Hosomi et al., 2015; y este trabajo). En un futuro se podría evaluar el tráfico hacia la vacuola de alguna proteína (como Pep12 o Cps1) en el mutante doble $f s v 1 \Delta v s / 1 \Delta$, para determinar si en ausencia de los dos genes se produce un bloqueo en el tráfico hacia este orgánulo.

Los datos anteriores sugieren que Vsl1 y Fsv1 tienen una función solapante a nivel de la vacuola. Sin embargo, en ausencia de $v s / 1^{+}$no existen alteraciones en el PVE y su sobreexpresión no remedia los defectos de $f s v 1 \Delta$ a ese nivel. Esto muestra que ambas proteínas no comparten una función en este orgánulo. En mamíferos sintaxina 8 participa tanto en la fusión homotípica de endosomas tardíos como en la fusión de estos con los lisosomas (Antonin et al., 2000; Pryor et al., 2004). En S. pombe Fsv1 participaría en la fusión de vesículas con el PVE, mientras que compartiría función con VIs1 en la fusión de este orgánulo con la vacuola. Vsl1 es una SNARE exclusiva de hongos (Kienle et al., 2009). Por tanto, es posible que Fsv1 en S. pombe se haya especializado más en el tráfico entre 
el TGN y el PVE, y Vsl1 en el tráfico entre PVE y vacuola, aunque todavía mantengan una función solapante a este último nivel.

\section{Tráfico de Fsv1 y dependencia del retrómero}

En este trabajo se ha visto que Fsv1 se localiza en el TGN y en el PVE y que circula entre estos orgánulos. Además, el retrómero es importante para el reciclaje de Fsv1 hacia el TGN. Así, en ausencia de este complejo Fsv1 queda retenida en el PVE y la vacuola. En el futuro debemos profundizar en el estudio de esta relación. Una de las cosas pendientes de analizar es si la deleción de otras subunidades del retrómero produce el mismo efecto sobre el tráfico de Fsv1 que la deleción de vps35+. En este sentido, sería interesante determinar si el tráfico de la SNARE depende de las SNXs convencionales (Vps5 y Vps17) o de otras como Snx3. Esta última colabora con el retrómero en el reciclaje del transportador de hierro Fet3-Ftr1 en S. cerevisiae (Strochlic et al., 2007). La deleción de estas SNXs permitiría responder a esta cuestión. Otro asunto que queda por analizar es la posible interacción física entre Fsv1 y el retrómero. La existencia de esta interacción confirmaría que la SNARE es un cargo de este complejo y que su deslocalización no se debe a algún efecto indirecto causado por la pérdida de función del retrómero.

La identificación de señales importantes para el correcto tráfico de un cargo puede dar una pista sobre el posible sitio de reconocimiento por el adaptador. Para comenzar a analizar esto con Fsv1, hemos construido diferentes formas truncadas de la proteína. De acuerdo con la localización de estas truncaciones, la posible señal de reconocimiento por el retrómero estaría dentro de la construcción GFP-Fsv1 $\mathrm{NCC}$. Es decir, la zona de la proteína posterior al último coiled-coil. En S.cerevisiae el transporte de Vam3 a la vacuola depende del reconocimiento por AP-3 de una señal localizada en una zona parecida de la SNARE (Darsow et al., 1998). Se han descrito diferentes señales importantes para el reconocimiento de algunos cargos por el retrómero. Sin embargo, en esta zona de Fsv1 sólo hemos encontrado una señal similar. Al mutarla hemos visto que no es importante para el reciclaje de la proteína desde el PVE. Es posible que exista un motivo de interacción con el retrómero diferente a los descritos, aunque también es posible que la interacción entre estas proteínas sea compleja y dependa de una estructura tridimensional concreta. De hecho, la interacción entre Ent3 o EntR y la SNARE Vti1 
parece ocurrir de este último modo (Miller et al., 2007; Wang et al., 2011). El hecho de que algunas construcciones de Fsv1 se observen en la vacuola, no permite distinguir entre las opciones anteriores, ya que estas formas truncadas podrían carecer de la conformación estructural específica para interaccionar con el retrómero o con otras proteínas que faciliten esta interacción. Por tanto, es necesaria más investigación para confirmar (e identificar) o descartar la existencia de un motivo de reconocimiento por el retrómero en Fsv1. En el futuro quizás sería interesante intercambiar diferentes partes de la construcción GFP-Fsv1 $\triangle$ NCC por partes de otra SNARE similar que no dependa del retrómero para su localización. Esta aproximación sería más conservativa con la estructura de la proteína. Una posible candidata sería Tlg1, ya que también es de tipo Qc y presenta un tamaño similar a Fsv1. Además, en S. cerevisiae Tlg1 y Syn8 (homologa a Fsv1) presentan una función parcialmente redundante. Sin embargo, previamente habría que investigar la influencia del retrómero en su localización.

\section{Influencia del retrómero en el tráfico de Gos1}

Además de mediar el retorno de Fsv1 al TGN, hemos visto que el retrómero participa también en el reciclaje de Gos1. En diversos estudios se ha descrito que esta SNARE participa en el tráfico a través del Golgi (McNew et al., 1998; Parlati et al., 2002; Tsui et al., 2001). Además, se ha utilizado como marcador de medial Golgi (Matsuura-Tokita et al., 2006). Sin embargo, el hecho de que Gos1 dependa del retrómero para su localización, sugiere que podría estar circulando a través del PVE. En este sentido, se ha descrito que Gos1 participa en la ruta CVT (Cytoplasm-to-Vacuole Targeting pathway; Ohashi y Munro, 2010). Esta ruta media el transporte de algunas hidrolasas (como Ape1 y Ams1) desde el citoplasma hacia la vacuola englobándolas en estructuras membranosas (Umekawa and Klionsky, 2012). Gos1 podría mediar la fusión de estas estructuras con el PVE o la vacuola (Ohashi and Munro, 2010). Sería posible que Gos1 participase en un proceso similar en S. pombe y que el retrómero reciclara las moléculas de esta SNARE (desde el PVE) que interviniesen en este proceso. En el futuro tendremos que evaluar la localización de Gos1 para determinar si parte se observa en el PVE.

Como los GGAs y Ent3 participan también en el reciclaje de Fsv1 (aunque en menor grado que el retrómero), sería interesante analizar si también intervienen en el reciclaje 
de Gos1. Además, esto nos permitiría contestar a la pregunta de si todas las proteínas que reciclan por el retrómero en $S$. pombe también dependen parcialmente de los GGAs/Ent3 para su localización. Tanto Vps10 como Fsv1 están parcialmente alteradas en ausencia de los adaptadores de clatrina. El análisis de Gos1 podría aportar información adicional en este sentido.

\section{El retrómero como regulador de SNAREs}

Hemos visto que el retrómero en S. pombe media el retorno de dos SNAREs (Fsv1 y Gos1) hacia el TGN. En un trabajo anterior se había observado que también era importante para el reciclaje de Pep12 en S. cerevisiae (Hettema et al., 2003). En conjunto, esto sugiere que el tráfico mediado por el retrómero podría ser un mecanismo general por el que las SNAREs que permiten la fusión de vesículas con el PVE retornen al TGN. Esto les posibilitaría mediar una nueva ronda de transporte. Sin embargo, no todas las SNAREs presentan una localización alterada en ausencia del retrómero. Syb1/Snc1 no se acumula en la vacuola en ausencia de este complejo, a pesar de que una parte de esta proteína viaje a través del PVE (Hettema et al., 2003; Ma et al., 2017; Zhao et al., 2016). Syb1/Snc1 depende de Snx4/42 para su reciclaje mientras que Fsv1 no (Hettema et al., 2003; Ma et al., 2017; Zhao et al., 2016; y resultados no mostrados). Esto puede hacer que nos planteemos por qué estas SNAREs dependen de adaptadores distintos. Quizás esto se deba a las diferencias en el tráfico de estas proteínas. Así, Syb1 llega al PVE desde la membrana plasmática y se recicla hacia el TGN como paso previo a su secreción. Fsv1 y algunos otros cargos que dependen del retrómero (como Vps10) circulan entre el TGN y el PVE sin pasar por la membrana plasmática. Se ha propuesto que Snx4/42 y el retrómero ocupan diferentes dominios o regiones dentro del PVE (Ma et al., 2017). A estos podrían llegar proteínas de diferente procedencia, lo cual facilitaría la segregación de los cargos y el reconocimiento por adaptadores diferentes. Estos podrían mediar el tráfico hacia diferentes dominios de membrana del TGN. Así se facilitaría el transporte posterior de los cargos hacia diferentes destinos (PVE o membrana plasmática). Esta hipótesis, que podría ser válida para estas proteínas, no lo sería para todos los cargos, ya que el retrómero también facilita el reciclaje de Can1, Chs3 y Ftr1 al TGN para su posterior secreción (Arcones et al., 2016; Shi et al., 2011; Strochlic et al., 2007). En este último caso 


\section{Discusión}

sería interesante averiguar por qué existen vías de tráfico redundantes (con intervención de diferentes adaptadores o cubiertas) para el transporte de proteínas con un destino similar. Sería necesaria información adicional para dar explicación a estas cuestiones. 
Conclusiones 

1. Gga22 colabora con Gga21 y/o Ent3 facilitando la salida de Vps10-GFP y de Ub:GFPCps1 del TGN. Además, estos adaptadores colaboran en el transporte de Ub:GFP-Cps1 desde el PVE hacia la vacuola.

2. En ausencia de los GGAs y Ent3 no se altera la localización de Vph1-GFP, lo que demuestra que estos adaptadores no facilitan el tráfico de todas las proteínas que siguen la ruta CPY.

3. La colaboración de Gga22 con Gga21 y/o con Ent3 es necesaria para que se produzca un tráfico retrógrado eficiente de Vps10-GFP y de GFP-Fsv1 desde el PVE hacia el TGN, así como para el reciclaje de GFP-Syb1 desde esta estructura.

4. La colaboración de Gga22 con Gga21 y/o con Ent3 es necesaria para que la organización del PVE sea correcta.

5. En el mutante fsv1 $\Delta$ la organización del PVE está alterada, aunque no se bloquea el tráfico hacia la vacuola. Además, Ub:GFP-Cps1 no llega correctamente al lumen de la vacuola, lo que indica que la funcionalidad del PVE está afectada.

6. VsI1 no desarrolla una función equivalente a la de Fsv1 en el PVE, aunque ambas SNAREs podrían tener una función solapante en la fusión de membranas en la vacuola.

7. El reciclaje de Fsv1 y de Gos1 desde el PVE hasta el TGN depende del retrómero.

8. La parte de Fsv1 presente en la construcción GFP-Fsv1 NNCC contiene las secuencias necesarias para su reciclaje por el retrómero. 

Materiales y métodos 



\section{Microorganismos empleados.}

En este trabajo se han empleado dos microorganismos diferentes:

- La bacteria Escherichia coli se ha usado en los trabajos rutinarios de clonación molecular.

- La levadura Schizosaccharomyces pombe se ha usado como modelo experimental para realizar la mayoría de experimentos.

Las cepas empleadas en este trabajo, sus características genéicas y su procedencia se detallan en la tabla SI del anexo.

\section{Medios y condiciones de cultivo.}

Todos los medios de cultivo empleados fueron preparados con agua destilada (milli RO) y esterilizados en el autoclave. Los correspondientes medios sólidos se prepararon mediante la adición de agar al $2 \%$.

\subsection{Medios y condiciones de cultivo para E. coli.}

Para el crecimiento de esta bacteria se utilizó de manera rutinaria el medio LB (LuriaBertani) compuesto por: bactotriptona al $1 \%$, extracto de levadura al $0,5 \%$ y $\mathrm{NaCl}$ al $1 \%$. En algunos casos se utilizó también el medio 2xYT (2x Yeast Extract Tryptone) compuesto por: bactotriptona al 1,6\%, extracto de levadura al $1 \%$ y $\mathrm{NaCl}$ al $1 \%$. Para la selección de clones resistentes a antibióticos se suplementaron los medios con $100 \mu \mathrm{g} / \mathrm{ml}$ de ampicilina (Roche) o con $50 \mu \mathrm{g} / \mathrm{ml}$ de kanamicina (Formedium).

Para su cultivo en medio líquido las células de $E$. coli se incubaron con agitación orbital a $200 \mathrm{rpm}$ a una temperatura de $37^{\circ} \mathrm{C}$. Para el crecimiento en medio sólido las células se incubaron en placas de Petri en estufas a $37^{\circ} \mathrm{C}$.

\subsection{Medios y condiciones de cultivo generales para S. pombe.}

Los medios de cultivo utilizados para el crecimiento de la levadura de fisión fueron descritos previamente por Moreno y colaboradores (Moreno et al., 1991). En este trabajo se han usado los siguientes: 
YES (Yeast Extract Suplemented): Es un medio rico compuesto por Glucosa al 3\%, extracto de levadura al 0,5\% y una mezcla con cantidades iguales de adenina, histidina, leucina, lisina y uracilo a 1,125 g/L. El pH del medio se ajusta a 5,6. Este medio se ha usado de manera general para el crecimiento vegetativo de $S$. pombe para realizar los diferentes experimentos, excepto en aquellos casos en los que se indique otra cosa. Para la selección de determinadas cepas el medio YES se suplementó con geneticina a $120 \mu \mathrm{g} / \mathrm{mL}$, con nourseotricina a $50 \mu \mathrm{g} / \mathrm{ml}$ o con higromicina a $400 \mu \mathrm{g} / \mathrm{ml}$, según fuese necesario.

Medio mínimo (EMM, Edinburgh Minimal Media): compuesto por glucosa al 2\%, ftalato monopotásico al 0,3\%, $\mathrm{Na}_{2} \mathrm{HPO}_{4}$ al $0,22 \%$ y $\mathrm{NH}_{4} \mathrm{Cl}$ al 0,5\%. El pH del EMM está ajustado a 5,6. Además, este medio lleva sales, vitaminas y minerales de acuerdo a lo especificado previamente (Moreno et al., 1991). El EMM se ha usado para la selección de cepas con determinadas auxotrofías y para cultivar aquellas que portaban plásmidos. En estos casos el EMM se suplementó con $225 \mathrm{mg} / \mathrm{L}$ de uracilo, lisina, adenina, leucina y/o histidina según fuera necesario. El EMM con todos los suplementos se denominó EMM completo.

Para el crecimiento de $S$. pombe en medio sólido se utilizaron placas de Petri que se incubaron en estufas a la temperatura correspondiente. En general, para el crecimiento en cultivos líquidos, las levaduras se incubaron a 28 ㄷ C en matraces con agitación a 200 rpm. En este caso los experimentos se realizaron siempre con cultivos en fase exponencial de crecimiento. Para ello se realizaba un preinóculo el día anterior al experimento y se dejaba crecer durante toda la noche. A la mañana siguiente se analizaba la concentración de células en el cultivo midiendo la absorbancia a $600 \mathrm{~nm}$ en un espectrofotómetro. Por las curvas de calibración realizadas previamente en el laboratorio se sabía que una densidad óptica (D.O.) de 1 equivalía a $10^{7}$ células $/ \mathrm{mL}$ de S. pombe. Teniendo en cuenta estos datos y el tiempo de generación de la levadura, se reinoculaba el cultivo a la concentración de células necesaria para realizar el experimento con las levaduras creciendo en fase exponencial (D.O. $\leq 1)$. 


\subsection{Ensayos de crecimiento en gota}

Este tipo de experimento se usa para analizar y comparar el crecimiento de distintas cepas ante diferentes tipos de estrés. Además, permiten observar las interacciones génicas existentes entre ellas. Para realizar estos ensayos se partía de cultivos líquidos creciendo en fase exponencial y se igualaba su D.0.600 a 1. A continuación, se realizaban diluciones seriadas $1 / 4$ hasta obtener un total de 6 concentraciones decrecientes de células. Posteriormente, usando un replicador se colocaba una gota de cada concentración sobre las placas con el medio de cultivo correspondiente. Las placas se incubaron a diferentes temperaturas o en presencia de $\mathrm{KCl}$ a $28 \circ \mathrm{C}$ (estrés osmótico/iónico) durante 2-5 días dependiendo de las condiciones.

\section{Conjugación y aislamiento de ascosporas al azar}

Con el objetivo de conseguir cepas con características de dos estirpes parentales se llevaron a cabo cruces genéticos. La inducción de la conjugación se produjo en placas de EMM, ya que para que se inicie este proceso es necesario que haya unas condiciones limitantes de nutrientes. Cuando se usaron estirpes heterotálicas de tipo sexual opuesto $\left(h^{+}\right.$y $\left.h^{-}\right)$, se mezcló la misma cantidad de células de cada progenitor. Si una de las cepas parentales era homotálica $\left(h^{90}\right)$, se utilizó menor cantidad de ella para disminuir la probabilidad de congujación entre sus propias células.

Tras unos 2-4 días de incubación (dependiendo de la temperatura) las células que han conjugado adecuadamente generan ascas con 4 ascosporas cada una. Una vez transcurrido este tiempo se realizó el aislamiento y selección de las ascosporas al azar. Para ello se tomó una pequeña muestra del cruce y se resuspendió en $1 \mathrm{ml}$ de agua estéril al que se añadieron $5 \mu \mathrm{l}$ de extracto enzimático $\beta$-glucuronidasa (Roche). Esta mezcla se incubó durante, aproximadamente, 16 horas a temperatura ambiente en agitación. Este tratamiento favorece la liberación de las esporas y degrada las paredes de las células vegetativas. Después se realizaron diluciones y se sembraron en medio rico YES. Una vez que las colonias crecieron en este medio se seleccionaron aquellas que poseían el genotipo de interés mediante su crecimiento en medios selectivos, a través de su análisis 
por PCR (Reacción en Cadena de la Polimerasa) y/o mediante su observación al microscopio.

\section{Procedimientos generales de biología molecular.}

\subsection{Vectores utilizados}

\subsubsection{Vectores de $E$. coli}

pBluescript $\mathrm{KS}^{+}$(Stratagene): Es un plásmido autoreplicativo de 2958 pares de bases (pb) que contiene el gen de resistencia a ampicilina para la selección en bacterias, el origen de replicación ColE1 y un fragmento del operón de lactosa de E. coli que codifica la enzima $\beta$-galactosidasa. Además, dispone de un sitio de clonación múltiple (MCS) que contiene 21 sitios únicos de restricción. Flanqueando el MCS se encuentran los promotores de las ADN polimerasas T3 y T7, que se utilizan para la síntesis de ARN in vitro. También contiene el origen de replicación f1 que permite la obtención de ADN monocatenario tras la infección de las células portadoras del plásmido con el fago auxiliar M13K07, lo cual es útil para la realización de mutagénesis dirigida in vitro.

PGEM-T (Promega): Es un plásmido con un tamaño de 3003 pb. En su secuencia contiene el gen de resistencia a ampicilina, el origen de replicación ColE1 y un fragmento del operón de lactosa de $E$. coli que codifica la enzima $\beta$-galactosidasa. Posee 13 sitios únicos de reconocimiento para endonucleasas de restricción y flanqueándolos se encuentran los promotores de las ARN polimerasas T3 y SP6. Además contiene el origen de replicación f1. Este vector es lineal y cuenta con una timina en cada extremo, por lo que se emplea para la clonación de fragmentos de ADN amplificados por PCR.

\subsubsection{Vectores de $S$. pombe}

pJR1-41XL (Moreno et al., 2000): Es un plásmido multicopia, ya que contiene la secuencia de replicación autónoma ars1 de S. pombe. Es una modificación del plásmido pREP41X (Maundrell, 1993). Contiene el gen de resistencia a ampicilina y el gen LEU2 de S. cerevisiae que permite el crecimiento en medios sin leucina de cepas de $S$. pombe con la mutación leu1-32. Además, tiene el promotor reprimible por tiamina del gen $n m t 1^{+} \mathrm{y}$ 
su terminador separados por un MCS. Esto permite clonar genes en el MCS y sobreexpresarlos en ausencia de tiamina o reprimirlos en su presencia.

pIJK148 (McLeod et al., 1987): Es un vector de 5,3 kb que contiene el gen leu1 ${ }^{+}$de $S$. pombe como marcador de selección en levadura, el gen de resistencia a ampicilina, el origen de replicación f1, el gen de la enzima $\beta$-galactosidasa, el origen de replicación ColE1 de E. coli y un MCS con 19 sitios de restricción únicos. Este plásmido carece de la secuencia de replicación autónoma ars1 por lo que no se puede autoreplicar en levadura. Se usa para la integración de secuencias de ADN en el locus leu1 ${ }^{+}$de $S$. pombe. Para que la integración del plásmido tenga lugar es necesario hacerlo lineal digiriéndolo con una enzima de restricción. De manera rutinaria se ha utilizado Tth111l que corta dentro del gen leu1+. Tras esto se puede transformar una cepa con la mutación leu1-32. Al integrarse el plásmido en esta cepa se reconstituye una copia del gen leu1 ${ }^{+}$silvestre, por lo que se pueden seleccionar los transformantes en un medio sin leucina.

pINTH81 (Fennessy et al., 2014): Es un plásmido integrativo construido a partir del vector pUC19 de E. coli. Tiene el gen de resistencia a ampicilina como marcador de selección en bacterias. Además, contiene un módulo de ADN con la mitad de la secuencia codificante del gen de resistencia a higromicina, seguida del promotor de $n m t 1^{+}$, de un MCS, del terminador de $n m t^{+}{ }^{+}$, del gen de resistencia a nourseotricina y de la otra mitad del gen de resistencia a higromicina (ver más adelante). Este módulo (tras hacerlo lineal cortando con la enzima Notl) se puede integrar en el genoma de una cepa que posee el gen de resistencia higromicina integrado artificialmente en una región intergénica de su genoma (Fennessy et al., 2014).

\subsection{Obtención de ADN}

Para la extracción rápida y a pequeña escala (mini-preps) de ADN plasmídico de $E$. coli se empleó el método de la rotura alcalina descrito previamente (Zhou et al., 1990). En este método las células se lisan por la adición de una mezcla de $\mathrm{NaOH}$ y dodecil sulfato sódico (SDS). La precipitación del ADN se produce por la adición de isopropanol y sales. Cuando fue preciso obtener ADN de mayor pureza y en mayor cantidad se empleó un kit comercial (QIAprep ${ }^{\circledR}$ Spin Miniprep Kit). 
La extracción de ADN plasmídico y genómico de S. pombe se realizó según los protocolos descritos previamente por Moreno y colaboradores (Moreno et al., 1991) y en el manual de laboratorio de Sambrook y colaboradores (Sambrook et al., 1989).

\subsection{Reacción en cadena de la polimerasa (PCR)}

La amplificación de fragmentos de ADN por PCR se llevó a cabo en el termociclador MyCycler ${ }^{\mathrm{TM}}$ (BioRad). De manera general se usó una mezcla de reacción (20 $\mu \mathrm{L}$ de volumen final) que contenía los 4 desoxinucleótidos trifosfato a una concentración final de 0,2 mM cada uno, $\mathrm{MgCl}_{2}$ a 2,5 mM, los oligonucleótidos usados como cebadores a 1 $\mu \mathrm{M}, 0,25$ unidades de la polimerasa (BIOTAQ ${ }^{\mathrm{TM}}$ de Bioline), el tampón suministrado por dicha casa comercial y un volumen variable de ADN molde en función de si era genómico o plasmídico. El volumen se completó con agua. En aquellos casos en los que la PCR se utilizó para amplificar un fragmento de ADN que se iba a clonar para su expresión en $S$. pombe, se usó en la reacción una enzima con capacidad correctora de errores (VELOCITY DNA Polymerase, BIOLINE) siguiendo las especificaciones de la casa comercial.

Para que la reacción de amplificación del ADN tenga lugar es necesario que se produzcan ciclos con los siguientes pasos: desnaturalización del ADN molde, anillamiento de los oligonucleótidos incorporados y extensión de las hebras sintetizadas. En cada uno de estos pasos es necesaria una temperatura determinada. Las condiciones de anillamiento y elongación variaron en cada caso en función de las características del oligonucleótido utilizado y de la longitud del fragmento a amplificar. El número de ciclos programados fue de 30-35, dependiendo del experimento.

\subsection{Manipulación general de ADN}

Los protocolos utilizados para la manipulación de ADN se recogen en distintos manuales (Sambrook et al., 1989; Sambrook, 2001). Además de las distintas indicaciones de estos manuales se tuvieron en cuenta las recomendaciones de las casas comerciales suministradoras del material.

El análisis de los fragmentos de ADN obtenidos por PCR o por tratamiento con enzimas de restricción se realizó mediante electroforesis en geles de agarosa (Hispanlab). 
Estos se elaboraron a diferentes concentraciones (entre $0,7 \%$ y $2 \%$ ), según el tamaño de los fragmentos a separar. Los geles se prepararon con tampón TAE (Tris acetato $40 \mathrm{mM}$, EDTA 1mM) al que se añadió Midori Green (Nippon Genetics Europe GmbH).

Para purificar los fragmentos de ADN después de su separación en geles de agarosa se utilizó el kit comercial NucleoSpin ${ }^{\circledR}$ de MACHEREY-NAGEL. Las ligaciones de fragmentos de ADN purificados se realizaron utilizando la enzima del fago T4 (Fermentas) e incubando la mezcla de ligación a 16ㄷ durante 12-16 horas. Posteriormente esta mezcla de ligación se utilizó para transformar E. coli.

\subsection{Secuenciación}

La secuenciación de fragmentos de ADN se realizó en el servicio de secuenciación de la empresa CENIT, que emplea un secuenciador automático capilar 3730xI DNA Analyzer (Applied Biosystems). La técnica usada se basa en modificaciones del método descrito por Sanger y colaboradores (Sanger et al., 1977). Se usan didesoxinucleótidos marcados con fluorocromos que son detectados por un láser. Las secuencias obtenidas se observaron en forma de cromatograma, junto con las letras correspondientes a cada nucleótido, con el programa Chromas.

\subsection{Mutagénesis dirigida in vitro}

Esta técnica se utilizó para introducir ciertos cambios en la secuencia del gen $f s v 1 .^{+}$ Para ello se siguió el método que se incluye en los siguientes pasos (Kunkel et al., 1987):

- Transformación de la cepa CJ236 de E. coli con el plásmido que portaba el inserto de ADN a mutagenizar. Esta cepa bacteriana contiene el episoma $\mathrm{F}^{\prime}$ que le permite ser infectada por el fago auxiliar M13K07. Además, posee dos mutaciones que son de utilidad en la mutagénesis dirigida. La mutación dut inactiva la enzima dUTPasa encargada de reducir la cantidad de dUTP en la célula, permitiendo que las moléculas de ADN sintetizadas porten esta base nitrogenada en los lugares en los que debería aparecer tiamina. La mutación ung inactiva la uracilo N-glicosilasa, impidiendo que el uracilo incorporado al ADN sea eliminado. 
- Extracción del ADN de cadena sencilla infectando a las bacterias con el fago M13 que, al replicarse, incorpora en su cápsida una de las cadenas del plásmido bicatenario con el inserto de interés.

- Fosforilación del oligonucleótido que porta la mutación deseada. Este se usó como cebador para la síntesis de la cadena complementaria a la hebra sencilla rica en uracilo, obtenida en el paso anterior. Para realizar la fosforilación se utilizó la enzima polinucleótido quinasa del fago T4 (Fermentas).

- Anillamiento del oligonucleótido fosforilado con la zona complementaria del ADN de cadena sencilla. Este paso se lleva a cabo incubando ambas moléculas de ADN durante 1 minuto a $100{ }^{\circ} \mathrm{C}$ (para permitir la desnaturalización del ADN) y dejando descender la temperatura lentamente por debajo de 35으 (para permitir el anillamiento del oligonucleótido al molde). Este proceso se llevó a cabo en un termociclador (MyCycler ${ }^{\mathrm{TM}}$; BioRad). Tras este proceso se añadió el tampón de síntesis con los cuatro dNTPs, la ADN ligasa T4 y la ADN polimerasa T7. Esta mezcla se incubó durante 5 minutos en hielo, 5 minutos a temperatura ambiente y 90 minutos a $37^{\circ} \mathrm{C}$ para que se produjera la síntesis de la cadena complementaria.

- Transformación de la cepa $\mathrm{DH} 5 \alpha$ de $E$. coli con la mezcla de reacción. En esta cepa la hebra rica en uracilo se degrada, replicándose exclusivamente la cadena sin uracilo que es la que ha incorporado la mutación deseada.

Este método se utilizó para cambiar la secuencia de nucleótidos ${ }_{550}$ TAT GCA ATG 558 del fragmento Fsv1 $\triangle$ NCC por la secuencia ${ }_{550} G C T$ GCA GCG ${ }_{558}$, con el fin de sustituir en la proteína el motivo de aminoácidos YAM por el AAA. También se usó para realizar las construcciones Fsv1 $1 \Delta \mathrm{SN}$ y Fsv1 $1 \Delta$ Int con deleciones internas del gen $f s v 1,{ }^{+}$que se realizaron como parte del trabajo de fin de máster de María del Mar Peña Ramón. En este caso, se usó un oligonucleótido que hibridaba a ambos lados de la región de ADN que se quería delecionar para que esta no se amplificase. La comprobación de la correcta modificación de la secuencia de nucleótidos y de las deleciones se realizó mediante secuenciación. 


\subsection{Construcción de plásmidos}

El dominio PH (Pleckstrin Homology) de la proteína humana FAPP1, usado como sonda para reconocer el PI4P presente en el TGN, se amplificó por PCR usando como molde el plásmido pRS406-PHO5-GFP-hFAPP1 PH (Addgene, Levine and Munro, 2002), quedando flanqueada por los sitios de restricción Mlul y Sall. Este fragmento se clonó precedido de la secuencia de la GFP (Green Fluorescent Protein) o de la mCherry (una proteína fluorescente roja), amplificadas como fragmentos flanqueados por los sitios Apal y Mlul. Para su expresión, esta construcción se puso bajo el promotor del gen $n d a 2^{+}$ (la región 5'no traducida de 571 pares de bases) amplificado como un fragmento con los sitios Pstl y Apal en sus extremos; y con el terminador del mismo gen (región 3'no traducida de 313 pares de bases de extensión) flanqueado por los sitios Sall y Sacl. La construcción completa se integró en el plásmido pINTH81 (Fennessy et al., 2014) digiriendo con las enzimas Pstl y Sacl (figura39). Para la transformación de S. pombe este plásmido se linealizó digiriéndolo con Notl y se integró en el locus artificial hph171K disrumpiéndolo (Fennessy et al., 2014). Los transformantes resultantes se seleccionaron por ser resistentes a nourseotricina y sensibles a higromicina. El dominio FYVE de la proteína humana EEA1 utilizado como sonda de unión al PI3P se amplificó por PCR y se clonó junto con la secuencia de la GFP o de la mCherry de la misma manera que la descrita para el dominio PH (Hoya et al., 2017). De esta forma se clonaron también GFP-Pep12, GFP-Ykt6, GFP-Vti1, GFP-Fsv1 y los diferentes fragmentos y modificaciones de esta última proteína, usando ADNc como molde para amplificar su secuencia. Los fragmentos Fsv1 $\Delta$ SN y Fsv1 1 Int se obtuvieron mediante mutagénesis dirigida en vez de por PCR. La expresión de estas sondas y proteínas bajo el control del promotor del gen $n d a 2^{+}$(que codifica la $\alpha$ tubulina) permite una expresión constitutiva de nivel medio.

Dependiendo de las condiciones experimentales, los dominios FYVE y PH se clonaron en el plásmido pINTH81, como se ha explicado anteriormente, y se integraron en el locus hph171K, o se clonaron en el plásmido pIJK148 de la misma manera (como un fragmento Pstl/Sacl), que se cortó con la enzima Tth111l para hacerlo lineal y se integró en el locus leu1 $1^{+}$de S. pombe. 
Plásmido original (pINTH81):
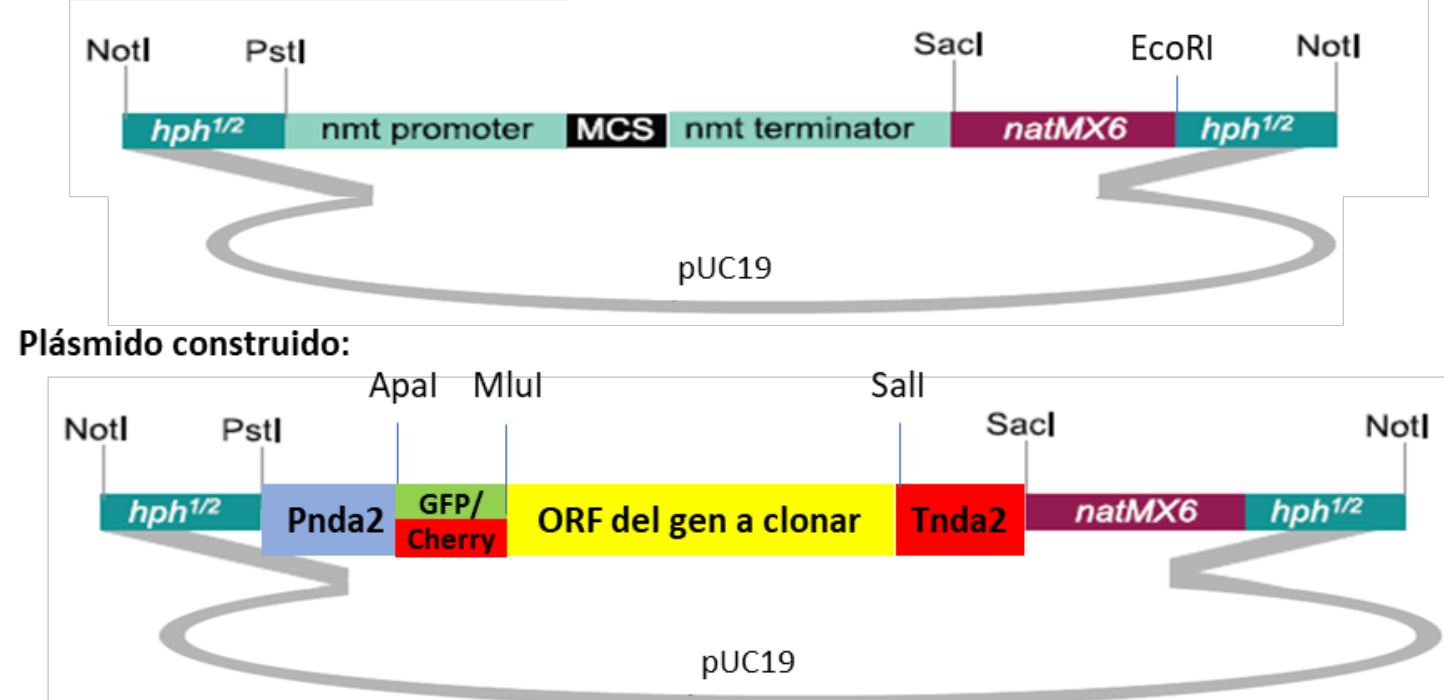

Figura 39. Construcción de plásmidos integrativos para el marcaje de proteínas con GFP o Cherry en su extremo $\mathbf{N}$-terminal y expresadas bajo el promotor del gen $\mathbf{n d a 2}^{+}$. En la parte superior se muestra el plásmido original (Fannessy et al., 2014). En la parte inferior se muestra el plásmido construido donde se clonó el gen correspondiente en cada caso. Para su integración en el locus artificial hph171K del genoma el plásmido se digirió con Notl.

La construcción Ub:GFP-Cps1 se clonó en el plásmido pINTH81 bajo el control del promotor $n d a 2^{+}$y del terminador $n m t 1^{+}$. Para ello se amplificaron por PCR los siguientes fragmentos: los primeros 228 nucleótidos de la fase de lectura abierta (ORF) del gen ubi4 flanqueados por los sitios Apal y HindIII, la secuencia de la GFP flanqueada por los sitios HindIII y Pstl y la secuencia codificante del gen cps1 flanqueada por los sitios Pstl y Sall. El plásmido resultante se cortó con la enzima Notl para integrar la construcción Ub:GFPCps1 en el locus hph171K.

Para el marcaje de Gos1 con GFP en su extremo N-terminal se amplificaron por PCR los siguientes fragmentos: la ORF del gen gos $1^{+}$flanqueada por los sitios Notl y Clal, la secuencia de la GFP con los sitios Notl en sus extremos, el promotor del gen gos $1^{+}(340$ pares de bases en posición $5^{\prime}$ del inicio de la ORF del gen) flanqueado por los sitios Apal y Notl) y el terminador de este mismo gen (1383 pares de bases en posición 3' de la ORF de $g o s 1^{+}$) con los sitios Clal y Sacl en sus extremos. Estos fragmentos se introdujeron en el plásmido plJK148 digerido con Apal y Sacl. Una vez construido el plásmido se digirió con la enzima Tth111l para integrar la construcción en el locus leu1 ${ }^{+}$de S. pombe. 
Para la sobreexpresión de $\mathbf{v s / \mathbf { 1 } ^ { + }}$ se amplificó la ORF de este gen flanqueada por los sitios Xhol y Smal y se clonó en el plásmido pJR1-41XL (Moreno et al., 2000).

Los oligonucleótidos utilizados para realizar estas construcciones se detallan en la tabla SII. Todas las construcciones se comprobaron mediante digestiones con enzimas de restricción y por secuenciación.

\subsection{Deleción de genes y marcaje de proteínas en su locus}

Las deleciones de distintos genes y los marcajes en el extremo C-terminal de las proteínas se han hecho transformando la cepa pku70八 (Fennessy et al., 2014) con distintos módulos de ADN amplificados por PCR como está descrito (Bähler et al., 1998). Para la amplificación se usaron oligonucleótidos de unos 100 pares de bases, de los que 80 eran homólogos con las dianas del genoma y 20 con los distintos módulos. Tras la transformación de la cepa pku70 y y la comprobación de la correcta integración de la construcción por PCR, los transformantes se cruzaron con cepas $p k u 70^{+}$para reintroducir el locus silvestre en la cepa resultante. Siguiendo este método se construyeron los mutantes $f \mathbf{s v} \mathbf{1 \Delta}, \boldsymbol{v p s} \mathbf{3 5 \Delta}$ y vs/1 $\mathbf{1}$, y los marcajes en el extremo C-terminal de las proteínas Vph1-GFP, Ent3-GFP, Vps10-GFP, Isp6-GFP, Vps27-RFP, Nhx1-GFP y Vps35-GFP. Los oligonucleótidos utilizados para construir estas cepas se detallan en la tabla SII

\subsection{Transformación de $E$. coli}

La transformación de células competentes de $E$. coli con mezclas de ligación se realizó de acuerdo con el procedimiento diseñado anteriormente (Kushner, 1978). Este método promueve la entrada de ADN en las células bacterianas sometiéndolas a un choque térmico. Para amplificar plásmidos ya construidos se empleó un método simplificado del anterior conocido como "transformación del minuto" (Golub, 1988).

\subsection{Transformación de S. pombe}

Las transformaciones de $S$. pombe se realizaron siguiendo el método del acetato de litio-sorbitol (Ito et al., 1983) con las modificaciones descritas por Bähler y colaboradores (Bähler et al., 1998). 


\section{Análisis y detección de proteínas}

\subsection{Obtención de extractos proteicos}

Para la obtención de extractos proteicos se utilizaron $30 \mathrm{ml}$ de cultivos en fase exponencial de crecimiento (D.0.600=0,8-1). Las células se recogieron por centrifugación (900 x g) y se lavaron con $1 \mathrm{ml}$ de ácido tricloroacético (TCA) al 20\% frío. A continuación, se resuspendieron en $50 \mu \mathrm{l}$ de la misma solución y se añadieron $500 \mu \mathrm{l}$ de bolitas de vidrio de 0,4-0,6 mm de diámetro (Braun Biotech International). Las células se rompieron en una Fast-Prep Fp120 (Savant Bio101) en tres ciclos de 16 segundos a una velocidad de 6 y a 4 ํㅡ, con una incubación de 5 minutos en hielo entre los pulsos de rotura. Posteriormente se le añadió a cada tubo $400 \mu \mathrm{l}$ de TCA frio al 5\% y se agitó en el vortex para lavar las bolitas de vidrio. Tras esto, se transfirieron los extractos celulares a un tubo nuevo y se centrifugaron durante 10 minutos $(0,8 \times \mathrm{g})$ a 4 으. El precipitado resultante se resuspendió en una solución con SDS al 2\% y 0,3 M de Tris Base y se calentó durante 7 minutos a $65^{\circ} \mathrm{C}$. Después las muestras se centrifugaron durante 2 minutos (17000 x g) y se transfirió el sobrenadante a un tubo limpio. Posteriormente se valoró la cantidad de proteína mediante el método colorimétrico de Bradford (Bradford, 1976) usando el reactivo de BioRad Protein Assay Dye Reagent y se igualó la concentración de proteínas de las muestras. Seguidamente se añadió a las muestras el tampón de carga $2 X$ Laemmli sample buffer (Tris $\mathrm{HCl}$ pH 6,8 100 mM, SDS 2\%, $\beta$-mercaptoetanol 0,286 M, glicerol al $20 \%$ y azul de bromofenol) y se calentaron de nuevo 7 minutos a $65^{\circ} \mathrm{C}$.

\subsection{Electroforesis y electrotransferencia de proteínas}

Una vez obtenidos los extractos proteicos se cargaron en geles de poliacrilamida (BioRad), donde las proteínas se separaron según su tamaño mediante electroforesis en condiciones desnaturalizantes (SDS-PAGE). Se emplearon geles de distinto porcentaje de poliacrilamida según el tamaño de la proteína a analizar. La electroforesis se realizó a 100$150 \mathrm{~V}$ durante 1-2 horas utilizando el tampón de carrera Laemmli (Tris base $3 \mathrm{~g} / \mathrm{l}$, glicina $14,4 \mathrm{~g} / \mathrm{l}$ y SDS 5\%).

Tras la electroforesis las proteínas se transfirieron a membranas de PVDF (Inmobilon ${ }^{\mathrm{TM}}-\mathrm{P}$, Millipore) para su posterior detección con anticuerpos. La transferencia 
se llevó a cabo utilizando el sistema Mini Trans Blot (BioRad) con el tampón de transferencia Tris/Glicina (Tris base $3 \mathrm{~g} / \mathrm{l}$, glicina 14,4 g/l y etanol al 10\%) durante unas 2 horas a 100 V. Para evitar el calentamiento del tampón se mantuvo la cubeta en un baño de agua con hielo durante todo el proceso.

\subsection{Inmunodetección de proteínas}

Las membranas con las proteínas se bloquearon incubándolas durante 1 hora con una solución de leche desnatada en polvo (Sveltesse-Nestlé) al 5\% disuelta en TBST (Tris$\mathrm{HCl} 20 \mathrm{mM} \mathrm{pH}$ 7,6, NaCl 137 mM y Tween-20 al 0,25\%). Tras el bloqueo la membrana se incubó con el anticuerpo primario correspondiente, diluido en la misma solución de bloqueo, durante toda la noche a $4 \stackrel{0}{ } \mathrm{C}$. Al día siguiente se lavó la membrana 2 veces durante 10 minutos con TBST para eliminar el anticuerpo que no se había unido. Después se incubó con el anticuerpo secundario correspondiente diluido en la solución de bloqueo durante 1 hora a temperatura ambiente. A continuación, se dieron otros 2 lavados de 10 minutos con TBST y se procedió al revelado. Los anticuerpos utilizados se detallan en la tabla I.

El revelado se llevó a cabo mediante la detección de la actividad peroxidasa (enzima ligada al anticuerpo secundario) por quimioluminiscencia. Para ello se empleo el kit WesternBright ${ }^{\mathrm{TM}} \mathrm{ECL}$ (Advansta). Cuando la intensidad de la señal era muy fuerte se usó el kit ECL ${ }^{\mathrm{TM}}$ Start (GE Healthcare). En ambos casos se siguieron las instrucciones proporcionadas por la casa comercial. La luminiscencia se detectó en películas fotosensibles (Medical X-Ray Film Blue, AGFA).

Tabla I. Anticuerpos utilizados en este trabajo.

\begin{tabular}{|c|c|c|}
\hline Anticuerpo & Dilución & Casa comercial \\
\hline Anti-GFP monoclonal (JL-8) & $1: 3000$ & BD Living Colors \\
\hline Anti-tubulina monoclonal (B-5-1-2) & $1: 10000$ & Sigma \\
\hline Anti-Cpy1 monoclonal (10A5) & $1: 150$ & ABCAM \\
\hline Anti-lgG de ratón unido a peroxidasa & $1: 10000$ & BioRad \\
\hline
\end{tabular}




\subsection{Ensayo de inmunoblot de colonias (dot blot)}

Los ensayos de dot blot de colonias se realizaron como se describió en (Hoya et al., 2017). En una membrana de nitrocelulosa dispuesta sobre una placa de EMM completo se depositaron 3,5 $\mu$ l de cultivos a una $\mathrm{DO}=2$. Después de incubar la membrana durante 4 días a $28^{\circ} \mathrm{C}$, esta se lavó extensivamente con TBST para eliminar las células y se bloqueó con una solución de albúmina de suero bovino al 1\% en TBST durante 1 hora a temperatura ambiente. Tras esto se procedió a la inmunodetección de Cpy1 incubando la membrana durante toda la noche con una dilución 1:150 del anticuerpo anti-Cpy1 (desarrollado frente a la proteína homóloga de S. cerevisiae) en albúmina de suero bovino al $1 \%$. Finalmente se procedió a la incubación con el anticuerpo secundario y al revelado, tal y como se ha descrito en el apartado anterior.

\section{Técnicas microscópicas}

\subsection{Microscopía de campo claro y contraste de fases}

La microscopía en campo claro y en contraste de fases se utilizó para la observación rutinaria de las células presentes en diferentes cultivos líquidos o sólidos. Con este fin se usaron los microscopios Leica DM RXS y Zeiss Axiophot.

\subsection{Microscopía de fluorescencia}

Para la adquisición de imágenes de muestras con fluorescencia, en función del experimento realizado (ver pies de cada figura), se utilizaron los siguientes microscopios:

Microscopio de epifluorescencia Leica DM RXA (objetivo 63x, apertura numérica 1,4) equipado con una lámpara de mercurio de 100 W (EBQ100) y una cámara digital Photometrics Sensys CCD. Las imágenes se adquirieron utilizando el programa Qfish 2.3.

Microscopio de epifluorescencia Nikon 90i (objetivo 100x, apertura numérica 1,45) equipado con una fuente de iluminación LED y con una cámara digital Hamamatsu ORCA ER. Las imágenes se adquirireron utilizando el programa Metamorph.

Microscopio Olympus IX71 (objetivo 100x, apertura numérica 1,4) equipado con un sistema personal Delta Vision (Applied Precision), con una lámpara de xenón como fuente 
de iluminación y la cámara digital Photometrics CoolSnap HQ2. Las imágenes se adquirieron utilizando el programa informático DeltaVision Softworx Resolve3D asociado al sistema. En general, con este equipo se adquirieron series de 3 planos en $Z$ a intervalos de 0,2 $\mu \mathrm{m}$ del plano medio celular. Tras la adquisición, las imágenes se procesaron con el programa de deconvolución Softworx DV (Applied Precision). Las imágenes mostradas son el plano medio de cada serie.

Microscopio confocal Spinning-Disk Olympus IX-81 (objetivo 100x, apertura numérica 1,4) equipado con un módulo confocal CSUX1-A1 (Yokogawa) y una cámara Evolve (Photometrics). Las imágenes se adquirieron usando el software Metamorph. Para los experimentos de colocalización se adquirieron series de 3 planos en $\mathrm{Z}$ a intervalos de 0,25 $\mu \mathrm{m}$ en la zona media de la célula. Las imágenes mostradas son el plano medio de cada serie, salvo que se indique otra cosa en la figura. Para analizar el tamaño de los puntos de Vps10-GFP se adquirieron planos a lo largo de toda la célula (series de 13 planos cada 0,32 $\mu \mathrm{m}$ ). Para los experimentos de seguimiento de vesículas (GFPSyb1/Cherry-FYVE) se capturaron series de 3 planos cada $0,25 \mu \mathrm{m}$ y cada 0,81 segundos.

En todos los casos se utilizaron los filtros adecuados para dejar pasar la luz de una determinada longitud de onda, según los espectros de excitación-emisión propios de los fluorocromos o proteínas fluorescentes utilizadas.

\subsubsection{Fluorescencia directa con proteínas de fusión.}

La proteína verde fluorescente (GFP) es un polipéptido de 238 aminoácidos procedente de la medusa Aequorea victoria (Chalfie et al., 1994). Esta proteína posee la capacidad de emitir luz verde cuando se excita con luz de longitud de onda de $488 \mathrm{~nm}$. Además, existe una proteína roja fluorescente (RFP) que procede del coral Dicosoma striata y emite fluorescencia roja cuando se excita con luz de una longitud de onda de $584 \mathrm{~nm}$. Existen variantes de ambas proteínas. En este trabajo se ha utilizado la EGFP (Enhanced Green Fluorescent Protein), más brillante que la GFP original, y tanto la mCherry, más brillante y estable que la RFP original, como esta última.

Todas estas proteínas mantienen su capacidad de emitir luz cuando se expresan de manera heteróloga en células eucariotas o procariotas. Por ello se suelen usar como 
sistema de detección in vivo de la expresión y localización subcelular de proteínas. Para usar esta técnica se fusiona en fase la secuencia de ADN que codifica la proteína fluorescente con la del gen de la proteína objeto de estudio. Con esta construcción se transforman las células de interés que expresarán la proteína de fusión. Esta se puede observar utilizando un microscopio de fluorescencia.

\subsubsection{Tinción con quinacrina}

La quinacrina es un compuesto que entra por difusión en la célula y emite fluorescencia en los orgánulos ácidos. Esto se debe a que en un compartimento celular con un $\mathrm{pH}$ ácido (como la vacuola), este compuesto se protona adquiriendo carga y perdiendo la capacidad de atravesar membranas, de forma que se acumula en su interior. Además, al adquirir carga positiva obtiene la capacidad de emitir fluorescencia (longitud de onda de 436/525 nm excitación/emisión). Para realizar la tinción con quinacrina (Sigma) se centrifugó $1 \mathrm{ml}$ de cultivo creciendo en fase exponencial en YES (1 minuto a $900 \times$ g) y se resuspendió en $500 \mu \mathrm{l}$ de medio YEPD (1\% extracto de levadura, 2\% peptona y $2 \%$ glucosa) tamponado con $50 \mathrm{mM}$ de $\mathrm{Na}_{2} \mathrm{HPO}_{4}(\mathrm{pH}=7,6)$. A esto se le añadieron $5 \mu \mathrm{l}$ de una solución de quinacrina a 20 mM en agua, para obtener una concentración final de quinacrina en las muestras de $200 \mu \mathrm{M}$, y se incubaron 5 minutos en oscuridad. Después las muestras se centrifugaron (10000 x g durante 10 segundos) y se lavaron con $500 \mu \mathrm{l}$ de glucosa al $2 \%$ tamponada con $50 \mathrm{mM}$ de $\mathrm{Na}_{2} \mathrm{HPO}_{4}(\mathrm{pH}=7,6)$. Finalmente, se volvieron a centrifugar las muestras (10000 x g durante 10 segundos), se eliminó el sobrenadante y se resuspendieron las células en una pequeña cantidad de la misma solución de glucosa, antes de ser visualizadas.

\subsubsection{Tinción con Blue CMAC}

La tinción con CellView Blue CMAC (ABP Biosciences) se ha utilizado para teñir el lumen de la vacuola (Davidson et al., 2016). Este compuesto fluorescente tiene un máximo de excitación/emisión a las longitudes de onda de 353/466 nm respectivamente. Para realizar la tinción se recogió $1 \mathrm{ml}$ de células $(900$ x g) creciendo en fase exponencial en YES y se lavaron dos veces con EMM completo. Tras esto las células se resuspendieron en $500 \mu \mathrm{l}$ del mismo medio con una concentración final del colorante de $100 \mu \mathrm{M}$ (añadido 
a partir de una solución a $10 \mathrm{mM}$ en DMSO) y se incubaron 30 minutos en un agitador orbital vertical a temperatura ambiente y en oscuridad. Después, las muestras se centrifugaron ( 1 minuto a $900 \mathrm{xg}$ ), se resuspendieron en $1 \mathrm{ml}$ de EMM y se incubaron 10 minutos en las condiciones anteriores. Finalmente, las células se recogieron por centrifugación (1 minuto a 900 x g), se resuspendieron en una pequeña cantidad de medio y se visualizaron.

\subsubsection{Tinción con FM4-64}

El FM4-64 [dibromuro de N-(3-trietilamoniopropil)-4-(6-(dietilamino) fenil) hexatrienil) piridina] es un colorante fluorescente lipofílico que entra en la célula a través del proceso de endocitosis. Así, se une a los lípidos de la membrana plasmática y es internalizado a través del sistema endosomal hasta las vacuolas (Vida and Emr, 1995). Para realizar la tinción con FM4-64 (Synaptored, Biotium) se centrifugó $1 \mathrm{ml}$ de cultivo (900 x g) creciendo en fase exponencial en YES. Se retiró parcialmente el sobrenadante dejando $100 \mu \mathrm{l}$ del mismo para resuspender las células. Posteriormente se añadieron 1,2 $\mu \mathrm{l}$ de una dilución 1:10 en agua de un stock de FM4-64 a 10 mM. Para visualizar la membrana de las vacuolas las muestras se incubaron 1 hora en un baño a $30^{\circ} \mathrm{C}$. Este compuesto tiene un máximo de excitación/emisión a una longitud de onda de 508/751 $\mathrm{nm}$

\subsubsection{Tratamiento con latrunculina $A$}

Este compuesto secuestra los monómeros de actina bloqueando la polimerización de los filamentos por el extremo (+). Como estos filamentos continúan despolimerizándose por el extremo (-), el efecto neto del tratamiento con latrunculina $A$ es la despolimerización de las estructuras de actina (Ayscough et al., 1997). Este tratamiento se llevó a cabo para evaluar si ciertas proteínas eran enviadas hacia la membrana plasmática y se acumulaban en presencia de esta droga, ya que la endocitosis en levaduras depende de la polimerización de actina y, por tanto, está inhibida en presencia de latrunculina A (Galletta et al., 2010). Para realizar el tratamiento con esta droga se tomaron $100 \mu \mathrm{l}$ de un cultivo creciendo en fase exponencial en YES y se le añadieron $2 \mu \mathrm{l}$ de latrunculina (de una solución en DMSO a $5 \mathrm{mM}$ ), para obtener una 
concentración final de la droga de $100 \mu \mathrm{M}$. La muestra se incubó durante 10-20 minutos a 30 ㄷ C dependiendo del experimento. Antes de visualizar la muestra se centrifugó (1 minuto a $900 \times$ g) para concentrar las células.

\subsubsection{Procesamiento y análisis de las imágenes adquiridas.}

Para los análisis de colocalización se utilizaron imágenes de 16-bits de dos canales diferentes capturadas con el microscopio confocal Spinning Disk. En estos experimentos se analizó la coincidencia de las partículas de un canal con las del otro en un único plano, para lo cual se utilizó el programa ImageJ. En primer lugar, las imágenes fueron filtradas con un median filter y con un unsharp mask para definir mejor las estructuras a cuantificar. Después se utilizó el plugin JACoP (Bolte and Cordelieres, 2006) para analizar la coincidencia de las partículas. Con este plugin se ajustó el threshold para cada imagen y se utilizó un método basado en objetos para cuantificar la coincidencia de las partículas. Para el análisis se tuvieron en consideración partículas mayores o iguales a 4 pixels $(0,071$ $\left.\mu m^{2}\right)$.

Para la cuantificación de la colocalización de los puntos de Ub:GFP-Cps1 y Cfr1-RFP las imágenes se filtraron como en el caso anterior. Después, se utilizó el canal azul (con la señal del colorante vacuolar (MAC) para sustraer la fluorescencia al canal verde y eliminar de esta forma la señal de Ub:GFP-Cps1 presente en la vacuola. La imagen del canal verde resultante se utilizó para analizar la colocalización con la del canal rojo utilizando el plugin JACoP como se ha descrito anteriormente.

Para analizar la presencia de PVEs agrandados, las imágenes de Vps10-GFP fueron filtradas como en los casos anteriores y se generó una proyección suma de los 13 planos capturados a lo largo de toda la célula. Sobre esta proyección se ajustó el threshold y se cuantificaron los puntos con un área mayor a 17 pixeles $\left(0,302 \mu \mathrm{m}^{2}\right)$ en las distintas cepas.

\section{Análisis estadístico de los resultados}

Los resultados obtenidos se han representado gráficamente y se han analizado estadísticamente utilizando el programa GraphPad Prism. El test estadístico usado en cada análisis se especifica en el pie de figura correspondiente. 


\section{Bases de datos y programas bioinformáticos utilizados}

Para la obtención de las secuencias de los diferentes genes y proteínas, así como para el análisis informático de sus secuencias se utilizaron los siguientes programas y bases de datos: SGD (base de datos de $S$. cerevisiae), PomBase (base de datos de $S$. pombe), BLAST (Basic Local Alignment Search Tool, programa de alineamiento de secuencias y búsqueda/comparación con las proteínas y genes depositados en las bases de datos) ClustalW (programa de alineamiento múltiple de secuencias de ADN y proteínas), ScanProsite (programa para buscar motivos en proteínas), ELM (Eukaryotic Linear Motif, programa de predicción de motivos en proteínas), Chromas (programa para la visualización de secuencias de ADN procedentes de secuenciación), SDM assist (programa para diseñar oligos para realizar mutagénesis dirigida), ApE (programa para analizar secuencias de ADN y hacer mapas de restricción). 

Anexo 



\section{Figuras suplementarias}

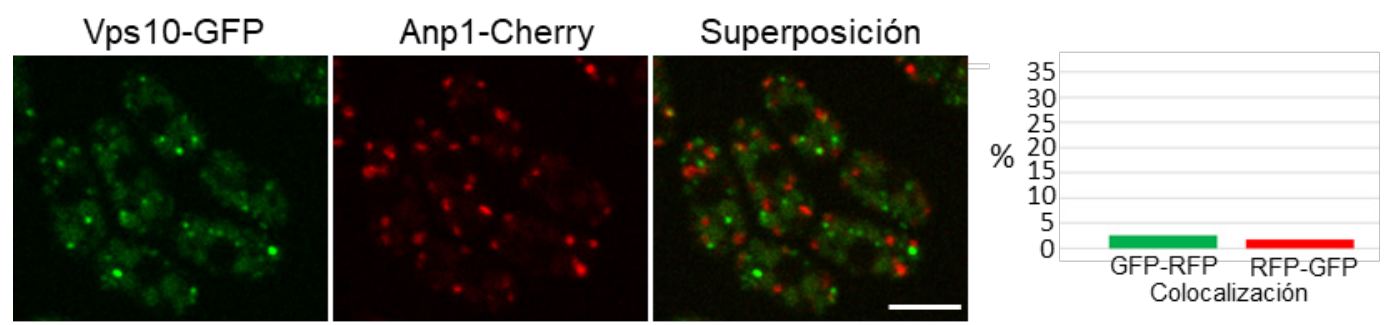

Figura S1. Colocalización de Vps10-GFP con el marcador de cis-Golgi Anp1-RFP. Las imágenes fueron capturadas con un microscopio confocal spinning disk y son el plano medio celular. Para las cuantificaciones se analizaron un mínimo de 400 puntos para cada marcador procedentes de un único experimento. Barras de escala, $5 \mu \mathrm{m}$.

A
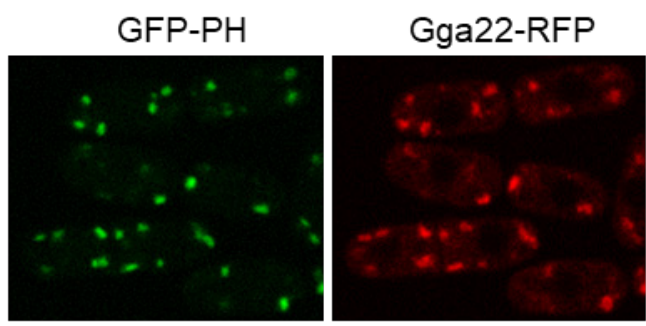

Superposición
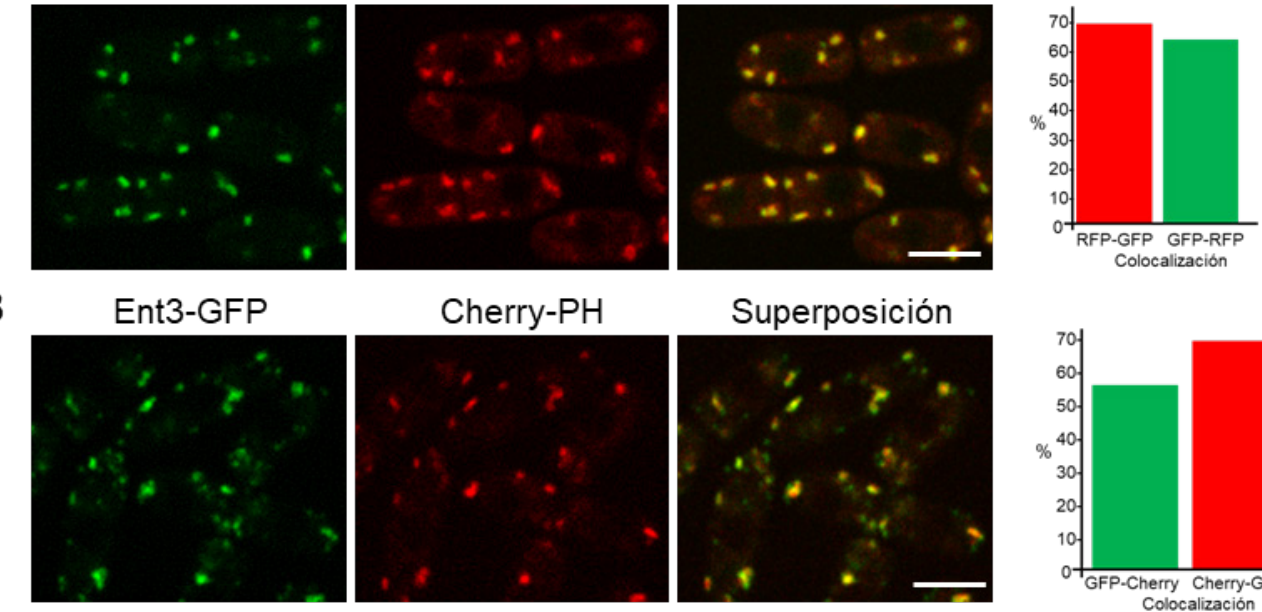

\section{Superposición}
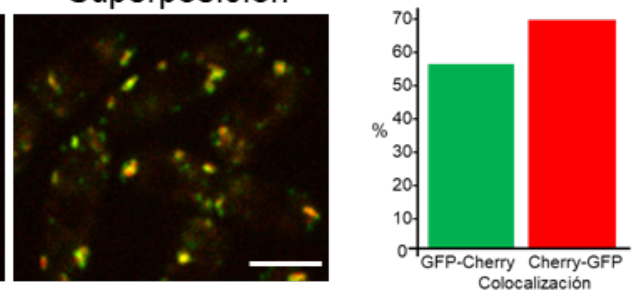

Figura S2. Coloclización de Ent3-GFP y Gga22-RFP con un marcador de TGN. A: colocalización de Gga22-RFP con el marcador de TGN GFP-PH. B: colocalización de Ent3-GFP con el marcador de TGN Cherry-PH. Las imágenes fueron capturadas con un microscopio confocal spinning disk y son el plano medio celular. Para las cuantificaciones se analizaron un mínimo de 300 puntos con cada marcador procedentes de un único experimento. Barras de escala, $5 \mu \mathrm{m}$. 


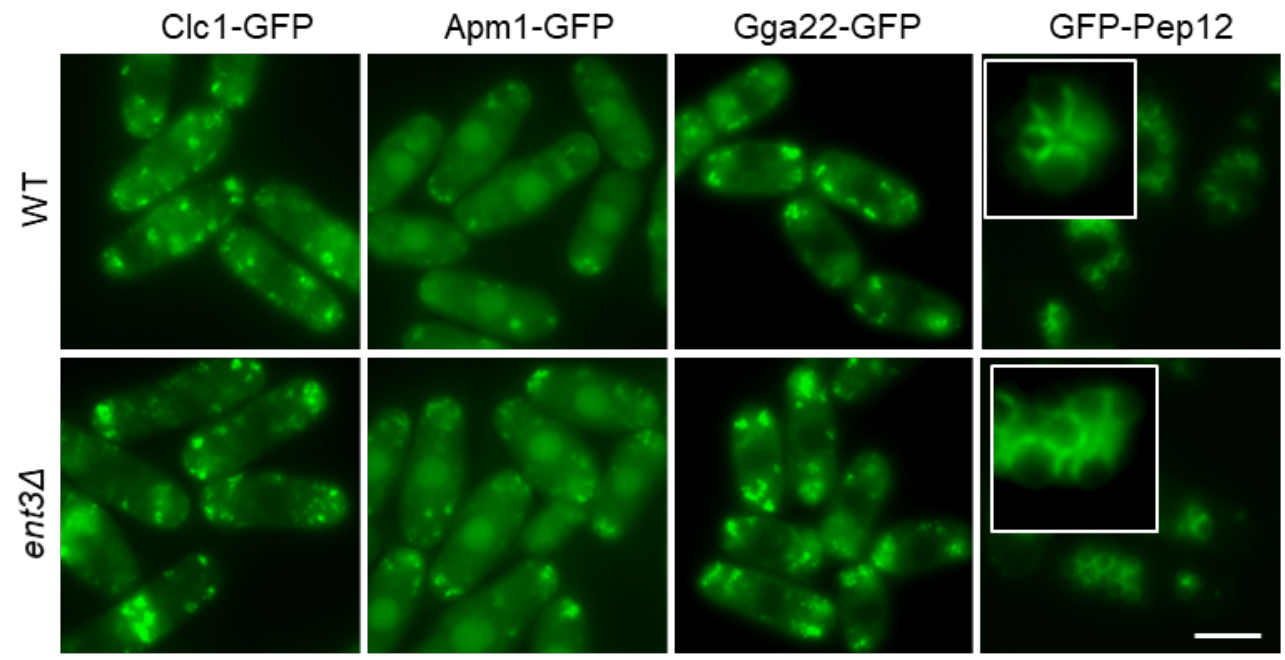

Figura S3. Distribución de diferentes proteínas involucradas en el tráfico vesicular en ausencia de Ent3. Para GFP-Pep12, los recuadros representan ampliaciones de las vacuolas. Las imágenes se capturaron con un microscopio de fluorescencia convencional Leica DM RXA. Barra de escala, $5 \mu \mathrm{m}$.

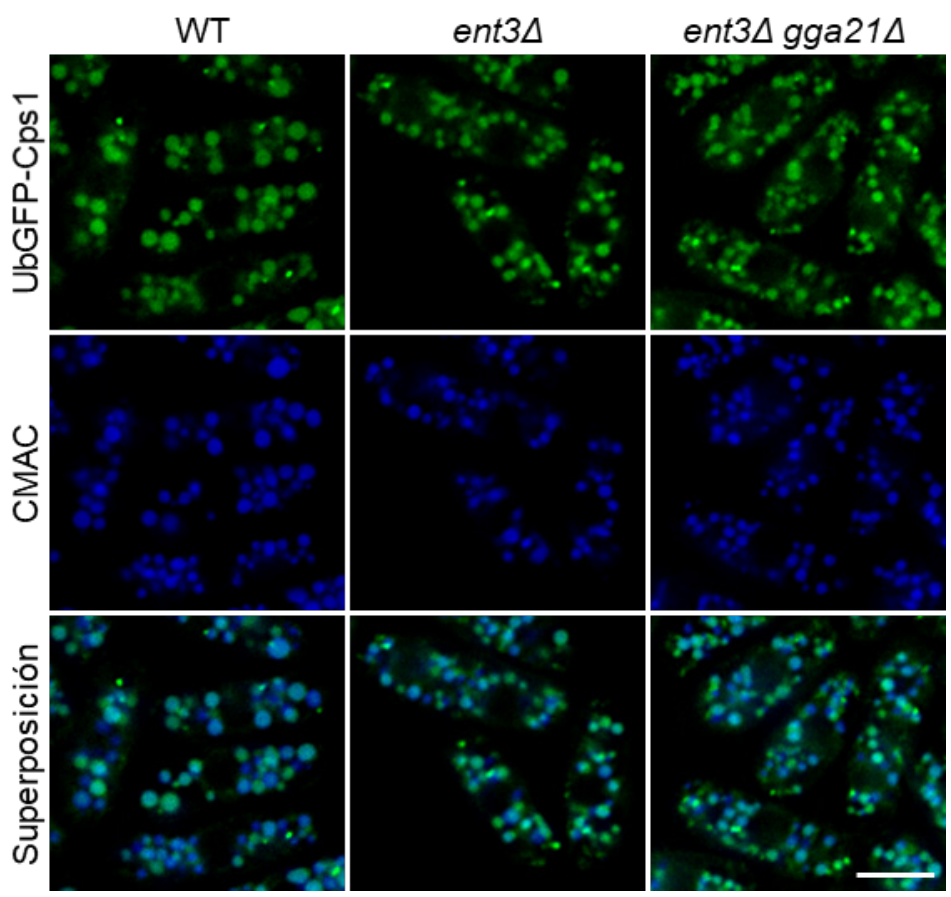

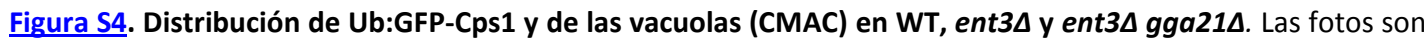
de un único plano, adquiridas con un sistema de microscopía Delta Vision. Barra de escala, $5 \mu \mathrm{m}$. 


\section{Tablas suplementarias.}

Tabla S1. Cepas usadas en este trabajo

\begin{tabular}{|c|c|c|}
\hline ESTIRPE & GENOTIPO & PROCEDENCIA \\
\hline \multicolumn{3}{|c|}{ Cepas de Schizosaccharomyces pombe } \\
\hline HVP30 & leu1-32 his3- $\Delta 1$ ura4- $\Delta 18$ ade6 $h$ - & Colección HVM \\
\hline HVP117 & leu1-32 his3- $\Delta 1$ ura4- $\Delta 18$ ade6 $h+$ & Colección HVM \\
\hline HVP1044 & cfr1::his3 ${ }^{+}$cfr1-RFP:ura4+ leu1-32 his3- $\Delta 1$ ura4- $\Delta 18$ ade6 h90 & Colección HVM \\
\hline HVP2092 & apm1::ura4 leu1-32 h- & T Kuno \\
\hline HVP2273 & GFP-syb1 leu1-32 h- & Y Toyoshima \\
\hline HVP3490 & apm1::ura4 ${ }^{+}$his3- $\Delta 1$ h- & Colección HVM \\
\hline HVP3664 & vps27::KAN leu1-32 ura4- $\triangle 18$ ade 6 h+ & P Perez \\
\hline HVP3701 & apm3::KAN leu1-32 ura4- $\triangle 18$ ade6 $h+$ & P Perez \\
\hline HVP3727 & apm1::ura4 ${ }^{+}$apm1-GFP:leu1 ${ }^{+}$leu1-32 ura4- $\Delta 18$ his3- $\Delta 1$ h- & Colección HVM \\
\hline HVP3739 & anp1-mCherry:ura4+ leu1-32 ura4- $\Delta 18$ ade6 $h+$ & S Oliferenko \\
\hline HVP3902 & GFP-Sec72::ura4 leu1-32 his3- $\Delta 1$ ura4 $h$ - & Este trabajo \\
\hline HVP3945 & pku70::his3 ${ }^{+}$leu1-32 his3- $\Delta 1$ ura4- $\Delta 18$ ade6 $h^{+}$ & I Hagan /YGRC \\
\hline HVP3953 & hph.171 h- & I Hagan /YGRC \\
\hline HVP3954 & gga21::KAN leu1-32 his3- $\Delta 1$ ura4- $\triangle 18$ ade6 $h-$ & Colección HVM \\
\hline HVP3956 & gga22::KAN leu1-32 his3- $\Delta 1$ ura4- $\Delta 18$ ade6 $h-$ & Colección HVM \\
\hline HVP3994 & gga21::KAN gga22::KAN his3- $\Delta 1$ h- & Colección HVM \\
\hline HVP4022 & pik3::KAN leu1-32 ura4- $\triangle 18$ ade6 $h+$ & P Perez \\
\hline HVP4068 & hph.171 leu1-32 his3- $\Delta 1$ ura4- $\Delta 18$ h+ & Este trabajo \\
\hline HVP4160 & $\begin{array}{l}\text { cfr1::his } 3^{+} \text {cfr1-RFP:ura4 }{ }^{+} \text {Pnda2:GFP-FYVE:Tnda2:NAT leu1-32 his3- } \Delta 1 \\
\text { ura4- } \Delta 18 \text { ade6 h? }\end{array}$ & Este trabajo \\
\hline HVP4243 & Pnda2:mCherry-FYVE:Tnda2:NAT leu1-32 his3- $\Delta 1$ ura4- $\Delta 18$ h+ & Este trabajo \\
\hline HVP4317 & gga22::KAN gga22-GFP:ura4+ leu1-32 his3- $\Delta 1$ ura4- $\Delta 18$ ade6 $h+$ & Colección HVM \\
\hline HVP4373 & gga22::KAN GFP-syb1:KAN $h ?$ & Colección HVM \\
\hline HVP4374 & gga21::KAN gga22::KAN GFP-syb1:KAN h? & Colección HVM \\
\hline HVP4504 & GFP-gos1:leu1 leu1-32 his3- $\Delta 1$ ura4- $\Delta 18$ ade6 $h$ - & Este trabajo \\
\hline HVP4509 & ent3::KAN leu1-32 his3- $\Delta 1$ ura4- $\Delta 18$ ade 6 h+ & P Perez \\
\hline HVP4523 & gga22::KAN Pnda2:mCherry-FYVE:Tnda2:NAT $h+$ & Este trabajo \\
\hline HVP4525 & gga21::KAN gga22::KAN Pnda2:mCherry-FYVE:Tnda2:NAT h+ & Este trabajo \\
\hline HVP4581 & ent3-GFP:KAN leu1-32 ura4- $\triangle 18 h-$ & Este trabajo \\
\hline HVP4637 & $\begin{array}{l}\text { gga22::KAN gga22-RFP:ura4+ Pnda2:GFP-FAPP1:Tnda2:NAT leu1-32 } \\
\text { his3- } \triangle 1 \text { ura4- } \triangle 18 \text { ade6 } h \text { ? }\end{array}$ & Este trabajo \\
\hline HVP4680 & clc1::KAN clc1-GFP:leu1 ${ }^{+}$leu1-32 his3- $\Delta 1$ ura4- $\Delta 18$ ade6? $h+$ & Colección HVM \\
\hline HVP4694 & vps35::NAT leu1-32 his3- $\Delta 1$ ura4- $\Delta 18$ ade6 $h+$ & Este trabajo \\
\hline HVP4695 & vps35::NAT leu1-32 his3- $\Delta 1$ ura4- $\Delta 18$ ade6 $h$ - & Este trabajo \\
\hline HVP4708 & vps10-GFP:KAN leu1-32 his3- $\triangle 1$ ura4- $\triangle 18$ ade6 $h$ - & Este trabajo \\
\hline HVP4709 & vps10-GFP:KAN leu1-32 his3- $\triangle 1$ ura4- $\triangle 18$ ade $6 \mathrm{ht}$ & Este trabajo \\
\hline HVP4714 & vps27-RFP:KAN leu1-32 his3- $\Delta 1$ ura4- $\Delta 18$ ade6 $h+$ & Este trabajo \\
\hline HVP4715 & vps27-RFP:KAN leu1-32 his3- $\Delta 1$ ura4- $\Delta 18$ ade6 $h$ - & Este trabajo \\
\hline HVP4730 & vps10-GFP:KAN gga21::KAN leu1-32 his3- $\Delta 1$ ura4- $\triangle 18$ ade 6 h+ & Este trabajo \\
\hline HVP4735 & vps10-GFP:KAN gga22::KAN leu1-32 his3- $\Delta 1$ ura4- $\triangle 18$ ade 6 h+ & Este trabajo \\
\hline
\end{tabular}




\begin{tabular}{|c|c|c|}
\hline HVP4737 & $\begin{array}{l}\text { vps10-GFP:KAN gga21::KAN gga22::KAN leu1-32 his3- } \triangle 1 \text { ura4- } \triangle 18 \\
\text { ade6 } h+\end{array}$ & Este trabajo \\
\hline HVP4746 & $\begin{array}{l}\text { ent3::KAN gga22::KAN gga22-GFP:ura4+ leu1-32 his3- } \triangle 1 \text { ura4- } \triangle 18 \\
\text { ade6 h- }\end{array}$ & Este trabajo \\
\hline HVP4751 & $\begin{array}{l}\text { vps10-GFP:KAN Pnda2:mCherry-FYVE:Tnda2:NAT leu1-32 his3- } \triangle 1 \\
\text { ura4- } \Delta 18 \mathrm{h+}\end{array}$ & Este trabajo \\
\hline HVP4752 & $\begin{array}{l}\text { vps10-GFP:KAN Pnda2:mCherry-FYVE:Tnda2:NAT leu1-32 his3- } \Delta 1 \\
\text { ura4- } \triangle 18 \text { h- }\end{array}$ & Este trabajo \\
\hline HVP4767 & vps10-GFP:KAN pik3::KAN leu1-32 his3? ura4- $\triangle 18$ ade6 h? & Este trabajo \\
\hline HVP4777 & ent3::KAN clc1::KAN clc1-GFP:leu1+ leu1-32 his3- $\Delta 1$ ura4- $\triangle 18$ ade6? h? & Este trabajo \\
\hline HVP4781 & ent3::KAN gga21::KAN leu1-32 his3? ura4- $\triangle 18$ ade6 $h+$ & Este trabajo \\
\hline HVP4782 & ent3::KAN gga22::KAN leu1-32 his3? ura4- $\triangle 18$ ade6 $h$ - & Este trabajo \\
\hline HVP4783 & ent3::KAN gga21::KAN gga22::KAN leu1-32 his3? ura4- $\Delta 18$ ade6 h+ & Este trabajo \\
\hline HVP4788 & vps27::KAN ent3::KAN leu1-32 ura4- $\triangle 18$ ade6 $h-$ & Este trabajo \\
\hline HVP4789 & $\begin{array}{l}\text { apm1::ura4 }{ }^{+} \text {apm1-GFP:leu1 }{ }^{+} \text {ent3::KAN leu1-32 ura4- } \Delta 18 \text { his3- } \Delta 1 \\
\text { ade6? h? }\end{array}$ & Este trabajo \\
\hline HVP4790 & $\begin{array}{l}\text { vps10-GFP:KAN Pnda2:mCherry-FYVE:Tnda2:NAT gga21::KAN leu1-32 } \\
\text { his3- } \Delta 1 \text { ura4- } \Delta 18 \text { h? }\end{array}$ & Este trabajo \\
\hline HVP4791 & $\begin{array}{l}\text { vps10-GFP:KAN Pnda2:mCherry-FYVE:Tnda2:NAT gga22::KAN leu1-32 } \\
\text { his3- } \triangle 1 \text { ura4- } \Delta 18 \text { h? }\end{array}$ & Este trabajo \\
\hline HVP4792 & $\begin{array}{l}\text { vps10-GFP:KAN Pnda2:mCherry-FYVE:Tnda2:NAT gga21::KAN } \\
\text { gga22::KAN leu1-32 his3- } \triangle 1 \text { ura4- } \triangle 18 \text { h? }\end{array}$ & Este trabajo \\
\hline HVP4805 & vps27::KAN gga21::KAN leu1-32 ura4- $\triangle 18$ ade6 $h-$ & Este trabajo \\
\hline HVP4806 & vps27::KAN gga21::KAN leu1-32 ura4- $\triangle 18$ ade6 $h+$ & Este trabajo \\
\hline HVP4808 & vps27::KAN gga21::KAN gga22::KAN leu1-32 ura4- $\triangle 18$ ade6 $h+$ & Este trabajo \\
\hline HVP4811 & $\begin{array}{l}\text { ent3-GFP:KAN gga21::KAN gga22::KAN leu1-32 his3- } \triangle 1 \text { ? ura4- } \triangle 18 \\
\text { ade6? h+ }\end{array}$ & Este trabajo \\
\hline HVP4814 & vps10-GFP:KAN ent3::KAN leu1-32 his3? ura4- $\triangle 18$ ade6 $h$ - & Este trabajo \\
\hline HVP4821 & vps10-GFP:KAN vps35::NAT leu1-32 his3- $\triangle 1$ ura4- $\triangle 18$ ade6 $h$ - & Este trabajo \\
\hline HVP4826 & $\begin{array}{l}\text { ent3-GFP:KAN Pnda2:Cherry-FAPP1:Tnda2:NAT leu1-32 his3- } \triangle 1 \text { ura4- } \\
\Delta 18 \text { ade6 } h+\end{array}$ & Este trabajo \\
\hline HVP4834 & vps10-GFP:KAN ent3::KAN gga21::KAN leu1-32 his3? ura4- $\triangle 18$ ade6 $h+$ & Este trabajo \\
\hline HVP4836 & vps10-GFP:KAN ent3::KAN gga22::KAN leu1-32 his3? ura4- $\triangle 18$ ade6 $h+$ & Este trabajo \\
\hline HVP4839 & $\begin{array}{l}\text { vps10-GFP:KAN ent3::KAN gga21::KAN gga22::KAN leu1-32 his3? ura4- } \\
\text { } 18 \text { ade6 } h \text { - }\end{array}$ & Este trabajo \\
\hline HVP4841 & vps10-GFP:KAN gga22::KAN vps35::NAT leu1-32 his3- $\triangle 1$ ura4- $\triangle 18$ h? & Este trabajo \\
\hline HVP4848 & vps10-GFP:KAN vps27::KAN leu1-32 his3? ura4- $\triangle 18$ ade6 $h+$ & Este trabajo \\
\hline HVP4850 & vps10-GFP:KAN ent3::KAN vps27::KAN leu1-32 his3? ura4- 118 ade6 $h+$ & Este trabajo \\
\hline HVP4857 & Pnda2:GFP-vti:Tnda2:NAT leu1-32 his3- $\Delta 1$ ura4- $\Delta 18$ h+ & Este trabajo \\
\hline HVP4866 & $\begin{array}{l}\text { vps10-GFP:KAN Pnda2:mCherry-FYVE:Tnda2:NAT ent3::KAN leu1-32 } \\
\text { his3- } \Delta 1 \text { ura4- } \triangle 18 \text { h- }\end{array}$ & Este trabajo \\
\hline HVP4876 & Pnda2:GFP-Pep12:Tnda2:NAT leu1-32 his3- $\Delta 1$ ura4- $\Delta 18$ h+ & Este trabajo \\
\hline HVP4877 & Pnda2:GFP-fsv1:Tnda2:NAT leu1-32 his3- $\Delta 1$ ura4- $\Delta 18 \mathrm{~h}+$ & Este trabajo \\
\hline HVP4878 & Pnda2:GFP-ykt6:Tnda2:NAT leu1-32 his3- $\Delta 1$ ura4- $\Delta 18$ h+ & Este trabajo \\
\hline HVP4879 & vph1-GFP:KAN leu1-32 his3- $\triangle 1$ ura4- $\Delta 18$ ade6 $h$ - & Este trabajo \\
\hline HVP4880 & vph1-GFP:KAN leu1-32 his3- $\triangle 1$ ura4- $\triangle 18$ ade6 h+ & Este trabajo \\
\hline HVP4883 & vph1-GFP:KAN ent3::KAN leu1-32 his3- $\Delta 1$ ura4- $\Delta 18$ ade6 $h+$ & Este trabajo \\
\hline HVP4885 & vph1-GFP:KAN gga22::KAN leu1-32 his3- $\triangle 1$ ura4- $\Delta 18$ ade6 $h+$ & Este trabajo \\
\hline
\end{tabular}




\begin{tabular}{|c|c|c|}
\hline HVP4887 & $\begin{array}{l}\text { vph1-GFP:KAN ent3::KAN gga22::KAN leu1-32 his3- } \triangle 1 \text { ura4- } \triangle 18 \text { ade6 } \\
\text { h+ }\end{array}$ & Este trabajo \\
\hline HVP4891 & vps10-GFP:KAN anp1-mCherry:ura4 $4^{+}$leu1-32 ura4- $\triangle 18$ ade6 $h ?$ & Este trabajo \\
\hline HVP4892 & $\begin{array}{l}\text { vps10-GFP:KAN cfr1::his3 }{ }^{+} \text {cfr1-RFP:ura4+ leu1-32 his3- } \Delta 1 \text { ura4- } \Delta 18 \\
\text { ade6 } h+\end{array}$ & Este trabajo \\
\hline HVP4897 & Pnda2:GFP-fsv1:Tnda2:NAT ent3::KAN leu1-32 his3- $\Delta 1$ ura4- $\Delta 18$ h- & Este trabajo \\
\hline HVP4899 & Pnda2:GFP-Pep12:Tnda2:NAT ent3::KAN leu1-32 his3- $\Delta 1$ ura4- $\Delta 18 \mathrm{~h}-$ & Este trabajo \\
\hline HVP4917 & $\begin{array}{l}\text { vps10-GFP:KAN Pnda2:mCherry-FYVE:Tnda2:NAT ent3::KAN } \\
\text { gga22::KAN leu1-32 his3- } \Delta 1 \text { ura4- } \triangle 18 \text { h+ }\end{array}$ & Este trabajo \\
\hline HVP4926 & $\begin{array}{l}\text { vps35-GFP:NAT ent3::KAN pku70::his3+ leu1-32 his3- } \Delta 1 \text { ura4- } \triangle 18 \text { ade6 } \\
\text { h- }\end{array}$ & Este trabajo \\
\hline HVP4930 & $\begin{array}{l}\text { vps35-GFP:NAT ent3::KAN gga22::KAN pku70::his3+ leu1-32 his3- } \Delta 1 \\
\text { ura4- } \triangle 18 \text { ade6 } h^{-}\end{array}$ & Este trabajo \\
\hline HVP4941 & fsv1::HPH leu1-32 his3- $\Delta 1$ ura4- $\Delta 18$ ade6 $h^{-}$ & Este trabajo \\
\hline HVP4942 & fsv1::HPH leu1-32 his3- $\Delta 1$ ura4- $\Delta 18$ ade6 $h^{+}$ & Este trabajo \\
\hline HVP4943 & $\begin{array}{l}\text { vps10-GFP:KAN cfr1::his3 }{ }^{+} \text {cfr1-RFP:ura4 }{ }^{+} \text {ent3::KAN leu1-32 his3- } \Delta 1 \\
\text { ura4- } \triangle 18 \text { ade6 } \text { h }^{+}\end{array}$ & Este trabajo \\
\hline HVP4946 & $\begin{array}{l}\text { vps10-GFP:KAN cfr1::his3 }{ }^{+} \text {cfr1-RFP:ura4 }{ }^{+} \text {gga22::KAN leu1-32 his3- } \Delta 1 \\
\text { ura4- } \Delta 18 \text { ade6 }{ }^{-}\end{array}$ & Este trabajo \\
\hline HVP4951 & $\begin{array}{l}\text { vps27-RFP:KAN gga21::KAN gga22::KAN leu1-32 his3- } \Delta 1 \text { ura4- } \Delta 18 \\
\text { ade6? } h-\end{array}$ & Este trabajo \\
\hline HVP4953 & $\begin{array}{l}\text { GFP-syb1:KAN Pnda2:mCherry-FYVE:Tnda2:NAT gga21::KAN } \\
\text { gga22::KAN leu1-32 his3? ura4? ade6? h? }\end{array}$ & Este trabajo \\
\hline HVP4964 & $\begin{array}{l}\text { Pnda2:GFP-fsv1:Tnda2:NAT gga21::KAN gga22::KAN leu1-32 his3- } \triangle 1 \\
\text { ura4- } \triangle 18 \text { h- }\end{array}$ & Este trabajo \\
\hline HVP4965 & $\begin{array}{l}\text { Pnda2:GFP-fsv1:Tnda2:NAT gga21::KAN gga22::KAN leu1-32 his3- } \Delta 1 \\
\text { ura4- } \Delta 18 \mathrm{~h}+\end{array}$ & Este trabajo \\
\hline HVP5002 & vps10-GFP:KAN fsv1::HPH leu1-32 his3- $\Delta 1$ ura4- $\Delta 18$ ade6 $h^{-}$ & Este trabajo \\
\hline HVP5003 & vps10-GFP:KAN fsv1::HPH leu1-32 his3- $\Delta 1$ ura4- $\Delta 18$ ade6 $h^{+}$ & Este trabajo \\
\hline HVP5016 & $\begin{array}{l}\text { Pnda2:GFP-Pep12:Tnda2:NAT gga21::KAN gga22::KAN leu1-32 his3- } \Delta 1 \\
\text { ura4- } \triangle 18 \text { ade6? } h \text { - }\end{array}$ & Este trabajo \\
\hline HVP5021 & Pnda2:GFP-pep12:Tnda2:NAT vs/1::KAN leu1-32 his3- $\Delta 1$ ura4- $\Delta 18$ h? & Este trabajo \\
\hline HVP5024 & $\begin{array}{l}\text { Pnda2:GFP-fsv1:Tnda2:NAT gga21::KAN gga22::KAN ent3::KAN leu1- } \\
32 \text { his3- } \triangle 1 \text { ura4- } \Delta 18 \text { h? }\end{array}$ & Este trabajo \\
\hline HVP5028 & 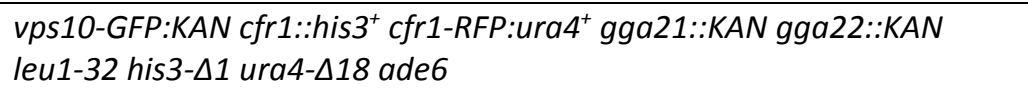 & Este trabajo \\
\hline HVP5029 & $\begin{array}{l}\text { vps10-GFP:KAN fsv1::HPH vps35::NAT leu1-32 his3- } \triangle 1 \text { ura4- } 18 \text { ade6 } \\
h^{-}\end{array}$ & Este trabajo \\
\hline HVP5033 & vps27-RFP::KAN fsv1::HPH leu1-32 his3- $\triangle 1$ ura4- $\triangle 18$ ade6 h+ & Este trabajo \\
\hline HVP5038 & vps35-GFP:NAT leu1-32 his3- $\Delta 1$ ura4- $\Delta 18$ ade6 $h+$ & Este trabajo \\
\hline HVP5039 & vps35-GFP:NAT leu1-32 his3- $\Delta 1$ ura4- $\Delta 18$ ade6 $h$ - & Este trabajo \\
\hline HVP5043 & $\begin{array}{l}\text { vps35-GFP:NAT gga21::KAN gga22::KAN leu1-32 his3- } \triangle 1 \text { ura4- } \triangle 18 \\
\text { ade6 } h \text { - }\end{array}$ & Este trabajo \\
\hline HVP5053 & Pnda2:GFP-fsv1:Tnda2:NAT vps35::NAT leu1-32 his3- $\Delta 1$ ura4- $\Delta 18$ h? & Este trabajo \\
\hline HVP5058 & vph1-GFP:KAN gga21::KAN leu1-32 his3- $\triangle 1$ ura4- $\triangle 18$ ade6 h+ & Este trabajo \\
\hline HVP5059 & $\begin{array}{l}\text { vph1-GFP:KAN gga21::KAN gga22::KAN leu1-32 his3- } \triangle 1 \text { ura4- } \triangle 18 \\
\text { ade6 } h \text { - }\end{array}$ & Este trabajo \\
\hline HVP5061 & Pnda2:GFP-pep12:Tnda2:NAT fsv1::HPH leu1-32 his3- $\triangle 1$ ura4- $\Delta 18$ h- & Este trabajo \\
\hline HVP5062 & Pnda2:GFP-pep12:Tnda2:NAT fsv1::HPH leu1-32 his3- $\Delta 1$ ura4- $\Delta 18$ h+ & Este trabajo \\
\hline
\end{tabular}




\begin{tabular}{|c|c|c|}
\hline HVP5064 & $\begin{array}{l}\text { Pnda2:GFP-fsv1:Tnda2:NAT gga22::KAN ent3::KAN leu1-32 his3- } \triangle 1 \\
\text { ura4- } \triangle 18 \mathrm{~h}-\end{array}$ & Este trabajo \\
\hline HVP5068 & vph1-GFP:KAN vps27::KAN leu1-32 his3- $\triangle 1$ ura4- $\Delta 18$ ade6 $h+$ & Este trabajo \\
\hline HVP5074 & Pnda2:GFP-ykt6Tnda2:NAT vps35::NAT leu1-32 his3- $\Delta 1$ ura4- $\Delta 18 \mathrm{h+}$ & Este trabajo \\
\hline HVP5076 & Pnda2:GFP-vti:Tnda2:NAT vps35::NAT leu1-32 his3- $\Delta 1$ ura4- $\Delta 18 \mathrm{h+}$ & Este trabajo \\
\hline HVP5077 & Pnda2:GFP-pep12:Tnda2:NAT vps35::NAT leu1-32 his3- $\Delta 1$ ura4- $\Delta 18$ h- & Este trabajo \\
\hline HVP5078 & GFP-gos1:leu1 vps35::NAT leu1-32 his3- $\Delta 1$ ura4- $\triangle 18$ ade 6 h+ & Este trabajo \\
\hline HVP5079 & GFP-gos1:leu1 vps35:NAT leu1-32 his3- $\Delta 1$ ura4- $\triangle 18$ ade6 $h$ - & Este trabajo \\
\hline HVP5080 & Pnda2:GFP-pep12:Tnda2:NAT apm3::KAN leu1-32 his3- $\Delta 1$ ura4- $\Delta 18$ h+ & Este trabajo \\
\hline HVP5084 & GFP-syb1::leu1+ leu1-32 vps35::NATh- & Este trabajo \\
\hline HVP5086 & isp6::ura4 ${ }^{+}$psp3::NATh- & $\begin{array}{l}\text { M Cabrera / E } \\
\text { Hidalgo }\end{array}$ \\
\hline HVP5094 & Pnda2:GFP-pep12:Tnda2:NAT apm3::KAN fsv1::HPH h+ & Este trabajo \\
\hline HVP5096 & cpy1-mCherry:KAN leu1-32 his3- $\Delta 1$ h- & L L Du \\
\hline HVP5099 & vp35-GFP::NAT fsv1::HPH leu1-32 his3- $\triangle 1$ ura4- $\triangle 18$ ade6 $h ?$ & Este trabajo \\
\hline HVP5104 & cpy1-mCherry:KAN fsv1::HPH leu1-32 his3- $\triangle 1$ h- & Este trabajo \\
\hline HVP5121 & vps10-GFP:KAN psp3::NATh- & Este trabajo \\
\hline HVP5122 & vps10-GFP isp6::ura4 ${ }^{+} h-$ & Este trabajo \\
\hline HVP5123 & vps10-GFP isp6::ura4 ${ }^{+}$psp3::NATh- & Este trabajo \\
\hline HVP5124 & vps10-GFP:KAN vps35::NAT psp3::NAT & Este trabajo \\
\hline HVP5125 & vps10-GFP:KAN vps35::NAT isp6::ura $4^{+}$ & Este trabajo \\
\hline HVP5127 & vps10-GFP vps35::NAT isp6::ura4 ${ }^{+}$psp3::NAT & Este trabajo \\
\hline HVP5128 & Pnda2:ub:GFP-cps1:Tnmt1:NAT leu1-32 his3- $\Delta 1$ ura4- $\Delta 18$ ade6 $h$ - & Este trabajo \\
\hline HVP5129 & Pnda2:ub:GFP-Cps1:Tnmt1:NAT fsv1::HPH leu1-32 his3- $\Delta 1$ ura4- $\Delta 18$ h- & Este trabajo \\
\hline HVP5130 & $\begin{array}{l}\text { Pnda2:ub:GFP-Cps1:Tnmt1:NAT fsv1::HPH leu1-32 his3- } \Delta 1 \text { ura4- } \triangle 18 \\
h+\end{array}$ & Este trabajo \\
\hline HVP5135 & $\begin{array}{l}\text { Pnda2:ub:GFP-cps1:Tnmt1:NAT gga21::KAN gga22::KAN leu1-32 his3- } \\
\Delta 1 \text { ura4- } \triangle 18 \text { ade6 } h \text { - }\end{array}$ & Este trabajo \\
\hline HVP5150 & $\begin{array}{l}\text { Pnda2:GFP-fsv1:Tnda2:NAT cfr1-RFP:ura4 }{ }^{+} \text {cfr1::his3 }{ }^{+} \text {leu1-32 his3- } \Delta 1 \\
\text { ura4- } \Delta 18 h \text { ? }\end{array}$ & Este trabajo \\
\hline HVP5153 & vps10-GFP:KAN gga21::KAN gga22::KAN isp6::ura4 ${ }^{+} h+$ & Este trabajo \\
\hline HVP5155 & vps10-GFP:KAN gga21::KAN gga22::KAN psp3::NAT h+ & Este trabajo \\
\hline HVP5157 & vps10-GFP:KAN gga21::KAN gga22::KAN isp6::ura4+ psp3::NAT h- & Este trabajo \\
\hline HVP5162 & $\begin{array}{l}\text { Pnda2:GFP-fsv1:Tnda2:NAT vps27-RFP:KAN leu1-32 his3- } \triangle 1 \text { ura4- } \triangle 18 \\
h ?\end{array}$ & Este trabajo \\
\hline HVP5168 & $\begin{array}{l}\text { Pnda2:ub:GFP-cps1:Tnmt1:NAT vps27::KAN leu1-32 his3- } \triangle 1 \text { ura4- } \triangle 18 \\
\text { ade6 } h \text { - }\end{array}$ & Este trabajo \\
\hline HVP5200 & nhx1-GFP:KAN leu1-32 his3- $\Delta 1$ ura4- $\triangle 18$ ade6 $h$ - & Este trabajo \\
\hline HVP5204 & $\begin{array}{l}\text { nhx1-GFP:KAN gga21::KAN gga22::KAN leu1-32 his3- } \triangle 1 \text { ura4- } \triangle 18 \text { ade6 } \\
\text { h? }\end{array}$ & Este trabajo \\
\hline HVP5205 & $\begin{array}{l}\text { Pnda2.ub:GFP-cps1:Tnmt1:NAT ent3::KAN leu1-32 his3- } \triangle 1 \text { ura4- } \triangle 18 \\
\text { ade6 } h \text { ? }\end{array}$ & Este trabajo \\
\hline HVP5206 & $\begin{array}{l}\text { vps10-GFP:KAN Pnda2:mCherry-FYVE:Tnda2:NAT apm1::ura4 }{ }^{+} \text {leu1-32 } \\
\text { his3- } \triangle 1 \text { ura4- } \Delta 18 \text { h? }\end{array}$ & Este trabajo \\
\hline HVP5212 & $\begin{array}{l}\text { vps10-GFP:KAN Pnda2:mCherry-FYVE:Tnda2:NAT ent3::KAN } \\
\text { gga21::KAN gga22::KAN leu1-32 his3- } \triangle 1 \text { ura4- } \Delta 18 \text { h? }\end{array}$ & Este trabajo \\
\hline HVP5213 & 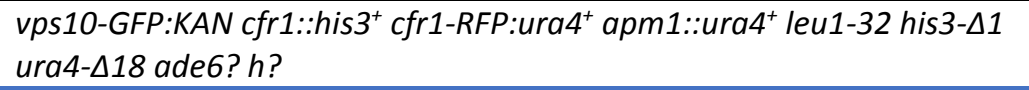 & Este trabajo \\
\hline
\end{tabular}




\begin{tabular}{|c|c|c|}
\hline HVP5224 & 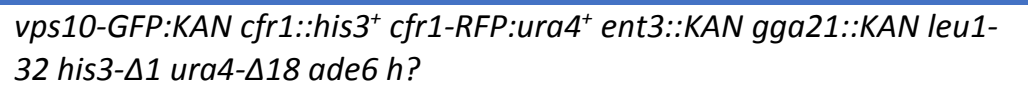 & Este trabajo \\
\hline HVP5225 & 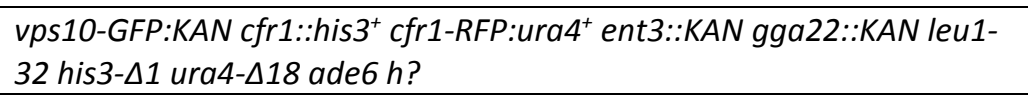 & Este trabajo \\
\hline HVP5226 & $\begin{array}{l}\text { vps10-GFP:KAN cfr1::his3 }{ }^{+} \text {cfr1-RFP:ura } 4^{+} \text {ent3::KAN gga21::KAN } \\
\text { gga22::KAN leu1-32 his3- } \Delta 1 \text { ura4- } \Delta 18 \text { ade6 } h-\end{array}$ & Este trabajo \\
\hline HVP5227 & $\begin{array}{l}\text { Pnda2:ub:GFP-cps1:Tnmt1:NAT ent3::KAN gga21::KAN leu1-32 his3- } \Delta 1 \\
\text { ura4- } \triangle 18 \text { ade6 h? }\end{array}$ & Este trabajo \\
\hline HVP5228 & $\begin{array}{l}\text { Pnda2:ub:GFP-cps1:Tnmt1:NAT ent3::KAN gga22::KAN leu1-32 his3- } \triangle 1 \\
\text { ura4- } \triangle 18 \text { ade6 h? }\end{array}$ & Este trabajo \\
\hline HVP5229 & $\begin{array}{l}\text { Pnda2:ub:GFP-cps1:Tnmt1:NAT ent3::KAN gga21::KAN gga22::KAN } \\
\text { leu1-32 his3- } \Delta 1 \text { ura4- } \triangle 18 \text { ade6 } h \text { ? }\end{array}$ & Este trabajo \\
\hline HVP5230 & $\begin{array}{l}\text { isp6-GFP:KAN Pnda2:mCherry-FYVE:Tnda2:leu1+ leu1-32 his3- } \Delta 1 \text { ura4- } \\
\Delta 18 \text { ade6 h? }\end{array}$ & Este trabajo \\
\hline HVP5231 & 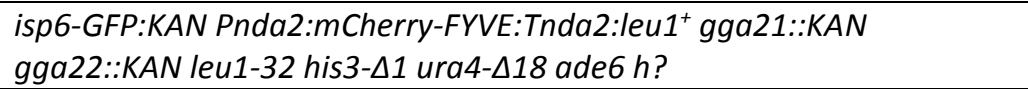 & Este trabajo \\
\hline HVP5234 & Pnda2:GFP-fsv1TM:Tnda2:NAT leu1-32 his3- $\Delta 1$ ura4- $\Delta 18 \mathrm{ht}$ & Este trabajo \\
\hline HVP5235 & Pnda2:GFP-fsv1TMSN:Tnda2:NAT leu1-32 his3- $\Delta 1$ ura4- $\Delta 18 \mathrm{h+}$ & Este trabajo \\
\hline HVP5236 & Pnda2:GFP-fsv1 $\Delta N C C: T n d a 2: N A T$ leu1-32 his3- $\Delta 1$ ura4- $\Delta 18 \mathrm{h+}$ & Este trabajo \\
\hline HVP5237 & Pnda2:GFP-fsv1DNC1:Tnda2:NAT leu1-32 his3- $\Delta 1$ ura4- $\Delta 18 \mathrm{h+}$ & Este trabajo \\
\hline HVP5238 & 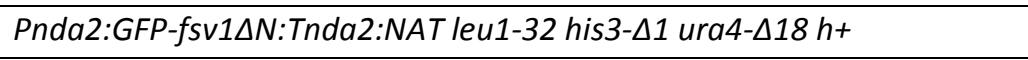 & Este trabajo \\
\hline HVP5246 & $\begin{array}{l}\text { Pnda2:GFP-fsv1 fsv1 } \triangle N C C: T n d a 2: N A T \text { vps35::NAT leu1-32 his3- } \Delta 1 \\
\text { ura4- } \Delta 18 \mathrm{ht}\end{array}$ & Este trabajo \\
\hline HVP5247 & GFP-Sec72::ura4 ${ }^{+}$fsv1::HPH leu1-32 his3- $\Delta 1$ ura4 $h ?$ & Este trabajo \\
\hline HVP5253 & $\begin{array}{l}\text { vps10-GFP:KAN Pnda2:mCherry-FYVE:Tnda2:NAT apm3::KAN } \\
\text { gga21::KAN gga22::KAN leu1-32 his3- } \Delta 1 \text { ura4- } \Delta 18 \text { h? }\end{array}$ & Este trabajo \\
\hline HVP5255 & $\begin{array}{l}\text { cfr1::his3 } 3^{+} \text {cfr1-RFP:ura4 } 4^{+} \text {Pnda2:GFP-FYVE:Tnda2:NAT gga21::KAN } \\
\text { gga22::KAN leu1-32 his3- } \Delta 1 \text { ura4- } \Delta 18 \text { ade6 h? }\end{array}$ & Este trabajo \\
\hline HVP5263 & pREP41x vps10-GFP:KAN leu1-32 his3- $\Delta 1$ ura4- $\Delta 18$ ade6 $h+$ & Este trabajo \\
\hline HVP5264 & 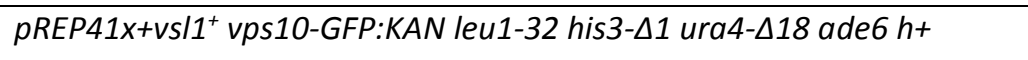 & Este trabajo \\
\hline HVP5265 & pREP41x vps10-GFP:KAN fsv1::HPH leu1-32 his3- $\Delta 1$ ura4- $\triangle 18$ ade6 $h+$ & Este trabajo \\
\hline HVP5266 & $\begin{array}{l}\text { pREP41x+vs/1+ vps10-GFP:KAN fsv1::HPH leu1-32 his3- } \Delta 1 \text { ura4- } \Delta 18 \\
\text { ade6 } h+\end{array}$ & Este trabajo \\
\hline HVP5267 & $\begin{array}{l}\text { Pnda2:ub:GFP-cps1:Tnmt1:NAT cfr1::his3 }{ }^{+} \text {cfr1-RFP:ura4 }{ }^{+} \text {leu1-32 his3- } \\
\Delta 1 \text { ura4- } 18 \text { ade6 } h-\end{array}$ & Este trabajo \\
\hline HVP5268 & 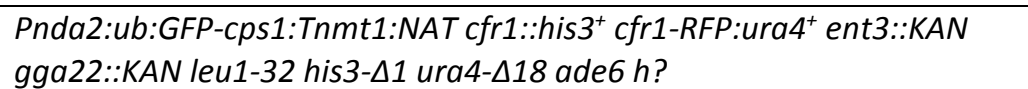 & Este trabajo \\
\hline HVP5269 & $\begin{array}{l}\text { Pnda2:ub:GFP-cps1:Tnmt1:NAT cfr1::his3 } 3^{+} \text {cfr1-RFP:ura4 }{ }^{+} \text {gga21::KAN } \\
\text { gga22::KAN leu1-32 his3- } \Delta 1 \text { ura4- } \Delta 18 \text { ade6 } h \text { ? }\end{array}$ & Este trabajo \\
\hline HVP5270 & $\begin{array}{l}\text { Pnda2:ub:GFP-cps1:Tnmt1:NAT Pnda2:mCherry-FYVE:Tnda2:leu1 }{ }^{+} \\
\text {leu1-32 his3- } \Delta 1 \text { ura4- } \Delta 18 \text { ade6? h+ }\end{array}$ & Este trabajo \\
\hline HVP5272 & $\begin{array}{l}\text { Pnda2:ub:GFP-cps1:Tnmt1:NAT Pnda2:mCherry-FYVE:Tnda2:leu1 }{ }^{+} \\
\text {gga21::KAN gga22::KAN leu1-32 his3- } \Delta 1 \text { ura4- } \Delta 18 \text { ade6? } h \text { ? }\end{array}$ & Este trabajo \\
\hline HVP5273 & $\begin{array}{l}\text { Pnda2:ub:GFP-cps1:Tnmt1:NAT Pnda2:mCherry-FYVE:Tnda2:leu1 }{ }^{+} \\
\text {ent3::KAN gga22::KAN leu1-32 his3- } \Delta 1 \text { ura4- } \Delta 18 \text { ade6? h? }\end{array}$ & Este trabajo \\
\hline HVP5276 & 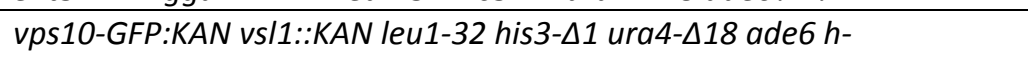 & Este trabajo \\
\hline HVP5279 & $\begin{array}{l}\text { cpy1-mCherry:KAN Pnda2:GFP-FYVE:Tnda2:NAT leu1-32 his3-U1ura4? } \\
\text { ade6? h? }\end{array}$ & Este trabajo \\
\hline HVP5282 & $\begin{array}{l}\text { cpy1-mCherry:KAN Pnda2:GFP-FYVE:Tnda2:NAT gga21::KAN } \\
\text { gga22::KAN leu1-32 his3- } 1 \text { 1ura4? ade6? h? }\end{array}$ & Este trabajo \\
\hline HVP5287 & vs/1::KAN leu1-32 his3- $\triangle 1$ ura4- $\Delta 18$ ade6 $h-$ & Este trabajo \\
\hline
\end{tabular}




\begin{tabular}{|c|c|c|}
\hline HVP5288 & vs/1::KAN leu1-32 his3- $\Delta 1$ ura4- $\triangle 18$ ade 6 h+ & Este trabajo \\
\hline HVP5294 & vps10-GFP:KAN ent3::KAN gga21::KAN gga22::KAN isp6::ura4 ${ }^{+}$h90 & Este trabajo \\
\hline HVP5301 & vps10-GFP:KAN ent3::KAN gga22::KAN isp6::ura4 ${ }^{+} h-$ & Este trabajo \\
\hline HVP5314 & $\begin{array}{l}\text { vps10-GFP:KAN Pnda2:mCherry-FYVE:Tnda2:NAT ent3::KAN } \\
\text { gga21::KAN leu1-32 his3- } \Delta 1 \text { ura4- } \triangle 18 \text { h- }\end{array}$ & Este trabajo \\
\hline HVP5315 & $\begin{array}{l}\text { Pnda2:GFP-Pep12:Tnda2:NAT ent3::KAN gga22::KAN leu1-32 his3- } \Delta 1 \\
\text { ura4- } \triangle 18 \text { ade6? h+ }\end{array}$ & Este trabajo \\
\hline HVP5319 & $\begin{array}{l}\text { GFP-syb1:KAN Pnda2:mCherry-FYVE:Tnda2:NAT ent3::KAN } \\
\text { gga22::KAN leu1-32 his3? ura4? ade6? h? }\end{array}$ & Este trabajo \\
\hline HVP5320 & $\begin{array}{l}\text { GFP-syb1:KAN Pnda2:mCherry-FYVE:Tnda2:NAT ent3::KAN } \\
\text { gga21::KAN gga22::KAN leu1-32 his3? ura4? ade6? h? }\end{array}$ & Este trabajo \\
\hline HVP5331 & $\begin{array}{l}\text { Pnda2:GFP-fsv1 } \triangle N C C\left(Y_{184} A ; M_{186} A\right): T n d a 2: N A T \text { leu1-32 his3- } \Delta 1 \text { ura4- } \\
\Delta 18 h+\end{array}$ & Este trabajo \\
\hline HVP5346 & $\begin{array}{l}\text { vps10-GFP:KAN fsv1::HPH vps35::NAT apm3::KAN leu1-32 his3- } \triangle 1 \\
\text { ura4- } \triangle 18 \mathrm{~h} \text { ? }\end{array}$ & Este trabajo \\
\hline HVP5368 & Pnda2:ub:GFP-Cps1:Tnmt1:NAT vs/1::KAN leu1-32 his3- $\triangle 1$ ura4- $\Delta 18$ h? & Este trabajo \\
\hline HVP5369 & Pnda2:GFP-fsv1 1 INT:Tnda2:NAT leu1-32 his3- $\Delta 1$ ura4- $\Delta 18$ h+ & Este trabajo \\
\hline HVP5370 & Pnda2:GFP-fsv1 $\triangle S N: T n d a 2: N A T$ leu1-32 his3- $\Delta 1$ ura4- $\Delta 18$ h+ & Este trabajo \\
\hline \multicolumn{3}{|c|}{ Cepas de Escherichia coli } \\
\hline DH5 $\alpha$ & $\begin{array}{l}\text { supE44, lacU169 (80lacZM15), hsdR17, RecA1, endA1, gyrA96, thi-1, } \\
\text { relA1 }\end{array}$ & Invitrogen \\
\hline CJ236 & dut-1, ung-1, thi-1, relA-1; $p C J 104\left(\mathrm{Cm}^{r}\right)$ & BioRad \\
\hline DH10B & $\begin{array}{l}F^{\prime} \text { mcrA } \Delta(m r r-h s d \text { RMS-mor } B C), \phi 80 \text { dlac } Z \Delta M 15, \Delta l a c X 74 \text {, endA1, } \\
\text { recA1, deoR } \Delta \text { (ara,leu)7697, araD139 galU galK nupG rpsL } \lambda \text { - }\end{array}$ & Invitrogen \\
\hline
\end{tabular}

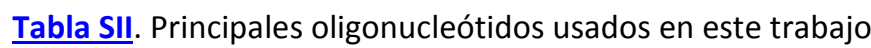

\begin{tabular}{|c|c|c|}
\hline NOMBRE & SECUENCIA 5'-3' & UTILIDAD \\
\hline PndaPst-F & TATATACTGCAGACGCTTAATGCATTTATTGCA & $\begin{array}{l}\text { Clonación promotor } \\
\text { nda2 }^{+}\end{array}$ \\
\hline PndaApa-R & TATATAGGGCCCAATTTGTGATAATAACGAATG & $\begin{array}{l}\text { Clonación promotor } \\
\text { nda2 }^{+}\end{array}$ \\
\hline GFPApa-F & TATATAGGGCCCATGAAAGGAGAAGAACTTTTCACT & Clonación GFP \\
\hline GFPMlu-R & TATATAACGCGTTTTGTATAGTTCATCCATGCCATG & Clonación GFP \\
\hline GFPNotA-F & TATATATAGGCGGCCGCGCTGCTGCTGCTGCT & Clonación GFP \\
\hline GFPNotA-R & TATATATAGCGGCCGCCAGCAGCAGCAGCAGCAGC & Clonación GFP \\
\hline Cherry-ApaF & $\begin{array}{l}\text { TATATATAGGGCCCATGGCTGCCGCAGCCGCTGCAGTGAGCAAGG } \\
\text { GCGAGGAGGAT }\end{array}$ & Clonación mCherry \\
\hline Cherry-MluR & TATATAACGCGTTGCAGCCGCTGCTGCAGCCGCTGC & Clonación mCherry \\
\hline FYVEMlu-F & TATATAACGCGTTGGCAATCTAGTCAACGGAGAG & Clonación dominio FYVE \\
\hline FYVESal-R & TATATAGTCGACTTATCCTTGCAAGTCATTGAAACATGC & Clonación dominio FYVE \\
\hline FAPPMlu-F & TATATAACGCGTATGGAGGGTGTGTTGTACAAG & Clonación dominio $\mathrm{PH}$ \\
\hline FAPPSal-R & TATATAGTCGACTCATGTATCAGTCAAACATGCTTTG & Clonación dominio $\mathrm{PH}$ \\
\hline TndaSal-F & TATATAGTCGACTAATTTATCCAATAATCGCTTTTATAC & 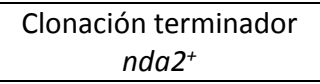 \\
\hline TndaSac-R & TATATAGAGCTCCCACAGAAAGGAGAAATTGA & $\begin{array}{c}\text { Clonación terminador } \\
\text { nda2 }^{+}\end{array}$ \\
\hline
\end{tabular}




\begin{tabular}{|c|c|c|}
\hline Pep12_Mlu-F & TATATATAACGCGTATGTCTTTTGTTGACTTGGAGCAAG & Clonación de pep12+ \\
\hline Pep12_Sal-R & TATATATAGTCGACCTAGCCCATTATTAAAGCTGTTAA & Clonación de pep $12^{+}$ \\
\hline Ykt6_Mlu-F & TATATATAACGCGTATGAAGCTGTATTCTGTCTCTATAC & Clonación de $y k t 6^{+}$ \\
\hline Ykt6_Sal-R & TATATATAGTCGACTTAAGCTATTATACAGCAAGAATTT & Clonación de $y k t 6^{+}$ \\
\hline Vti1MluATG-F & TATATAACGCGTATGGAGACGTACGAGCAAGAA & Clonación de vti1 ${ }^{+}$ \\
\hline VtiStpSal-R & TATATAGTCGACCTAACGAAATTTGCTATAAAG & Clonación de vti1 ${ }^{+}$ \\
\hline Fsv1_Mlu-F & TATATATAACGCGTATGTCAAATTTGCTTCTGATCATTG & Clonación de $f s v 1^{+}$ \\
\hline Fsv1_Sal-R & TATATATAGTCGACCTAAATGGAAGCCACAAGTAATAAC & Clonación de $f s v 1^{+}$ \\
\hline Fsv1TM & TATATATAACGCGTGCTAAACAGTATCCCAGATGCTTT & Clonación Fsv1TM \\
\hline Fsv1TM+SN & TATATATAACGCGTAACGTTTTGGCTCAAATGCATCAG & Clonación Fsv1TM+SN \\
\hline Fsv1DN+CC & TATATATAACGCGTATTCCTGCTGACGGAACAAGTGCC & Clonación Fsv1 $1 \Delta+C C$ \\
\hline Fsv1DN+C1 & TATATATAACGCGTTACAGAGTACGAGAATCCGAAGCA & Clonación Fsv1 $\Delta N+C 1$ \\
\hline Fsv1DN & TATATATAACGCGTAATCCCGATGAAGAAATTGAGTCT & Clonación Fsv1 $1 \Delta N$ \\
\hline Fsv1Dint-R & TTGCTGATGCATTTGAGCCAACTGCAGTGAGGATGCACGCCGCTG & Clonación Fsv1 $1 \Delta I N T$ \\
\hline Fsv1DSN-R & $\begin{array}{l}\text { CTTTCGGCTGACCTTGTTTAATCGCTGCAGTACGTTTATGGGATCA } \\
\text { GGGTCATTGCC }\end{array}$ & Clonación Fsv1 $\triangle S N$ \\
\hline Fsv1yAm-R & TTCGGACAATTCTGTATTCGCTGCAGCTCCCATCCGCTTTTGC & $\begin{array}{c}\text { Clonación Fsv1 } \triangle N+C C \\
(A A A)\end{array}$ \\
\hline UbApa-F & TATATATATGGGCCCATGCAGATTTTTCGTCAAGACATTA & Clonación ubi4 ${ }^{+}$ \\
\hline UbHnd-R & AAATTTAAAAAGCTTACCGCCACGAAGACGAAGAACAA & Clonación ubi4 ${ }^{+}$ \\
\hline Cps1Pst-F & ATATATATCTGCAGATGTCCACTTCTAACGACCCAGTT & Clonación cps1 $1^{+}$ \\
\hline Cps1SalStp-R & AAATTTAAAGTCGACTTACGCTTCTTCACCGGAATCAGA & Clonación cps1 $1^{+}$ \\
\hline Gos1 ApaF & TATATAGGGCCCACCGACTGAAAGTTGGTTGAG & $\begin{array}{l}\text { Clonación promotor } \\
\text { gos } 1^{+}\end{array}$ \\
\hline Gos1 NotR & TATATATAGCGGCCGCCCATGGCTAAAGAGATCTTCAAA & $\begin{array}{l}\text { Clonación promotor } \\
\text { gos } 1^{+}\end{array}$ \\
\hline Gos1 NotF & TATATATAGGCGGCCGCATGAAGTCTATGCTTTTGAGAG & Clonación ORF gos $1^{+}$ \\
\hline Gos1 ClaIR & TATATAATCGATTTAATGAAAAAAAAGGAACAAAAGC & Clonación ORF gos $1^{+}$ \\
\hline Gos1 ClaF & TATATAATCGATGTTGCATGTTTTATGAAACGT & $\begin{array}{l}\text { Clonación terminador } \\
\text { gos } 1^{+}\end{array}$ \\
\hline Gos1 SaclR & TATATAGAGCTCGCCAATTTTAAGTCTTGAATTATATTAC & $\begin{array}{l}\text { Clonación terminador } \\
\text { gos } 1^{+}\end{array}$ \\
\hline VsI1XhATG-F & TATATATACTCGAGATGGCGCTAAAAATTAAAATACCAG & Clonación vs/1+ \\
\hline VsI1StpSm-R & TTTAAATACCCGGGTTAACCCAATTTGCGAAGGCCAGC & Clonación vs/1 $1^{+}$ \\
\hline Vsl1D-F1 & $\begin{array}{l}\text { TTATAACGATAGTGCAGTAAATCCGATACAGTAGTCTGTTGTTCAT } \\
\text { GAACTCATTGTTGATCAACCTGTTCATAGCAAGTCGGATCCCCGGG } \\
\text { TTAATTAA }\end{array}$ & Deleción vs/1+ \\
\hline Vsl1D-R1 & $\begin{array}{l}\text { TAGAAAACAAGACAAAACTGCAAAAGAAGATTCCATTAAATTTCG } \\
\text { TGAAATTAAATCAAATACTCATAAACACCCAAATAGAATTCGAGCT } \\
\text { CGTTTAAAC }\end{array}$ & Deleción vs/1+ \\
\hline Vsl1-F1 & GATAATCGTAAAGGCATCTCGC & $\begin{array}{c}\text { Comprobación deleción } \\
v s / 1^{+}\end{array}$ \\
\hline Vsl1-R1 & AGGAACTACAAGCCAAACCAAA & $\begin{array}{c}\text { Comprobación deleción } \\
v s / 1^{+}\end{array}$ \\
\hline fsv1D-F & $\begin{array}{l}\text { CGTATTACTGTAAACTTCACTAATGTTTGTGTTTTTAGGGGCATGAT } \\
\text { GAACATGATTACTCAAGAAAGTAACCAGCGACTCGGATCCCCGGG } \\
\text { TTAATTAA }\end{array}$ & Deleción $f s v 1^{+}$ \\
\hline fsv1D-R & $\begin{array}{l}\text { AGGACGTGAAATAAAAGAATTAAGTGAAAGTGTAACAGAGTTAC } \\
\text { AGCAAGTACAATTGCTAAGTGATATTTATTTGCACCGAATTCGAGC } \\
\text { TCGTTTAAAC }\end{array}$ & Deleción $f s v 1^{+}$ \\
\hline
\end{tabular}




\begin{tabular}{|c|c|c|}
\hline Fsv1-F1 & ATCTGGCAGCTAATGAGCAAAT & $\begin{array}{l}\text { Comprobación deleción } \\
\qquad s v 1^{+}\end{array}$ \\
\hline Fsv1-R1 & TAAAGGGAAGGTTCGTTTAGCA & $\begin{array}{c}\text { Comprobación deleción } \\
f s v 1^{+}\end{array}$ \\
\hline Vps35D-F & $\begin{array}{l}\text { TGGGCCGCTAGTAAAACTATACTGAAATTACAATTACGTTGGTTAA } \\
\text { ATTGAAACACTTGGAAGTGGATATTTAGGGCTCTCGGATCCCCGG } \\
\text { GTTAATTAA }\end{array}$ & Deleción vps35+ \\
\hline Vps35D-R & $\begin{array}{l}\text { AAAATGAATAAATTAGTAATACAAAAATTTTATTAGAAGTATATTA } \\
\text { GGGAGTAAGACATGATATAAACGCATACGAGAAAGAATTCGAGC } \\
\text { TCGTTTAAAC }\end{array}$ & Deleción vps35+ \\
\hline Vps35-Left & TAGGCGCGATATTTGTGATATG & $\begin{array}{c}\text { Comprobación deleción } \\
\text { vps } 35^{+}\end{array}$ \\
\hline Vps35-Right & TAGGTGTTTGACGAAGTGCTTG & $\begin{array}{c}\text { Comprobación deleción y } \\
\text { marcaje Ct vps } 35^{+}\end{array}$ \\
\hline Vps35ctTag-F & $\begin{array}{l}\text { CTCTTAAAAATCATTTAGAAAGAGCAACTGCTTACGCAGAGAAAC } \\
\text { GTTCTGAAGATGAACGTTGGTCTAGTATTTTTCAACGGATCCCCGG } \\
\text { GTTAATTAA }\end{array}$ & Marcaje Ct de vps35+ \\
\hline Vps35ctTag-R & $\begin{array}{l}\text { AGAAAAAAATCTAAGAACCTGAAATATAGCTGTCAAGAGAAAAAT } \\
\text { GAATAAATTAGTAATACAAAAATTTTATTAGAAGTGAATTCGAGCT } \\
\text { CGTTTAAAC }\end{array}$ & Marcaje Ct de vps35+ \\
\hline Vps35CtTag-Left & CCGACCTTATTGCTAGTGATCC & $\begin{array}{c}\text { Comprobar marcaje } \mathrm{Ct} \\
\text { de vps } 35^{+}\end{array}$ \\
\hline Ent3CtTag-F & $\begin{array}{l}\text { CTAGGGAAAGAGTTGTTTCGTCTTCTAGCGAACCGGTTTCTAAAAC } \\
\text { CCAAAACTTCCTAGACAACGACAATCTCCTATTGCGGATCCCCGGG } \\
\text { TTAATTAA }\end{array}$ & Marcaje Ct de ent3+ \\
\hline Ent3CtTag-R & $\begin{array}{l}\text { TAACGATCAAGGGCTGGAGATAGTTTAAATGAGATAGGAAACGA } \\
\text { CTACTTAAATTCCATAGCAAACACATGCTAATAGGAGAATTCGAGC } \\
\text { TCGTTTAAAC }\end{array}$ & Marcaje Ct de ent3 ${ }^{+}$ \\
\hline Ent3-F2 & TAATACCTCTTCACAAGCCGGT & $\begin{array}{c}\text { Comprobar marcaje Ct } \\
\text { de ent } 3^{+}\end{array}$ \\
\hline Ent3-R1 & CTTATAAGGCCACCAATTGCAT & $\begin{array}{c}\text { Comprobar marcaje } \mathrm{Ct} y \\
\text { deleción de ent } 3^{+}\end{array}$ \\
\hline Ent3-F1 & CGCATTTGACACCTACAAAATGTGTGTGAA & $\begin{array}{c}\text { Comprobar deleción de } \\
\text { ent } 3^{+}\end{array}$ \\
\hline Vps10CtTag-F & $\begin{array}{l}\text { CTACACCGACGAATGGTGAATTTGAAAATGCGGCATTCCTTCAAA } \\
\text { ATTATGAGATAGATGATGATGACGAAGAGTCAGTTCGGATCCCCG } \\
\text { GGTTAATTAA }\end{array}$ & Marcaje Ct de vps $10^{+}$ \\
\hline Vps10CtTag-R & $\begin{array}{l}\text { GATCATTAATATAAGAACGTGGCATAGCTGCTTTACATGATGAGT } \\
\text { GGAATGATTGACAAACATGCCCAGGTTAAGTTAAAGAATTCGAGC } \\
\text { TCGTTTAAAC }\end{array}$ & Marcaje Ct de vps $10^{+}$ \\
\hline Vps10CtTag-Left & AGTGGCTGGTTGCATTCTTTAT & $\begin{array}{c}\text { Comprobar marcaje } \mathrm{Ct} \\
\text { de vps } 10^{+}\end{array}$ \\
\hline Vps10CtTag-Right & GGTTTATCCCGCAAATGAATTA & $\begin{array}{c}\text { Comprobar marcaje } \mathrm{Ct} \\
\text { de } v p s 10^{+}\end{array}$ \\
\hline Isp6CtTag-F & $\begin{array}{l}\text { TGGGTATTCACGATGTACTCTTGTCTATTCCTGTTGGTAGCAGCAC } \\
\text { TATTAACCTTCTCGCTTTCAATGGTGCTCAAGAACGGATCCCCGGG } \\
\text { TTAATTAA }\end{array}$ & Marcaje Ct de isp6 $6^{+}$ \\
\hline Isp6CtTag-R & $\begin{array}{l}\text { TGTAAAGAACAATCATAAAAGGAGCAAACGTTTTCAAAAAAATAA } \\
\text { AACAATTACTCGATGTATTGAAAATCAAACACCGAGAATTCGAGCT } \\
\text { CGTTTAAAC }\end{array}$ & Marcaje Ct de isp6 $6^{+}$ \\
\hline Isp6CtTag-Left & GTAGCTGTGTTGACATCTTCGC & $\begin{array}{c}\text { Comprobar marcaje Ct } \\
\text { de isp } 6^{+}\end{array}$ \\
\hline Isp6CtTag-Right & AGGCGGCGATATTAAATGTAGA & $\begin{array}{c}\text { Comprobar marcaje Ct } \\
\text { de isp } 6^{+}\end{array}$ \\
\hline Vps27CtTag-F & $\begin{array}{l}\text { GTTATGATGATTTAATGAATGGCAATGATAAGCAAGGTAATGATA } \\
\text { TTCCTGAAGTTCAAGAAGCATCTTTAATCGAGCTTCGGATCCCCGG } \\
\text { GTTAATTAA }\end{array}$ & Marcaje Ct de vps $27^{+}$ \\
\hline Vps27CtTag-R & $\begin{array}{l}\text { ATTTTAGGTTACAATTGATCAATTTTGAAAAACAAAAAAATATTAA } \\
\text { AAGGATCGTAAACAGACATGCATTGTCGATAAATGAATTCGAGCT } \\
\text { CGTTTAAAC }\end{array}$ & Marcaje Ct de vps27 $7^{+}$ \\
\hline
\end{tabular}




\begin{tabular}{|c|c|c|}
\hline Vps27CtTag-Left & TTCGTCTCCGGTAACAGAAAAT & $\begin{array}{c}\text { Comprobación marcaje } \\
\text { Ct de vps } 27^{+}\end{array}$ \\
\hline Vps27CtTag-Right & GTTGACTGGAAAAACTCCAAGG & $\begin{array}{c}\text { Comprobación marcaje } \\
\text { Ct de } v p s 27^{+}\end{array}$ \\
\hline Vph1CtTag-F & $\begin{array}{l}\text { ATTGGGTTGAAGGCATGTCTAAGCATTTTGAAGGTGAAGGATATG } \\
\text { CTTTTACCCCTTTCACTTTCAAAGTGACCGCGGAGCGGATCCCCGG } \\
\text { GTTAATTAA }\end{array}$ & Marcaje Ct de vph1 ${ }^{+}$ \\
\hline Vph1CtTag-R & $\begin{array}{l}\text { TTCTTTTAACTAAGATTCTAAAGAGCAGCAATTTGTAAACTTCTTAT } \\
\text { AAGCTATTAATTTAATGATTAATTATTTACGAAGAATTCGAGCTCG } \\
\text { TTTAAAC }\end{array}$ & Marcaje Ct de vph1 ${ }^{+}$ \\
\hline Vph1CtTag-Left & CGTATGACCGGAATTGTAGGAT & 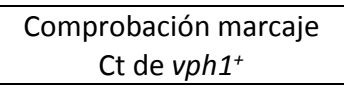 \\
\hline Vph1CtTag-Right & TGAAATCCAGTAGCAATCTCCA & 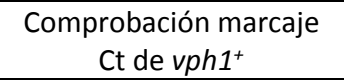 \\
\hline Nhx1CtTag-F & $\begin{array}{l}\text { AATGGTTAACGCGCTTTGATGAAGAGGTCATAAAACCAGTGCTTC } \\
\text { TGGAGAGAGATAACCTTAAAAATGGAACAAAAAAACGGATCCCC } \\
\text { GGGTTAATTAA }\end{array}$ & Marcaje Ct de $\mathrm{Nh}_{x} 1^{+}$ \\
\hline Nhx1CtTag-R & $\begin{array}{l}\text { AAAATTCATAAATGATAAAAGGAGAAACGAGGTCGTAAGACCAA } \\
\text { AAGCATATTCATTAAACTGACACGAACATATACTGTGAATTCGAGC } \\
\text { TCGTTTAAAC }\end{array}$ & Marcaje Ct de $\mathrm{Nh}_{x 1^{+}}$ \\
\hline Nhx1CtTag Left & GAACATTTTGATGAAGGCAACA & 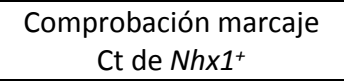 \\
\hline Nhx1CtTag Right & TTGTTGGAAAATCATCGACTTG & $\begin{array}{c}\text { Comprobación marcaje } \\
\text { Ct de } \mathrm{Nhx}^{+}\end{array}$ \\
\hline Gga21F1 & AGCTTTTCAGCTGAACCAGA & $\begin{array}{l}\text { Comprobar deleción de } \\
\text { gga21+ }\end{array}$ \\
\hline Gga21R1 & GAGATTATTAGGTCAAAGACATTC & $\begin{array}{l}\text { Comprobar deleción de } \\
\text { gga21+ }\end{array}$ \\
\hline Gga22F1 & GCAAGTTTTATGGTTACTTAAAC & $\begin{array}{l}\text { Comprobar deleción de } \\
g g a 22^{+}\end{array}$ \\
\hline Gga22R1 & ATTCAGTGGGATTAGAGCTCAAC & $\begin{array}{c}\text { Comprobar deleción de } \\
g g a 22^{+}\end{array}$ \\
\hline K2 & GTCGCACCTGATTGCCCGACAT & $\begin{array}{l}\text { Comprobación deleción } \\
\text { genes con marcador KAN }\end{array}$ \\
\hline K4 & CAGTCGTCACTCATGGTGATTTCTC & $\begin{array}{l}\text { Comprobación deleción } \\
\text { genes con marcador KAN }\end{array}$ \\
\hline CloNAT-F & TCACCAACGTCAACGCACCGGCGAT & $\begin{array}{l}\text { Comprobación deleción } \\
\text { genes con marcador NAT }\end{array}$ \\
\hline CloNAT-R & ACTGGTGCGGTACCGGTAAGC & $\begin{array}{l}\text { Comprobación deleción } \\
\text { genes con marcador NAT }\end{array}$ \\
\hline Hph-F & GTACACAAATCGCCCGCAGAAGCG & $\begin{array}{l}\text { Comprobación deleción } \\
\text { genes con marcador } \mathrm{HPH}\end{array}$ \\
\hline Hph-R & CCTACATCGAAGCTGAAAGCA & $\begin{array}{l}\text { Comprobación deleción } \\
\text { genes con marcador } \mathrm{HPH}\end{array}$ \\
\hline
\end{tabular}



Bibliografía 

Abazeed, M.E., Fuller, R.S., 2008. Yeast Golgi-localized, gamma-Ear-containing, ADP-ribosylation factor-binding proteins are but adaptor protein-1 is not required for cell-free transport of membrane proteins from the trans-Golgi network to the prevacuolar compartment. Mol. Biol. Cell 19, 4826-4836.

Abubakar, Y.S., Zheng, W., Olsson, S., Zhou, J., 2017. Updated Insight into the Physiological and Pathological Roles of the Retromer Complex. Int. J. Mol. Sci. 18.

Anand, V.C., Daboussi, L., Lorenz, T.C., Payne, G.S., 2009. Genome-wide analysis of AP-3dependent protein transport in yeast. Mol. Biol. Cell 20, 1592-1604.

Anitei, M., Hoflack, B., 2012. Bridging membrane and cytoskeleton dynamics in the secretory and endocytic pathways. Nat Cell Biol 14, 11-9.

Anton, C., Taubas, J.V., Roncero, C., 2018. The Functional Specialization of Exomer as a Cargo Adaptor During the Evolution of Fungi. Genetics 208, 1483-1498.

Anton, C., Zanolari, B., Arcones, I., Wang, C., Mulet, J.M., Spang, A., Roncero, C., 2017. Involvement of the exomer complex in the polarized transport of Ena1 required for Saccharomyces cerevisiae survival against toxic cations. Mol Biol Cell 28, 3672-3685.

Antonescu, C.N., Aguet, F., Danuser, G., Schmid, S.L., 2011. Phosphatidylinositol-(4,5)bisphosphate regulates clathrin-coated pit initiation, stabilization, and size. Mol. Biol. Cell 22, 2588-2600.

Antonin, W., Holroyd, C., Fasshauer, D., Pabst, S., Fischer von Mollard, G., Jahn, R., 2000. A SNARE complex mediating fusion of late endosomes defines conserved properties of SNARE structure and function. EMBO J. 19, 6453-6464.

Antonny, B., Burd, C., De Camilli, P., Chen, E., Daumke, O., Faelber, K., Ford, M., Frolov, V.A., Frost, A., Hinshaw, J.E., Kirchhausen, T., Kozlov, M.M., Lenz, M., Low, H.H., McMahon, H., Merrifield, C., Pollard, T.D., Robinson, P.J., Roux, A., Schmid, S., 2016. Membrane fission by dynamin: what we know and what we need to know. EMBO J. 35, 2270-2284.

Arakel, E.C., Schwappach, B., 2018. Formation of COPI-coated vesicles at a glance. J Cell Sci 131, jcs209890.

Arasada, R., Pollard, T.D., 2011. Distinct roles for F-BAR proteins Cdc15p and Bzz1p in actin polymerization at sites of endocytosis in fission yeast. Curr. Biol. CB 21, 1450-1459.

Arcones, I., Sacristán, C., Roncero, C., 2016. Maintaining protein homeostasis: early and late endosomal dual recycling for the maintenance of intracellular pools of the plasma membrane protein Chs3. Mol. Biol. Cell 27, 4021-4032.

Arighi, C.N., Hartnell, L.M., Aguilar, R.C., Haft, C.R., Bonifacino, J.S., 2004. Role of the mammalian retromer in sorting of the cation-independent mannose 6-phosphate receptor. J. Cell Biol. 165, 123-133.

Arlt, H., Reggiori, F., Ungermann, C., 2015. Retromer and the dynamin Vps1 cooperate in the retrieval of transmembrane proteins from vacuoles. J. Cell Sci. 128, 645-655. 
Ayscough, K.R., Stryker, J., Pokala, N., Sanders, M., Crews, P., Drubin, D.G., 1997. High rates of actin filament turnover in budding yeast and roles for actin in establishment and maintenance of cell polarity revealed using the actin inhibitor latrunculin-A. J Cell Biol 137, 399-416.

Bähler, J., Wu, J.Q., Longtine, M.S., Shah, N.G., McKenzie, A., 3rd, Steever, A.B., Wach, A., Philippsen, P., Pringle, J.R., 1998. Heterologous modules for efficient and versatile PCR-based gene targeting in Schizosaccharomyces pombe. Yeast 14, 943-951.

Barfield, R.M., Fromme, J.C., Schekman, R., 2009. The Exomer Coat Complex Transports Fus1p to the Plasma Membrane via a Novel Plasma Membrane Sorting Signal in Yeast. Mol Biol Cell 20, 4985-96.

Bassett, D.E., Boguski, M.S., Hieter, P., 1996. Yeast genes and human disease. Nature 379, 589590.

Beck, R., Ravet, M., Wieland, F.T., Cassel, D., 2009. The COPI system: Molecular mechanisms and function. FEBS Lett. 583, 2701-2709.

Beckley, J.R., Chen, J.S., Yang, Y., Peng, J., Gould, K.L., 2015. A Degenerate Cohort of Yeast Membrane Trafficking DUBs Mediates Cell Polarity and Survival. Mol Cell Proteomics 14, 3132 41.

Berger, A.C., Salazar, G., Styers, M.L., Newell-Litwa, K.A., Werner, E., Maue, R.A., Corbett, A.H., Faundez, V., 2007. The subcellular localization of the Niemann-Pick Type $C$ proteins depends on the adaptor complex AP-3. J. Cell Sci. 120, 3640-3652.

Bhave, M., Papanikou, E., Iyer, P., Pandya, K., Jain, B.K., Ganguly, A., Sharma, C., Pawar, K., Austin, J., 2nd, Day, K.J., Rossanese, O.W., Glick, B.S., Bhattacharyya, D., 2014. Golgi enlargement in Arfdepleted yeast cells is due to altered dynamics of cisternal maturation. J Cell Sci 127, 250-7.

Bilan, F., Thoreau, V., Nacfer, M., Dérand, R., Norez, C., Cantereau, A., Garcia, M., Becq, F., Kitzis, A., 2004. Syntaxin 8 impairs trafficking of cystic fibrosis transmembrane conductance regulator (CFTR) and inhibits its channel activity. J. Cell Sci. 117, 1923-1935.

Bilodeau, P.S., Winistorfer, S.C., Allaman, M.M., Surendhran, K., Kearney, W.R., Robertson, A.D., Piper, R.C., 2004. The GAT Domains of Clathrin-associated GGA Proteins Have Two Ubiquitin Binding Motifs. J. Biol. Chem. 279, 54808-54816.

Black, M.W., Pelham, H.R., 2000. A selective transport route from Golgi to late endosomes that requires the yeast GGA proteins. J Cell Biol 151, 587-600.

Boeddinghaus, C., Merz, A.J., Laage, R., Ungermann, C., 2002. A cycle of Vam7p release from and PtdIns 3-P-dependent rebinding to the yeast vacuole is required for homotypic vacuole fusion. J. Cell Biol. 157, 79-90.

Boehm, J., Letourneur, F., Ballensiefen, W., Ossipov, D., Démollière, C., Schmitt, H.D., 1997. Sec12p requires Rer1p for sorting to coatomer (COPI)-coated vesicles and retrieval to the ER. J. Cell Sci. 110 ( Pt 8), 991-1003.

Boehm, M., Bonifacino, J.S., 2002. Genetic analyses of adaptin function from yeast to mammals. Gene 286, 175-186.

Boehm, M., Bonifacino, J.S., 2001. Adaptins: the final recount. Mol Biol Cell 12, 2907-20. 
Boettner, D.R., Chi, R.J., Lemmon, S.K., 2012. Lessons from yeast for clathrin-mediated endocytosis. Nat Cell Biol 14, 2-10.

Bolte, S., Cordelieres, F.P., 2006. A guided tour into subcellular colocalization analysis in light microscopy. J Microsc 224, 213-32.

Boman, A.L., 2001. GGA proteins: new players in the sorting game. J Cell Sci 114, 3413-8.

Boman, A.L., Salo, P.D., Hauglund, M.J., Strand, N.L., Rensink, S.J., Zhdankina, O., 2002. ADPribosylation factor (ARF) interaction is not sufficient for yeast GGA protein function or localization. Mol Biol Cell 13, 3078-95.

Bonifacino, J.S., 2014. Adaptor proteins involved in polarized sorting. J Cell Biol 204, 7-17.

Bonifacino, J.S., 2004. The GGA proteins: adaptors on the move. Nat. Rev. Mol. Cell Biol. 5, 23-32.

Bonifacino, J.S., Glick, B.S., 2004. The mechanisms of vesicle budding and fusion. Cell 116, $153-$ 166.

Bonifacino, J.S., Lippincott-Schwartz, J., 2003. Coat proteins: shaping membrane transport. Nat Rev Mol Cell Biol 4, 409-14.

Bonifacino, J.S., Rojas, R., 2006. Retrograde transport from endosomes to the trans-Golgi network. Nat. Rev. Mol. Cell Biol. 7, 568-579.

Bowers, K., Stevens, T.H., 2005. Protein transport from the late Golgi to the vacuole in the yeast Saccharomyces cerevisiae. Biochim Biophys Acta 1744, 438-54.

Bradford, M.M., 1976. A rapid and sensitive method for the quantitation of microgram quantities of protein utilizing the principle of protein-dye binding. Anal. Biochem. 72, 248-254.

Brickner, J.H., Blanchette, J.M., Sipos, G., Fuller, R.S., 2001. The TIg SNARE complex is required for TGN homotypic fusion. J. Cell Biol. 155, 969-978.

Bright, N.A., Gratian, M.J., Luzio, J.P., 2005. Endocytic Delivery to Lysosomes Mediated by Concurrent Fusion and Kissing Events in Living Cells. Curr. Biol. 15, 360-365.

Bröcker, C., Engelbrecht-Vandré, S., Ungermann, C., 2010. Multisubunit Tethering Complexes and Their Role in Membrane Fusion. Curr. Biol. 20, R943-R952.

Brodsky, F.M., 2012. Diversity of Clathrin Function: New Tricks for an Old Protein. Annu Rev Cell Dev Biol.

Cai, H., Reinisch, K., Ferro-Novick, S., 2007. Coats, tethers, Rabs, and SNAREs work together to mediate the intracellular destination of a transport vesicle. Dev Cell 12, 671-82.

Carroll, S.Y., Stirling, P.C., Stimpson, H.E., Giesselmann, E., Schmitt, M.J., Drubin, D.G., 2009. A yeast killer toxin screen provides insights into $\mathrm{a} / \mathrm{b}$ toxin entry, trafficking, and killing mechanisms. Dev Cell 17, 552-60.

Cartagena-Lirola, H., Duran, A., Valdivieso, M.H., 2006. The Schizosaccharomyces pombe cfr $1^{+}$ gene participates in mating through a new pathway that is independent of fus $1^{+}$. Yeast $23,375-$ 88. 
Casler, J.C., Papanikou, E., Barrero, J.J., Glick, B.S., 2019. Maturation-driven transport and AP-1dependent recycling of a secretory cargo in the Golgi. J Cell Biol 218, 1582-1601.

Cereghino, J.L., Marcusson, E.G., Emr, S.D., 1995. The cytoplasmic tail domain of the vacuolar protein sorting receptor Vps10p and a subset of VPS gene products regulate receptor stability, function, and localization. Mol Biol Cell 6, 1089-102.

Chalfie, M., Tu, Y., Euskirchen, G., Ward, W.W., Prasher, D.C., 1994. Green fluorescent protein as a marker for gene expression. Science 263, 802-805.

Chapa-y-Lazo, B., Allwood, E.G., Smaczynska-de Rooij, I.I., Snape, M.L., Ayscough, K.R., 2014. Yeast Endocytic Adaptor AP-2 Binds the Stress Sensor Mid2 and Functions in Polarized Cell Responses. Traffic Cph. Den. 15, 546-557.

Cheever, M.L., Sato, T.K., de Beer, T., Kutateladze, T.G., Emr, S.D., Overduin, M., 2001. Phox domain interaction with PtdIns(3)P targets the Vam7 t-SNARE to vacuole membranes. Nat. Cell Biol. 3, 613-618.

Chen, B., Zhao, L., Li, X., Ji, Y.-S., Li, N., Xu, X.-F., Chen, Z.-Y., 2014. Syntaxin 8 Modulates the Postsynthetic Trafficking of the TrkA Receptor and Inflammatory Pain Transmission. J. Biol. Chem. 289, 19556-19569.

Chen, C.-Y., Brodsky, F.M., 2005. Huntingtin-interacting protein 1 (Hip1) and Hip1-related protein (Hip1R) bind the conserved sequence of clathrin light chains and thereby influence clathrin assembly in vitro and actin distribution in vivo. J. Biol. Chem. 280, 6109-6117.

Chi, R.J., Liu, J., West, M., Wang, J., Odorizzi, G., Burd, C.G., 2014. Fission of SNX-BAR-coated endosomal retrograde transport carriers is promoted by the dynamin-related protein Vps1. J. Cell Biol. 204, 793-806.

Chidambaram, S., Müllers, N., Wiederhold, K., Haucke, V., Mollard, G.F. von, 2004a. Specific Interaction between SNAREs and Epsin N-terminal Homology (ENTH) Domains of Epsin-related Proteins in trans-Golgi Network to Endosome Transport. J. Biol. Chem. 279, 4175-4179.

Chidambaram, S., Mullers, N., Wiederhold, K., Haucke, V., von Mollard, G.F., 2004b. Specific interaction between SNAREs and epsin N-terminal homology (ENTH) domains of epsin-related proteins in trans-Golgi network to endosome transport. J Biol Chem 279, 4175-9.

Chidambaram, S., Zimmermann, J., von Mollard, G.F., 2008. ENTH domain proteins are cargo adaptors for multiple SNARE proteins at the TGN endosome. J Cell Sci 121, 329-38.

Choy, R.W.-Y., Cheng, Z., Schekman, R., 2012. Amyloid precursor protein (APP) traffics from the cell surface via endosomes for amyloid $\beta(A \beta)$ production in the trans-Golgi network. Proc. Natl. Acad. Sci. U. S. A. 109, E2077-2082.

Christ, L., Raiborg, C., Wenzel, E.M., Campsteijn, C., Stenmark, H., 2017. Cellular Functions and Molecular Mechanisms of the ESCRT Membrane-Scission Machinery. Trends Biochem. Sci. 42, 4256.

Chu, D.S., Pishvaee, B., Payne, G.S., 1996. The light chain subunit is required for clathrin function in Saccharomyces cerevisiae. J Biol Chem 271, 33123-30. 
Clairfeuille, T., Mas, C., Chan, A.S.M., Yang, Z., Tello-Lafoz, M., Chandra, M., Widagdo, J., Kerr, M.C., Paul, B., Mérida, I., Teasdale, R.D., Pavlos, N.J., Anggono, V., Collins, B.M., 2016. A molecular code for endosomal recycling of phosphorylated cargos by the SNX27-retromer complex. Nat. Struct. Mol. Biol. 23, 921-932.

Codlin, S., Mole, S.E., 2009. S. pombe btn1, the orthologue of the Batten disease gene CLN3, is required for vacuole protein sorting of Cpy1p and Golgi exit of Vps10p. J Cell Sci 122, 1163-73.

Coe, J.G., Lim, A.C., Xu, J., Hong, W., 1999. A role for Tlg1p in the transport of proteins within the Golgi apparatus of Saccharomyces cerevisiae. Mol. Biol. Cell 10, 2407-2423.

Collins, B.M., McCoy, A.J., Kent, H.M., Evans, P.R., Owen, D.J., 2002. Molecular architecture and functional model of the endocytic AP2 complex. Cell 109, 523-535.

Conibear, E., Stevens, T.H., 1998. Multiple sorting pathways between the late Golgi and the vacuole in yeast. Biochim Biophys Acta 1404, 211-30.

Cooper, A.A., Stevens, T.H., 1996. Vps10p cycles between the late-Golgi and prevacuolar compartments in its function as the sorting receptor for multiple yeast vacuolar hydrolases. J. Cell Biol. 133, 529-541.

Copic, A., Starr, T.L., Schekman, R., 2007. Ent3p and Ent5p exhibit cargo-specific functions in trafficking proteins between the trans-Golgi network and the endosomes in yeast. Mol Biol Cell $18,1803-15$.

Costaguta, G., Duncan, M.C., Fernandez, G.E., Huang, G.H., Payne, G.S., 2006. Distinct roles for TGN/endosome epsin-like adaptors Ent3p and Ent5p. Mol Biol Cell 17, 3907-20.

Costaguta, G., Stefan, C.J., Bensen, E.S., Emr, S.D., Payne, G.S., 2001. Yeast Gga coat proteins function with clathrin in Golgi to endosome transport. Mol. Biol. Cell 12, 1885-1896.

Cowles, C.R., Odorizzi, G., Payne, G.S., Emr, S.D., 1997. The AP-3 adaptor complex is essential for cargo-selective transport to the yeast vacuole. Cell 91, 109-18.

Daboussi, L., Costaguta, G., Ghukasyan, R., Payne, G.S., 2017. Conserved role for Gga proteins in phosphatidylinositol 4-kinase localization to the trans-Golgi network. Proc Natl Acad Sci U A 114, 3433-3438.

Daboussi, L., Costaguta, G., Payne, G.S., 2012. Phosphoinositide-mediated clathrin adaptor progression at the trans-Golgi network. Nat Cell Biol 14, 239-48.

Dancourt, J., Barlowe, C., 2010. Protein sorting receptors in the early secretory pathway. Annu. Rev. Biochem. 79, 777-802.

Darsow, T., Burd, C.G., Emr, S.D., 1998. Acidic Di-leucine Motif Essential for AP-3-dependent Sorting and Restriction of the Functional Specificity of the Vam3p Vacuolar t-SNARE. J. Cell Biol. 142, 913-922.

Daumke, O., Roux, A., Haucke, V., 2014. BAR domain scaffolds in dynamin-mediated membrane fission. Cell 156, 882-892.

Davidson, R., Pontasch, J.A., Wu, J.Q., 2016. Sbg1 Is a Novel Regulator for the Localization of the beta-Glucan Synthase Bgs1 in Fission Yeast. PLoS One 11, e0167043. 
Day, K.J., Casler, J.C., Glick, B.S., 2018. Budding Yeast Has a Minimal Endomembrane System. Dev. Cell 44, 56-72.e4.

De Craene, J.-O., Bertazzi, D.L., Bär, S., Friant, S., 2017. Phosphoinositides, Major Actors in Membrane Trafficking and Lipid Signaling Pathways. Int. J. Mol. Sci. 18.

De Craene, J.-O., Ripp, R., Lecompte, O., Thompson, J.D., Poch, O., Friant, S., 2012. Evolutionary analysis of the ENTH/ANTH/VHS protein superfamily reveals a coevolution between membrane trafficking and metabolism. BMC Genomics 13, 297.

de Leon, N., Hoya, M., Curto, M.A., Moro, S., Yanguas, F., Doncel, C., Valdivieso, M.H., 2016. The AP-2 complex is required for proper temporal and spatial dynamics of endocytic patches in fission yeast. Mol Microbiol 100, 409-24.

de Leon, N., Sharifmoghadam, M.R., Hoya, M., Curto, M.A., Doncel, C., Valdivieso, M.H., 2013. Regulation of cell wall synthesis by the clathrin light chain is essential for viability in Schizosaccharomyces pombe. PLoS One 8, e71510.

De, M., Abazeed, M.E., Fuller, R.S., 2013. Direct binding of the Kex2p cytosolic tail to the VHS domain of yeast Gga2p facilitates TGN to prevacuolar compartment transport and is regulated by phosphorylation. Mol Biol Cell 24, 495-509.

De Matteis, M.A., Luini, A., 2008. Exiting the Golgi complex. Nat Rev Mol Cell Biol 9, 273-84.

Dell'Angelica, E.C., 2009. AP-3-dependent trafficking and disease: the first decade. Curr. Opin. Cell Biol. 21, 552-559.

Dell'Angelica, E.C., Payne, G.S., 2001. Intracellular cycling of lysosomal enzyme receptors: cytoplasmic tails' tales. Cell 106, 395-8.

Dell'Angelica, E.C., Puertollano, R., Mullins, C., Aguilar, R.C., Vargas, J.D., Hartnell, L.M., Bonifacino, J.S., 2000. GGAs: a family of ADP ribosylation factor-binding proteins related to adaptors and associated with the Golgi complex. J. Cell Biol. 149, 81-94.

Deloche, O., Schekman, R.W., 2002. Vps10p Cycles between the TGN and the Late Endosome via the Plasma Membrane in Clathrin Mutants. Mol. Biol. Cell 13, 4296-4307.

Deloche, O., Yeung, B.G., Payne, G.S., Schekman, R., 2001. Vps10p transport from the trans-Golgi network to the endosome is mediated by clathrin-coated vesicles. Mol. Biol. Cell 12, 475-485.

Demmel, L., Gravert, M., Ercan, E., Habermann, B., Müller-Reichert, T., Kukhtina, V., Haucke, V., Baust, T., Sohrmann, M., Kalaidzidis, Y., Klose, C., Beck, M., Peter, M., Walch-Solimena, C., 2008. The Clathrin Adaptor Gga2p Is a Phosphatidylinositol 4-phosphate Effector at the Golgi Exit. Mol. Biol. Cell 19, 1991-2002.

Deng, Y., Guo, Y., Watson, H., Au, W.C., Shakoury-Elizeh, M., Basrai, M.A., Bonifacino, J.S., Philpott, C.C., 2009. Gga2 mediates sequential ubiquitin-independent and ubiquitin-dependent steps in the trafficking of ARN1 from the trans-Golgi network to the vacuole. J Biol Chem 284, 23830-41.

Dilcher, M., Köhler, B., Mollard, G.F. von, 2001. Genetic Interactions with the Yeast Q-SNARE VTI1Reveal Novel Functions for the R-SNARE YKT6. J. Biol. Chem. 276, 34537-34544. 
Dingjan, I., Linders, P.T.A., Verboogen, D.R.J., Revelo, N.H., Ter Beest, M., van den Bogaart, G., 2018. Endosomal and Phagosomal SNAREs. Physiol. Rev. 98, 1465-1492.

Doherty, G.J., McMahon, H.T., 2009. Mechanisms of endocytosis. Annu Rev Biochem 78, 857902.

Doray, B., Ghosh, P., Griffith, J., Geuze, H.J., Kornfeld, S., 2002. Cooperation of GGAs and AP-1 in packaging MPRs at the trans-Golgi network. Science 297, 1700-3.

Duden, R., Hosobuchi, M., Hamamoto, S., Winey, M., Byers, B., Schekman, R., 1994. Yeast betaand beta'-coat proteins (COP). Two coatomer subunits essential for endoplasmic reticulum-toGolgi protein traffic. J. Biol. Chem. 269, 24486-24495.

Duncan, M.C., Costaguta, G., Payne, G.S., 2003. Yeast epsin-related proteins required for Golgiendosome traffic define a gamma-adaptin ear-binding motif. Nat. Cell Biol. 5, 77-81.

Erpapazoglou, Z., Froissard, M., Nondier, I., Lesuisse, E., Haguenauer-Tsapis, R., Belgareh-Touzé, N., 2008. Substrate- and ubiquitin-dependent trafficking of the yeast siderophore transporter Sit1. Traffic Cph. Den. 9, 1372-1391.

Eugster, Anne, Frigerio, G., Dale, M., Duden, R., 2004. The alpha- and beta'-COP WD40 domains mediate cargo-selective interactions with distinct di-lysine motifs. Mol. Biol. Cell 15, 1011-1023.

Eugster, A., Pecheur, E.I., Michel, F., Winsor, B., Letourneur, F., Friant, S., 2004. Ent5p is required with Ent3p and Vps27p for ubiquitin-dependent protein sorting into the multivesicular body. Mol Biol Cell 15, 3031-41.

Faini, M., Beck, R., Wieland, F.T., Briggs, J.A.G., 2013. Vesicle coats: structure, function, and general principles of assembly. Trends Cell Biol. 23, 279-288.

Fennessy, D., Grallert, A., Krapp, A., Cokoja, A., Bridge, A.J., Petersen, J., Patel, A., Tallada, V.A., Boke, E., Hodgson, B., Simanis, V., Hagan, I.M., 2014. Extending the Schizosaccharomyces pombe molecular genetic toolbox. PLoS One 9, e97683.

Feyder, S., De Craene, J.-O., Bär, S., Bertazzi, D.L., Friant, S., 2015. Membrane trafficking in the yeast Saccharomyces cerevisiae model. Int. J. Mol. Sci. 16, 1509-1525.

Fjorback, A.W., Seaman, M., Gustafsen, C., Mehmedbasic, A., Gokool, S., Wu, C., Militz, D., Schmidt, V., Madsen, P., Nyengaard, J.R., Willnow, T.E., Christensen, E.I., Mobley, W.B., Nykjær, A., Andersen, O.M., 2012. Retromer binds the FANSHY sorting motif in SorLA to regulate amyloid precursor protein sorting and processing. J. Neurosci. Off. J. Soc. Neurosci. 32, 1467-1480.

Follett, J., Norwood, S.J., Hamilton, N.A., Mohan, M., Kovtun, O., Tay, S., Zhe, Y., Wood, S.A., Mellick, G.D., Silburn, P.A., Collins, B.M., Bugarcic, A., Teasdale, R.D., 2014. The Vps35 D620N mutation linked to Parkinson's disease disrupts the cargo sorting function of retromer. Traffic Cph. Den. 15, 230-244.

Foote, C., Nothwehr, S.F., 2006. The clathrin adaptor complex 1 directly binds to a sorting signal in Ste13p to reduce the rate of its trafficking to the late endosome of yeast. J. Cell Biol. 173, 615626.

Fotin, A., Cheng, Y., Sliz, P., Grigorieff, N., Harrison, S.C., Kirchhausen, T., Walz, T., 2004. Molecular model for a complete clathrin lattice from electron cryomicroscopy. Nature 432, 573-579. 
Frankel, E.B., Audhya, A., 2018. ESCRT-dependent cargo sorting at multivesicular endosomes. Semin. Cell Dev. Biol. 74, 4-10.

Franzusoff, A., Redding, K., Crosby, J., Fuller, R.S., Schekman, R., 1991. Localization of components involved in protein transport and processing through the yeast Golgi apparatus. J. Cell Biol. 112, 27-37.

Friant, S., Pécheur, E.I., Eugster, A., Michel, F., Lefkir, Y., Nourrisson, D., Letourneur, F., 2003. Ent3p Is a PtdIns(3,5)P2 effector required for protein sorting to the multivesicular body. Dev. Cell 5, 499-511.

Fukasawa, M., Varlamov, O., Eng, W.S., Söllner, T.H., Rothman, J.E., 2004. Localization and activity of the SNARE Ykt6 determined by its regulatory domain and palmitoylation. Proc. Natl. Acad. Sci. U. S. A. $101,4815-4820$.

Gaidarov, I., Keen, J.H., 1999. Phosphoinositide-Ap-2 Interactions Required for Targeting to Plasma Membrane Clathrin-Coated Pits. J. Cell Biol. 146, 755-764.

Galletta, B.J., Mooren, O.L., Cooper, J.A., 2010. Actin dynamics and endocytosis in yeast and mammals. Curr. Opin. Biotechnol. 21, 604-610.

Gallon, M., Clairfeuille, T., Steinberg, F., Mas, C., Ghai, R., Sessions, R.B., Teasdale, R.D., Collins, B.M., Cullen, P.J., 2014. A unique PDZ domain and arrestin-like fold interaction reveals mechanistic details of endocytic recycling by SNX27-retromer. Proc. Natl. Acad. Sci. U. S. A. 111, E3604-3613.

Gallon, M., Cullen, P.J., 2015. Retromer and sorting nexins in endosomal sorting. Biochem. Soc. Trans. 43, 33-47.

Gautreau, A., Oguievetskaia, K., Ungermann, C., 2014. Function and Regulation of the Endosomal Fusion and Fission Machineries. Cold Spring Harb. Perspect. Biol. 6.

Gerrard, S.R., Levi, B.P., Stevens, T.H., 2000. Pep12p is a multifunctional yeast syntaxin that controls entry of biosynthetic, endocytic and retrograde traffic into the prevacuolar compartment. Traffic 1, 259-69.

Gillingham, A.K., 2018. At the ends of their tethers! How coiled-coil proteins capture vesicles at the Golgi. Biochem. Soc. Trans. 46, 43-50.

Gillingham, A.K., Munro, S., 2007. The small G proteins of the Arf family and their regulators. Annu. Rev. Cell Dev. Biol. 23, 579-611.

Girao, H., Geli, M.I., Idrissi, F.Z., 2008. Actin in the endocytic pathway: from yeast to mammals. FEBS Letters 582, 2112-9.

Goettsch Claudia, Kjolby Mads, Aikawa Elena, 2018. Sortilin and Its Multiple Roles in Cardiovascular and Metabolic Diseases. Arterioscler. Thromb. Vasc. Biol. 38, 19-25.

Goffeau, A., Barrell, B.G., Bussey, H., Davis, R.W., Dujon, B., Feldmann, H., Galibert, F., Hoheisel, J.D., Jacq, C., Johnston, M., Louis, E.J., Mewes, H.W., Murakami, Y., Philippsen, P., Tettelin, H., Oliver, S.G., 1996. Life with 6000 genes. Science 274, 546, 563-7. 
Goh, L.K., Huang, F., Kim, W., Gygi, S., Sorkin, A., 2010. Multiple mechanisms collectively regulate clathrin-mediated endocytosis of the epidermal growth factor receptor. J. Cell Biol. 189, 871-883.

Goitre, L., Trapani, E., Trabalzini, L., Retta, S.F., 2014. The Ras superfamily of small GTPases: the unlocked secrets. Methods Mol. Biol. Clifton NJ 1120, 1-18.

Golub, E.I., 1988. "One minute" transformation of competent E. coli by plasmid DNA. Nucleic Acids Res 16, 1641.

Gomez, T.S., Billadeau, D.D., 2009. A FAM21-containing WASH complex regulates retromerdependent sorting. Dev. Cell 17, 699-711.

Gomez-Navarro, N., Miller, E., 2016. Protein sorting at the ER-Golgi interface. J Cell Biol 215, 769778.

Goode, B.L., Eskin, J.A., Wendland, B., 2015. Actin and Endocytosis in Budding Yeast. Genetics 199, 315-358.

Grosshans, B.L., Ortiz, D., Novick, P., 2006. Rabs and their effectors: Achieving specificity in membrane traffic. Proc. Natl. Acad. Sci. U. S. A. 103, 11821-11827.

Guo, Y., Sirkis, D.W., Schekman, R., 2014. Protein sorting at the trans-Golgi network. Annu Rev Cell Dev Biol 30, 169-206.

Ha, S.-A., Torabinejad, J., DeWald, D.B., Wenk, M.R., Lucast, L., De Camilli, P., Newitt, R.A., Aebersold, R., Nothwehr, S.F., 2003. The Synaptojanin-like Protein Inp53/Sjl3 Functions with Clathrin in a Yeast TGN-to-Endosome Pathway Distinct from the GGA Protein-dependent Pathway. Mol. Biol. Cell 14, 1319-1333.

Haft, C.R., de la Luz Sierra, M., Bafford, R., Lesniak, M.A., Barr, V.A., Taylor, S.I., 2000. Human orthologs of yeast vacuolar protein sorting proteins Vps26, 29, and 35: assembly into multimeric complexes. Mol. Biol. Cell 11, 4105-4116.

Harbour, M.E., Breusegem, S.Y., Seaman, M.N.J., 2012. Recruitment of the endosomal WASH complex is mediated by the extended "tail" of Fam21 binding to the retromer protein Vps35. Biochem. J. 442, 209-220.

Harbour, M.E., Breusegem, S.Y.A., Antrobus, R., Freeman, C., Reid, E., Seaman, M.N.J., 2010. The cargo-selective retromer complex is a recruiting hub for protein complexes that regulate endosomal tubule dynamics. J. Cell Sci. 123, 3703-3717.

Hasilik, A., Tanner, W., 1978. Biosynthesis of the Vacuolar Yeast Glycoprotein Carboxypeptidase Y. Eur. J. Biochem. 85, 599-608.

Hatakeyama, R., Péli-Gulli, M.-P., Hu, Z., Jaquenoud, M., Garcia Osuna, G.M., Sardu, A., Dengjel, J., De Virgilio, C., 2019. Spatially Distinct Pools of TORC1 Balance Protein Homeostasis. Mol. Cell 73, 325-338.e8.

Hayashi, R., Moore, S., Stein, W.H., 1973. Carboxypeptidase from yeast. Large scale preparation and the application to $\mathrm{COOH}$-terminal analysis of peptides and proteins. J. Biol. Chem. 248, 22962302. 
Hayles, J., Wood, V., Jeffery, L., Hoe, K.-L., Kim, D.-U., Park, H.-O., Salas-Pino, S., Heichinger, C., Nurse, P., 2013. A genome-wide resource of cell cycle and cell shape genes of fission yeast. Open Biol. 3, 130053.

He, X., Li, F., Chang, W.P., Tang, J., 2005. GGA proteins mediate the recycling pathway of memapsin 2 (BACE). J Biol Chem 280, 11696-703.

Henne, W.M., Boucrot, E., Meinecke, M., Evergren, E., Vallis, Y., Mittal, R., McMahon, H.T., 2010. FCHo proteins are nucleators of clathrin-mediated endocytosis. Science 328, 1281-1284.

Henne, W.M., Buchkovich, N.J., Emr, S.D., 2011. The ESCRT pathway. Dev Cell 21, 77-91.

Hermey, G., 2009. The Vps10p-domain receptor family. Cell. Mol. Life Sci. 66, 2677-2689.

Hettema, E.H., Lewis, M.J., Black, M.W., Pelham, H.R., 2003. Retromer and the sorting nexins Snx4/41/42 mediate distinct retrieval pathways from yeast endosomes. Embo J 22, 548-57.

Hierro, A., Rojas, A.L., Rojas, R., Murthy, N., Effantin, G., Kajava, A.V., Steven, A.C., Bonifacino, J.S., Hurley, J.H., 2007. Functional architecture of the retromer cargo-recognition complex. Nature 449, 1063-1067.

Hinners, I., Tooze, S.A., 2003. Changing directions: clathrin-mediated transport between the Golgi and endosomes. J Cell Sci 116, 763-71.

Hirst, J., Barlow, L.D., Francisco, G.C., Sahlender, D.A., Seaman, M.N., Dacks, J.B., Robinson, M.S., 2011. The fifth adaptor protein complex. PLoS Biol 9, e1001170.

Hirst, J., Borner, G.H., Antrobus, R., Peden, A.A., Hodson, N.A., Sahlender, D.A., Robinson, M.S., 2012. Distinct and overlapping roles for AP-1 and GGAs revealed by the "knocksideways" system. Curr Biol 22, 1711-6.

Hirst, J., Irving, C., Borner, G.H., 2013. Adaptor protein complexes AP-4 and AP-5: new players in endosomal trafficking and progressive spastic paraplegia. Traffic 14, 153-64.

Hirst, J., Itzhak, D.N., Antrobus, R., Borner, G.H.H., Robinson, M.S., 2018. Role of the AP-5 adaptor protein complex in late endosome-to-Golgi retrieval. PLOS Biol. 16, e2004411.

Hirst, J., Lindsay, M.R., Robinson, M.S., 2001. GGAs: roles of the different domains and comparison with AP-1 and clathrin. Mol Biol Cell 12, 3573-88.

Hirst, J., Lui, W.W., Bright, N.A., Totty, N., Seaman, M.N., Robinson, M.S., 2000. A family of proteins with gamma-adaptin and VHS domains that facilitate trafficking between the trans-Golgi network and the vacuole/lysosome. J Cell Biol 149, 67-80.

Hirst, J., Miller, S.E., Taylor, M.J., von Mollard, G.F., Robinson, M.S., 2004. EpsinR is an adaptor for the SNARE protein Vti1b. Mol Biol Cell 15, 5593-602.

Hirst, J., Sahlender, D.A., Choma, M., Sinka, R., Harbour, M.E., Parkinson, M., Robinson, M.S., 2009. Spatial and functional relationship of GGAs and AP-1 in Drosophila and HeLa cells. Traffic 10, 1696-710.

Holthuis, J.C., Nichols, B.J., Dhruvakumar, S., Pelham, H.R., 1998. Two syntaxin homologues in the TGN/endosomal system of yeast. EMBO J. 17, 113-126. 
Hong, W., 2005. SNAREs and traffic. Biochim. Biophys. Acta 1744, 120-144.

Hong, W., Lev, S., 2014. Tethering the assembly of SNARE complexes. Trends Cell Biol. 24, 35-43.

Hosomi, A., Higuchi, Y., Yagi, S., Takegawa, K., 2015. Vsl1p cooperates with Fsv1p for vacuolar protein transport and homotypic fusion in Schizosaccharomyces pombe. Microbiol. Read. Engl. $161,89-98$.

Hosomi, A., Nakase, M., Takegawa, K., 2011. Schizosaccharomyces pombe Pep12p is required for vacuolar protein transport and vacuolar homotypic fusion. J Biosci Bioeng 112, 309-14.

Howell, G.J., Holloway, Z.G., Cobbold, C., Monaco, A.P., Ponnambalam, S., 2006. Cell biology of membrane trafficking in human disease. Int. Rev. Cytol. 252, 1-69.

Hoya, M., Yanguas, F., Moro, S., Prescianotto-Baschong, C., Doncel, C., de Leon, N., Curto, M.A., Spang, A., Valdivieso, M.H., 2017. Traffic Through the Trans-Golgi Network and the Endosomal System Requires Collaboration Between Exomer and Clathrin Adaptors in Fission Yeast. Genetics 205, 673-690.

Huang, F., Khvorova, A., Marshall, W., Sorkin, A., 2004. Analysis of clathrin-mediated endocytosis of epidermal growth factor receptor by RNA interference. J. Biol. Chem. 279, 16657-16661.

Huang, H.-C., Chen, C.-C., Chang, W.-C., Tao, M.-H., Huang, C., 2012. Entry of hepatitis B virus into immortalized human primary hepatocytes by clathrin-dependent endocytosis. J. Virol. 86, 94439453.

Hung, C.W., Aoh, Q.L., Joglekar, A.P., Payne, G.S., Duncan, M.C., 2012. Adaptor autoregulation promotes coordinated binding within clathrin coats. J Biol Chem 287, 17398-407.

Hung, C.-W., Duncan, M.C., 2016. Clathrin binding by the adaptor Ent5 promotes late stages of clathrin coat maturation. Mol. Biol. Cell 27, 1143-1153.

Huotari, J., Helenius, A., 2011. Endosome maturation. Embo J 30, 3481-500.

Huranova, M., Muruganandam, G., Weiss, M., Spang, A., 2016. Dynamic assembly of the exomer secretory vesicle cargo adaptor subunits. EMBO Rep 17, 202-19.

Idrissi, F.-Z., Geli, M.I., 2014. Zooming in on the molecular mechanisms of endocytic budding by time-resolved electron microscopy. Cell. Mol. Life Sci. 71, 641-657

Ito, H., Fukuda, Y., Murata, K., Kimura, A., 1983. Transformation of intact yeast cells treated with alkali cations. J Bacteriol 153, 163-168.

Iwaki, T., Hosomi, A., Tokudomi, S., Kusunoki, Y., Fujita, Y., Giga-Hama, Y., Tanaka, N., Takegawa, K., 2006. Vacuolar protein sorting receptor in Schizosaccharomyces pombe. Microbiol. Read. Engl. $152,1523-1532$.

Iwaki, T., Onishi, M., Ikeuchi, M., Kita, A., Sugiura, R., Giga-Hama, Y., Fukui, Y., Takegawa, K., 2007. Essential roles of class $E$ Vps proteins for sorting into multivesicular bodies in Schizosaccharomyces pombe. Microbiology 153, 2753-64.

Jackson, L.P., 2014. Structure and mechanism of COPI vesicle biogenesis. Curr. Opin. Cell Biol. 29, 67-73. 
Jackson, L.P., Kelly, B.T., McCoy, A.J., Gaffry, T., James, L.C., Collins, B.M., Höning, S., Evans, P.R., Owen, D.J., 2010. A large-scale conformational change couples membrane recruitment to cargo binding in the AP2 clathrin adaptor complex. Cell 141, 1220-1229.

Jackson, L.P., Lewis, M., Kent, H.M., Edeling, M.A., Evans, P.R., Duden, R., Owen, D.J., 2012. Molecular Basis for Recognition of Dilysine Trafficking Motifs by COPI. Dev. Cell 23, 1255-1262.

Jensen, D., Schekman, R., 2011. COPII-mediated vesicle formation at a glance. J Cell Sci 124, 1-4.

Jia, D., Gomez, T.S., Billadeau, D.D., Rosen, M.K., 2012. Multiple repeat elements within the FAM21 tail link the WASH actin regulatory complex to the retromer. Mol. Biol. Cell 23, 23522361.

Jørgensen, M.U., Emr, S.D., Winther, J.R., 1999. Ligand recognition and domain structure of Vps10p, a vacuolar protein sorting receptor in Saccharomyces cerevisiae. Eur. J. Biochem. 260, 461-469.

Jungmann, J., Munro, S., 1998. Multi-protein complexes in the cis Golgi of Saccharomyces cerevisiae with alpha-1,6-mannosyltransferase activity. EMBO J. 17, 423-434.

Kaether, C., Scheuermann, J., Fassler, M., Zilow, S., Shirotani, K., Valkova, C., Novak, B., Kacmar, S., Steiner, H., Haass, C., 2007. Endoplasmic reticulum retention of the gamma-secretase complex component Pen2 by Rer1. EMBO Rep. 8, 743-748.

Kaksonen, M., Toret, C.P., Drubin, D.G., 2005. A modular design for the clathrin- and actinmediated endocytosis machinery. Cell 123, 305-20.

Kama, R., Robinson, M., Gerst, J.E., 2007. Btn2, a Hook1 ortholog and potential Batten diseaserelated protein, mediates late endosome-Golgi protein sorting in yeast. Mol. Cell. Biol. 27, 605621.

Kamiguchi, H., Long, K.E., Pendergast, M., Schaefer, A.W., Rapoport, I., Kirchhausen, T., Lemmon, V., 1998. The neural cell adhesion molecule L1 interacts with the AP-2 adaptor and is endocytosed via the clathrin-mediated pathway. J. Neurosci. Off. J. Soc. Neurosci. 18, 5311-5321.

Kasai, K., Akagawa, K., 2001. Roles of the cytoplasmic and transmembrane domains of syntaxins in intracellular localization and trafficking. J. Cell Sci. 114, 3115-3124.

Kasai, K., Suga, K., Izumi, T., Akagawa, K., 2007. Syntaxin 8 has two functionally distinct di-leucinebased motifs. Cell. Mol. Biol. Lett. 13, 144-154.

Kastning, K., Kukhtina, V., Kittler, J.T., Chen, G., Pechstein, A., Enders, S., Lee, S.H., Sheng, M., Yan, Z., Haucke, V., 2007. Molecular determinants for the interaction between AMPA receptors and the clathrin adaptor complex AP-2. Proc. Natl. Acad. Sci. U. S. A. 104, 2991-2996.

Katzmann, D.J., Babst, M., Emr, S.D., 2001. Ubiquitin-Dependent Sorting into the Multivesicular Body Pathway Requires the Function of a Conserved Endosomal Protein Sorting Complex, ESCRTI. Cell 106, 145-155.

Kienle, N., Kloepper, T.H., Fasshauer, D., 2009. Phylogeny of the SNARE vesicle fusion machinery yields insights into the conservation of the secretory pathway in fungi. BMC Evol. Biol. 9, 19. 
Kim, D.U., Hayles, J., Kim, D., Wood, V., Park, H.O., Won, M., Yoo, H.S., Duhig, T., Nam, M., Palmer, G., Han, S., Jeffery, L., Baek, S.T., Lee, H., Shim, Y.S., Lee, M., Kim, L., Heo, K.S., Noh, E.J., Lee, A.R., Jang, Y.J., Chung, K.S., Choi, S.J., Park, J.Y., Park, Y., Kim, H.M., Park, S.K., Park, H.J., Kang, E.J., Kim, H.B., Kang, H.S., Park, H.M., Kim, K., Song, K., Song, K.B., Nurse, P., Hoe, K.L., 2010. Analysis of a genome-wide set of gene deletions in the fission yeast Schizosaccharomyces pombe. Nat Biotechnol 28, 617-23.

Kim, J.J., Lipatova, Z., Majumdar, U., Segev, N., 2016. Regulation of Golgi Cisternal Progression by Ypt/Rab GTPases. Dev. Cell 36, 440-452. 6

Kirchhausen, T., Harrison, S.C., 1981. Protein organization in clathrin trimers. Cell 23, 755-761.

Kirchhausen, T., Owen, D., Harrison, S.C., 2014. Molecular Structure, Function, and Dynamics of Clathrin-Mediated Membrane Traffic. Cold Spring Harb. Perspect. Biol. 6.

Kita, A., Li, C., Yu, Y., Umeda, N., Doi, A., Yasuda, M., Ishiwata, S., Taga, A., Horiuchi, Y., Sugiura, R., 2011. Role of the Small GTPase Rho3 in Golgi/Endosome trafficking through functional interaction with adaptin in Fission Yeast. PloS One 6, e16842.

Kita, A., Sugiura, R., Shoji, H., He, Y., Deng, L., Lu, Y., Sio, S.O., Takegawa, K., Sakaue, M., Shuntoh, H., Kuno, T., 2004. Loss of Apm1, the micro1 subunit of the clathrin-associated adaptor-protein1 complex, causes distinct phenotypes and synthetic lethality with calcineurin deletion in fission yeast. Mol Biol Cell 15, 2920-31.

Krauss, M., Kinuta, M., Wenk, M.R., De Camilli, P., Takei, K., Haucke, V., 2003. ARF6 stimulates clathrin/AP-2 recruitment to synaptic membranes by activating phosphatidylinositol phosphate kinase type Igamma. J Cell Biol 162, 113-24.

Kunkel, T.A., Roberts, J.D., Zakour, R.A., 1987. Rapid and efficient site-specific mutagenesis without phenotypic selection. Methods Enzym. 154, 367-382.

Kurokawa, K., Osakada, H., Kojidani, T., Waga, M., Suda, Y., Asakawa, H., Haraguchi, T., Nakano, A., 2019. Visualization of secretory cargo transport within the Golgi apparatus. J. Cell Biol. 218, 1602-1618.

Kushner, R.S., 1978. An improved method for transformation of Escherichia coli with ColE1 derived plasmids, Genetic engineering. Elsevier, Amsterdam.

Kweon, Y., Rothe, A., Conibear, E., Stevens, T.H., 2003. Ykt6p Is a Multifunctional Yeast R-SNARE That Is Required for Multiple Membrane Transport Pathways to the Vacuole. Mol. Biol. Cell 14, 1868-1881.

Lafer, E.M., 2002. Clathrin-protein interactions. Traffic 3, 513-20.

Lakadamyali, M., Rust, M.J., Zhuang, X., 2006. Ligands for clathrin-mediated endocytosis are differentially sorted into distinct populations of early endosomes. Cell 124, 997-1009.

Lauwers, E., Jacob, C., Andre, B., 2009. K63-linked ubiquitin chains as a specific signal for protein sorting into the multivesicular body pathway. J Cell Biol 185, 493-502.

Lee, S.A., Kovacs, J., Stahelin, R.V., Cheever, M.L., Overduin, M., Setty, T.G., Burd, C.G., Cho, W., Kutateladze, T.G., 2006. Molecular mechanism of membrane docking by the Vam7p PX domain. J. Biol. Chem. 281, 37091-37101. 
Lemmon, S.K., Jones, E.W., 1987. Clathrin requirement for normal growth of yeast. Science 238, 504-9.

Lemmon, S.K., Traub, L.M., 2000. Sorting in the endosomal system in yeast and animal cells. Curr Opin Cell Biol 12, 457-466.

Leto, D., Saltiel, A.R., 2012. Regulation of glucose transport by insulin: traffic control of GLUT4. Nat. Rev. Mol. Cell Biol. 13, 383-396.

Leupold, U., 1958. Studies on recombination in Schizosaccharomyces pombe. Cold Spring Harb Symp Quant Biol 23, 161-70.

Leupold, U., 1949. Die Vererbung von Homothallie und Heterothallie bei Schizosaccharomyces pombe. Zurich.

Levine, T.P., Munro, S., 2002. Targeting of Golgi-specific pleckstrin homology domains involves both Ptdlns 4-kinase-dependent and -independent components. Curr Biol 12, 695-704.

Lewis, M.J., Nichols, B.J., Prescianotto-Baschong, C., Riezman, H., Pelham, H.R.B., 2000. Specific Retrieval of the Exocytic SNARE Snc1p from Early Yeast Endosomes. Mol. Biol. Cell 11, 23-38.

Lewis, M.J., Pelham, H.R., 1990. A human homologue of the yeast HDEL receptor. Nature 348, 162-163.

Lewis, M.J., Pelham, H.R.B., 2002. A New Yeast Endosomal SNARE Related to Mammalian Syntaxin 8. Traffic 3, 922-929.

Liu, J., Sun, Y., Drubin, D.G., Oster, G.F., 2009. The Mechanochemistry of Endocytosis. PLOS Biol. 7, e1000204.

Liu, J.-J., 2016. Retromer-Mediated Protein Sorting and Vesicular Trafficking. J. Genet. Genomics Yi Chuan Xue Bao 43, 165-177.

Liu, K., Surendhran, K., Nothwehr, S.F., Graham, T.R., 2008. P4-ATPase Requirement for AP1/Clathrin Function in Protein Transport from the trans-Golgi Network and Early Endosomes. Mol. Biol. Cell 19, 3526-3535.

Liu, T.-T., Gomez, T.S., Sackey, B.K., Billadeau, D.D., Burd, C.G., 2012. Rab GTPase regulation of retromer-mediated cargo export during endosome maturation. Mol. Biol. Cell 23, 2505-2515.

Llinares, E., Barry, A.O., André, B., 2015. The AP-3 adaptor complex mediates sorting of yeast and mammalian PQ-loop-family basic amino acid transporters to the vacuolar/lysosomal membrane. Sci. Rep. 5, 16665.

Losev, E., Reinke, C.A., Jellen, J., Strongin, D.E., Bevis, B.J., Glick, B.S., 2006. Golgi maturation visualized in living yeast. Nature 441, 1002-6.

Lucas, M., Gershlick, D.C., Vidaurrazaga, A., Rojas, A.L., Bonifacino, J.S., Hierro, A., 2016. Structural Mechanism for Cargo Recognition by the Retromer Complex. Cell 167, 1623-1635.e14.

Lui, W.W.Y., Collins, B.M., Hirst, J., Motley, A., Millar, C., Schu, P., Owen, D.J., Robinson, M.S., 2003. Binding partners for the $\mathrm{COOH}$-terminal appendage domains of the GGAs and gammaadaptin. Mol. Biol. Cell 14, 2385-2398. 
Ma, M., Burd, C.G., Chi, R.J., 2017. Distinct complexes of yeast Snx4 family SNX-BARs mediate retrograde trafficking of Snc1 and Atg27. Traffic 18, 134-144.

Ma, W., Goldberg, J., 2013. Rules for the recognition of dilysine retrieval motifs by coatomer. EMBO J. 32, 926-937.

Ma, Y., Takeuchi, M., Sugiura, R., Sio, S.O., Kuno, T., 2009. Deletion mutants of AP-1 adaptin subunits display distinct phenotypes in fission yeast. Genes Cells Devoted Mol. Cell. Mech. 14, 1015-1028.

MacGurn, J.A., Hsu, P.-C., Emr, S.D., 2012. Ubiquitin and membrane protein turnover: from cradle to grave. Annu. Rev. Biochem. 81, 231-259.

Maldonado-Báez, L., Dores, M.R., Perkins, E.M., Drivas, T.G., Hicke, L., Wendland, B., 2008. Interaction between Epsin/Yap180 adaptors and the scaffolds Ede1/Pan1 is required for endocytosis. Mol. Biol. Cell 19, 2936-2948.

Manolson, M.F., Proteau, D., Preston, R.A., Stenbit, A., Roberts, B.T., Hoyt, M.A., Preuss, D., Mulholland, J., Botstein, D., Jones, E.W., 1992. The VPH1 gene encodes a 95-kDa integral membrane polypeptide required for in vivo assembly and activity of the yeast vacuolar $\mathrm{H}(+)-$ ATPase. J. Biol. Chem. 267, 14294-14303.

Marcusson, E.G., Horazdovsky, B.F., Cereghino, J.L., Gharakhanian, E., Emr, S.D., 1994. The sorting receptor for yeast vacuolar carboxypeptidase $Y$ is encoded by the VPS10 gene. Cell 77, 579-586.

Massaad, M.J., Franzusoff, A., Herscovics, A., 1999. The processing alpha1,2-mannosidase of Saccharomyces cerevisiae depends on Rer1p for its localization in the endoplasmic reticulum. Eur. J. Cell Biol. 78, 435-440.

Matsuura-Tokita, K., Takeuchi, M., Ichihara, A., Mikuriya, K., Nakano, A., 2006. Live imaging of yeast Golgi cisternal maturation. Nature 441, 1007-1010.

Maundrell, K., 1993. Thiamine-repressible expression vectors pREP and pRIP for fission yeast. Gene 123, 127-130.

Maurer, M.E., Cooper, J.A., 2006. The adaptor protein Dab2 sorts LDL receptors into coated pits independently of AP-2 and ARH. J. Cell Sci. 119, 4235-4246.

McLeod, M., Stein, M., Beach, D., 1987. The product of the mei3+ gene, expressed under control of the mating- type locus, induces meiosis and sporulation in fission yeast. Embo J 6, 729-736.

McMahon, H.T., Boucrot, E., 2015. Membrane curvature at a glance. J Cell Sci 128, 1065-1070.

McNally, K.E., Cullen, P.J., 2018. Endosomal Retrieval of Cargo: Retromer Is Not Alone. Trends Cell Biol. 28, 807-822.

McNally, K.E., Faulkner, R., Steinberg, F., Gallon, M., Ghai, R., Pim, D., Langton, P., Pearson, N., Danson, C.M., Nägele, H., Morris, L.L., Singla, A., Overlee, B.L., Heesom, K.J., Sessions, R., Banks, L., Collins, B.M., Berger, I., Billadeau, D.D., Burstein, E., Cullen, P.J., 2017. Retriever is a multiprotein complex for retromer-independent endosomal cargo recycling. Nat. Cell Biol. 19, $1214-1225$. 
McNew, J.A., Coe, J.G.S., Søgaard, M., Zemelman, B.V., Wimmer, C., Hong, W., Söllner, T.H., 1998. Gos1p, a Saccharomyces cerevisiae SNARE protein involved in Golgi transport. FEBS Lett. 435, 8995.

McNew, J.A., Sogaard, M., Lampen, N.M., Machida, S., Ye, R.R., Lacomis, L., Tempst, P., Rothman, J.E., Söllner, T.H., 1997. Ykt6p, a prenylated SNARE essential for endoplasmic reticulum-Golgi transport. J. Biol. Chem. 272, 17776-17783.

Mercanti, V., Marchetti, A., Lelong, E., Perez, F., Orci, L., Cosson, P., 2010. Transmembrane domains control exclusion of membrane proteins from clathrin-coated pits. J Cell Sci 123, 332935.

Miller, S.E., Collins, B.M., McCoy, A.J., Robinson, M.S., Owen, D.J., 2007. A SNARE-adaptor interaction is a new mode of cargo recognition in clathrin-coated vesicles. Nature 450, 570-574.

Mills, I.G., Praefcke, G.J.K., Vallis, Y., Peter, B.J., Olesen, L.E., Gallop, J.L., Butler, P.J.G., Evans, P.R., McMahon, H.T., 2003. EpsinR. J. Cell Biol. 160, 213-222.

Misra, S., Puertollano, R., Kato, Y., Bonifacino, J.S., Hurley, J.H., 2002. Structural basis for acidiccluster-dileucine sorting-signal recognition by VHS domains. Nature 415, 933-937.

Miura, E., Hasegawa, T., Konno, M., Suzuki, M., Sugeno, N., Fujikake, N., Geisler, S., Tabuchi, M., Oshima, R., Kikuchi, A., Baba, T., Wada, K., Nagai, Y., Takeda, A., Aoki, M., 2014. VPS35 dysfunction impairs lysosomal degradation of $\alpha$-synuclein and exacerbates neurotoxicity in a Drosophila model of Parkinson's disease. Neurobiol. Dis. 71, 1-13.

Mizuno-Yamasaki, E., Rivera-Molina, F., Novick, P., 2012. GTPase networks in membrane traffic. Annu. Rev. Biochem. 81, 637-659.

Mollard, G.F. von, Nothwehr, S.F., Stevens, T.H., 1997. The Yeast v-SNARE Vti1p Mediates Two Vesicle Transport Pathways through Interactions with the t-SNAREs Sed5p and Pep12p. J. Cell Biol. 137, 1511-1524.

Moreno, M.B., Duran, A., Ribas, J.C., 2000. A family of multifunctional thiamine-repressible expression vectors for fission yeast. Yeast 16, 861-72.

Moreno, S., Klar, A., Nurse, P., 1991. Molecular genetic analysis of fission yeast Schizosaccharomyces pombe. Methods Enzym. 194, 795-823.

Moseley, J.B., Goode, B.L., 2006. The yeast actin cytoskeleton: from cellular function to biochemical mechanism. Microbiol. Mol. Biol. Rev. MMBR 70, 605-645.

Motley, A., Bright, N.A., Seaman, M.N.J., Robinson, M.S., 2003. Clathrin-mediated endocytosis in AP-2-depleted cells. J. Cell Biol. 162, 909-918.

Mukaiyama, H., Iwaki, T., Idiris, A., Takegawa, K., 2011. Processing and maturation of carboxypeptidase $Y$ and alkaline phosphatase in Schizosaccharomyces pombe. Appl Microbiol Biotechnol 90, 203-13.

Muñiz, M., Zurzolo, C., 2014. Sorting of GPI-anchored proteins from yeast to mammals--common pathways at different sites? J. Cell Sci. 127, 2793-2801. 
Munn, A.L., Silveira, L., Elgort, M., Payne, G.S., 1991. Viability of clathrin heavy-chain-deficient Saccharomyces cerevisiae is compromised by mutations at numerous loci: implications for the suppression hypothesis. Mol Cell Biol 11, 3868-78.

Naslavsky, N., Caplan, S., 2018. The enigmatic endosome - sorting the ins and outs of endocytic trafficking. J. Cell Sci. 131.

Nass, R., Rao, R., 1998. Novel Localization of a Na+/H+ Exchanger in a Late Endosomal Compartment of Yeast IMPLICATIONS FOR VACUOLE BIOGENESIS. J. Biol. Chem. 273, 2105421060.

Nishikawa, S., Nakano, A., 1993. Identification of a gene required for membrane protein retention in the early secretory pathway. Proc. Natl. Acad. Sci. U. S. A. 90, 8179-8183.

Nothwehr, S.F., Bruinsma, P., Strawn, L.A., 1999. Distinct domains within Vps35p mediate the retrieval of two different cargo proteins from the yeast prevacuolar/endosomal compartment. Mol. Biol. Cell 10, 875-890.

Nothwehr, S.F., Ha, S.-A., Bruinsma, P., 2000. Sorting of Yeast Membrane Proteins into an Endosome-to-Golgi Pathway Involves Direct Interaction of Their Cytosolic Domains with Vps35p. J. Cell Biol. 151, 297-310.

Nothwehr, S.F., Hindes, A.E., 1997. The yeast VPS5/GRD2 gene encodes a sorting nexin-1-like protein required for localizing membrane proteins to the late Golgi. J. Cell Sci. 110 ( Pt 9), 10631072.

Novick, P., 2016. Regulation of membrane traffic by Rab GEF and GAP cascades. Small GTPases 7, 252-256.

O'Donnell, A.F., Apffel, A., Gardner, R.G., Cyert, M.S., 2010. Alpha-arrestins Aly1 and Aly2 regulate intracellular trafficking in response to nutrient signaling. Mol. Biol. Cell 21, 3552-3566.

Odorizzi, G., Babst, M., Emr, S.D., 1998. Fab1p PtdIns(3)P 5-Kinase Function Essential for Protein Sorting in the Multivesicular Body. Cell 95, 847-858.

Ohashi, Y., Munro, S., 2010. Membrane Delivery to the Yeast Autophagosome from the GolgiEndosomal System. Mol. Biol. Cell 21, 3998-4008.

Okamoto, M., Kurokawa, K., Matsuura-Tokita, K., Saito, C., Hirata, R., Nakano, A., 2012. Highcurvature domains of the ER are important for the organization of ER exit sites in Saccharomyces cerevisiae. J. Cell Sci. 125, 3412-3420.

Paczkowski, J.E., Fromme, J.C., 2014. Structural basis for membrane binding and remodeling by the exomer secretory vesicle cargo adaptor. Dev Cell 30, 610-24.

Paczkowski, J.E., Richardson, B.C., Fromme, J.C., 2015. Cargo adaptors: structures illuminate mechanisms regulating vesicle biogenesis. Trends Cell Biol 25, 408-16.

Paczkowski, J.E., Richardson, B.C., Strassner, A.M., Fromme, J.C., 2012. The exomer cargo adaptor structure reveals a novel GTPase-binding domain. Embo J 31, 4191-203.

Page, L.J., Sowerby, P.J., Lui, W.W., Robinson, M.S., 1999. Gamma-synergin: an EH domaincontaining protein that interacts with gamma-adaptin. J. Cell Biol. 146, 993-1004. 
Palade, G., 1975. Intracellular aspects of the process of protein synthesis. Science 189, 347-358.

Paleotti, O., Macia, E., Luton, F., Klein, S., Partisani, M., Chardin, P., Kirchhausen, T., Franco, M., 2005. The small G-protein Arf6GTP recruits the AP-2 adaptor complex to membranes. J. Biol. Chem. 280, 21661-21666.

Pan, X., Zaarur, N., Singh, M., Morin, P., Kandror, K.V., 2017. Sortilin and retromer mediate retrograde transport of Glut4 in 3T3-L1 adipocytes. Mol. Biol. Cell 28, 1667-1675.

Papanikou, E., Day, K.J., Austin, J., Glick, B.S., 2015. COPI selectively drives maturation of the early Golgi. eLife 4.

Papanikou, E., Glick, B.S., 2014. Golgi compartmentation and identity. Curr. Opin. Cell Biol. 29, 74-81.

Park, S.Y., Guo, X., 2014. Adaptor protein complexes and intracellular transport. Biosci. Rep. 34.

Parlati, F., Varlamov, O., Paz, K., McNew, J.A., Hurtado, D., Söllner, T.H., Rothman, J.E., 2002. Distinct SNARE complexes mediating membrane fusion in Golgi transport based on combinatorial specificity. Proc. Natl. Acad. Sci. U. S. A. 99, 5424-5429.

Payne, G.S., Baker, D., van Tuinen, E., Schekman, R., 1988. Protein transport to the vacuole and receptor-mediated endocytosis by clathrin heavy chain-deficient yeast. J Cell Biol 106, 1453-61.

Payne, G.S., Hasson, T.B., Hasson, M.S., Schekman, R., 1987. Genetic and biochemical characterization of clathrin-deficient Saccharomyces cerevisiae. Mol Cell Biol 7, 3888-98.

Payne, G.S., Schekman, R., 1985. A test of clathrin function in protein secretion and cell growth. Science 230, 1009-14.

Pelham, H.R., 2004. Membrane traffic: GGAs sort ubiquitin. Curr Biol 14, R357-9.

Perez, P., Rincon, S.A., 2010. Rho GTPases: regulation of cell polarity and growth in yeasts. Biochem J 426, 243-53.

Peyroche, A., Courbeyrette, R., Rambourg, A., Jackson, C.L., 2001. The ARF exchange factors Gea1p and Gea2p regulate Golgi structure and function in yeast. J. Cell Sci. 114, 2241-2253.

Peyroche, A., Paris, S., Jackson, C.L., 1996. Nucleotide exchange on ARF mediated by yeast Gea1 protein. Nature 384, 479-481.

Phan, H.L., Finlay, J.A., Chu, D.S., Tan, P.K., Kirchhausen, T., Payne, G.S., 1994. The Saccharomyces cerevisiae APS1 gene encodes a homolog of the small subunit of the mammalian clathrin AP-1 complex: evidence for functional interaction with clathrin at the Golgi complex. EMBO J. 13, $1706-1717$.

Piper, R.C., Cooper, A.A., Yang, H., Stevens, T.H., 1995. VPS27 controls vacuolar and endocytic traffic through a prevacuolar compartment in Saccharomyces cerevisiae. J Cell Biol 131, 603-17.

Poupon, V., Girard, M., Legendre-Guillemin, V., Thomas, S., Bourbonniere, L., Philie, J., Bright, N.A., McPherson, P.S., 2008. Clathrin light chains function in mannose phosphate receptor trafficking via regulation of actin assembly. Proc. Natl. Acad. Sci. U. S. A. 105, 168-173. 
Prekeris, R., Yang, B., Oorschot, V., Klumperman, J., Scheller, R.H., 1999. Differential Roles of Syntaxin 7 and Syntaxin 8 in Endosomal Trafficking. Mol. Biol. Cell 10, 3891-3908.

Prosser, D.C., Drivas, T.G., Maldonado-Baez, L., Wendland, B., 2011. Existence of a novel clathrinindependent endocytic pathway in yeast that depends on Rho1 and formin. J Cell Biol 195, 65771.

Pryor, P.R., Mullock, B.M., Bright, N.A., Lindsay, M.R., Gray, S.R., Richardson, S.C.W., Stewart, A., James, D.E., Piper, R.C., Luzio, J.P., 2004. Combinatorial SNARE complexes with VAMP7 or VAMP8 define different late endocytic fusion events. EMBO Rep. 5, 590-595.

Puertollano, R., Aguilar, R.C., Gorshkova, I., Crouch, R.J., Bonifacino, J.S., 2001a. Sorting of mannose 6-phosphate receptors mediated by the GGAs. Science 292, 1712-6.

Puertollano, R., Randazzo, P.A., Presley, J.F., Hartnell, L.M., Bonifacino, J.S., 2001b. The GGAs promote ARF-dependent recruitment of clathrin to the TGN. Cell 105, 93-102.

Qiao, L., Hamamichi, S., Caldwell, K.A., Caldwell, G.A., Yacoubian, T.A., Wilson, S., Xie, Z.-L., Speake, L.D., Parks, R., Crabtree, D., Liang, Q., Crimmins, S., Schneider, L., Uchiyama, Y., Iwatsubo, T., Zhou, Y., Peng, L., Lu, Y., Standaert, D.G., Walls, K.C., Shacka, J.J., Roth, K.A., Zhang, J., 2008. Lysosomal enzyme cathepsin $\mathrm{D}$ protects against alpha-synuclein aggregation and toxicity. Mol. Brain 1, 17.

Raiborg, C., Bremnes, B., Mehlum, A., Gillooly, D.J., D’Arrigo, A., Stang, E., Stenmark, H., 2001. FYVE and coiled-coil domains determine the specific localisation of Hrs to early endosomes. J. Cell Sci. 114, 2255-2263.

Ramachandran, R., 2011. Vesicle scission: dynamin. Semin. Cell Dev. Biol. 22, 10-17.

Ramirez-Macias, I., Barlow, L.D., Anton, C., Spang, A., Roncero, C., Dacks, J.B., 2018. Evolutionary cell biology traces the rise of the exomer complex in Fungi from an ancient eukaryotic component. Sci Rep 8, 11154.

Raymond, C.K., Howald-Stevenson, I., Vater, C.A., Stevens, T.H., 1992. Morphological classification of the yeast vacuolar protein sorting mutants: evidence for a prevacuolar compartment in class E vps mutants. Mol Biol Cell 3, 1389-402.

Reggiori, F., Pelham, H.R., 2001. Sorting of proteins into multivesicular bodies: ubiquitindependent and -independent targeting. EMBO J. 20, 5176-5186.

Reider, A., Barker, S.L., Mishra, S.K., Im, Y.J., Maldonado-Báez, L., Hurley, J.H., Traub, L.M., Wendland, B., 2009. Syp1 is a conserved endocytic adaptor that contains domains involved in cargo selection and membrane tubulation. EMBO J. 28, 3103-3116.

Reider, A., Wendland, B., 2011. Endocytic adaptors - social networking at the plasma membrane. J Cell Sci 124, 1613-1622.

Ren, X., Farias, G.G., Canagarajah, B.J., Bonifacino, J.S., Hurley, J.H., 2013. Structural Basis for Recruitment and Activation of the AP-1 Clathrin Adaptor Complex by Arf1. Cell 152, 755-767.

Renigunta, V., Fischer, T., Zuzarte, M., Kling, S., Zou, X., Siebert, K., Limberg, M.M., Rinné, S., Decher, N., Schlichthörl, G., Daut, J., 2014. Cooperative endocytosis of the endosomal SNARE protein syntaxin-8 and the potassium channel TASK-1. Mol. Biol. Cell 25, 1877-1891. 
Risselada, H.J., Grubmüller, H., 2012. How SNARE molecules mediate membrane fusion: recent insights from molecular simulations. Curr. Opin. Struct. Biol. 22, 187-196.

Ritz, A.M., Trautwein, M., Grassinger, F., Spang, A., 2014. The Prion-like Domain in the ExomerDependent Cargo Pin2 Serves as a trans-Golgi Retention Motif. Cell Rep 7, 249-60.

Roberts, C.J., Nothwehr, S.F., Stevens, T.H., 1992. Membrane protein sorting in the yeast secretory pathway: evidence that the vacuole may be the default compartment. J Cell Biol 119, 69-83.

Robinson, M.S., 2004. Adaptable adaptors for coated vesicles. Trends Cell Biol 14, 167-74.

Rockenbauch, U., Ritz, A.M., Sacristan, C., Roncero, C., Spang, A., 2012. The complex interactions of Chs5p, the ChAPs, and the cargo Chs3p. Mol Biol Cell 23, 4402-15.

Rohde, G., Wenzel, D., Haucke, V., 2002. A phosphatidylinositol (4,5)-bisphosphate binding site within $\mu 2$-adaptin regulates clathrin-mediated endocytosis. J. Cell Biol. 158, 209-214.

Rojas, R., van Vlijmen, T., Mardones, G.A., Prabhu, Y., Rojas, A.L., Mohammed, S., Heck, A.J.R., Raposo, G., van der Sluijs, P., Bonifacino, J.S., 2008. Regulation of retromer recruitment to endosomes by sequential action of Rab5 and Rab7. J. Cell Biol. 183, 513-526.

Sahgal, P., Alanko, J., Icha, J., Paatero, I., Hamidi, H., Arjonen, A., Pietilä, M., Rokka, A., Ivaska, J., 2019. GGA2 and RAB13 promote activity-dependent $\beta 1$-integrin recycling. J. Cell Sci. jcs.233387.

Sakamoto, C., Kawamoto, C., Takeuchi, K., Miyamoto, I., Shuntoh, H., 2004. Fission yeast epsin, Ent1p is required for endocytosis and involved in actin organization. Kobe J. Med. Sci. 50, 47-57.

Sambrook, J., Fritsch, E.F., Manniatis, T., 1989. Molecular Cloning: A laboratory manual. Cold Spring Harbor laboratory press., Cold Spring Harbor, N.Y.

Sambrook, J., Russell, D.W., 2001. molecular Cloning: A laboratory manual. CSHL Press, New York.

Sanchatjate, S., Schekman, R., 2006. Chs5/6 Complex: A Multiprotein Complex That Interacts with and Conveys Chitin Synthase III from the Trans-Golgi Network to the Cell Surface. Mol Biol Cell $17,4157-66$.

Sanger, F., Nicklen, S., Coulson, A.R., 1977. DNA sequencing with chain-terminating inhibitors. Proc Natl Acad Sci USA 74, 5463-5467.

Sannerud, R., Annaert, W., 2009. Trafficking, a key player in regulated intramembrane proteolysis. Semin. Cell Dev. Biol. 20, 183-190.

Santos, B., and Snyder, M., 2003. Specific protein targeting during cell differentiation: polarized localization of Fus $1 \mathrm{p}$ during mating depends on Chs $5 \mathrm{p}$ in Saccharomyces cerevisiae. Eukaryot. Cell 2, 821-825.

Santos, B., and Snyder, M., 1997. Targeting of chitin synthase 3 to polarized growth sites in yeast requires Chs5p and Myo2p. JCell Biol 136, 95-110.

Sato, K., Sato, M., Nakano, A., 1997. Rer1p as common machinery for the endoplasmic reticulum localization of membrane proteins. Proc. Natl. Acad. Sci. U. S. A. 94, 9693-9698. 
Schmid, E.M., Ford, M.G., Burtey, A., Praefcke, G.J., Peak-Chew, S.Y., Mills, I.G., Benmerah, A., McMahon, H.T., 2006. Role of the AP2 beta-appendage hub in recruiting partners for clathrincoated vesicle assembly. PLoS Biol 4, e262.

Schroeter, S., Beckmann, S., Schmitt, H.D., 2016. Coat/Tether Interactions-Exception or Rule? Front. Cell Dev. Biol. 4, 44.

Schuh, A.L., Audhya, A., 2014. The ESCRT machinery: from the plasma membrane to endosomes and back again. Crit. Rev. Biochem. Mol. Biol. 49, 242-261.

Scott, C.C., Vacca, F., Gruenberg, J., 2014. Endosome maturation, transport and functions. Semin Cell Dev Biol 31, 2-10.

Scott, P.M., Bilodeau, P.S., Zhdankina, O., Winistorfer, S.C., Hauglund, M.J., Allaman, M.M., Kearney, W.R., Robertson, A.D., Boman, A.L., Piper, R.C., 2004. GGA proteins bind ubiquitin to facilitate sorting at the trans-Golgi network. Nat Cell Biol 6, 252-9.

Seaman, M.N., 2004. Cargo-selective endosomal sorting for retrieval to the Golgi requires retromer. J Cell Biol 165, 111-22.

Seaman, M.N., McCaffery, J.M., Emr, S.D., 1998. A membrane coat complex essential for endosome-to-Golgi retrograde transport in yeast. J Cell Biol 142, 665-81.

Seaman, M.N.J., 2007. Identification of a novel conserved sorting motif required for retromermediated endosome-to-TGN retrieval. J. Cell Sci. 120, 2378-2389.

Seaman, M.N.J., Marcusson, E.G., Cereghino, J.L., Emr, S.D., 1997. Endosome to Golgi Retrieval of the Vacuolar Protein Sorting Receptor, Vps10p, Requires the Function of the VPS29, VPS30, and VPS35 Gene Products. J. Cell Biol. 137, 79-92.

Seeger, M., Payne, G.S., 1992. A role for clathrin in the sorting of vacuolar proteins in the Golgi complex of yeast. Embo J 11, 2811-8.

Semenza, J.C., Hardwick, K.G., Dean, N., Pelham, H.R.B., 1990. ERD2, a yeast gene required for the receptor-mediated retrieval of luminal ER proteins from the secretory pathway. Cell 61, 13491357.

Sharpe, H.J., Stevens, T.J., Munro, S., 2010. A comprehensive comparison of transmembrane domains reveals organelle-specific properties. Cell 142, 158-69.

Shi, H., Rojas, R., Bonifacino, J.S., Hurley, J.H., 2006. The retromer subunit Vps26 has an arrestin fold and binds Vps35 through its C-terminal domain. Nat. Struct. Mol. Biol. 13, 540-548.

Shi, Y., Stefan, C.J., Rue, S.M., Teis, D., Emr, S.D., 2011. Two novel WD40 domain-containing proteins, Ere1 and Ere2, function in the retromer-mediated endosomal recycling pathway. Mol. Biol. Cell 22, 4093-4107.

Shiba, Y., Katoh, Y., Shiba, T., Yoshino, K., Takatsu, H., Kobayashi, H., Shin, H.-W., Wakatsuki, S., Nakayama, K., 2004. GAT (GGA and Tom1) domain responsible for ubiquitin binding and ubiquitination. J. Biol. Chem. 279, 7105-7111.

Silveira, L.A., Wong, D.H., Masiarz, F.R., Schekman, R., 1990. Yeast clathrin has a distinctive light chain that is important for cell growth. J Cell Biol 111, 1437-49. 
Singer-Krüger, B., Lasić, M., Bürger, A.-M., Haußer, A., Pipkorn, R., Wang, Y., 2008. Yeast and human $\mathrm{Ys} / 2 \mathrm{p} / \mathrm{hMon} 2$ interact with Gga adaptors and mediate their subcellular distribution. EMBO J. 27, 1423-1435.

Singh, P.K., Kapoor, A., Lomash, R.M., Kumar, K., Kamerkar, S.C., Pucadyil, T.J., Mukhopadhyay, A., 2018. Salmonella SipA mimics a cognate SNARE for host Syntaxin8 to promote fusion with early endosomes. J. Cell Biol. 217, 4199-4214.

Sipiczki, M., 2000. Where does fission yeast sit on the tree of life? Genome Biol 1, REVIEWS1011. Song, S., Cong, W., Zhou, S., Shi, Y., Dai, W., Zhang, H., Wang, X., He, B., Zhang, Q., 2019. Small GTPases: Structure, biological function and its interaction with nanoparticles. Asian J. Pharm. Sci. 14, 30-39.

Sørensen, S.O., Hazel, H.B.V.D., Kielland-Brandt, M.C., Winther, J.R., 1994. pH-dependent processing of yeast procarboxypeptidase $Y$ by proteinase $A$ in vivo and in vitro. Eur. J. Biochem. 220, 19-27.

Sosa, R.T., Weber, M.M., Wen, Y., O'Halloran, T.J., 2012. A single $\beta$ adaptin contributes to AP1 and AP2 complexes and clathrin function in Dictyostelium. Traffic Cph. Den. 13, 305-316.

Spang, A., 2009. On vesicle formation and tethering in the ER-Golgi shuttle. Curr. Opin. Cell Biol. $21,531-536.3$

Spasic, D., Raemaekers, T., Dillen, K., Declerck, I., Baert, V., Serneels, L., Füllekrug, J., Annaert, W., 2007. Rer1p competes with APH-1 for binding to nicastrin and regulates $\gamma$-secretase complex assembly in the early secretory pathway. J. Cell Biol. 176, 629-640.

Spormann, D.O., Heim, J., Wolf, D.H., 1992. Biogenesis of the yeast vacuole (lysosome). The precursor forms of the soluble hydrolase carboxypeptidase yscS are associated with the vacuolar membrane. J. Biol. Chem. 267, 8021-8029.

Stahelin, R.V., Long, F., Diraviyam, K., Bruzik, K.S., Murray, D., Cho, W., 2002. Phosphatidylinositol 3-phosphate induces the membrane penetration of the FYVE domains of Vps27p and Hrs. J. Biol. Chem. 277, 26379-26388.

Stefan, C.J., Audhya, A., Emr, S.D., 2002. The yeast synaptojanin-like proteins control the cellular distribution of phosphatidylinositol (4,5)-bisphosphate. Mol. Biol. Cell 13, 542-557.

Stepp, J.D., Huang, K., Lemmon, S.K., 1997. The Yeast Adaptor Protein Complex, AP-3, Is Essential for the Efficient Delivery of Alkaline Phosphatase by the Alternate Pathway to the Vacuole. J. Cell Biol. 139, 1761-1774.

Stimpson, H.E.M., Toret, C.P., Cheng, A.T., Pauly, B.S., Drubin, D.G., 2009. Early-arriving Syp1p and Ede1p function in endocytic site placement and formation in budding yeast. Mol. Biol. Cell 20, 4640-4651.

Strochlic, T.I., Setty, T.G., Sitaram, A., Burd, C.G., 2007. Grd19/Snx3p functions as a cargo-specific adapter for retromer-dependent endocytic recycling. J. Cell Biol. 177, 115-125.

Subramaniam, V.N., Loh, E., Horstmann, H., Habermann, A., Xu, Y., Coe, J., Griffiths, G., Hong, W., 2000. Preferential association of syntaxin 8 with the early endosome. J. Cell Sci. 113 ( Pt 6), 9971008. 
Suda, Y., Nakano, A., 2012. The yeast Golgi apparatus. Traffic Cph. Den. 13, 505-510.

Sun, B., Chen, L., Cao, W., Roth, A.F., Davis, N.G., 2004. The Yeast Casein Kinase Yck3p Is Palmitoylated, then Sorted to the Vacuolar Membrane with AP-3-dependent Recognition of a YXX $\varphi$ Adaptin Sorting Signal. Mol. Biol. Cell 15, 1397-1406.

Swaney, D.L., Beltrao, P., Starita, L., Guo, A., Rush, J., Fields, S., Krogan, N.J., Villen, J., 2013. Global analysis of phosphorylation and ubiquitylation cross-talk in protein degradation. Nat Methods 10 , 676-82.

Sztul, E., Lupashin, V., 2006. Role of tethering factors in secretory membrane traffic. Am. J. Physiol.-Cell Physiol. 290, C11-C26.

Tabuchi, M., Iwaihara, O., Ohtani, Y., Ohuchi, N., Sakurai, J., Morita, T., Iwahara, S., Takegawa, K., 1997. Vacuolar protein sorting in fission yeast: cloning, biosynthesis, transport, and processing of carboxypeptidase Y from Schizosaccharomyces pombe. J Bacteriol 179, 4179-89.

Tabuchi, M., Yanatori, I., Kawai, Y., Kishi, F., 2010. Retromer-mediated direct sorting is required for proper endosomal recycling of the mammalian iron transporter DMT1. J. Cell Sci. 123, 756766.

Takegawa, K., DeWald, D.B., Emr, S.D., 1995. Schizosaccharomyces pombe Vps34p, a phosphatidylinositol-specific PI 3-kinase essential for normal cell growth and vacuole morphology. J Cell Sci 108 ( Pt 12), 3745-56.

Takegawa, K., Hosomi, A., Iwaki, T., Fujita, Y., Morita, T., Tanaka, N., 2003. Identification of a SNARE protein required for vacuolar protein transport in Schizosaccharomyces pombe. Biochem. Biophys. Res. Commun. 311, 77-82.

Trahey, M., Hay, J.C., 2010. Transport vesicle uncoating: it's later than you think. F1000 Biol Rep 2, 47.

Trautwein, M., Schindler, C., Gauss, R., Dengjel, J., Hartmann, E., Spang, A., 2006. Arf1p, Chs5p and the ChAPs are required for export of specialized cargo from the Golgi. Embo J 25, 943-54.

Tsui, M.M.K., Tai, W.C.S., Banfield, D.K., 2001. Selective Formation of Sed5p-containing SNARE Complexes Is Mediated by Combinatorial Binding Interactions. Mol. Biol. Cell 12, 521-538.

Tzeng, H.-T., Wang, Y.-C., 2016. Rab-mediated vesicle trafficking in cancer. J. Biomed. Sci. 23, 70.

Umekawa, M., Klionsky, D.J., 2012. The Cytoplasm-to-Vacuole Targeting Pathway: A Historical Perspective [WWW Document]. Int. J. Cell Biol.

Ungermann, C., von Mollard, G.F., Jensen, O.N., Margolis, N., Stevens, T.H., Wickner, W., 1999. Three v-SNAREs and Two t-SNAREs, Present in a Pentameric cis-SNARE Complex on Isolated Vacuoles, Are Essential for Homotypic Fusion. J. Cell Biol. 145, 1435-1442.

Ungermann, C., Wickner, W., 1998. Vam7p, a vacuolar SNAP-25 homolog, is required for SNARE complex integrity and vacuole docking and fusion. EMBO J. 17, 3269-3276.

Ungewickell, E., Branton, D., 1981. Assembly units of clathrin coats. Nature 289, 420.

Urbanowski, J.L., Piper, R.C., 2001. Ubiquitin sorts proteins into the intralumenal degradative compartment of the late-endosome/vacuole. Traffic 2, 622-30. 
Valdivia, R.H., Baggott, D., Chuang, J.S., Schekman, R.W., 2002. The yeast clathrin adaptor protein complex 1 is required for the efficient retention of a subset of late Golgi membrane proteins. Dev Cell 2, 283-294.

Valls, L.A., Hunter, C.P., Rothman, J.H., Stevens, T.H., 1987. Protein sorting in yeast: the localization determinant of yeast vacuolar carboxypeptidase $\mathrm{Y}$ resides in the propeptide. Cell 48, 887-897.

van Weering, J.R.T., Sessions, R.B., Traer, C.J., Kloer, D.P., Bhatia, V.K., Stamou, D., Carlsson, S.R., Hurley, J.H., Cullen, P.J., 2012. Molecular basis for SNX-BAR-mediated assembly of distinct endosomal sorting tubules. EMBO J. 31, 4466-4480.

Vida, T.A., Emr, S.D., 1995. A new vital stain for visualizing vacuolar membrane dynamics and endocytosis in yeast. J Cell Biol 128, 779-92.

Vilariño-Güell, C., Wider, C., Ross, O.A., Dachsel, J.C., Kachergus, J.M., Lincoln, S.J., Soto-Ortolaza, A.I., Cobb, S.A., Wilhoite, G.J., Bacon, J.A., Behrouz, B., Melrose, H.L., Hentati, E., Puschmann, A., Evans, D.M., Conibear, E., Wasserman, W.W., Aasly, J.O., Burkhard, P.R., Djaldetti, R., Ghika, J., Hentati, F., Krygowska-Wajs, A., Lynch, T., Melamed, E., Rajput, A., Rajput, A.H., Solida, A., Wu, R.-M., Uitti, R.J., Wszolek, Z.K., Vingerhoets, F., Farrer, M.J., 2011. VPS35 mutations in Parkinson disease. Am. J. Hum. Genet. 89, 162-167.

Vjestica, A., Tang, X.Z., Oliferenko, S., 2008. The actomyosin ring recruits early secretory compartments to the division site in fission yeast. Mol Biol Cell 19, 1125-38.

von Mollard, G.F., Stevens, T.H., 1999. The Saccharomyces cerevisiae v-SNARE Vti1p Is Required for Multiple Membrane Transport Pathways to the Vacuole. Mol. Biol. Cell 10, 1719-1732.

Wang, C.W., Hamamoto, S., Orci, L., Schekman, R., 2006. Exomer: A coat complex for transport of select membrane proteins from the trans-Golgi network to the plasma membrane in yeast. J Cell Biol 174, 973-83.

Wang, J., Fedoseienko, A., Chen, B., Burstein, E., Jia, D., Billadeau, D.D., 2018. Endosomal receptor trafficking: Retromer and beyond. Traffic Cph. Den. 19, 578-590.

Wang, J., Gossing, M., Fang, P., Zimmermann, J., Li, X., von Mollard, G.F., Niu, L., Teng, M., 2011. Epsin N-terminal homology domains bind on opposite sides of two SNAREs. Proc. Natl. Acad. Sci. U. S. A. $108,12277-12282$.

Wang, T., Li, L., Hong, W., 2017. SNARE proteins in membrane trafficking. Traffic Cph. Den. 18, 767-775.

Wang, X., Huang, T., Bu, G., Xu, H., 2014. Dysregulation of protein trafficking in neurodegeneration. Mol. Neurodegener. 9, 31.

Wang, Y.J., Wang, J., Sun, H.Q., Martinez, M., Sun, Y.X., Macia, E., Kirchhausen, T., Albanesi, J.P., Roth, M.G., Yin, H.L., 2003. Phosphatidylinositol 4 phosphate regulates targeting of clathrin adaptor AP-1 complexes to the Golgi. Cell 114, 299-310.

Watson, R.T., Khan, A.H., Furukawa, M., Hou, J.C., Li, L., Kanzaki, M., Okada, S., Kandror, K.V., Pessin, J.E., 2004. Entry of newly synthesized GLUT4 into the insulin-responsive storage compartment is GGA dependent. Embo J 23, 2059-70. 
Weinberg, J., Drubin, D.G., 2012. Clathrin-mediated endocytosis in budding yeast. Trends Cell Biol 22, 1-13.

Whitley, P., Reaves, B.J., Hashimoto, M., Riley, A.M., Potter, B.V.L., Holman, G.D., 2003. Identification of mammalian Vps24p as an effector of phosphatidylinositol 3,5-bisphosphatedependent endosome compartmentalization. J. Biol. Chem. 278, 38786-38795.

Whittle, J.R.R., Schwartz, T.U., 2010. Structure of the Sec13-Sec16 edge element, a template for assembly of the COPII vesicle coat. J. Cell Biol. 190, 347-361.

Wickner, W., Haas, A., 2000. Yeast homotypic vacuole fusion: a window on organelle trafficking mechanisms. Annu. Rev. Biochem. 69, 247-275.

Wilson, C.M., Naves, T., Akhrass, H.A., Vincent, F., Melloni, B., Bonnaud, F., Lalloué, F., Jauberteau, M.-O., 2016. A new role under sortilin's belt in cancer. Commun. Integr. Biol. 9, e1130192.

Wood, V., Gwilliam, R., Rajandream, M.A., Lyne, M., Lyne, R., Stewart, A., Sgouros, J., Peat, N., Hayles, J., Baker, S., Basham, D., Bowman, S., Brooks, K., Brown, D., Brown, S., Chillingworth, T., Churcher, C., Collins, M., Connor, R., Cronin, A., Davis, P., Feltwell, T., Fraser, A., Gentles, S., Goble, A., Hamlin, N., Harris, D., Hidalgo, J., Hodgson, G., Holroyd, S., Hornsby, T., Howarth, S., Huckle, E.J., Hunt, S., Jagels, K., James, K., Jones, L., Jones, M., Leather, S., McDonald, S., McLean, J., Mooney, P., Moule, S., Mungall, K., Murphy, L., Niblett, D., Odell, C., Oliver, K., O'Neil, S., Pearson, D., Quail, M.A., Rabbinowitsch, E., Rutherford, K., Rutter, S., Saunders, D., Seeger, K., Sharp, S., Skelton, J., Simmonds, M., Squares, R., Squares, S., Stevens, K., Taylor, K., Taylor, R.G., Tivey, A., Walsh, S., Warren, T., Whitehead, S., Woodward, J., Volckaert, G., Aert, R., Robben, J., Grymonprez, B., Weltjens, I., Vanstreels, E., Rieger, M., Schafer, M., Muller-Auer, S., Gabel, C., Fuchs, M., Dusterhoft, A., Fritzc, C., Holzer, E., Moestl, D., Hilbert, H., Borzym, K., Langer, I., Beck, A., Lehrach, H., Reinhardt, R., Pohl, T.M., Eger, P., Zimmermann, W., Wedler, H., Wambutt, R., Purnelle, B., Goffeau, A., Cadieu, E., Dreano, S., Gloux, S., et al., 2002. The genome sequence of Schizosaccharomyces pombe. Nature 415, 871-80.

Xie, L., Boyle, D., Sanford, D., Scherer, P.E., Pessin, J.E., Mora, S., 2006. Intracellular trafficking and secretion of adiponectin is dependent on GGA-coated vesicles. J. Biol. Chem. 281, 7253-7259.

Ybe, J.A., Perez-Miller, S., Niu, Q., Coates, D.A., Drazer, M.W., Clegg, M.E., 2007. Light chain Cterminal region reinforces the stability of clathrin heavy chain trimers. Traffic Cph. Den. 8, 11011110.

Ybe, J.A., Ruppel, N., Mishra, S., VanHaaften, E., 2003. Contribution of cysteines to clathrin trimerization domain stability and mapping of light chain binding. Traffic Cph. Den. 4, 850-856.

Yeung, B.G., Payne, G.S., 2001. Clathrin interactions with C-terminal regions of the yeast AP-1 beta and gamma subunits are important for AP-1 association with clathrin coats. Traffic Cph. Den. $2,565-576$.

Yeung, B.G., Phan, H.L., Payne, G.S., 1999. Adaptor complex-independent clathrin function in yeast. Mol Biol Cell 10, 3643-59.

Yoon, T.-Y., Munson, M., 2018. SNARE complex assembly and disassembly. Curr. Biol. 28, R397R401. 
Yu, J.W., Lemmon, M.A., 2001. All Phox Homology (PX) Domains from Saccharomyces cerevisiae Specifically Recognize Phosphatidylinositol 3-Phosphate. J. Biol. Chem. 276, 44179-44184.

Yu, X., Breitman, M., Goldberg, J., 2012. A Structure-Based Mechanism for Arf1-Dependent Recruitment of Coatomer to Membranes. Cell 148, 530-542.

Yu, Y., Li, C., Kita, A., Katayama, Y., Kubouchi, K., Udo, M., Imanaka, Y., Ueda, S., Masuko, T., Sugiura, R., 2013. Sip1, an AP-1 accessory protein in fission yeast, is required for localization of Rho3 GTPase. PloS One 8, e68488.

Zhao, D., Liu, X.-M., Yu, Z.-Q., Sun, L.-L., Xiong, X., Dong, M.-Q., Du, L.-L., 2016. Atg20- and Atg24family proteins promote organelle autophagy in fission yeast. J. Cell Sci. 129, 4289-4304.

Zhdankina, O., Strand, N.L., Redmond, J.M., Boman, A.L., 2001. Yeast GGA proteins interact with GTP-bound Arf and facilitate transport through the Golgi. Yeast Chichester Engl. 18, 1-18.

Zhou, C., Yang, Y., Jong, A.Y., 1990. Mini-prep in ten minutes. Biotechniques 8, 172-173.

Ziman, M., Chuang, J.S., Tsung, M., Hamamoto, S., Schekman, R., 1998. Chs6p-dependent anterograde transport of Chs3p from the chitosome to the plasma membrane in Saccharomyces cerevisiae. Mol Biol Cell 9, 1565-1576.

Zimmermann, J., Chidambaram, S., Fischer von Mollard, G., 2010. Dissecting Ent3p: the ENTH domain binds different SNAREs via distinct amino acid residues while the C-terminus is sufficient for retrograde transport from endosomes. Biochem J 431, 123-34.

Zimprich, A., Benet-Pagès, A., Struhal, W., Graf, E., Eck, S.H., Offman, M.N., Haubenberger, D., Spielberger, S., Schulte, E.C., Lichtner, P., Rossle, S.C., Klopp, N., Wolf, E., Seppi, K., Pirker, W., Presslauer, S., Mollenhauer, B., Katzenschlager, R., Foki, T., Hotzy, C., Reinthaler, E., Harutyunyan, A., Kralovics, R., Peters, A., Zimprich, F., Brücke, T., Poewe, W., Auff, E., Trenkwalder, C., Rost, B., Ransmayr, G., Winkelmann, J., Meitinger, T., Strom, T.M., 2011. A mutation in VPS35, encoding a subunit of the retromer complex, causes late-onset Parkinson disease. Am. J. Hum. Genet. 89, 168-175. 